\title{
干HE LAS
}

Designing the quintessential New Zealand dwelling for a future with less glass

LAUREN HAYES 
"We are life itself

Remembering our way

We are life itself

The dreaming of the sea

We still have time

We still have some time

In the anthropocene

What does your

freedom mean?" 
ACKNOWLEDGMENTS

To my supervisor Emina for the amazing time, dedication, advice and encouragement

my incre dibly supportive friends, classmates and flatmates over the years

Jo, John, Ellie and Caiti for giving me a place to escape.

Rob, Oma and Opa, for always believing in me

A 120 thesis submitted to the Victoria University of Wellington in partial fulfillment of the requirements for the degree of Master of Architecture (Professional)

Victoria University of Wellington $2 \mathrm{O} 2$ 


\section{$\mathbb{C} O \mathbb{N}=E \mathbb{N}=S$}

$\begin{array}{lr}\text { Abstract } & \mathbf{8} \\ \text { Preface } & \mathbf{1 1} \\ \text { Introduction } & \mathbf{1 4} \\ \text { Research Question } & 18 \\ \text { Aims } & 18 \\ \text { Objectives } & 18 \\ \text { Scope } & 19 \\ \text { Methodology } & 20 \\ \text { Chapter 1: The Material Crisis } & \\ \text { 1.1. Effect of urbanisation } & 23 \\ \text { Chapter 2: The Global Sand Shortage } & \\ \text { 2.1. The meaning of sand } & 33 \\ \text { 2.2. Global sand consumption } & 36 \\ \text { 2.3. Nature's manufacture of sand } & 40 \\ \text { 2.4. Sand composition } & 41 \\ \text { 2.5. Ecological destruction } & 42 \\ \text { 2.6. Regulation of sand mining } & 45 \\ \text { 2.7. Reflection } & 46 \\ \text { Chapter 3: Glazing Study } & \\ \text { 3.1. Knowledge gap } & 49 \\ \text { 3.2. A short history of glass } & 50 \\ \text { 3.3. The scientific role of glass } & 58 \\ \text { 3.4. Methodology } & 60 \\ \text { 3.5. Case study selection } & 62 \\ \text { 3.6. Results } & 63 \\ \text { 3.7. Discussion } & 71 \\ \text { 3.8. Findings } & 73 \\ \text { Chapter 4: Framework Formation } & \\ \text { 4.1. Aims } & 79 \\ \text { 4.2. New Zealand vernacular } & 80 \\ \text { 4.3. Precedent Review } & 82 \\ \text { 4.4. Common themes } & 84 \\ \text { 4.5. Framework development } & 96 \\ \text { 4.6. Design framework } & 98 \\ & \end{array}$

$\begin{array}{ll}\text { Chapter 5: Site } & \\ \text { 5.1. Site selection } & 101 \\ \text { 5.2. Site aspects } & 102 \\ \text { 5.3. Site analysis } & 102 \\ \text { 5.4. Precedent analysis } & 105 \\ \text { 5.5. Reflection } & 105\end{array}$

Chapter 6: Poetic Elements of Design

$\begin{array}{ll}\text { 6.1. Purpose } & 111 \\ \text { 6.2. Positioning the view } & 113 \\ \text { 6.3. Postive \& negative space } & 128 \\ \text { 6.4. Multi-functional space } & 142 \\ \text { 6.5. Public \& private space } & 148 \\ \text { 6.6. Texture \& shadow } & 154 \\ \text { 6.7. Forms \& materiality } & 164 \\ \text { 6.8. Critical reflection } & 175\end{array}$

6.8. Critical reflection

Chapter 7: Simulation Model

7.1. Purpose

7.2. Software selection

7.3. Limitations

7.4. Specifications

7.5. Generating results

7.6. Study aims

7.7. Floor plans

7.8. Iteration 1

7.9. Iteration 2

7.10. Iteration 3

7.11. Iteration 4

7.12. Iteration 5

7.13. Iteration 6

7.14. Lighting render analysis

7.15. Critical reflection

105 148

8.1. Contributions

177

181

Bibliography

Figures List

266

Appendix

280 
Sand and aggregate are the world's second-most extracted resource behind only water, and more than $75 \%$ of dredged-up sand is used in construction as a critical component of glass and concrete, often causing significant damage to ecosystems and coastlines. Sand extraction is rapidly increasing worldwide, while the recognition that worldwide supplies are finite is still limited. The United Nations have acknowledged sustainable natural resource use as a pivotal factor to improving economic prosperity and human wellbeing globally.

Meanwhile, New Zealand architecture is increasingly dependent on glass as a key conveyor of the landscape, freedom and command of space. This reliance presents a major contradiction between sustainable natural resource use and themes in idealised residential architecture.

This opposition between the poetic aspects of successful architecture and practical application of

sustainable principles is also evident in existing scholarship. This research portfolio attempts to develop

approaches on how this issue could be addressed.

This thesis contributes to the development of much needed scholarship that addresses and problematises the issues associated with the fact that in the near future, the construction industry be more deliberate in how much glass is used for minimal wastefulness but maximum impact. It will investigate opportunities of designing with less glass through poetic design in parallel with scientific analysis, examining existing buildings' sand usage and determining limitations for a framework for designing with less glass.

This thesis aims to raise awareness of the discrepancies between sustainable resource use and current New Zealand architecture themes. The acknowledgment of these issues must be accelerated in the architecture community to prepare for the imminent crises of the sand shortage and its architectura implications.

This content is unavailable. Please consult the figure list for more details. 
PREFACE

TWO ANECDOTES

ONE

66 It was love at first sight. As the raven circled over the endless ocean, he saw a beautiful mermaid and was entranced. He flew close and asked her to marry him, and she arreed - but on one condition: "Make me some land where I can sit on a beach and dry my hair and I will marry you." The raven This content is unavailable. Please consult the figure list for more details.

knew he would need help with this task and, in return for not insignifican favours but without revealing his

intentions, enlisted the seal and the frog to procure some sand from the bottom of the sea. The raven then flew up into the strong winds above the ocean and scattered the grains to every corner of the world. At the place where each grain fell into the ocean, an island was formed: small islands from the tiny grains, large omes from the biggest grains. The mermaid was delighted, for the first time in her life drying her hair on a sandy beach. And then she and the raven were married." (Welland, 2009) 
This legend, as told by tribes of the Pacific Northwest of America, whose ancestors were the raven and the mermaid, is one among many similar creation stories of varying cultures from Eurasia to America to the Pacific Islands, and is collectively known as the "earth-diver" myth.

However, it remains what it is: a story.

$$
\text { TWO }
$$

Scientifically, sand has also been related to the origins of the

universe. Clues collected from more than thirty thousand Antarctic specimens of meteorite offer hints as to processes that predate the formation of our earth, planets and sun altogether (Scharf, 2013). Scientific research since the 1970s points to these microscopic 'presolar grains' originating in other stars, some of which were produced during great supernova explosions (Scharf, 2013). In 2013, Haenecour et al. first discovered the existence of two supernova silica grains amongs these Antarctic meteor specimens: silica being modern day sand, thus indicating sand has been a key mineral of the universe since long before the solar system's existence (Haenecour et al., 2013).

This content is unavailable. Please consult the figure list for more details. 
Sand has been seen as a pivotal factor in both mythical and scientific creation stories alike, forming the basis of the universe as we know it. The contradiction between these two strikes a parallel with this thesis as a whole: how to resolve the dynamic relationship between the poetic and the scientific roles of glass in sustainability of the built environment. This work investigates how to successfully propose reductions in reliance on glass, especially in applications such as sustainable high-end residential architecture in New Zealand.

Research so far conducted in the field of sustainable architecture has focused on the pragmatic, scientific approach. While architects are perhaps some of the more informed members of the public when it comes to sustainability issues, awards and recognition in the industry have not necessarily adopted the same criteria yet, and seem to still focus on the poetic aspects of design. This presents

a gap existing scholarship on the subject of sustainable architecture, and this work aims to make a

modest but direct contribution in this area.

Sand plays a key role in the tangible and intangible creation stories of

This content is unavailable. Please consult the figure list for more details. the universe, but is also a crucial part of modern-day lifestyles around the world: it is a key component of computers, mobile phones, cosmetics, glass, concrete and even paper (Delestrac, 2013; Torres et al., 2017). However in recent years it has become clear that the world is running out of sand. This is not known as yet by many.

As we watch our forests burning, glaciers melting and lakes drying up, the notion of the sand shortage is acknowledged by comparatively few when it comes to sustainable future in the construction industry. Sand is second only to water as the world's most sought-after natural resource, and it is extracted more than fossil fuels and biomass combined (Weyler, 2017). The extraction of sand is causing major destruction of ecosystems, coastlines and habitats worldwide, drying up lakes and riverbeds, and causing islands to vanish beneath the waves. This is because desert sand is not suitable for construction due to its roundness; river and ocean sand is rougher and therefore binds better but it is also significantly more scarce (section 2.3). Demand for sand will only escalate in future years as sea level rise increases the need for sea walls and infill (Delestrac

2013). This problem falls significantly upon the shoulders of architecture because more than three-quarters of dredged-up sand is locked away in construction and infrastructure as a key component of glass and concrete (Torres et al., 2017). Yet replacing sand in glass is not only impossible, but it would also present a contradiction to the general identity of modern architecture. This is especially evident in high- 
end New Zealand contemporary housing which is heavily reliant on glass as the conveyor of our most valued possession: the landscape. Therefore, sand shortage issues in New Zealand represent the overal contradiction that exists between poetic architectural language and sustainable architecture science, and begs the question:

\section{Can poetic and scientific}

design processes be combined to produce

\section{more successful}

\section{architectural outcomes}

for solving sustainability issues such as the global

\section{sand crisis?}

This thesis contributes to the development of much needed scholarship which addresses and problematises the issues associated with the fact that in the near future the construction industry will have to find alternatives to using glass as a heroed material in architecture. Research in this area is needed

and must be prioritised in order to prevent the collapse of ecosystems and coastlines worldwide.

Thus, while sand has been a key player in cultural anthropic and cosmic history, humanity now needs to shift its focus to alternative

materials, or better yet, alternative ways of designing with less glass to achieve the same poetic

architectural results that are so often sought after, and are particularly prevalent in countries like New Zealand that tend to hero glass as transmitter of the view.
Therefore this research aims to demonstrate how the architectural desires of New Zealanders' notion of home can be achieved whilst significantly reducing the usage of sand. Most importantly, the research aims to raise awareness of the discrepancies and contradictions between using glass sustainably and current themes in New Zealand residential architecture, which tends to rely on windows as a key conveyor of the view. 


\section{RESEARCH \\ QUESTION}

What are the poetic and scientific architectural implications for

designing the quintessential New Zealand dwelling for a future with

less glass, where the idealised home captures the view of the heroed landscape?

\section{A I M S}

The aim of this thesis is to raise awareness of the global sand

shortage and its relationship to the built environment. It aims to make a contribution towards articulating how the problem could be addressed.

\section{O B J E C TIVES}

1.Demonstrate that the key features of a quintessential New Zealand dwelling can be achieved with less glass whilst significantly reducing the usage of sand through both poetic

and scientific design processes.

2.Understand the role of the window in New Zealand residential architecture and its relationship to the heroed view.

3.Analyse existing precedents to understand the qualitative themes in contemporary New Zealand residential architecture.

4.Develop a series of design strategies and principles that allow for the significant reduction of glass whilst maintaining both poetic and scientific environmental comfort conditions.

\section{S C OPE}

The global sand shortage is an issue of colossal scale which has a very broad variety of social, cultural environmental and economic implications. This thesis contributes research to only one aspect of the wider problem. Narrowing the issue to an architectural context presents two options for the scope of this research: reduction of glass, or reduction of concrete in buildings. At an architectural scale a wide range of literature already contributes to the latter. In contrast there is nearly no research relating to the reduction of glass in architecture in relation to sustainability, presenting a much more difficult issue to resolve. Additionally there are no sustainable commercial alternatives to glass, compared to a range of concrete alternatives. Therefore this work will focus on glass. Even the field of reducing glass in architecture presents a wide range of issues. The scope of this research is limited to residential architecture in New Zealand due to the heavy reliance our quintessential residential architecture places on glass in New Zealand especially, whereas commercial architecture is less reliant on glass for its ability to transmit the view. Furthermore, the scope is limited to providing design principles for building with less glass, rather than providing alternatives to glass. Plastic materials are the only commercially available products to glass, which are associated with their own significant environmental and health issues. Recycled glass was also considered, however current consumption of glass far outweighs the amount that can be recycled, and the process of recyling glass is associated with high levels of $\mathrm{CO}_{2}$ emissions and energy usage. 
METHODOLOGY

A literature review of texts relating to the background of the global sand shortage established a gap of knowledge between the sand crisis issues and the construction industry.

A statistical case study review

will help determine the role of

glass in New Zealand residential

architecture, hypothesising that

there is a major reliance on glass

to convey the landscape. It will

investigate whether this is a quality

that is present in a selection of high-

end residential building case studies

compared to standard specification

homes.

This thesis hypothesises that

the research will show a major

contradiction between glass usage

in quintessential New Zealand

dwellings and sand shortage issues.

It also considers a conflict between

the poetic nature of award-winning

dwellings and the scientific aspects

of sustainable building. The research will inform the construction of a framework for designing with less glass to establish design principles and techniques identified from a precedent review of successful residential architecture.

Applying the framework to a site will test the ability to convey the landscape through other poetic opportunities in the architecture as an alternative to significant use of glass. Design exploration through multimedia processes (both analogue and digital) will test poetic aspects of designing dwellings with less glass, and consider the ability for poetic design techniques to contribute to solving sustainability issues relating to the construction industry.

The research through design will inform the revision of a framework which could inform future New Zealand residential architecture that aspires to successfully convey the landscape with significant reduction of glass. 
This content is unavailable. Please consult the figure list for more details.
Chapter 1

\section{THE MATERIAL $C R I S \mid S$}

1.1. EFFECT OF

$$
\text { URBANISATION }
$$

Over the last century,

industrialisation and urbanisation

have had enormous environmental impacts, including the exploitations

and abolitions of the earth's natural

resource deposits. This is due to associated environmental costs

such as climate change, biodiversity

loss, desertification and ecological degradation (Behrens et al.,2007).

In 2015, the United Nations unveiled

a set of seventeen Sustainable

Development Goals, designed

to provide a "better and more

sustainable future for all" (United

Nations,2015). Replacing the

Millennium Development Goals of

2000 , these new goals recognise

that sustainable natural resource

use is a pivotal factor to improving

economic prosperity and human 
wellbeing in order to achieve overall objectives. Unlike the

Millennium Development Goals,

these objectives not only recognise the need for improved human

wellbeing and equality, but also

raise awareness to the science that proves an improved environmental ecological situation will benefit the planet as a whole (United Nations Environment Program,2016).

Bárcena and Potočnik (2016) stated in the United Nations Environment Programme's report Global Materia Flows and Resource Productivity:

\section{"It has been widely} acknowledged that such a world can only be achieved if we take better care of, conserve and use natural resources and significantly improve resource efficiency in both consumption and production in the years to come."

This shift in the belief that sustainability is becoming a focal point of global development has been reflected in new architecture since the turn of the century.

\section{Exponential increases in}

industrialisation and urbanisation as a result of evolving social, economic and technological needs over the past fifty years in particular have

had an everlasting impact on our planet's changing environment. This

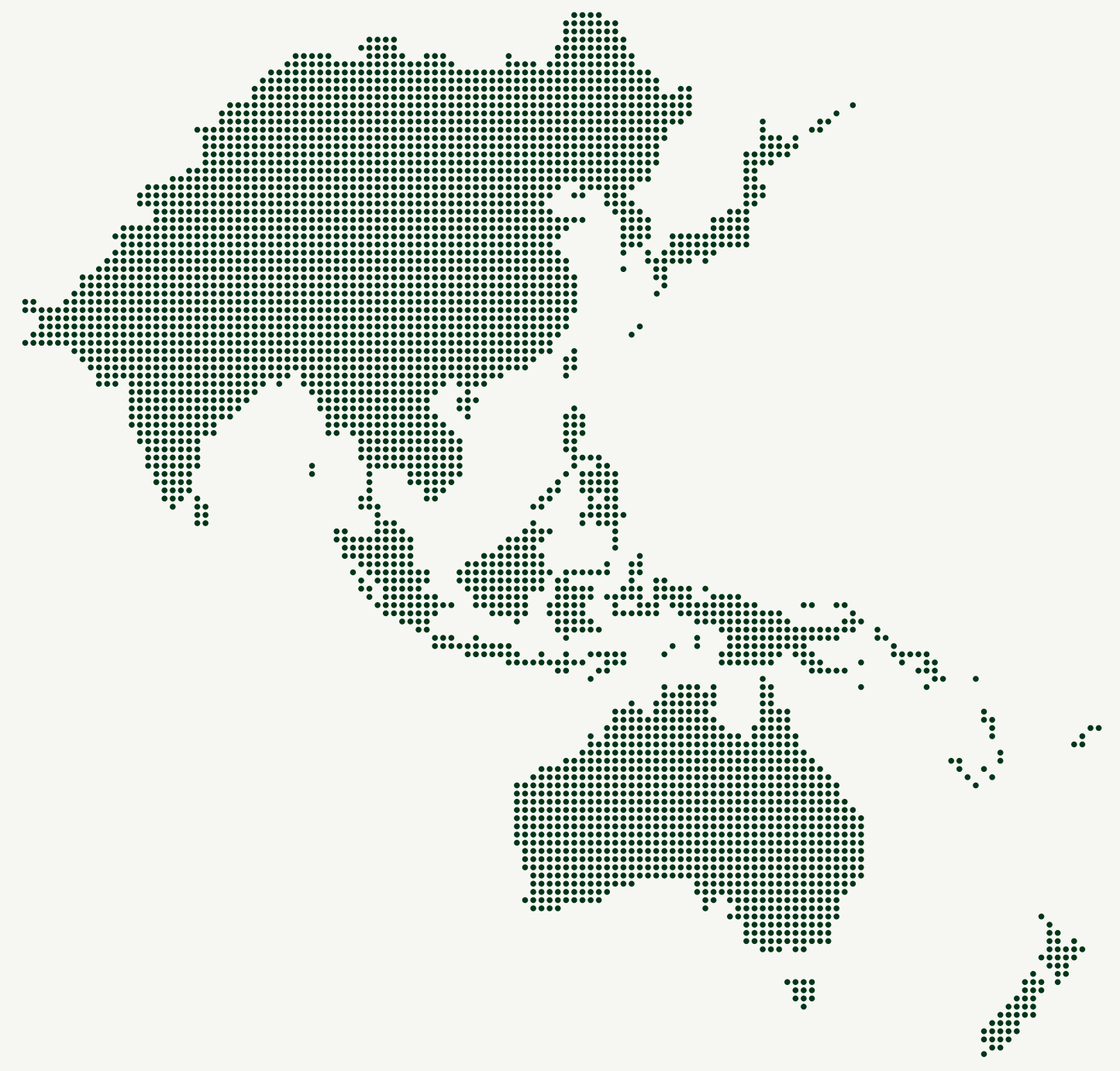


has drawn global attention to the issues of climate change, resource depletion and accumulating waste.

While population growth has contributed to the rising demand for materials, more significantly has been the global expansion of the middle class. Millions of civilians lifted out of poverty over the past fifty years has resulted in new consumers requiring products

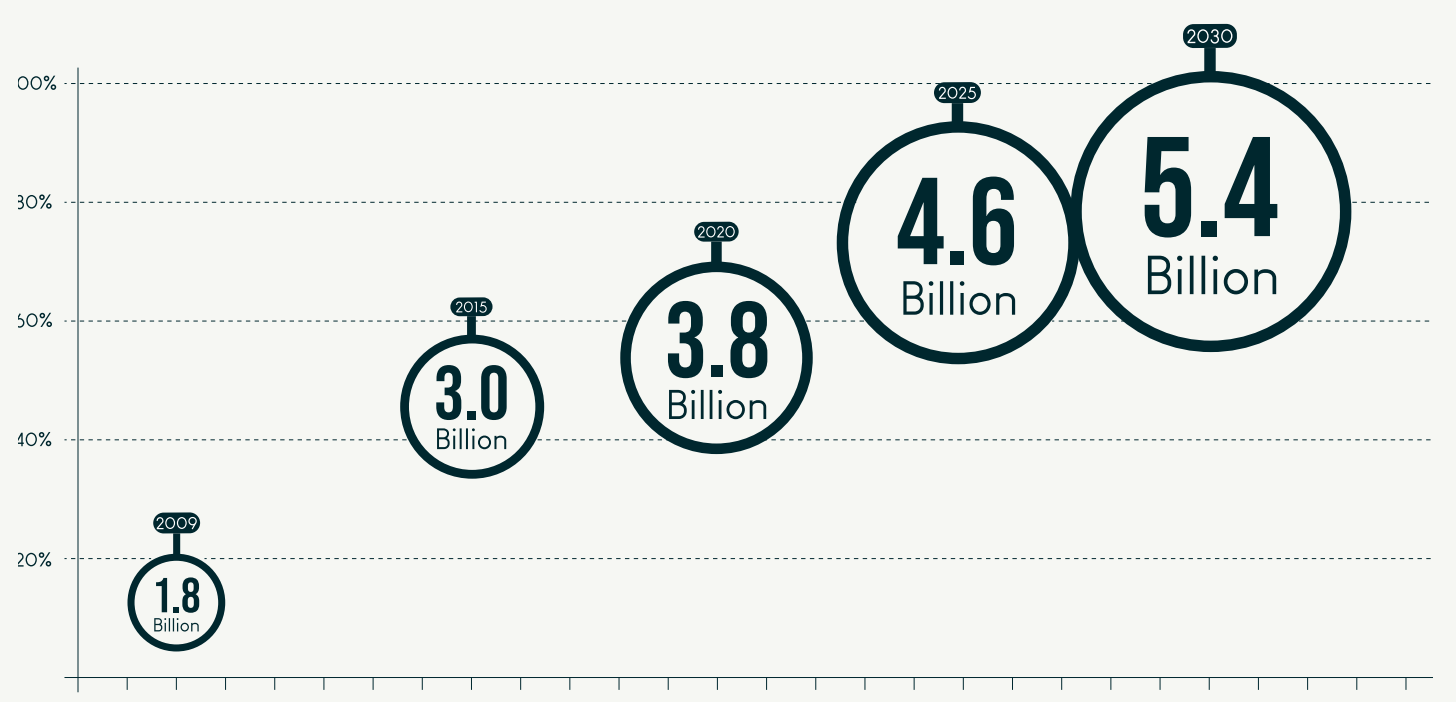

Fig.13.The rise of the middle class between 2009-2025

and services with a higher material intensity, causing the global

economy to need significantly more materials per unit of Gross Domestic Product (Schandl et al.,2018). Since

2009, the global middle class population has increased from 1.8 billion to 4.1 billion, with a projected rise to 5.4 billion by 2030 (Fig.1.3) (Kharas,2010). This social change is particularly prevalent in developing countries such as in Asia and the Pacific (Fig1.2). Consequently, this contributes to growing environmental pressure with "detrimental effects for the ability to mitigate major environmental impacts and stay within planetary boundaries

(Rockstrom et al.,2009; Steffen et al.,2015; Schandl et al.,2018). In

2019, the global population required

1.75 times the amount of resources that can be regenerated in a year to sustain current behaviours

(Fig.1.4) (Global Footprints Network,
2019). This demonstrates that a decrease in population is not the key to solving natural resource exploitation and depletion issues. Manufacture and construction methods must be altered to rely on fewer mineral resources. These exponentially increasing changes in society have seen an extraordinary expansion in the extraction of natural resources.

Schandl et al.,

(2018) collaborated various studies evaluating the global demand for materials, finding that in 1970-2019 material resource extraction more 


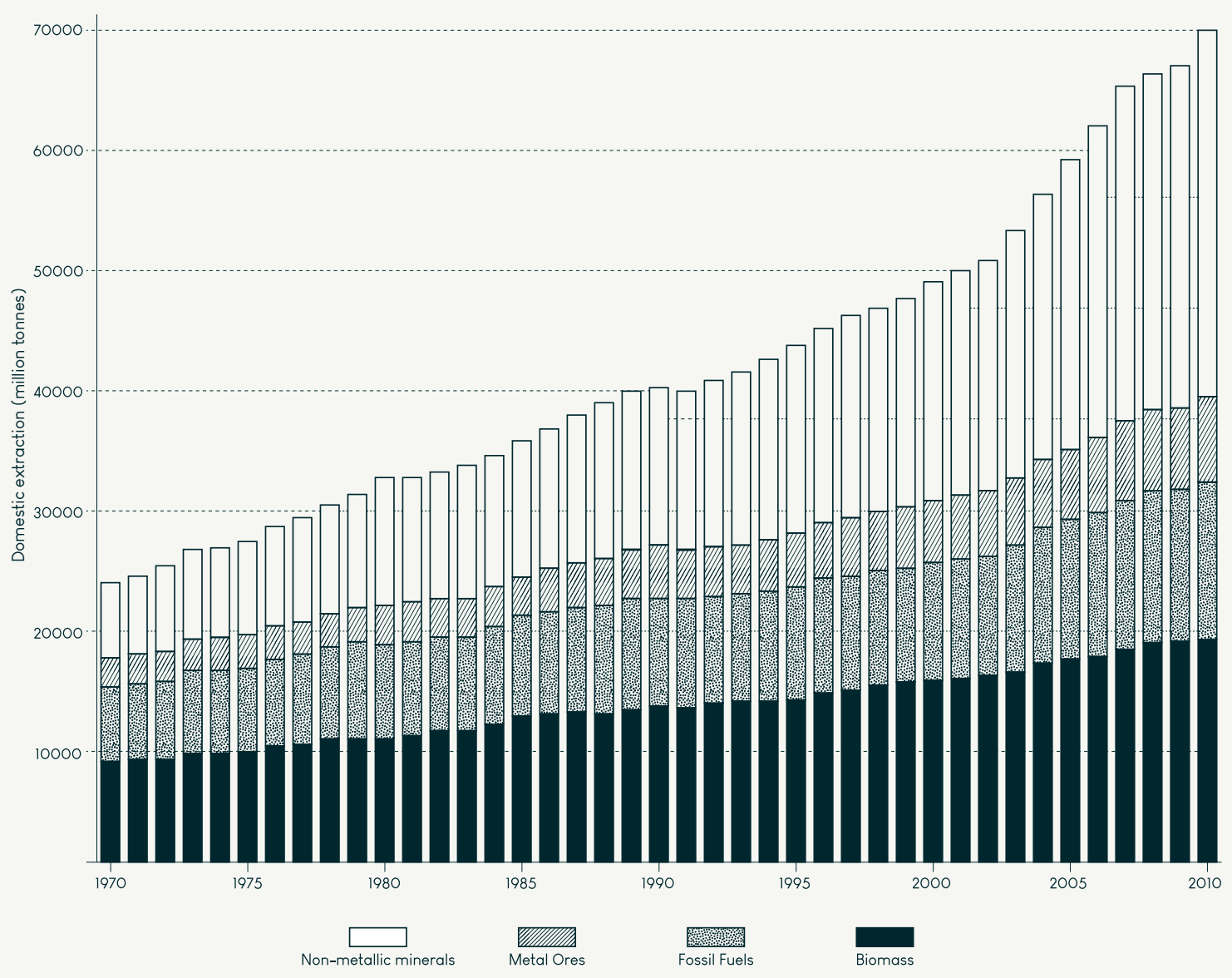

Fig15.Graph showing the 3-fold rise of domestic extraction of natural resources between 1970 and 2010 than tripled, increasing from 22 billion tonnes to 70 billion tonnes.

The largest increase proportionally was non-metallic minerals (Fig.1.5). Furthermore, Kraussmann et al.

(2014) evaluated that the global use of natural resources used in buildings and infrastructure increased 23-fold between 1900 and 2010. This increase came at a time when global economic and population growth have been slowing, and is strongly related to

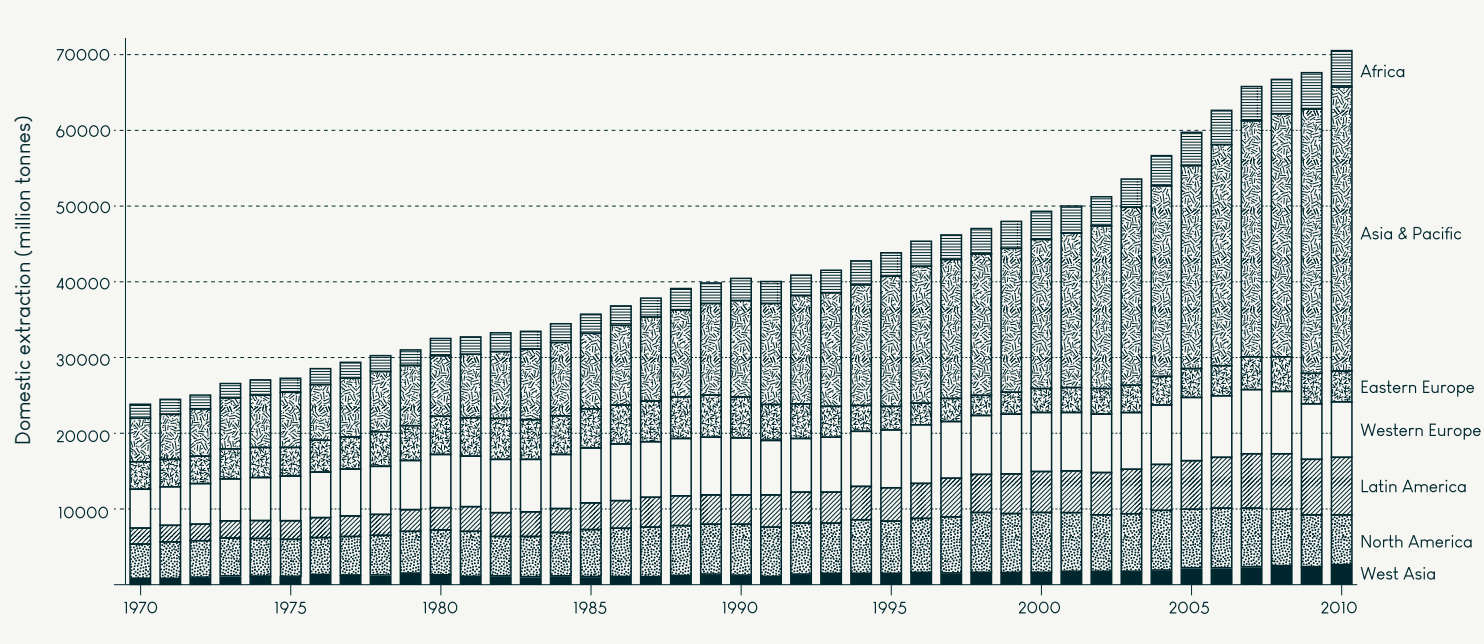

Fig.1.6.Exponentially increasing domestic extraction means Asia and the Pacific are failing to meet demand

the industrialisation and urbanisation of emerging economies, such as China and other Asia and Pacific nations, requiring "unprecedented amounts of iron, steel, cement energy and construction materials" (Schandl et al.,2018). However, the more densely populated regions of

Europe, Asia and the Pacific have been failing to meet demand for their extraction of natural resources, thus relying on large imports from other regions (Fig1.6) 
Furthermore, Schandl (2018) discovered that 30 billion tonnes of extracted material were required to produce 10 billion tonnes of directly traded goods (Fig1.7) Expressly this means two thirds of extracted material for trade becomes accumulated waste, and exemplifies the need for locally sourced materials, particularly for isolated countries such as New

Zealand where overseas trade incurs significant carbon footprints.

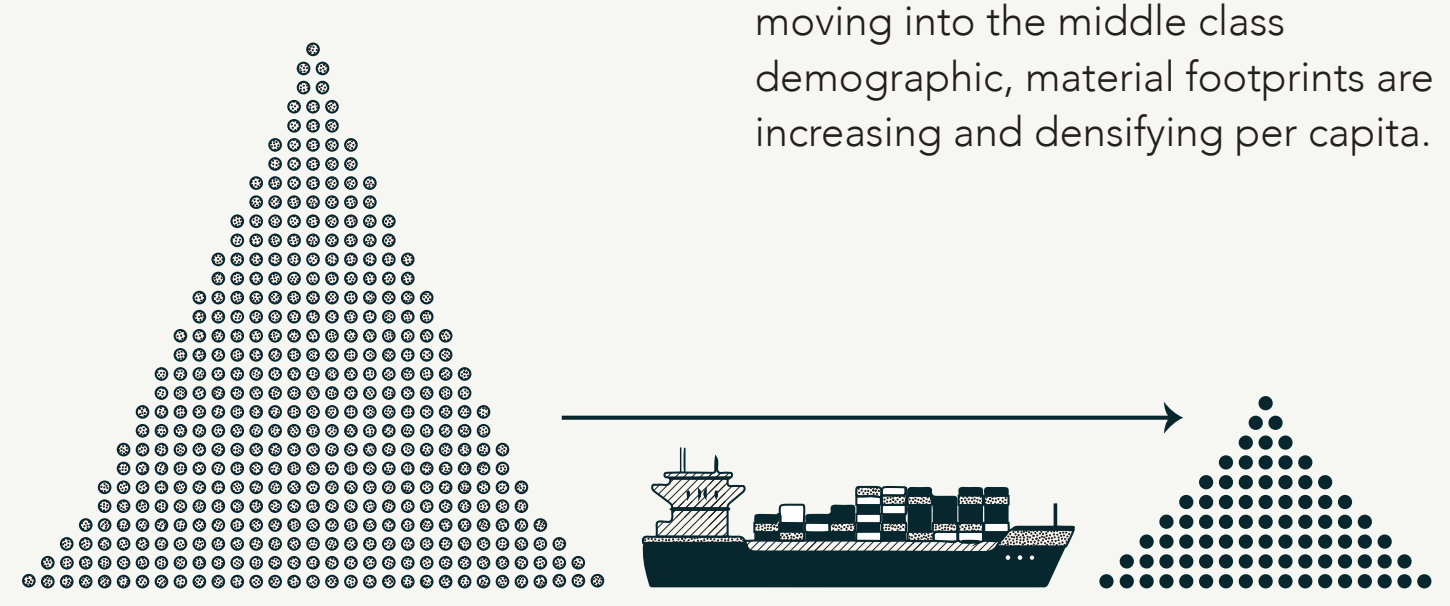

Fig1.7. 30 billion tomnes of extracted material are required to produce 10 billion tomnes of directly traded goods.

Moreover, New Zealand's position as a country with a very high development index (HDI) suggests that the nation's materials footprint per capita is more than double that of the world average (Figure 11) (UNEP,2016; Schandl et al.,2018).

Therefore, this research

demonstrates that slowing or

decreasing population growth is not the key to solving natural resource exploitation issues. In parallel with more of the global population moving into the middle class demographic, material footprints are creasing and densifying per capita.

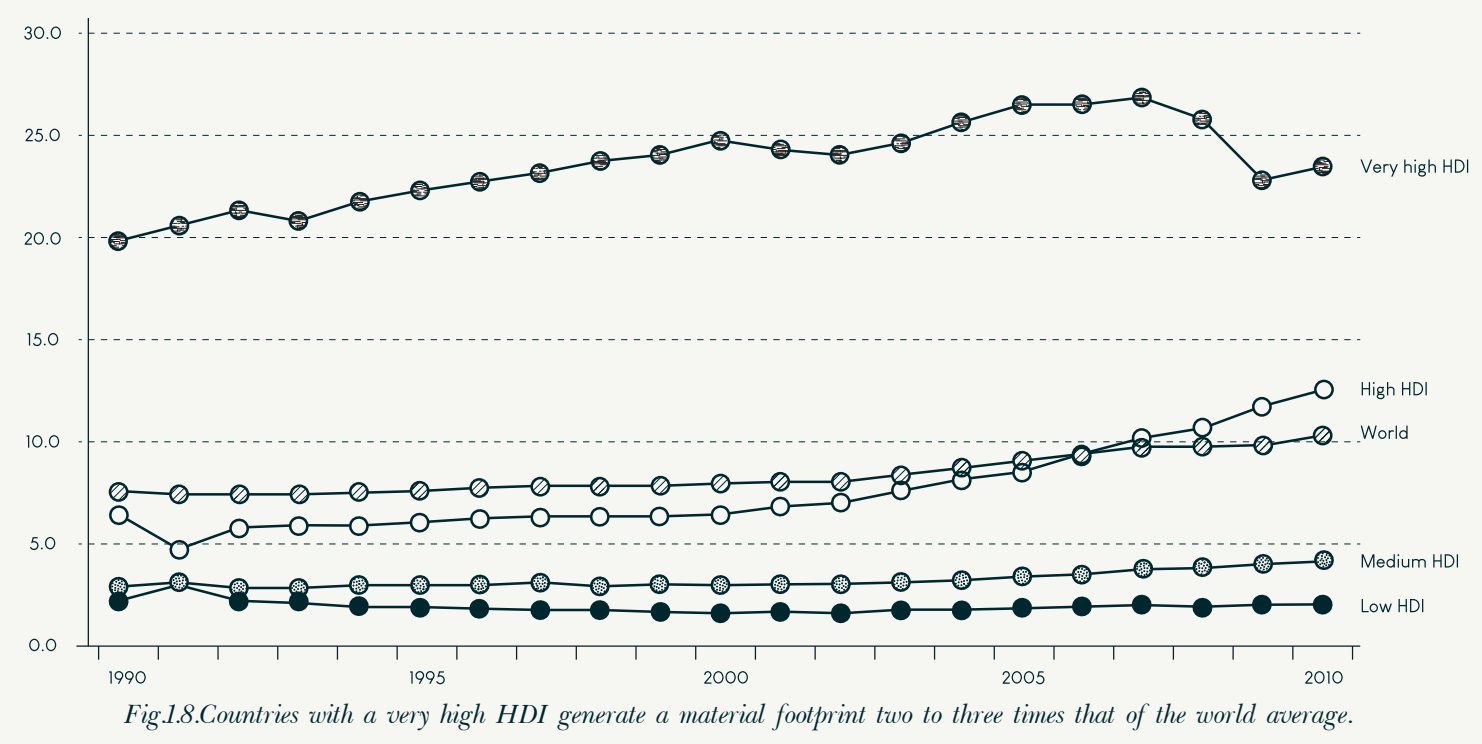

Manufacture and construction

methods must be altered to rely on

fewer mineral resources in order

to slow its exponentially increasing

exploitation. Without change, the

earth cannot renew the materials

needed to sustain our current

lifestyles. 
Chapter 2

\section{THE GLOBAL SAND SHORTAGE}

This content is unavailable. Please

consult the figure list for more details. 2.1. THE MEANING OF
SAND

The fight for natural resources has been a pivotal debate among scientists, politicians and media for thirty years as the global climate crisis reaches a pinnacle. As we watch sea levels rising, glaciers melting and forests burning, the

scarcity of sand is acknowledged by comparatively few.

Beiser, (2018) describes sand as "something most of us barely

ever think about and yet can't live without" and that "it is to cities what flour is to bread, what cells are to our bodies". What is not known by many is that sand is a prevalent material in electronics, cosmetics, wine, infrastructure, glass, concrete and even paper (Delestrac,2013).

Sand is often the basis for

creation myths around the world 
(Welland,2009). Analogies with sand lie deep within the majority of the

world's cultures, from sandcastles,

to the Sandman who eases children

to sleep to Buddhist monks who

have painted with it for centuries

(Beiser, 2018). The idealistic,

romaticised view of paradise is, for

many, a beach. For some cities - San

Francisco, Chicago, Hong Kong

and Singapore, for example - sand

is the material upon which the city

is built: land artificially built from

sand dredged up from underwate

(Beiser,2018).

For centuries sand has been used as a symbol of infinite time (Fig2.2.), and is seen as a limitless resource: astronomers often refer to the amount of stars in the universe

being greater than grains of sand on earth (Tweedie,2018). But the truth

is the opposite: just like any natural resource, it is finite. The world is running out, and its extraction process has disastrous effects on many aspects of the natural environment (Delestrac,2013; Torres et al.2017). And yet, we use almost 50 billion tons of sand and gravel every year, enough to cover New

Zealand twice over (Freedonia,2016).

The sand shortage has the potential to be one of the greatest crises of the current generation,

however scarce media attention has deemed it uncharted to many. In July 2014, the United Nations

Environment Programme released a paper entitled Sand, rarer than one thinks (Peduzzi,2014). In the years that followed, somewhat mystifying articles appeared in the world's tabloids. "The world is running out of sand" in the New Yorker (Owen,2017)، "The world's
This content is unavailable. Please consult the figure list for more details. 
disappearing sand" in the New York Times (Beiser,2016), and "Is the world running out of sand?" from The Guardian (Tweedie,2018) are jus a few of the puzzled headlines that began to surface in media outlets around the world, continuously proving how little recognition the world has for the sand crisis.

Thus, this thesis contributes to rising awareness of the issues associated with the limited availability of sand.

\subsection{GLOBAL SAND CONSUMPTION}

While sand has been used for construction for thousands of years from the time of the Egyptians today's unprecedented consumption is the exponential increase in the size and number of cities, partly due to urbanisation: the rise of the middle class providing incentive for people to move from rural to urban areas (Chapter 1). Cities are made of concrete, asphalt and glass: all which require huge amounts of sand to manufacture. Therefore, the sand crisis falls significantly upon the shoulders of architecture, and raises questions around how the industry can design with more renewable materials with less sand.

Domestic extraction of global material resources has more than tripled in the past fifty years, with the largest and most quickly increasing proportion being nonmetallic minerals. This sub-category includes sand, gravel, clay, limestone and gypsum. Although nonmetallic minerals account for almost 50\% of global material use, they are the category with the highest uncertainty surrounding their quantifiable usage (Miatto,2017). Miatto et al.'s 2017 study Global

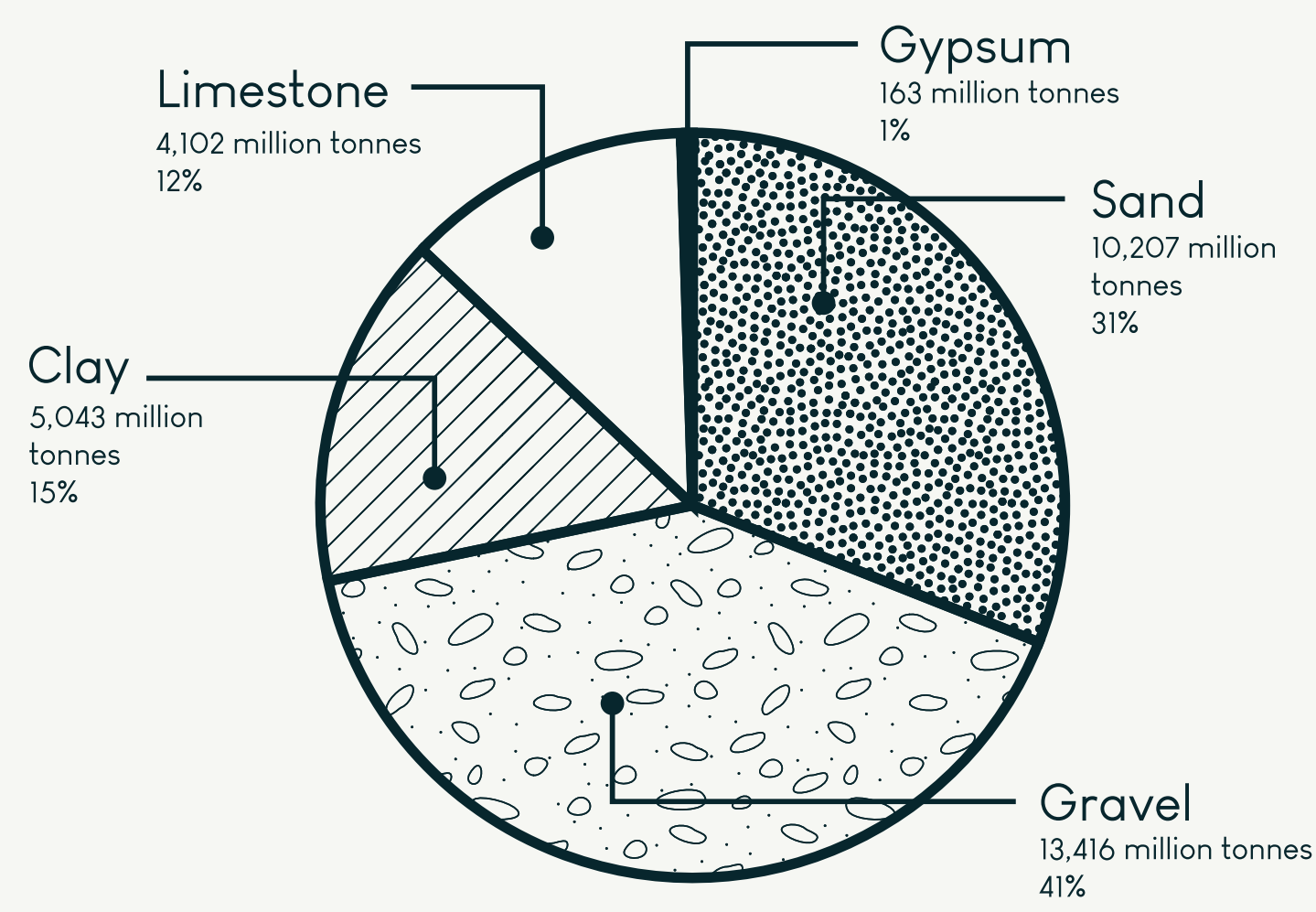

Fig.23.Sand accounted for 31\% of all extracted nonmetallic minerals in 2010 
China: 42.9

USA: 29.25

billion tonnes

1900-2000

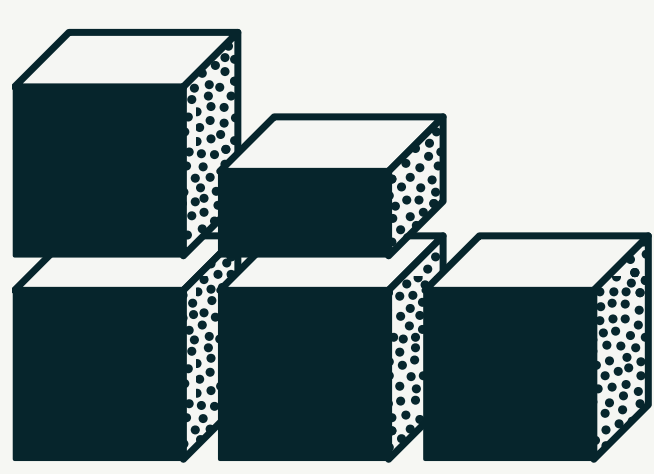

Fig. 2.4.China used more sand in billion tonnes

\section{6-2019}

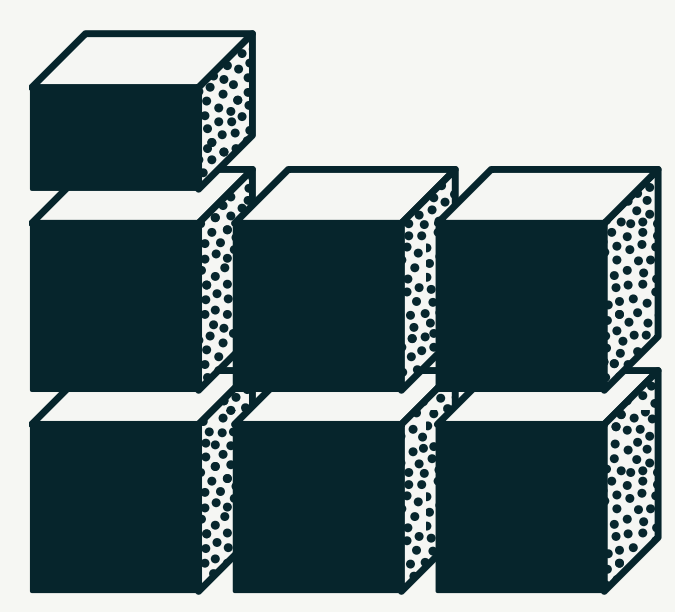

Patterns and Trends for Non-Metallic Minerals used for Construction

provided perhaps the first accurate

study to quantify nonmetallic

mineral usage, finding that sand

accounted for around one

of this category in 2010 (Fig.2.3.)

This figure has increased 3 -fold

since the 1970s largely due to

urbanisation in Asia and the Pacific

(Chapter 1). This has resulted in

China consuming more sand in the

last three years than the United

States did last century (Fig2.4.)

(Swanson,2015; Owen,2017). The

United Nations estimates the sand

used globally in 2012 could have

constructed a $27 \mathrm{~m}$ high by $27 \mathrm{~m}$ wide

concrete wall around the equator

(Constable,2017).

There is such a demand for sand in

the middle east that Dubai, a city

on the edge of the world's fourth largest desert, imported sand from Australia for the construction of

the Burj Khalifa (the world's tallest building), having exhausted its marine sand deposits during the construction of the Palm islands and the World islands (Rayasam,2016; Tweedie,2018; Gifford,2020). The islands remain largely unoccupied today (Wainwright,2018).

Examples like this show the dependency the construction industry has on sand, but also how quickly marine deposits can be completely depleted. The industry must alter its reliance on sand to prevent the collapse of a natural system producing the valuable resource. 
This content is unavailable. Please consult the figure list for more details.

Fig.2.5.Sand grains found on a beach (left) compared to nearby sand dunes (right)

\subsection{NATURE'S \\ MANUFACTURE

$$
\text { OF SAND }
$$

Sand is formed by erosive processes over thousands of years. This means it takes thousands of years to renew, and is being extracted at a rate far greater than its renewal. This makes it nearly impossible to keep up with its exponentially increasing global consumption (section 2.2).

Sand is seemingly plentiful to many, perhaps due to its visible abundance: deserts cover approximately one third of the earth's land surface. However,

what is not known by many is that desert sand is not suitable for

the manufacture of materials for construction, including concrete and glass (Peduzzi,2014). This is due to the shape of the grains themselves. Desert sand grains are much more spherical in form, while marine sand grains (sand extracted from river beds and ocean beds) are much less uniform in shape (Fig.2.5). The roundness of the grains found in deserts is caused by the strong winds that plague desert environments (Zhang et al.,2006). Grains of sand blown about in the wind endlessly collide with each other, knocking off any rough edges and causing them to become more round (Welland,2009). This is in comparison to river or beach sand, where water provides a cushioning effect. The difference in shape means that marine sand stick together much more easily than desert sand, giving it significantly improved structural integrity. As Beiser (2008) put it:

"Making concrete with desert sand is like trying to build something out of a stack of marbles instead of little bricks".
Thus, marine sand is now being depleted from the world's river beds and ocean beds, causing devastating environmental effects (section 2.4)

2.4.SAND

COMPOSITION

Sand is usually defined as a grain between $0.05 \mathrm{~mm}$ and $2 \mathrm{~mm}$, or anything able to be carried by the wind but big enough that it doesn't stay in the air (Alden,2017). Most sand is made of quartz - crystalline silica or $\mathrm{SiO}_{2}$. The farther from its source, the more pure the silica content is (Alden,2017). Sand can also be made of volcanic ash (black sand), gypsum, shells, coral, plankton or even parrotfish excretion (NOAA,2020). Silica sand is of interest in this thesis because it is what is used for construction materials such as concrete and glass. 
This is because unlike other types of sand, silica sand is much harder and therefore stronger, and is insoluble in water (Castro,2013).

\section{Silica sand is essentially}

decomposed rock, formed through

erosion by rocks travelling slowly

down rivers and streams, often

starting thousands of kilometres

from the ocean. Weathering

processes such as wind, rain and

freezing cycles break down the rock

into smaller grains (Castro,2013).

The process can take thousands or

millions of years, eventually making

it to the ocean where waves and

tides cause them to erode further

into what is defined as sand (NOAA

2020).

\subsection{ECOLOGICAL DESTRUCTION}

Humans have exercised the natural benefits of riverbeds for centuries, but industrialisation has excelled the use of these natural resources like sand far beyond the rate at which the earth can naturally reproduce them. Most sand is created by the process of erosion of rocks through riverbeds and ending at the ocean (section 2.4). Rivers are a major source of sand globally because cities tend to be located near rivers, so transportation costs are low (Koehnken et al.,2020). It is this sand which is suitable for manufacturing construction materials such as cement as glass (section 2.3). However, river sand is much less plentiful than desert sand: while the global demand for sand is estimated to be up to 50 million tonnes annually, riverbed sand availability is only 7 million tonnes (Kumar,2013 Rege,2016). Marine sand mining causes major destruction to the communities, ecosystems and coastlines that get in the way of mining (Connelly et al.,2020). One example is the Puyangjiang River which has been transformed into sand quarries, and was listed as "one of the worst cases of ecologica degradation" in the region (Connelly et al.,2020; Liu et al.,2016).

Sand mining not only affects human activity but also disturbs the habitats of flora and fauna (Krause et al.,2010; Fraser et al.,2017). For example, sand is essential for many species of fish, providing environmental conditions needed for breeding, feeding and hiding (Padmalal\&Maya,2014). The act of dredging sand disturbs turbidity and sedimentation levels and reduces light availability to marine ecosystems (Fraser et al. 2017).

Sand in riverbeds acts as aquifer systems, storing large amounts of ground water which maintain river flow (Padmalal\&Maya,2014). Furthermore, sand is an effective filter for pollutants and therefore improves water quality for local ecosystems (Filho et al.,2004,

Padmalal\&Maya,2014; Peduzzi,2014).

One example of affected species is the Gangetic River Dolphin which has become all but extinct (Mazumder et al.,2014).

In their report Impacts of River Sand Mining, Padmalal and Maya report that "the impacts of river sand mining will not be readily felt at measurable levels as it requires a decade or more to surface". This addresses the need for immediate action for reducing the amount of sand that is used in construction, as it the peak of today's impacts will not be felt for ten years or more. 
One example is Poyang Lake,

China's largest freshwater lake, which

has almost completely dried up due

to sand dredging (Lai et al.,2014)

(Fig.2.8). This has devastating effects

for the local communities and

millions of migratory birds that rely

on the lake for fish (Constable,2017).

Riverbed sand dredging in Africa

is leaving poor rural communities

without water access (Fig.2.6)

(Constable,2017). In New Zealand

sand dredging at the mouth of

the Waikato river is causing the

nearby coastline at Port Waikato

to erode by as much as six metres

per year (Fig.2.7) (Wilson,2019;

O'Dwyer,2020). Sand mining has had devestating effects on coastal communities around the world

including in the Maldives, India, Florida and many other island

nations (Delestrac,2013).

Sand mining has cascading effects on ecosystems and communities.

For example, sand extraction processes cause coastline and river destabilisation, which undermines resilience to natural disasters like storm surges and tsunamis (Torres et al.,2017). This issue escalates as sea levels continue to rise. There is also evidence that significant sand extraction can encourage the spread of infectious diseases such as malaria (Torres et al.,2017; Merritt et al.,2010). Additionally, the sand black market contributes to major crime

issues and violence (section 2.6).

\subsection{REGULATION OF SAND MINING}

It is very difficult to regulate consumption and exportation of sand on both a local and global scale because it is an open pool resource (Delestrac,2013; Fraser et al.2017; Torres et al.2017). In most countries there are no laws surrounding who can take sand from rivers and beaches, because restricting its access comes at a very high cost (Torres et al.,2017). Sand is also a relatively easy resource to extract, compared to fossil fuels for example. The lack of sand extraction regulation has lead to overexploitation and degradation due to failure to recognise the consequences of sand mining, and failure to understand that sand is a finite resource (Torres et al.,2017).

Some places have attempted to regulate sand extraction to save their coastlines (Rege,2016). However, even in places where sand mining is regulated, sand has become subject to illegal 
extraction and trade (Rege,2016). The 'Sand Mafia' is considered to be "one of the most prominent, violent, and impenetrable organised crime groups" in India (Rege,2016;

Kumar,2013). The Singapore

government has been accused of illegally importing sand from Cambodia and other Southeast Asian countries for reclaimed land (Peduzzi,2014). One report found that Singapore's land area increases by about $10 \%$ every year, a feat primarily achieved by dumping millions of tonnes of sand into the ocean (Gabbatiss,2017). Examples such as this have lead to some countries in Southeast Asia, like Cambodia, banning the exportation of sand entirely, and new sand extraction plants have not been granted permission to run (Peduzzi,2014).

\subsection{REFLECTION}

Analysis of the wide range of issues and cascading effects of sand mining around the world further identifies the need to reduce the reliance the construction industry has on sand, considering its significant uptake of sand consumption. Research in the area must be accelerated in order to reduce the devestating effects on the environment, and to prepare the industry for the imminent crisis of the sand shortage.
This content is unavailable. Please consult the figure list for more details. 
Chapter 3

\section{GLAZING STUDY}

This content is unavailable. Please consult the figure list for more details.
3.1. KNOWLEDGE GAP It is widely acknowledged that sand is a key component of both glass and concrete. However, initial research determined there is a knowledge gap on the effect of the sand crisis on the glass industry in particular. This shows a lack of recognition of the architectural implications of designing with less glass, particularly for New Zealand and its idealised views of glass. 
Therefore, this thesis will focus on the use of glass in contemporary New Zealand architecture in order to attempt to bridge this gap of knowledge.

\subsection{SHORT HISTORY OF GLASS}

3.2.1. Reliance on glass

Humanity's relationship with glass is ever-evolving, shaped by technological and societal changes over time. The majority of architectural thinking surrounding the use of glass is derived from humans' relationship with nature, and the need for protection from natural forces and elements (Elkadi,2006). Glass has been important to the anthropogenic world for millennia: it has been used for construction since the time of the Egyptians (Beiser,2018).
In the 1500s, Italians invented the world's first completely clear glass, allowing telescopes, microscopes and other inventions to aid the scientific revolution (Beiser,2018)

But the industrial revolution brought about mass production and with it, the degradation of ecosystems worldwide due to sand dredging.

\subsubsection{Ruskin vs. Viollet-le-Duc}

The connection glass provides with nature has been debated by philosophers and designers for centuries. The Arcadian approach values architecture that follows natural laws and the unaltered

characteristics of natural materials. Elkadi(2006) argues that architects who promote this approach cannot extensively utilise glass because it is an unnatural, man-made material. In contrast, the Enlightenment period in Europe of the 18th
This content is unavailable. Please consult the figure list for more details. 
century suggested clear glass was necessary to "enhance the beauty" of other elements (Elkadi,2006).

Examples include the Hall of Mirrors in Versailles (Fig.3.2) and the Milan shopping mall. Ruskin and Violletle-Duc were at opposing ends of this spectrum. Ruskin rejected glass; he considered glass to be unnatural and harmful due to the large amounts of energy needed to produce it. Meanwhile Viollet-leDuc believed iron and glass were the materials of the future; ones which would turn architecture into a more efficient and modern discipline (Elkadi,2006).

\subsubsection{Industrial revolution}

The industrial revolution revealed further changing attitudes towards glass in architecture. This period saw the invention of the first large flat sheets of clear glass, providing architects with the power to challenge and manipulate environmental forces. The need for the façade to provide protection from exterior elements no longer interfered with the need to transmit light deep into the building's interior or to open up the envelope to views to the outside. Some of the first

buildings that benefitted from this were greenhouses (Fig.3.3)

3.2.4. The role of glass in modern architecture

In the twentieth century, the façade's role shifted from being a shield of natural forces to being a manipulator of them. These principles are still developing and being implemented today by the inclusion of double skin curtain walls, cross ventilation and other principles of passive design to reduce energy consumption. In 1914, Paul Scheerbart said:
"We live for the most part in closed rooms. These form the environment from which our culture grows. Our culture is to a certain extent the product of our architecture. If we want our culture to rise to a higher level, we are obliged, for better or for worse, to change our architecture. And this only becomes possible if we take away the closed character from the rooms in which we live. We can only do that by introducing glass to architecture".

Scheerbert's quote depicts a poetic modernist's view of the role of glass in architecture and anticipates the large, curtain-walled buildings of the mid 20th century. Some examples include Mies van der Rohe's Seagram building, the UN headquarters by Le Corbusier and Oscar Niemeyer, the Farnsworth House by Mies van der Rohe and the Charles and Ray Eames house (Fig.3.4\&3.5)

Corbusier in particular had a fascination with windows, coining the terming "ribbon window" as one of his five points of architecture, 
This content is unavailable. Please consult the figure list for more details. which were composed of horizontal cuts across entire facades to allow spaces to be equally lit and create unobstructed views across the landscape. Corbusier used

photography to drive the placement of windows to convey the landscape.

\subsubsection{Reflection}

Today, windows are still used in western architecture to frame the natural beauty and capture the view, a role which has not changed for over five hundred years (Elkadi,2006). This role is particularly evident in New Zealand homes, and despite the desirability of reducing the amount of glass we use in architecture, the importance of the view continues to be a major design driver in residential houses in New Zealand. This research

area has demonstrated an obvious role of glass in modern residential architecture in terms of the poetic aspects of design. However, there is an existing limitation in that

there is a limited understanding of how much sand is used for glass

in normal situations. The following study conducts a scientific study of the role of glass in New Zealand

residential architecture as a

comparison to the poetic aspect. 
This content is unavailable. Please

consult the figure list for more details.

This content is unavailable. Please

consult the figure list for more details. 
3.3. THE SCIENTIFIC $R O L E O F \quad G L A S S$

Sand is a key component of both concrete and glass, two of the world's most dependable construction materials, but as previously identified there is a knowledge gap on the effect of the sand shortage on the glass industry. This creates a lack of recognition of the architectural implications of designing with less glass, particularly for New Zealand where designers are becoming increasingly reliant on glass as a key conveyor of the landscape, freedom and command of space.

In New Zealand, sand and crushed aggregate for construction

accounted for $26.1 \%$ of the country's total domestic material extraction in 2017 (Lutter et al.,2020). Annual mineral industry statistics provided by the Petroleum \& Minerals department at New Zealand's

Ministry of Business, Innovation \& Employment shows that silica sand mining in New Zealand is variable, but is trending downwards over the past fifty years (Fig.3.6.) (MBIE,2020) However, the Ministry also found that 8.6 tonnes of sand and gravel are consumed per person per year: around 43 million tonnes annually (MBIE,2019). It can therefore be assumed that demand for glass in New Zealand is increasingly reliant on overseas imports, the production of which contributes to the growing global sand demand issues as well as increasing carbon emissions from its transportation. This demonstrates a need for decreasing the reliance the New Zealand architecture industry has on glass. Thus, a contradiction is presented between sustainable natural resource

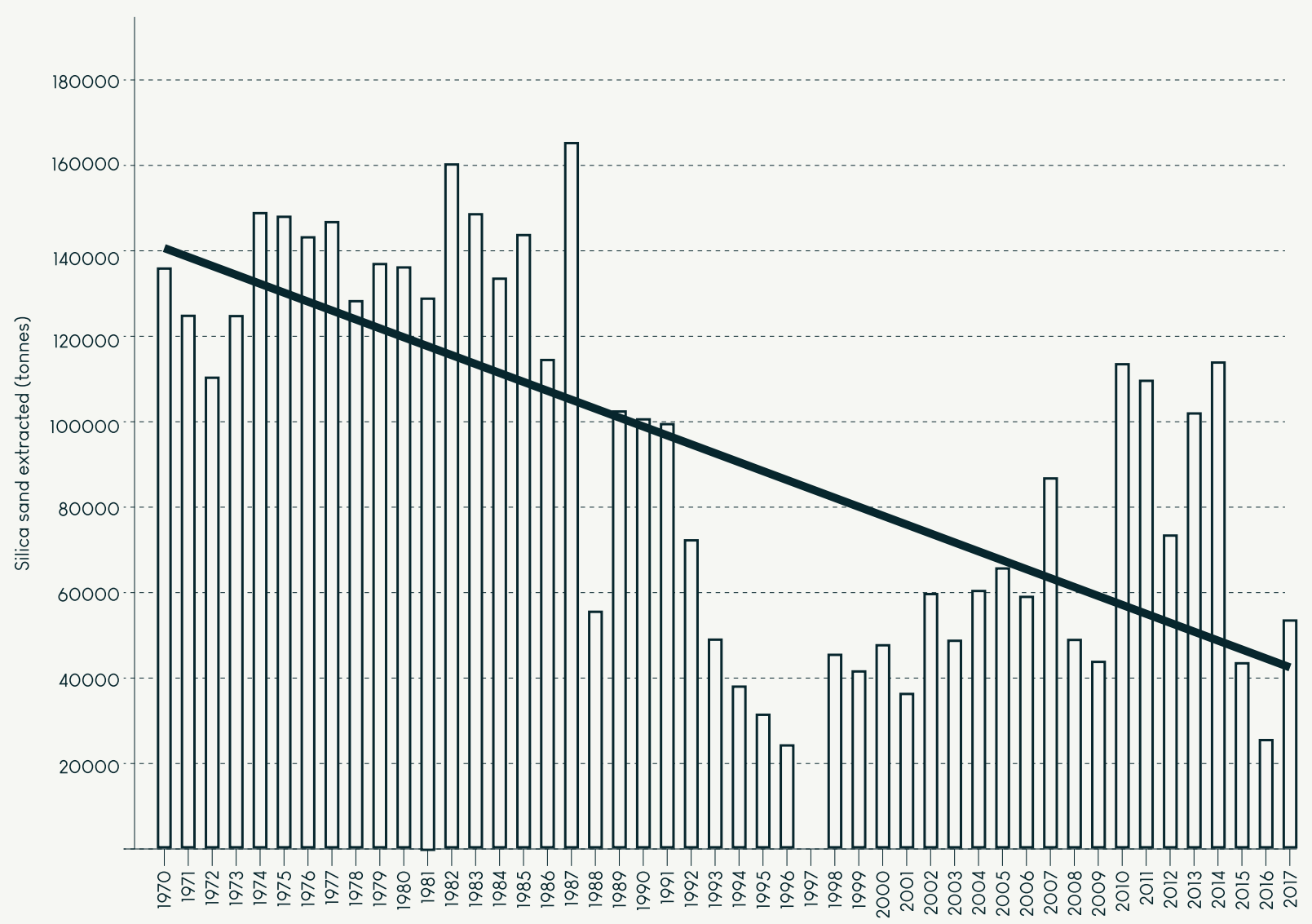

Fig.3.6.Silica sand extraction in New Zealand is decreasing 
use and trends in New Zealand architecture. This chapter aims to formalize these findings through a report on three types of residential dwellings in New Zealand in order to identify a framework for designing architecturally 'successful' dwellings with less glass.

\subsection{METHODOLOGY}

The sand usage of the case studies was calculated based on the volume of glass each building contained. This data was measured from the construction drawings of each project using digital scaling tools, and was based on a standardised $4 \mathrm{~mm}$ glass thickness. The glass weight was calculated by multiplying the volume by 2500 , as one cubic metre of glass is $2500 \mathrm{~kg}$. The sand content in kilograms of glass in New Zealand is around $75 \%$, thus to find the total silica sand content of the glass, the weight was multiplied by 0.75 (Hollingsworth,2016). The sand weight was then multiplied by a factor of 1.53 to find its volume in cubic metres. As the selected case studies were of varying floor areas, the total sand volume for each building is represented in cubic metres per square metre to give comparable value across the data set.

This methodology was developed as a way of estimating the comparable ratios of sand quantities in buildings, in the hope that future studies will allow for more standardised tools and theories surrounding the topic can be developed to provide bette insight into the extent of sand crisis issues in various contexts.

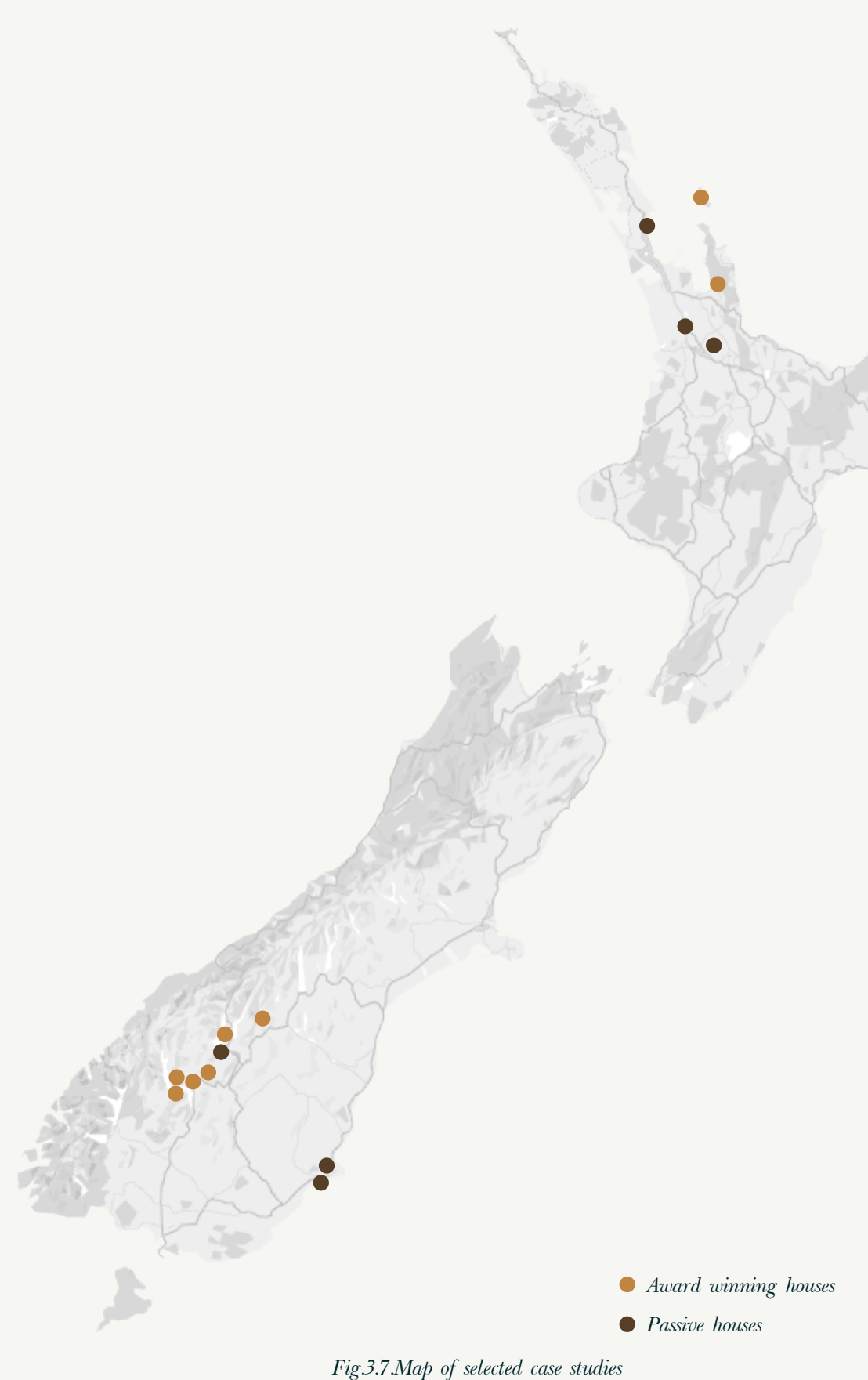




\subsection{CASE STUDY SELECTION}

Despite the desirability of reducing the use of glass in architecture, in recent years importance of the view continues to be major design driver in architectural residential dwellings in New Zealand. Meanwhile one existing limitation is that there is a limited popular understanding of how much sand is used for glass in normal situations. In order to quantify the issue, an analysis was undertaken of three types of dwellings in New Zealand: architectural award-winning homes, passive houses and standard specification design-and-build houses.

Eight case study award-winning residential buildings (category $A$ ), six passive houses (category B) and six standard specification houses (category C) were selected for sand content analysis.

Each of the award-winning case studies were selected for their relationship to the environment as a design driver, and their success at capturing the view through openings. Figures $26-33$ provide a visual of each selected case study in the award-winning architectural house category for context.

The second criteria for selection in Category A was the building's success in the New Zealand architecture market through awards such as the NZIA New ZealandArchitecture Awards.

Case studies were selected from opposing geographical regions of the country (Otago versus Northland, Auckland, \& upper Waikato) because this allowed for the greatest exploration of climatic factors alongside capturing the

view. The two regions allowed

for an architectural comparison between two of New Zealand's

most contrasting climatic conditions (Fig.3.7)

Buildings of different scales and from a variety of architecture firms were selected to assess disparate outcomes of design techniques for conveying the surrounding environment.

\subsection{RESULTS}

Tables 1-3 quantify the glazing areas and silica sand content measured from each case study. The glass content of each case study was evaluated as a percentage of the floor area. Every case study was double glazed with the exception of Category B - passive houses, all of which were triple glazed, the factor of which is accounted for in the total glazed area data. 
This content is unavailable. Please consult the figure list for more details. consult the figure list for more details.
This content is unavailable. Please consult the figure list for more details.

Fig.3.3. K Valley (Herbst Architects)

This content is unavailable. Please consult the figure list for more details.
This content is unavailable. Please consult the figure list for more details.

Fig.3.12. Closeburn Station (Warren\&Mahomey)

unavailable. Please consult the figure list for more details.
This content is unavailable. Please consult the figure list for more details.

Fig.3.13. Black Peak (Eliska Lewis)
This content is unavailable. Please consult the figure list for more details. 
CATEGORY A: AWARD-WINNING ARCHITECTURAL HOMES

\begin{tabular}{|c|c|c|c|c|c|c|c|}
\hline Project & Location & Designer & Awards & $\begin{array}{c}\text { Floor } \\
\text { Area } \\
\left(m^{2}\right)\end{array}$ & $\begin{array}{c}\text { Sand } \\
\text { content } \\
\left(\mathrm{cm}^{3} /\right. \\
\left.\mathrm{m}^{2}\right)\end{array}$ & $\begin{array}{c}\text { Glazed } \\
\text { Area } \\
\left(m^{2}\right)\end{array}$ & $\begin{array}{l}\text { Glazed } \\
\text { area } \\
\text { (\% of } \\
\text { floor } \\
\text { area }\end{array}$ \\
\hline $\begin{array}{l}\text { Timms } \\
\text { Bach }\end{array}$ & $\begin{array}{l}\text { Great Barrier } \\
\text { Island }\end{array}$ & $\begin{array}{l}\text { Herbst } \\
\text { Architects }\end{array}$ & $\begin{array}{l}2011 \text { NZIA } \\
\text { Auckland } \\
\text { Architecture } \\
\text { Award }\end{array}$ & 185 & 1711.5 & 32.2 & $17.5 \%$ \\
\hline $\begin{array}{l}\text { KValley } \\
\text { House }\end{array}$ & Coromandel & \begin{tabular}{|l} 
Herbst \\
Architects
\end{tabular} & $\begin{array}{l}\text { Home of the } \\
\text { Year } 2016\end{array}$ & 178 & 2824.4 & 51.3 & $28.8 \%$ \\
\hline $\begin{array}{l}\text { St Marks } \\
\text { Lane }\end{array}$ & Queenstown & $\begin{array}{l}\text { Dorrington } \\
\text { Atcheson }\end{array}$ & $\begin{array}{l}2019 \text { NZIA } \\
\text { Southern } \\
\text { Architecture } \\
\text { Awards } \\
\text { shortlist }\end{array}$ & 282 & 2951.4 & 84.9 & $30.1 \%$ \\
\hline $\begin{array}{l}\text { Mountain } \\
\text { Retreat }\end{array}$ & Closeburn & Fearon Hay & $\begin{array}{l}2009 \text { NZIA } \\
\text { New Zealand } \\
\text { Architecture } \\
\text { Award } \\
2008 \text { World } \\
\text { Architecture } \\
\text { Award }\end{array}$ & 100 & 3107.4 & 31.7 & $31.7 \%$ \\
\hline
\end{tabular}

\begin{tabular}{|l|l|l|l|l|l|l|l|}
\hline $\begin{array}{l}\text { Closeburn } \\
\text { Station }\end{array}$ & Closeburn & $\begin{array}{l}\text { Warren \& } \\
\text { Mahoney }\end{array}$ & $\begin{array}{l}\text { 2015 NZIA } \\
\text { Southern } \\
\text { Architecture } \\
\text { Award }\end{array}$ & 458 & 4207.2 & 196.5 & $42.9 \%$ \\
\hline $\begin{array}{l}\text { Black } \\
\text { Peak }\end{array}$ & Wanaka & Eliska Lewis & $\begin{array}{l}\text { 2019 NZIA } \\
\text { Southern } \\
\text { Architecture } \\
\text { Award }\end{array}$ & 337 & 4896.3 & 168.3 & $49.9 \%$ \\
\hline $\begin{array}{l}\text { Alpine } \\
\text { Terrace }\end{array}$ & Arrowtown & Fearon Hay & $\begin{array}{l}2019 \text { NZIA } \\
\text { Southern } \\
\text { Architecture } \\
\text { Award }\end{array}$ & 347 & 5040.9 & 178.4 & $51.4 \%$ \\
\hline Lindis & Lindis Valley & Architecture \\
Workshop & $\begin{array}{l}\text { 2019 NZIA } \\
\text { New Zealand } \\
\text { Architecture } \\
\text { Award } \\
\text { 2019 World } \\
\text { Architecture } \\
\text { Award }\end{array}$ & 670 & 6472.5 & 442.3 & $66.0 \%$ \\
\hline
\end{tabular}

Table 1. Calculated silica sand contents and glazing area of selected award-winning case studies. 


\begin{tabular}{|c|c|c|c|c|c|c|c|}
\hline Project & Location & Designer & Awards & $\begin{array}{c}\text { Floor } \\
\text { Area } \\
\left(\mathrm{m}^{2}\right)\end{array}$ & $\begin{array}{c}\text { Sand } \\
\text { content } \\
\left(\mathrm{cm}^{3} /\right. \\
\left.\mathrm{m}^{2}\right)\end{array}$ & $\begin{array}{c}\text { Glazed } \\
\text { Area } \\
\left(\mathrm{m}^{2}\right)\end{array}$ & $\begin{array}{l}\text { Glazed } \\
\text { area } \\
\text { (\% of } \\
\text { floor } \\
\text { area }\end{array}$ \\
\hline St Clair & Dunedin & Architype & & 236 & 2514.3 & 40.4 & $17.1 \%$ \\
\hline Taupiri & Waikato & eHaus & & 252 & 3004.8 & 51.5 & $20.4 \%$ \\
\hline Te Miro & Waikato & eHaus & & 322 & 3276.3 & 71.7 & $22.3 \%$ \\
\hline Kowhai & Dunedin & $\begin{array}{l}\text { Rafe } \\
\text { Maclean }\end{array}$ & $\begin{array}{l}2019 \text { NZIA } \\
\text { New Zealand } \\
\text { Architecture } \\
\text { Award }\end{array}$ & 117 & 3107.4 & 28.3 & $24.2 \%$ \\
\hline $\begin{array}{l}\text { George } \\
\text { Street }\end{array}$ & Wanaka & $\begin{array}{l}\text { Rafe } \\
\text { Maclean }\end{array}$ & & 211 & 3964.4 & 56.9 & $27.0 \%$ \\
\hline Öko Barn & Auckland & $\begin{array}{l}\text { Öko } \\
\text { Konstrukt }\end{array}$ & & 288 & 4896.3 & 46.4 & $16.1 \%$ \\
\hline
\end{tabular}

Table 2. Calculated silica sand contents and glazing area of selected passive house case studies

\begin{tabular}{|c|c|c|c|c|c|c|c|}
\hline Project & Location & Designer & Awards & $\begin{array}{c}\text { Floor } \\
\text { Area } \\
\left(\mathrm{m}^{2}\right)\end{array}$ & $\begin{array}{l}\text { Sand } \\
\text { content } \\
\left(\mathrm{cm}^{3} /\right. \\
\left.\mathrm{m}^{2}\right)\end{array}$ & $\begin{array}{c}\text { Glazed } \\
\text { Area } \\
\left(\mathrm{m}^{2}\right)\end{array}$ & $\begin{array}{l}\text { Glazed } \\
\text { area } \\
\text { (\% of } \\
\text { floor } \\
\text { area }\end{array}$ \\
\hline \multirow{6}{*}{\multicolumn{2}{|c|}{$\begin{array}{l}\text { Standard specification } \\
\text { design \& build homes, } \\
\text { designed for multiple } \\
\text { locations }\end{array}$}} & $\begin{array}{l}\text { Fletchers } \\
\text { Construction }\end{array}$ & & 161 & 2796.4 & 45.9 & $28.5 \%$ \\
\hline & & $\begin{array}{l}\text { Landmark } \\
\text { Homes }\end{array}$ & & 265 & 2341.0 & 63.2 & $23.8 \%$ \\
\hline & & $\begin{array}{l}\text { Jennian } \\
\text { Homes }\end{array}$ & & 322 & 3276.3 & 71.7 & $22.3 \%$ \\
\hline & & $\begin{array}{l}\text { Stonewood } \\
\text { Homes }\end{array}$ & & 244 & 3122.4 & 77.7 & $31.8 \%$ \\
\hline & & $\begin{array}{l}\text { Signature } \\
\text { Homes }\end{array}$ & & 163.3 & 2365.5 & 39.4 & $24.1 \%$ \\
\hline & & $\begin{array}{l}\text { David Reid } \\
\text { Homes }\end{array}$ & & 146 & 4043.6 & 146 & $41.3 \%$ \\
\hline
\end{tabular}

Table 3. Calculated silica sand contents and glazing area of selected standard specification house case studies 


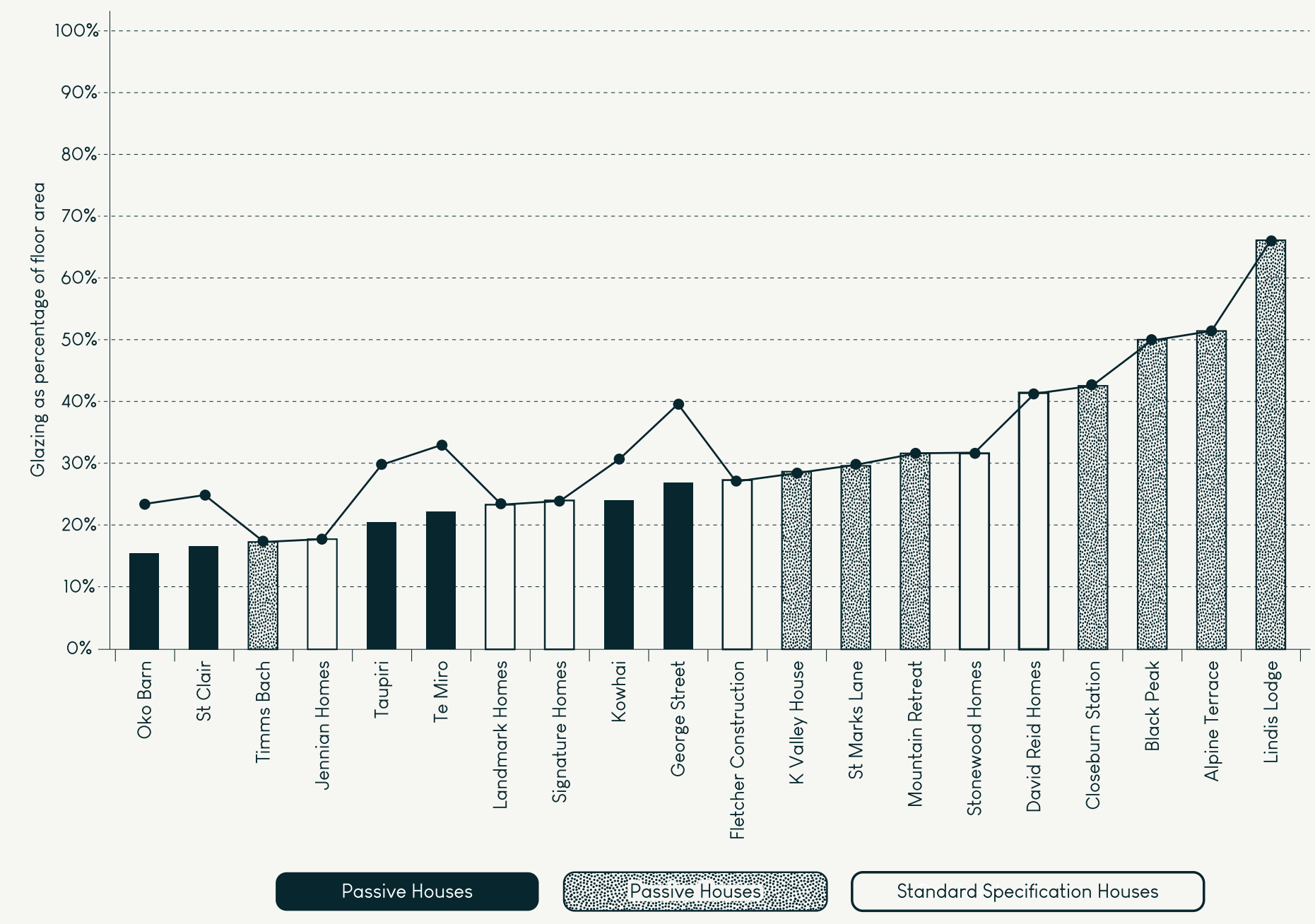

Fig.3.17. Glazing as a percentage of floor area in selected case studies

\subsection{DISCUSSION}

3.7.1. Architectural success versus glazing proportions

The undertaken study explores an area with limited knowledge. While it is possible to assert that further analysis and broader sampling is needed to refine and confirm the findings presented here, the reported data start to indicate trends which grant further exploration. This makes the study preliminary and explorative in nature, and necessary to foster more research in the area.

Results show that award-winning houses tended to have higher glazing percentages than both passive houses and standard specification houses. The extent of glazing evident in many analysed award-winning houses finds that architectural success in New Zealand homes tends to be represented by projects with large windows that use the landscape as a design driver. Meanwhile, passive houses and standard specification houses tended to have lower glazing per $\mathrm{m}^{2}$ floor area. However, there were some instances of architectural success being apparent in houses whilst maintaining lower glazing ratios, as seen in both Timms Bach by Herbst and Rafe Maclean's passive house, as well as the K Valley House by Herbst which received the Home of the Year award in 2016.

These homes all had glazing ratios of less than $30 \%$ of the floor area and Timms Bach demonstrated that architectural success could be achieved with a glazing ratio of just $17.5 \%$. This shows that while these homes are deemed architecturally successful, it is possible to have both captivating architecture that conveys 
the view and a low glazing ratio.

\subsubsection{Passive houses}

Passive houses tended to have lower glazing to floor area percentages, and had more consistent values per square metre. Passive houses also consistently achieved lower results despite having triple glazing as opposed to double glazing. This demonstrates that not only is it possible to have lower glazing ratios, but that perhaps an optimal specific range of glazing ratios contributes to a building's sustainable success in terms of its net energy usage - a factor that is often overlooked when evaluating architectural success through the marketing of awardwinning New Zealand homes.

3.7.3. Geographical advantages Results showed that Category A dwellings in the Northern regions of New Zealand tended to have lower glazing ratios than their Southern counterparts. This is perhaps to be expected due to the higher average temperatures of the Northern regions, thus requiring less glazing to prevent overheating. This therefore presents a greater challenge for designing in Southern regions with less glass.

\subsubsection{Standardised tools}

The study found largely varied glass to floor area ratios, ranging from $17.1 \%$ to $66 \%$, with a median of $27.9 \%$. Passive houses tended to have lower and more consistent glazed area ratios, indicating an optimal value range for reducing net energy usage while achieving architectural success. One case study showed that award-winning architecture can be achieved whilst maintaining a very low glass to floor area ratio. Therefore a design limitation of a maximum $20 \%$ of the floor area should be equivalent to the total glazed area of the building The comparison between the awardwinning building with the least amount of glass (Kowhai house) and the most amount of glass

(Lindis Lodge) showed that even if Kowhai house had the same square meterage of floor area as the Lindis Lodge, its glass usage would still be around a quarter that of Lindis Lodge (Figures36 \& 37).

\subsection{FINDINGS OF THE STUDY}

The study brought to consideration the importance of considering sand as a limited resource for architectural construction. It brings the knowledge already evident in other disciplines to an architectural audience, and by doing so

highlights the importance of the sand shortage as an architectura problem. The original and in many ways preliminary study of a range of houses shows some clear patterns that houses with higher emphasis on the view also use more glass. What is relevant to note is that the same houses are currently still receiving architectural recognition and

celebration without a recognition of the adverse impacts of the extensive use of glass in these houses. In the future of architecture, this position will need to change, and it is exciting that some examples already use less glass and receive architectural recognition. Finally, the work sets a clear and measurable target for the reductions in use of glass in residential architecture, which can assist anybody interested to adjust their practices to more 
easily achieve the needed change. The research brings to light the

need for more standardized tools for

quantifying the use of non-metallic

minerals in buildings in order for

ecosystem impacts of using sand in

the construction industry to be more

accurately evaluated.

Overall, this study provided a

much-needed scientific look at the

role of glass in contemporary New

Zealand architecture. It provides a

comparison to existing literature

on the role of glass in residential

architecture, which is currently

limited to the poetic aspects of

design.
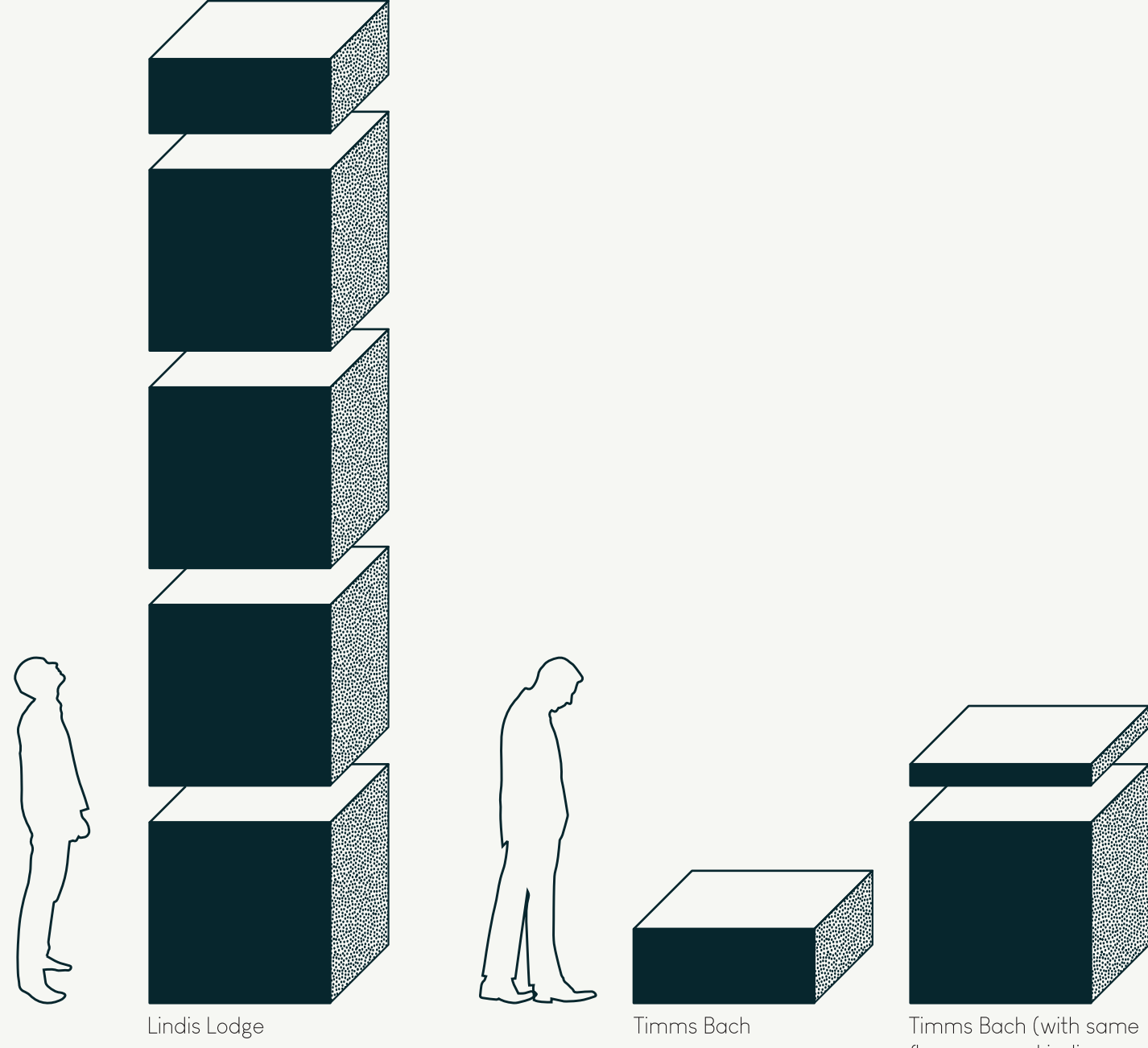

Timms Bach (with sam

Fig.3.18.Visul representation of sand usage in the Lindis Lodge compared to Timms bach Source: Author 


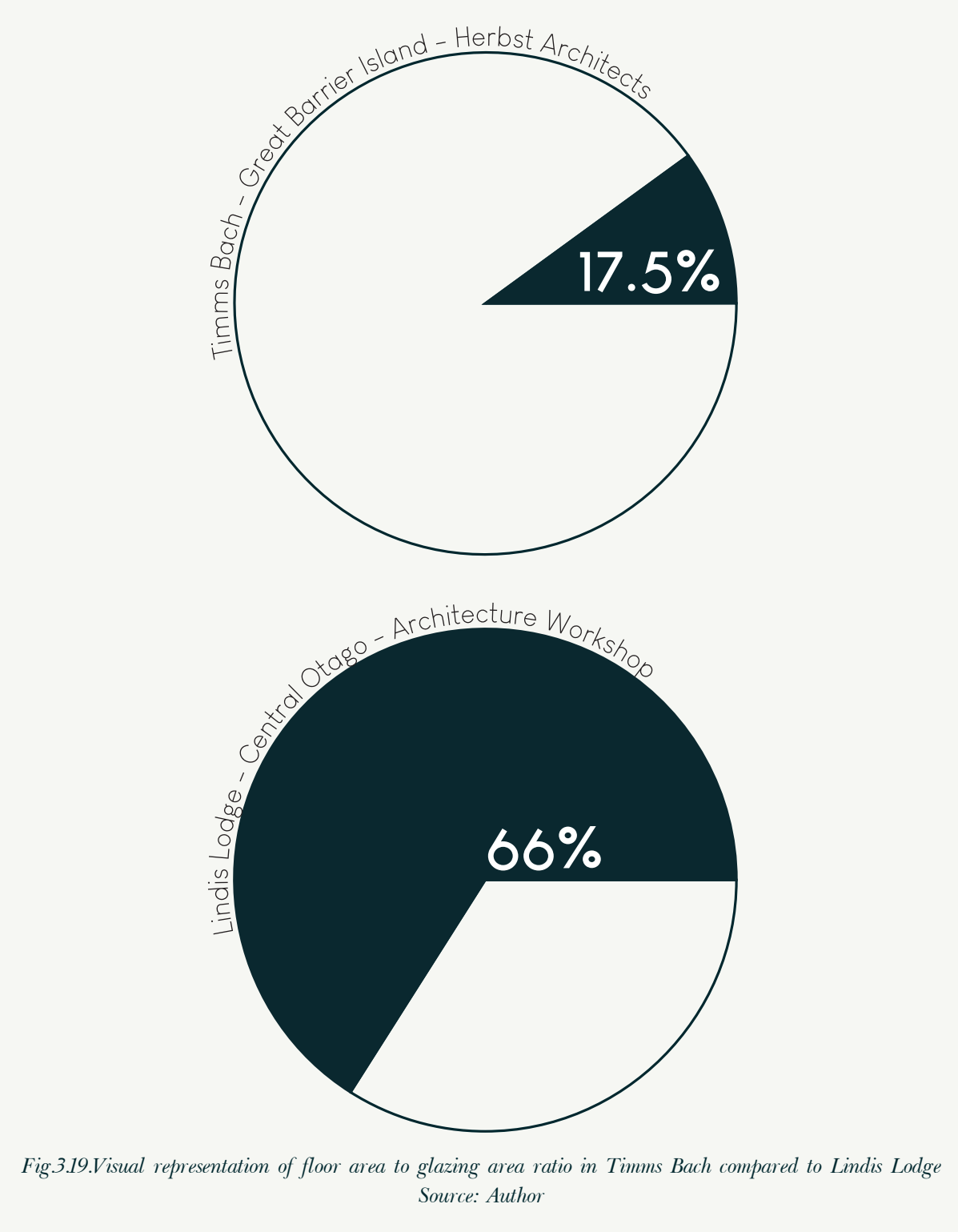


This content is unavailable. Please consult the figure list for more details.

\section{FRAMEWORK FORMATION}

\author{
4.1. AIM OF THE \\ FRAMEWORK
}

The study of the role of glass in New Zealand residential architecture conducted in Chapter 3 showed a significant difference in the amount of glass used in award-winning houses compared to passive houses and standard specification dwellings.

This demonstrates that the view of the landscape has become one of New Zealanders' most desired possessions when it comes to residential architecture - a quality which is almost exclusively achieved through the use of glass. Therefore, this thesis aims to establish and test a design framework for reducing the amount of glass in high-end residential buildings.

Previous research demonstrated that there was a significant gap of knowledge relating to the link 
between the sand shortage and architecture. This also demonstrates a gap in existing research between scientific fact and poetic design. The aim for this chapter is to establish

a link between the two ways of designing through the creation of a framework.

\subsection{NEW ZEALAND VERNACULAR}

4.2.1.Influence of the landscape

The New Zealand home has always been influenced by the landscape. After the Treaty of Waitangi was signed and the first settlers arrived, transforming the landscape to meet the needs of people was of utmost importance, rather than vice versa and forcing European architectural styles to adapt to the harsh climate and land (McKay,2016). Most house were built of timber as a result of deforestation to clear farmland.

Corrugated iron was popular for

both rooves and walls, as it could

be efficiently stacked to import

from Britain. Both materials remain

iconic symbols in the New Zealand vernacular today.

The 'bach' became another influencer of traditional New

Zealand dwellings, as symbol of the outdoors-oriented world immigrants desired when fleeing the working and middle class lifestyle of Europe (McKay,2016). The bach became a central figure in defining New Zealand architecture: most of our governmental, institutional and commercial buildings remain largely indistinguishable from international style (McKay,2016). Modernism saw houses develop regional accents through their use of local materials and acknowledgment of the climate, in contrast to the international

brutalist style. Designers also began

to acknowledge the New Zealand

vernacular with houses beginning

to resemble the whare nui or farm

sheds. These houses became the

first true examples of New Zealand

architecture with cross-cultural

references, and still influence

residential architecture in this

country today.

4.2.3. The modern New Zealand vernacular

The modern New Zealand vernacular - influenced by the climate, local materials and the view - has become a sought-after high-end residential desire of many New Zealanders today. However, high-end New Zealand residential architecture still lacks a focus on sustainability, an issue designers need to take more seriously (Connolly et al.,2020).
The contemporary New Zealand vernacular or award-winning homes considered to be the epitome of New Zealand residential architecture rarely exhibit sustainable principles, instead being valued for their success in terms of poetic design. This framework will therefore combine poetic design techniques observed in selected precedents with the scientific and sustainable principles for designing with less glass (section 3.7.4). 


\subsection{PRECEDENT REVIEW}

4.3.1. Precedent selection

This chapter comprises of a selection of precedents with the to inform the construction of a design framework for designing architectural homes with less glass.

The two selected precedents were chosen from the glazing study for having glazing square meterage

lower than the suggested $20 \%$ of floor area, as well as their status as award-winning buildings. As the aim of this thesis is to provide reference for achieving a successful building in terms of it being a quintessentially New Zealand residential building, award-winning dwellings from around New Zealand were chosen to inform the design framework.

The status of "award-winning" labels these precedents as having successful poetic aspects of design.

\subsubsection{Section aims}

The aim of this precedent study is to understand how New Zealand dwellings achieve the award-winning status in terms of architectural elements and design language whilst being sustainable and within the previously identified 15\% glazing ratio. It will provide an understanding of current poetic themes in New Zealand residential architecture.

\subsubsection{Precedent 1}

Timms Bach, also known as Kaitoke Bach, was completed by Herbst Architects in 2010. Located off the shores of Auckland on Great Barrier Island, the bach won an Auckland Architecture Award in 2011.
This content is unavailable. Please consult the figure list for more details. 
The bach is exceptional at capturing its natural surroundings within the interior through its use of timber as the primary building material. Indoor-outdoor flow is essential

for providing dwellers with connection to the landscape at every opportunity, using negative space between two volumetric or positive elements to define outdoor living space. The structure is sympathetic to the environment through its use of materials, tectonic elements, low-lying rooves and positioning windows carefully to edit out neighbours either side.

4.3.4. Precedent 2: Kowhai House

Rafe Maclean's passive 'Kowhai' house was awarded a New

Zealand Architecture Award by the NZIA in 2019. Situated on a steep and marginal site in suburban Dunedin, the treehouse- like dwelling is connected to its natural surroundings by careful positioning of windows providing views to the outdoors. The house is sustainable in many aspects including its efficiency as a thermal "cocoon" and optimisation of resources (NZIA,2019). Its humble material selection includes a timber interior and corrugated aluminium exterior, reminiscent of early New

Zealand baches and farmsheds. The incorporation of timber highlights on the exterior provides a hint as

to what is inside. Its simple yet clever and practical spatial layout exercises minimal waste of materials. Spaces are clearly defined and in those which need less light, such as bedrooms as opposed to common spaces, windows are minimal. In this example reducing window area was necessary to retain the efficiency of the house's thermal properties,
This content is unavailable. Please consult the figure list for more details. 
however is also a likely useful technique in the aim to reduce glass. These two aims therefore demonstrate how a contemporary New Zealand dwelling can be successful both in terms of its poetic design language and its sustainable design elements.

\subsection{COMMON \\ THEMES IN \\ NEW ZEALAND \\ RESIDENTIAL \\ ARCHITECTURE}

From the precedents analysed alongside general analysis of New Zealand residential architecture

during the research process, the following framework was

conceptualised based on common design elements, ideas and trends across the case studies. The intent of

this framework is to inform designers for designing with less glass. Key ideas that made it possible for the analysed case studies to maintain the "successful" status in New Zealand architecture have been extrapolated (Fig.4.4\&4.5)

4.4.1. Public versus private space Designating public and private space allows designers to create spaces with different glazing options based upon the primary role of each space. Private spaces are more intimate thus requiring less light.

For example, bedrooms are likely to require less glazing area due to their nature as a private space, in contrast to living areas. Public and private spaces can also be defined visually through materiality.

\subsubsection{Orientation}

Orientation of the building is important in any architectur

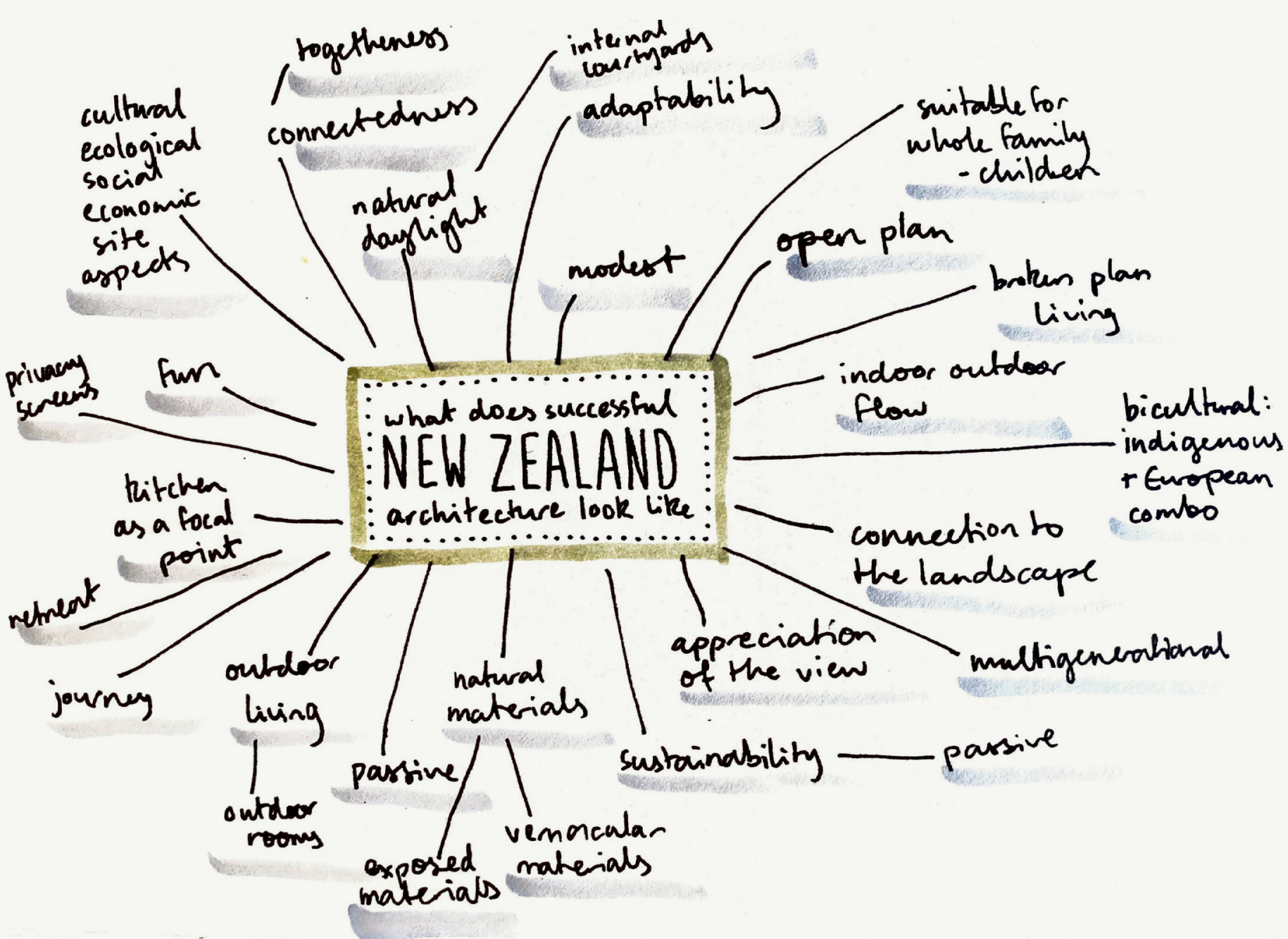

Fig.4.4.Initial mindmap of architectural themes 


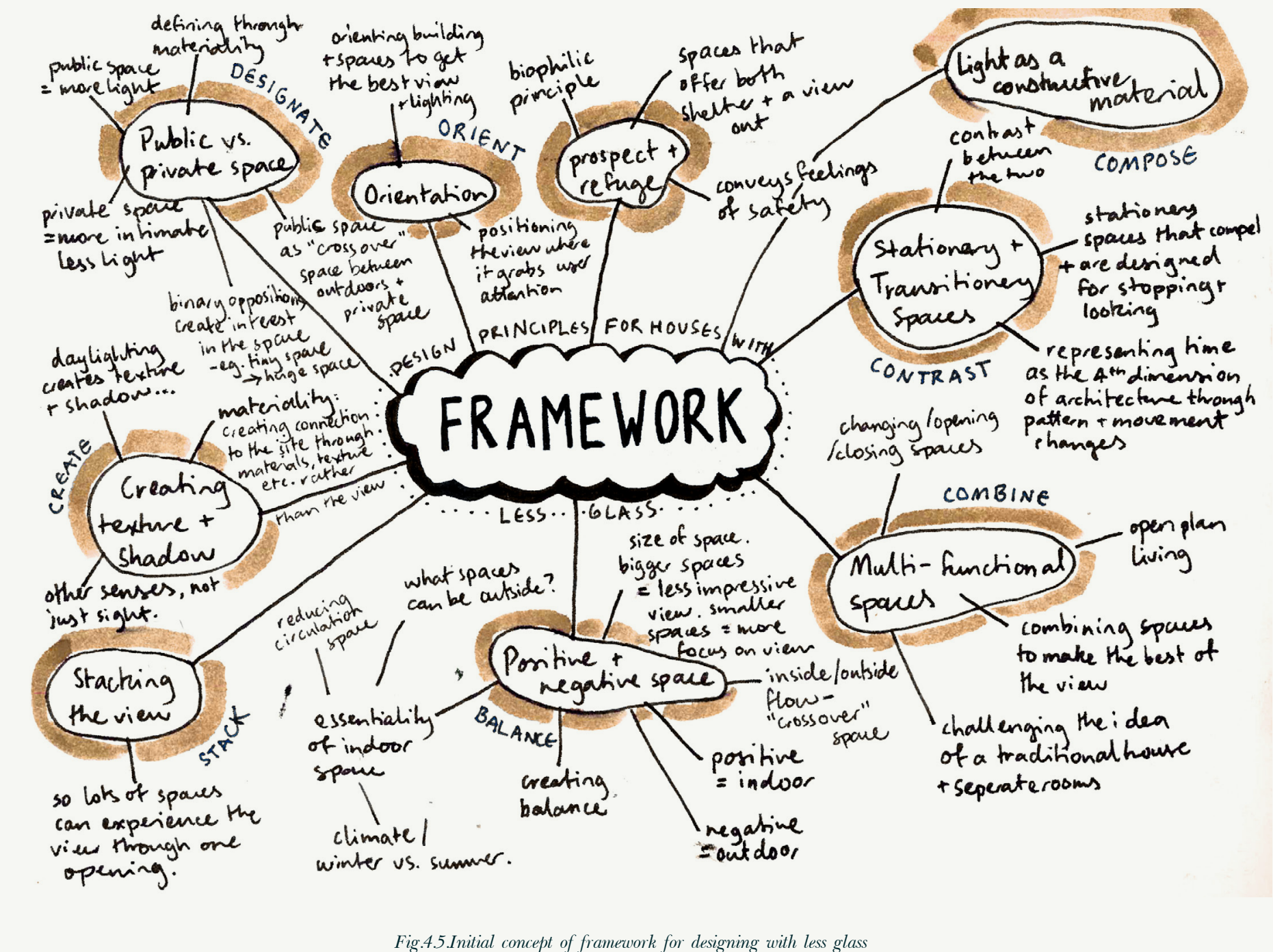

project, however in the interest of reducing glass it is of greater importance. Orientating the

building so that spaces that require the most light or are likely to benefit

the most from the view, such as

living and dining spaces, mean that less glazing will be required in

order to achieve the same result.

Orientation means orientating

windows, viewshafts and spaces in

general to maximise the benefits of glazed areas.

\subsubsection{Prospect \& Refuge}

Prospect and refuge is one of the 14 patterns of biophilic design Browning et al. identified in their 2014 research. Although perhaps unintentionally, prospect and refuge is becoming a common theme in New Zealand residential architecture.
The idea of a view of the outdoor environment coupled with an enclosed structure, a design that incorporates prospect and refuge conveys feelings of safety that are inherent with the natural instincts of human ancestors (Fig4.6.). This idea is subconsciously present in many of the selected case studies. Examples of this are the $\mathrm{K}$ Valley house by Herbst (Fig.4.7), and the

Mountain Retreat house by Fearon Hay (Fig.4.8)

4.4.4. Light as a constructive material

Guzowski's book The Art of Architectural Daylighting (2018) discusses the use of daylight not only as a comfort measure, but as the most intangible architectural material - in fact, the only material that can embody the dimension of time as the movement of 
This content is unavailable. Please consult the figure list for more details.

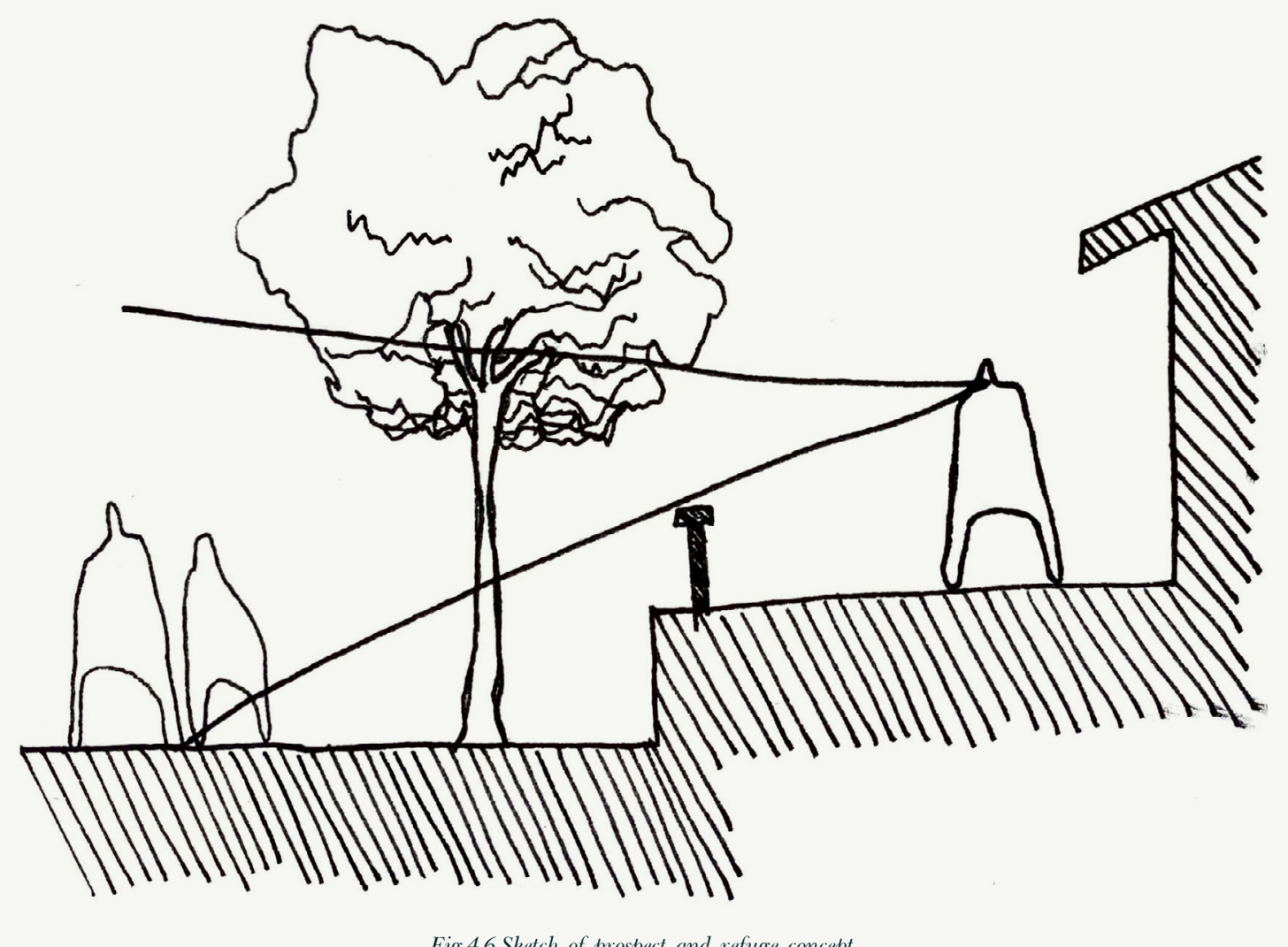

Fig.4.7. Prosspect and refuge demonstrated in $K$ Valley house

This content is unavailable. Please consult the figure list for more details. 
shadow changes over a day or a year (Guzowski,2018). Along with climate and sight, daylight is what roots architecture to its place (Guzowski,2018). The evolution of trends in daylighting design is influenced by digital and technological advances, including the recent ability of measurability to demonstrate human environmental comfort, productivity and health and energy savings. However, a risk of this behaviour in daylighting design is diminishing its qualitative aspects (Guzowski,2018). Daylight has both poetic and practical potentials. Light interacts with building form, materials and textures to embody the mood of the sky and qualities of place: qualities that are not usually able to be measured, but which enhance our relationship with the world we live (Guzowski,2018). Guzowski writes that daylighting should explore the full potential of the design, from site planning to construction detailing, in order to celebrate both poetic and practical benefits of daylight, and that analogue methods are still key to the design process.

\subsubsection{Stationary \& Transitionary} Spaces

Binary oppositions between

stationary spaces and transitionary spaces help define use of space and create contrast between spaces.

Stationary spaces are those in which stillness is present, such as living or sleeping spaces. Transitionary spaces are those in between such as stairwells, corridors and entrances.

The contrast between stationary and transitionary spaces is important in designing with less glass because it allows designers to place windows where the view is most likely to be enjoyed. The use of windows in

stationary spaces creates spaces that compel the user to stop and look therefore improving the connection the user has with the view.

\subsubsection{Multi-functional spaces}

Combining spaces that have the potential to be multi-functional allows one space to make the best of the view out through a single window. For example, an open plan living space means kitchen, dining and living could all benefit from one window. Challenging the idea of a traditional house with separate rooms could therefore be beneficia to reducing the amount of glass.

Open plan living has become a quintessential part of $\mathrm{New}$ Zealanders' lifestyles - it is difficult to find a house built in the last twenty years that does not incorporate open plan living space. The kitchen is the heart of the home, providing users with a place to gather and connect. This style of living is

reminiscent of the Maori whare nui which later become integrated into European residential architecture in New Zealand (McKay,2016).

\subsubsection{Positive \& Negative Space}

Positive and negative space as a binary opposition refers to a balance between indoor (positive) and

outdoor (negative) space. Outdoo space in this circumstance is space that is defined as a room or part of a room, but is not enclosed indoors, ie. open to the elements. This brings to light a discussion of essentiality of indoor space: what spaces, which traditionally are indoor enclosed spaces, can be outside instead? 
A balance between positive and negative space can be achieved through contrasting size of spaces. In relation to reducing glass, smaller space not only require less materials, but have the ability to place more emphasis on the view.

Crossover space between positive and negative space is also important as it creates the "indoor outdoo flow" concept that is desired by the vast majority of New Zealanders.

\subsubsection{Stacking the view}

Stacking the view has become common throughout award-winning residential architecture in New Zealand. This concept involves creating openings that penetrate through the building, in order for multiple spaces to experience the view through one opening. This leads to obvious reduced glass usage. Stacking of the view is perhaps most observable in Eliska Lewis' Black Peak house in Wanaka. Stacking of the view has been cleverly integrated so the building becomes semi-transparent in the landscape (Fig.4.9)

\subsubsection{Texture \& Shadow}

Introducing texture and shadow adds interest to the space and has

the potential to bring the outdoors in. Texture through materiality can create connection to the site. It also allows the space to be explored through senses other that simply sight.

Shadow can be used to introduce the fourth dimension of time to the architecture: it allows the space to change over the course of the day

or year as the sun creates movement within the space. Shadow itself
This content is unavailable. Please consult the figure list for more details. 
can also be used in turn to create texture with specific panel or glazing designs. Both of these techniques

can be employed to create connection to the site through

elements other than a window or

view to the outdoors, thus requiring less glass.

An example of successful use of texture and shadow is the Lindis Lodge by Architecture Workshop (Fig.4.10). Clever facade panels

create interesting texture through shadow on the floor, while interior materials such as stone and

biomorphic timber structures create connection to the surrounding

landscape.

\subsection{FRAMEWORK}

DEVEOPMENT

This analysis of quintessential design techniques of the modern New

Zealand 'vernacular' resulted in the construction of a design framework

for designing the ideal New Zealand home with less glass. The analysed aspects of design fell into three

main categories: poetic, positional and programmatic.

The framework also includes the

glazing per square metre of floor

area ratio of $15 \%$, as concluded from the glazing study in Chapter 4.
This content is unavailable. Please consult the figure list for more details. 
1

\section{POETIC}

Create texture \& shadow

-Daylighting through windows

creates texture \& shadow. Use other methods to achieve the same effect such as biophilic design principles

-Create connection to the site through materials and texture rather than conveying the view

-Design for all the senses, not just sight

Compose light as a constructive material

-Utilise lighting as a material to define space

Designate public \& private space

-Use binary oppositions to create interest

-Define public and private space through materiality

\section{Balance positive \& negative space}

-Define the essential indoor

"positive" zones

-Utilise positive (indoor) and

negative (outdoor) space to reduce need for glass

-Create flow between positive and negative spaces using crossover

zones

Contrast stationary \& transitionary spaces

-Capture the view through stationary spaces that compel the user to stop and look

-Daylighting allows architecture to utilise time as the fourth dimension. Use transitionary spaces that capture changes in pattern and movement to achieve this instead.

\section{2}

SCIENTIFIC

\section{Position the view}

-Orient the building and spaces towards the view and best

daylighting

-Position the view where it best captures the user's attention

-Be aware of which spaces would (and wouldn't) benefit from the view

Stack the view

-Utilise sight lines throughout the building so windows can capture the view from more than one moment or position.

-Stack spaces and utilise view ports so the view can be transmitted deeper into the building

\section{Designate public \& private space}

-Private spaces are more intimate so need less light

-Private spaces tend to be smaller than public spaces, so smaller windows are more suitable proportionally

Combine multi-functional spaces

-Challenge the idea of a traditional house where separate spaces are divided by walls

Combine spaces to make the most of the view

-Explore how open-plan living can have the ability to affect the amount of glazing needed

$$
+<15 \%
$$

threshold 


\section{SITE}

\subsection{SITE SELECTION}

For the initial design exploration phase, a site was selected to provide opportunity for integrated site elements into the design. This was an essential part of the design process because it reduces the need for large windows with the role of bringing the environment into the architecture's interior. Instead the site could be used to inform other architectural elements.

The site selected is 45 Mount Gold Place in Wanaka, New Zealand. In recent years Wanaka, Queenstown and the lakes have become an extremely desirable locations for New Zealanders to build homes, with Central Otago homes often winning prestigious New Zealand architecture awards. This particular site offered what many New Zealanders might describe as the

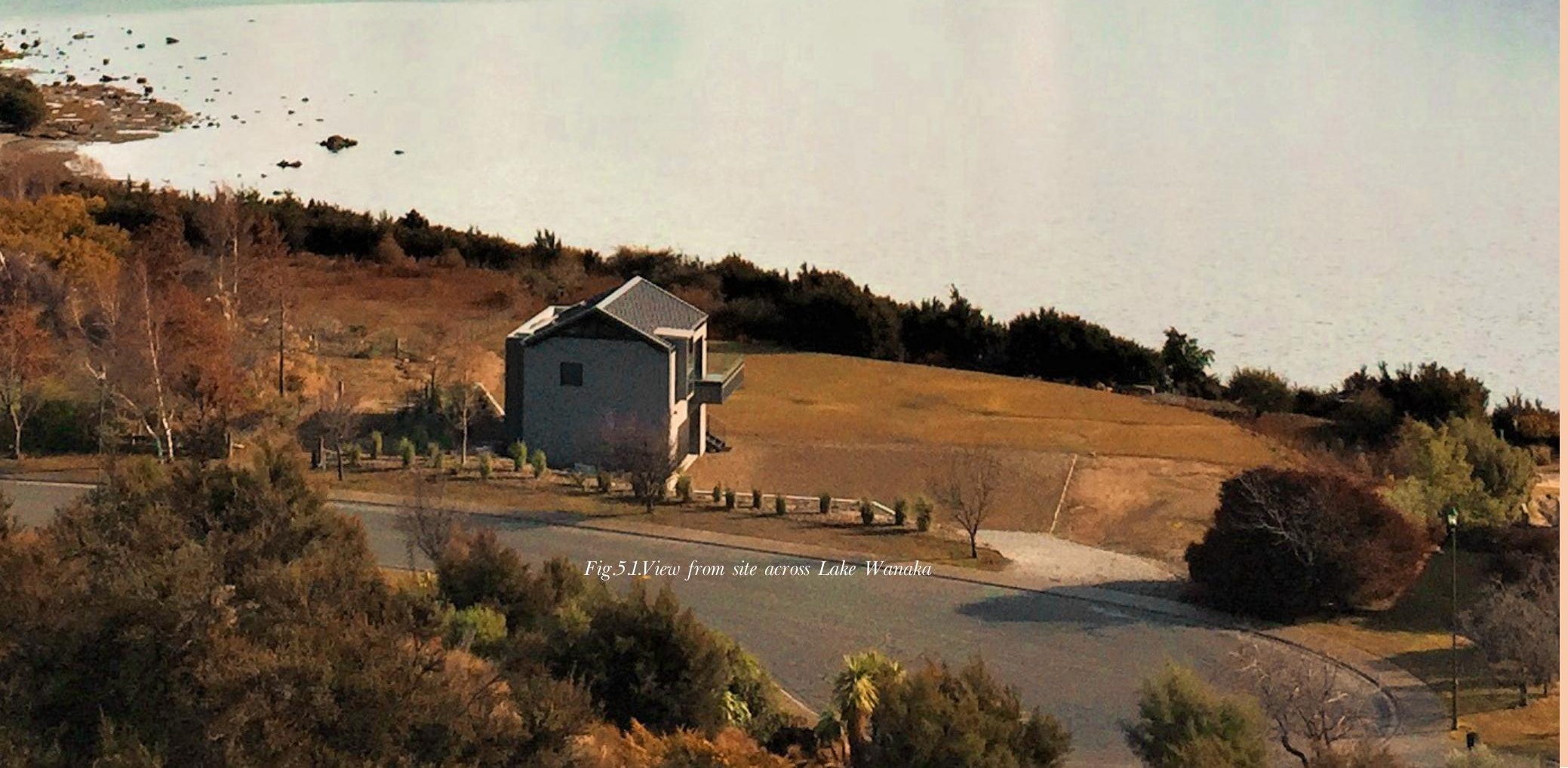


perfect place to build a home, with expansive views to the mountain ranges across lake Wanaka (Fig.5.1).

This view was an important aspect of the site selection because it is one of the contradicting factors that makes reducing glass difficult while achieving the architectural desires of New Zealand homeowners. The aim was to use the view and surrounding nature of the site as a design driver, and to generate alternative ways to integrate the environment into the building without extensive glass use.

\subsection{SITE ASPECTS}

Central Otago experiences some of the most extreme weather New Zealand has to offer, particularly in terms of its temperature range. The region typically experiences temperatures between $-3^{\circ} \mathrm{C}$ and $24^{\circ} \mathrm{C}$. It holds New Zealand's record for lowest air temperature, $-21.6^{\circ} \mathrm{C}$ in 1995, but also held the country's hottest temperature, $35.2^{\circ} \mathrm{C}$ in 1959 until 1973 (NIWA,2015). The climate of the Central Otago region was an important aspect of site selection because it allows for designing for the country's most extreme conditions.

\subsection{SITE ANALYSIS}

Site analysis was explored with the aim of realising the best views to later inform window placement iterations (Fig5.2). Initial sketches of the site identified key elemental forms, which would later inform series 3 (section 5.4).

This exercise induced the realisation that by identifying the best view, glass usage could be reduced. Window placement could be informed by the direction of the

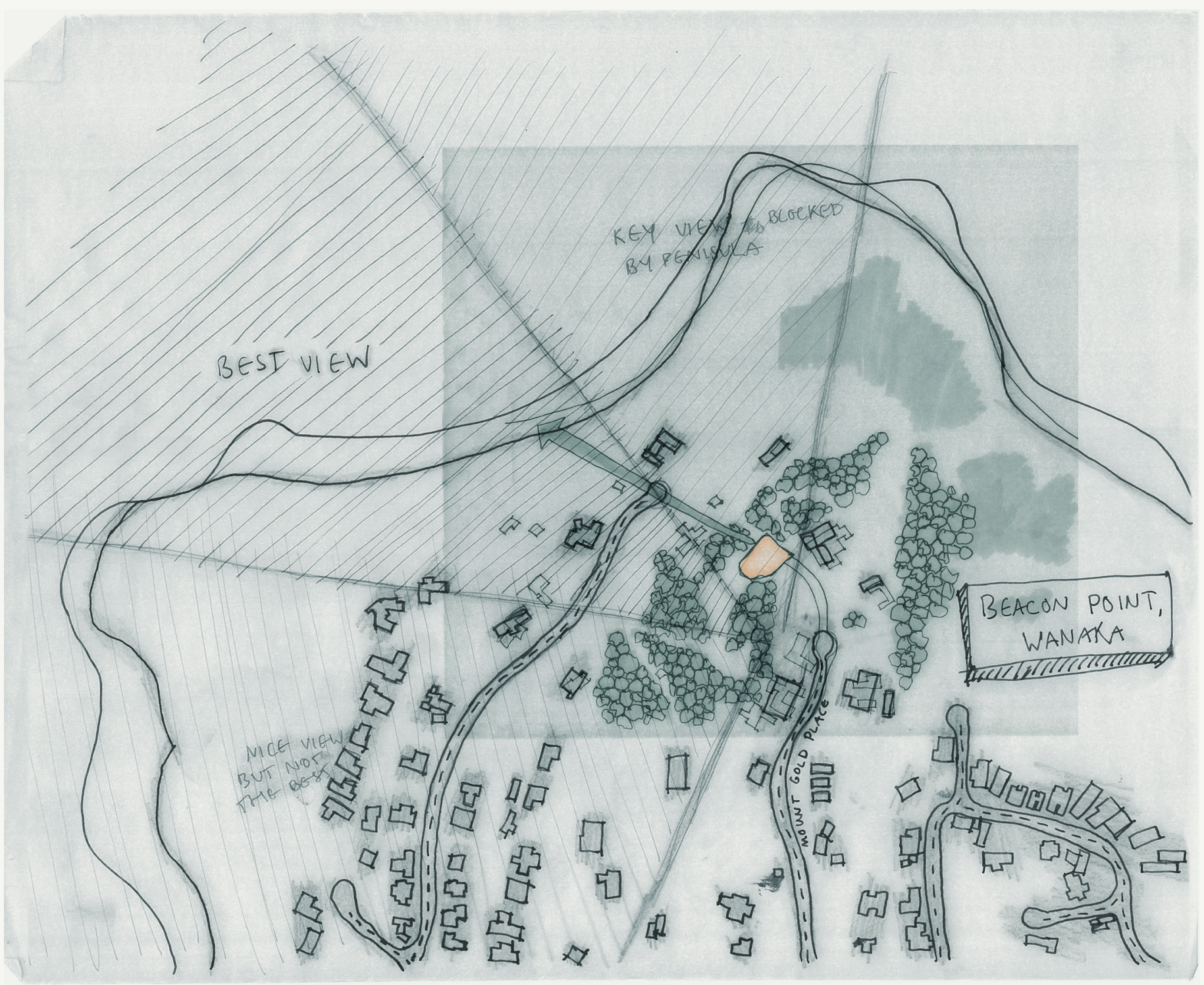

Fig.52.Exploration identifing best views from the site 


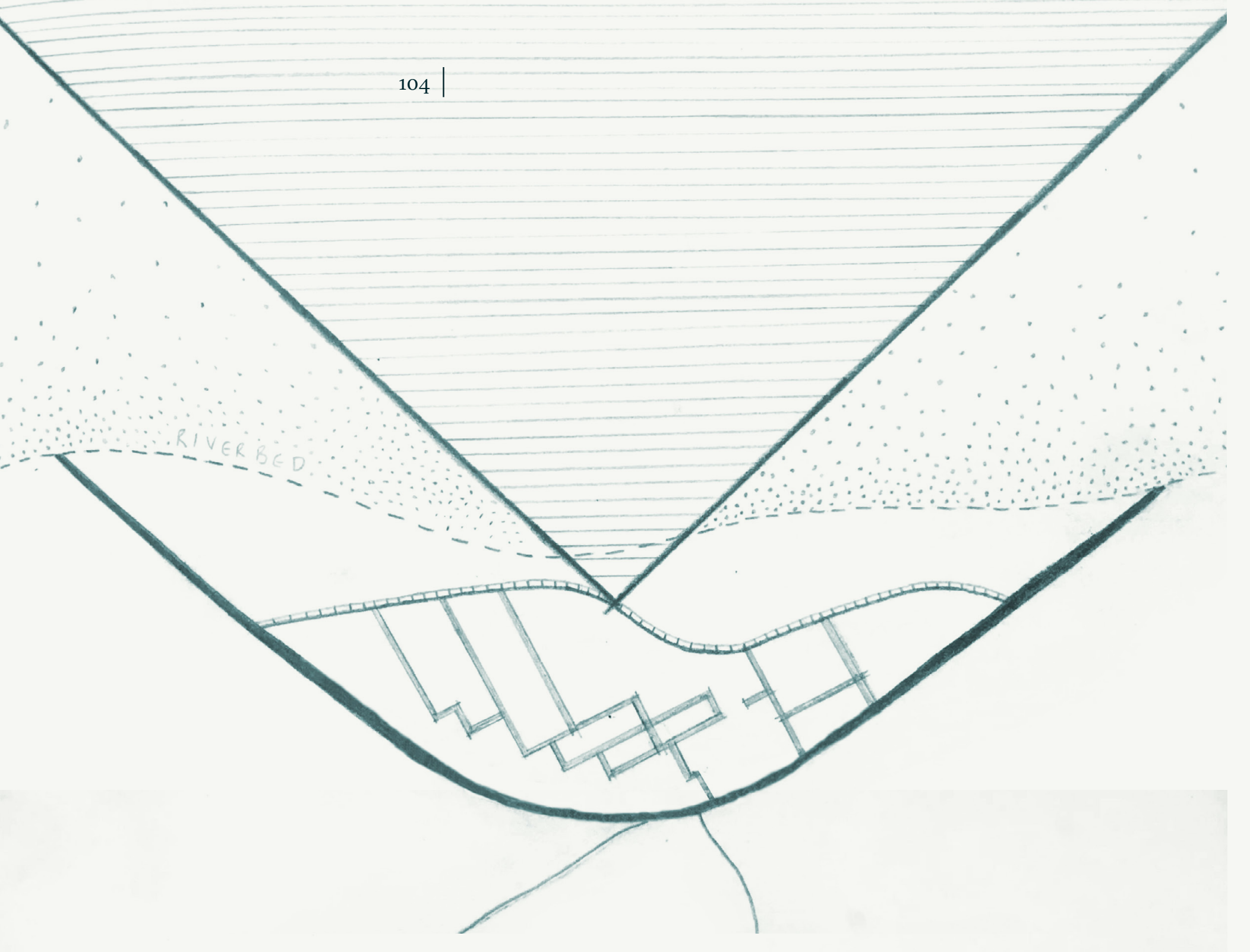

best view, allowing for maximum experience of the view while eliminating extra glass usage where the view is less notable. Therefore by identifying the best view and placing windows accordingly, both reduced glass usage and heightened experience for the user is achieved.

\subsection{PRECEDENT ANALYSIS}

One precedent that achieves this idea to some level is the Lindis Lodge by Architecture Workshop. Being a cocoon shape, the building has only two clear facades. While the Northern facade is almost entirely glass, the Southern facade has minimal glazing. While the extensive use of glass on the North facade is less than desirable in this thesis, the minimised glazing on the Southern facade offers some admirable design ideas relating to the design framework (section 5.4) With the entrance to the building on the southern, non-glazed facade, it separates public and private space and offers a form of prospect and refuge (Fig.5.3). Additionally, it evokes a sense of mystery as one approach the building, thus heightening the experience of the view later (Fig.5.4)

\subsection{REFLECTION}

During the site analysis phase it became clear that while the Wanaka site might be considered an ideal location for many New Zealanders, it is not always achievable, particularly given the expensive nature of similar locations. Therefore, designing initially for this site could inform designs for other locations aspiring to reduce glass usage, such as urban 
sites or apartment buildings. Design ideas and principles discovered

while designing for a site with an

idealised view could be utilised in

an urban site, with an attempt to

reduce glazing being achieved by

bringing aspects of the view to the

interior in alternative ways.

Therefore going forward, this design process will design initially for

the Wanaka site, but later analyse how those design elements and

principles could be utilised in a

more realistic urban site (Fig.5.5).

This allows for the development

of poetic aspects of design using

the site as a design driver, aspects

which could not as easily be applied

to an urban site. The Wanaka site

offers the poetic conditions of the

environment that is sought after

by New Zealanders, but is less

achievable in urban sites. The poetic design principles developed and tested on such a site could then be included in a revised framework.

This content is unavailable. Please consult the figure list for more details.

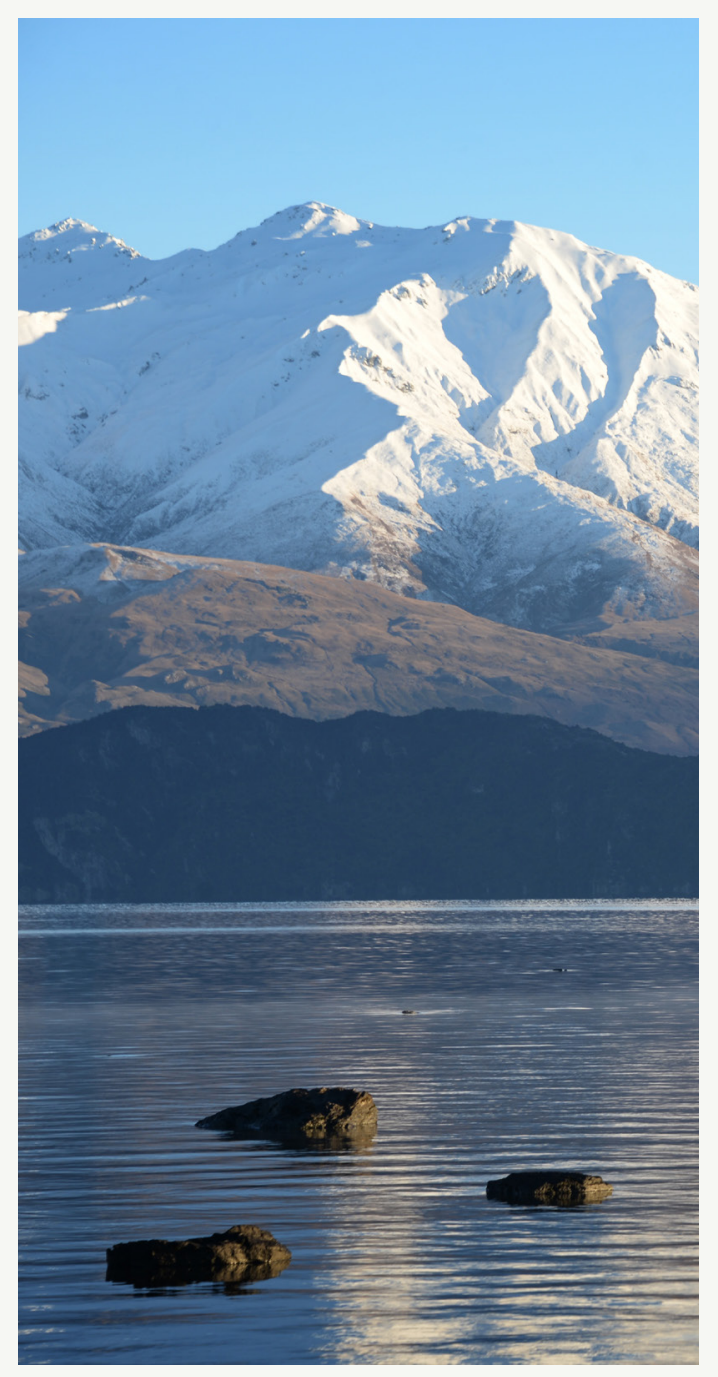

This content is unavailable. Please consult the figure list for more details.

Fig.5.5. How can the view be translated to urban and suburban sites? 
(1)

(2)

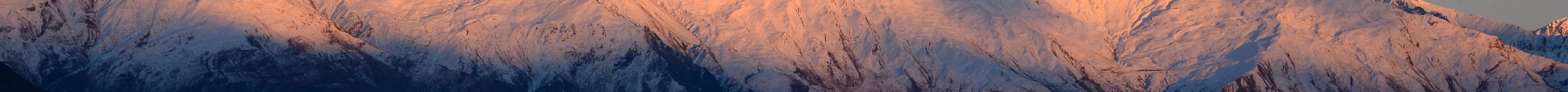
S.

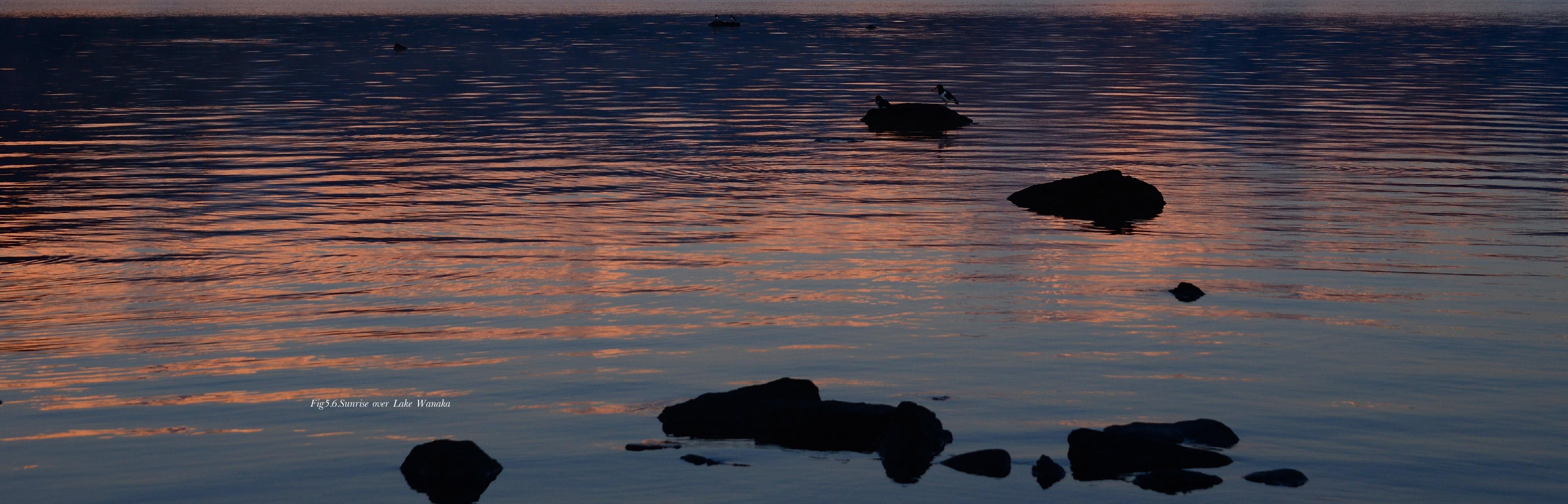


Chapter 6

\section{POETIC ELEMENTS $O F \quad D E S I G N$}

6.1.PURPOSE OF INITIAL DESIGN PHASE

The site selection phase showed that initially designing for an idealised site in terms of the view could inform how urban sites can achieve similar results. This chapter explores how the view can best be captured with reduced glass usage, using poetic concepts from the original design framework

(Chapter 5). This chapter attempts to test the framework's objective of developing a series of design strategies that allow for significant reduction of glass whilst maintaining poetic aspects of capturing the view, thus contributing to the resolving of a scientific issue through poetic design processes.

The Wanaka site was used to give context to the design phase, thus provide design drivers for a dwelling aimed at architectural success. 


\subsection{POSITIONING THE VIEW}

6.2.1. Purpose of the series

This series explored how the view could be best positioned in the building in order to reduce the amount of glazing required. This included design techniques such as stacking the view to create sigh lines and orientating the building and spaces to benefit from the best view. Viewing frames are used often by artists (including Vincent van Gogh) to frame the subject of the piece prior to its creation, and carefully positioned windows can achieve the same on a larger scale within buildings (Brower, 2000).

Stacking the view is a practical application to provide the poetic aspect of framing the landscape and allowing it to permeate deeper through the building. Stacking the view through openings in walls allows more than one space to benefit from the light and view through one window, thus reducing the amount of glazing required in the building overall (Fig.6.1).

The purpose of this series was to therefore:

Poetically: allow the landscape to be experienced by the user from multiple viewpoints throughout the building, and frame the view to translate the poetic elements of the landscape more effectively with less glass.

Scientifically: Orientate the building so that spaces receive adequate amounts of light, and provide light to more than one space through a singular window in order to reduce the amount of required glass.

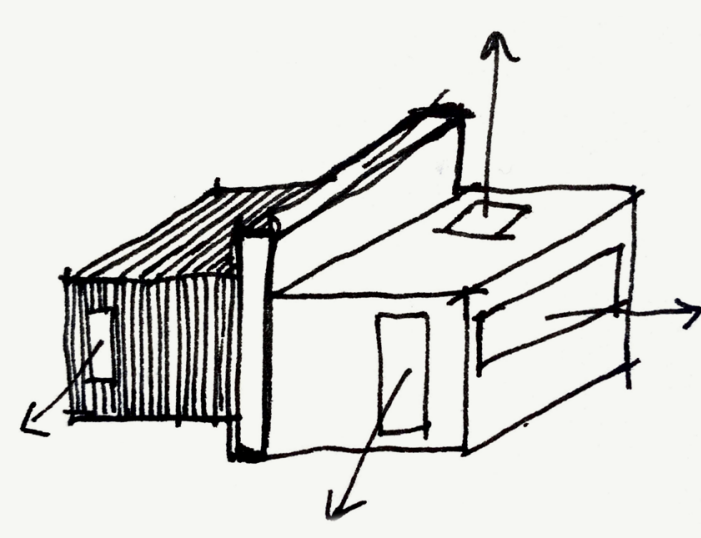

Fig.61.Concept of positioning windows and spaces to captur 


\subsubsection{Iteration 1}

Generalising the concept of stacking

the view into parti diagrams to

understand how elements such as

walls, tectonics and furniture could

be utilised to stack the view

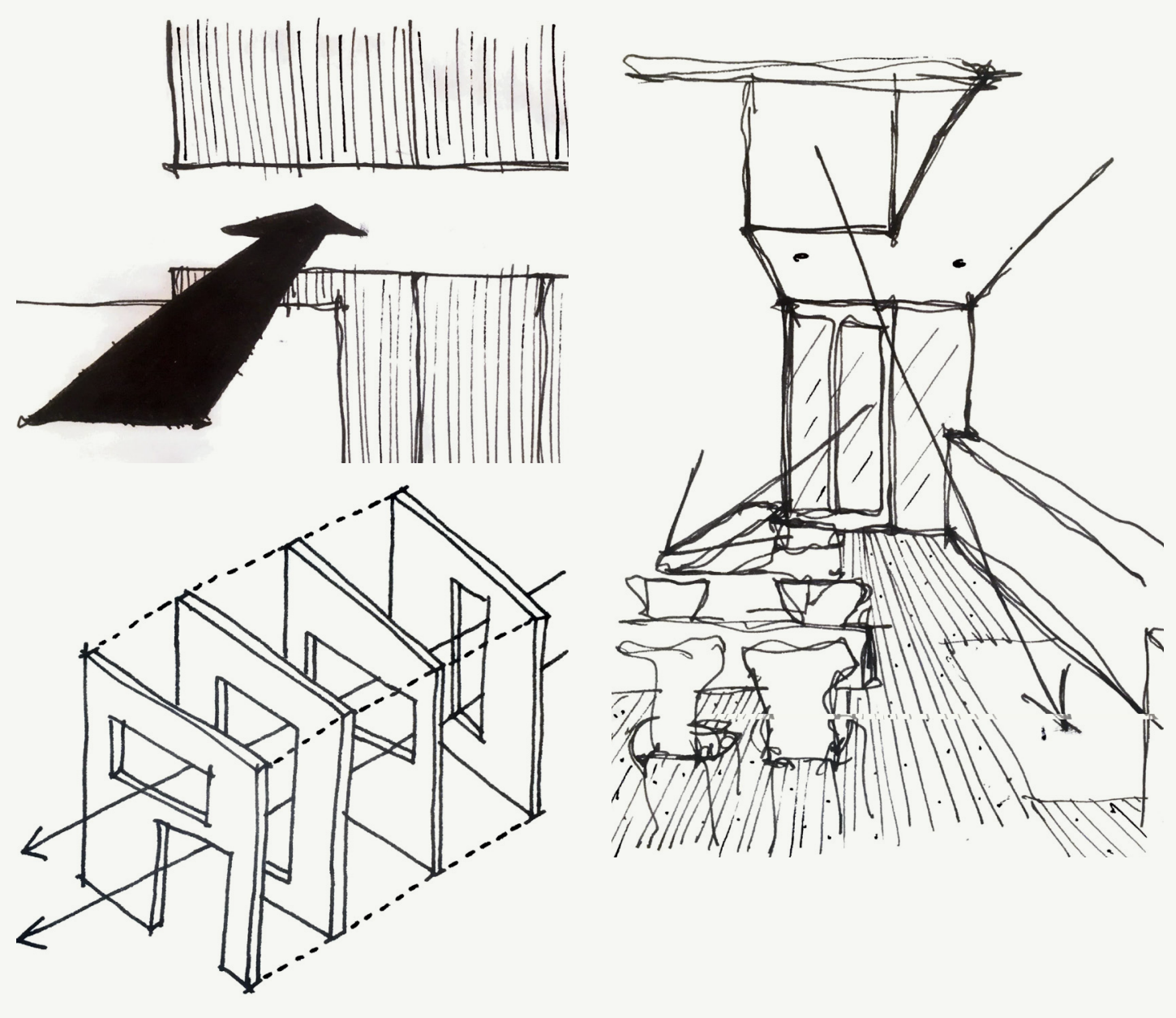

Fig.6.2.Initial sketches informing how the view could be stacked
6.2.3. Iteration 2

Exploring how massing elements

could be used to frame the view. By creating a focal point in one space, a displaced curve with openings directs

the viewer's eye towards certain

viewpoints in the landscape. Framing the landscape effectively reduces the

need for larger glazing panels.

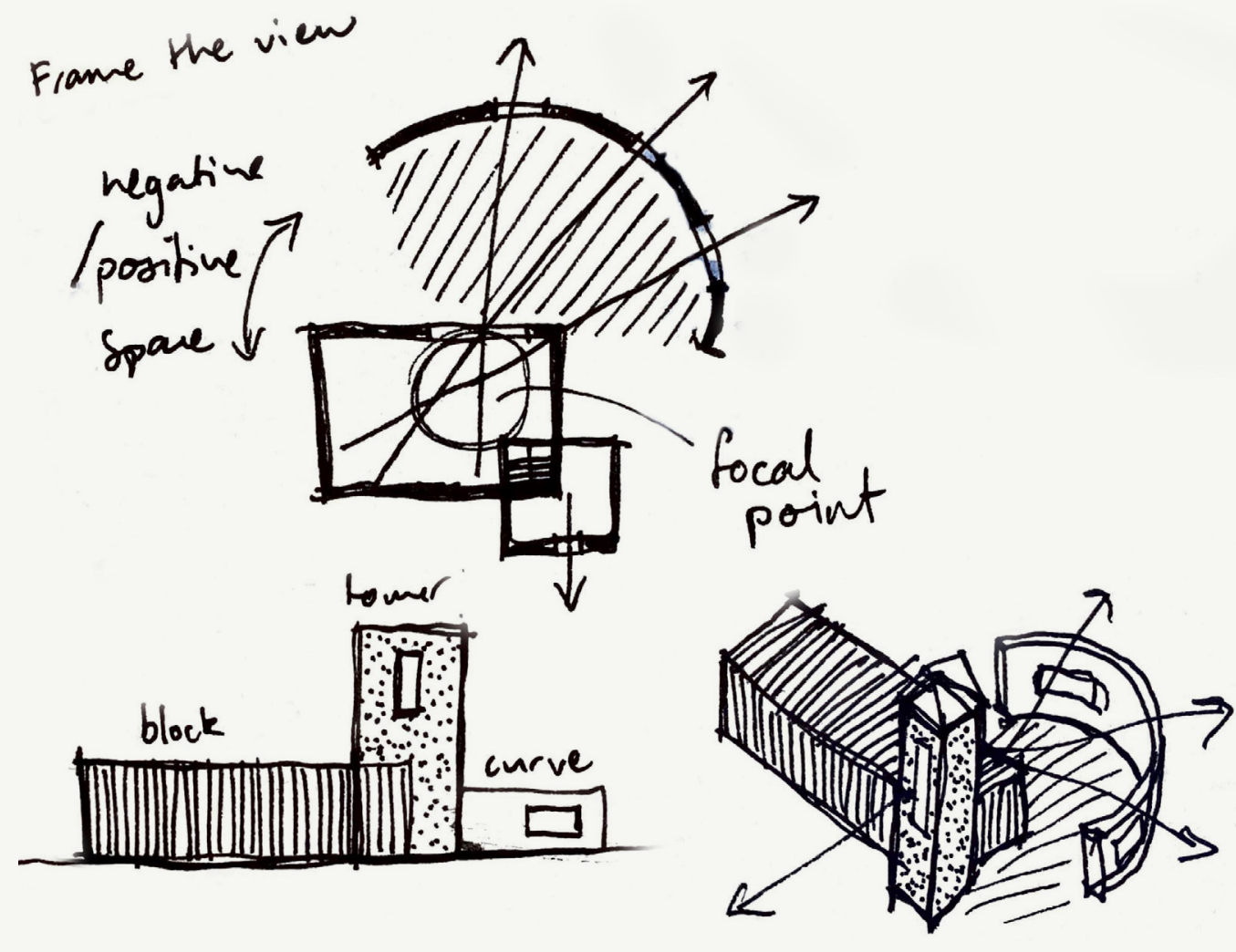



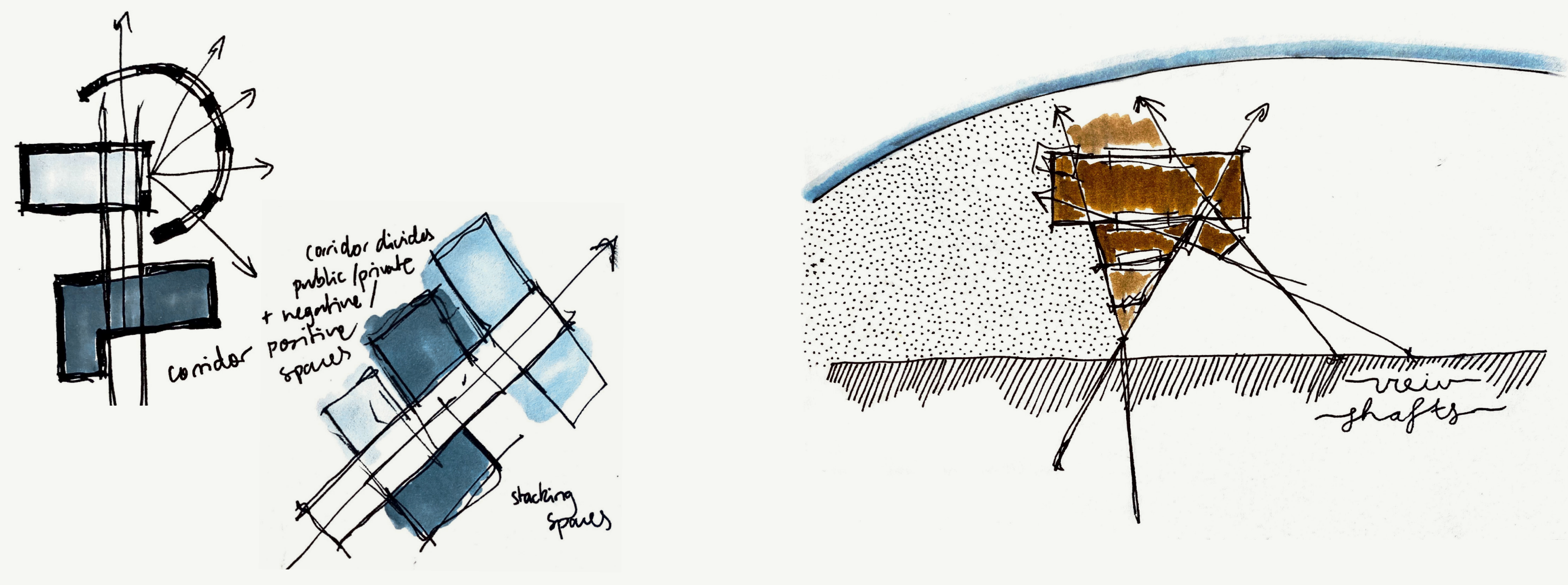


\subsubsection{Iteration 3}

Collaging demonstrated how

materiality in stacked spaces can

define space and draw the user's eye

towards the view of the exterior.

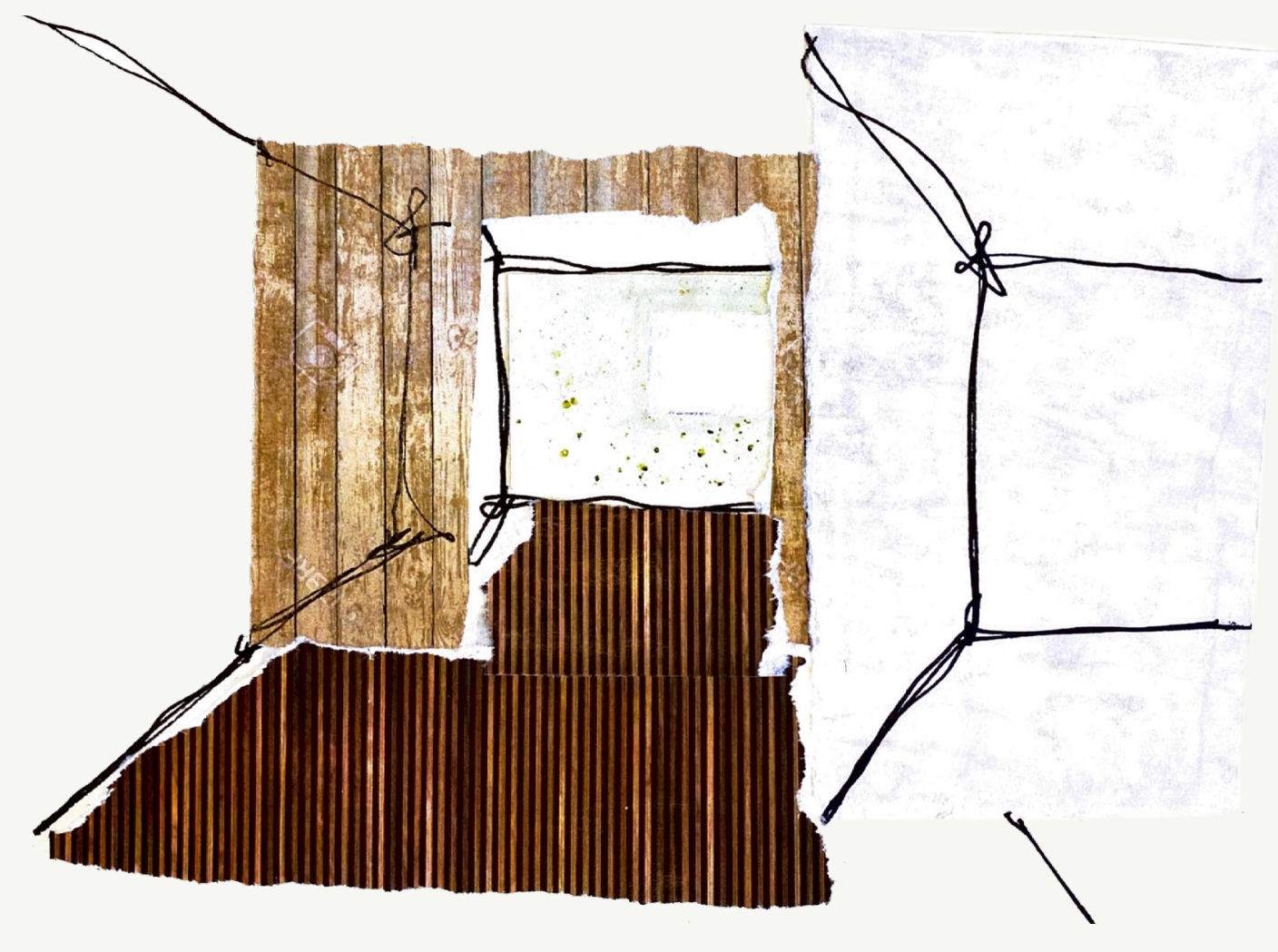

Fig.6.6.5tacking the view and spaces utilising a central corridor

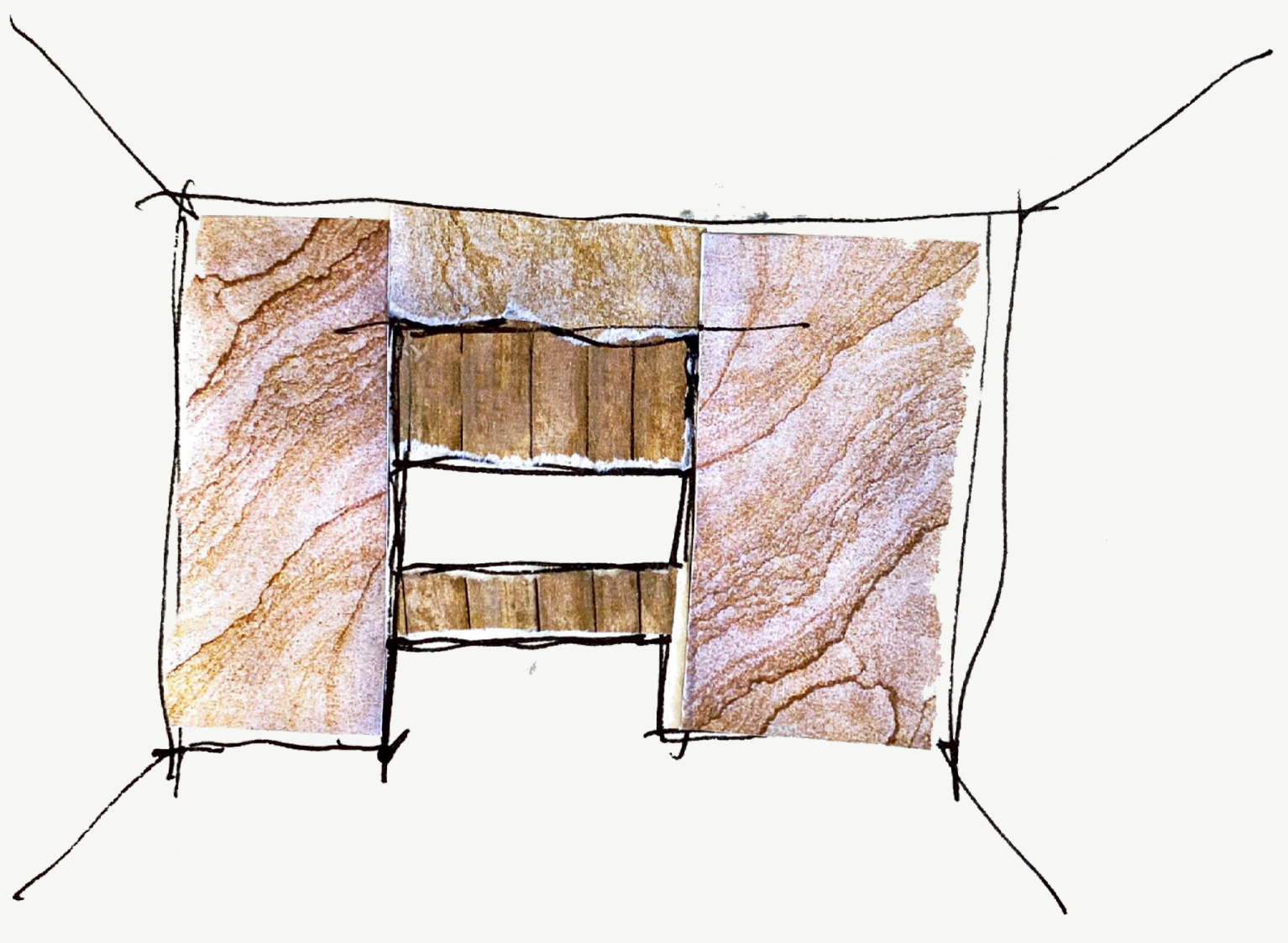

Fig.6.7.Sketching space in perspective, then overlaying view frames to create sight lines directed towards the best view 


\subsubsection{Iteration 4}

Sketching spaces in perspective and

overlaying view frames to create

sight lines directed towards the

view demonstrate how angles can

be utilised to create privacy whilst

stacking the view
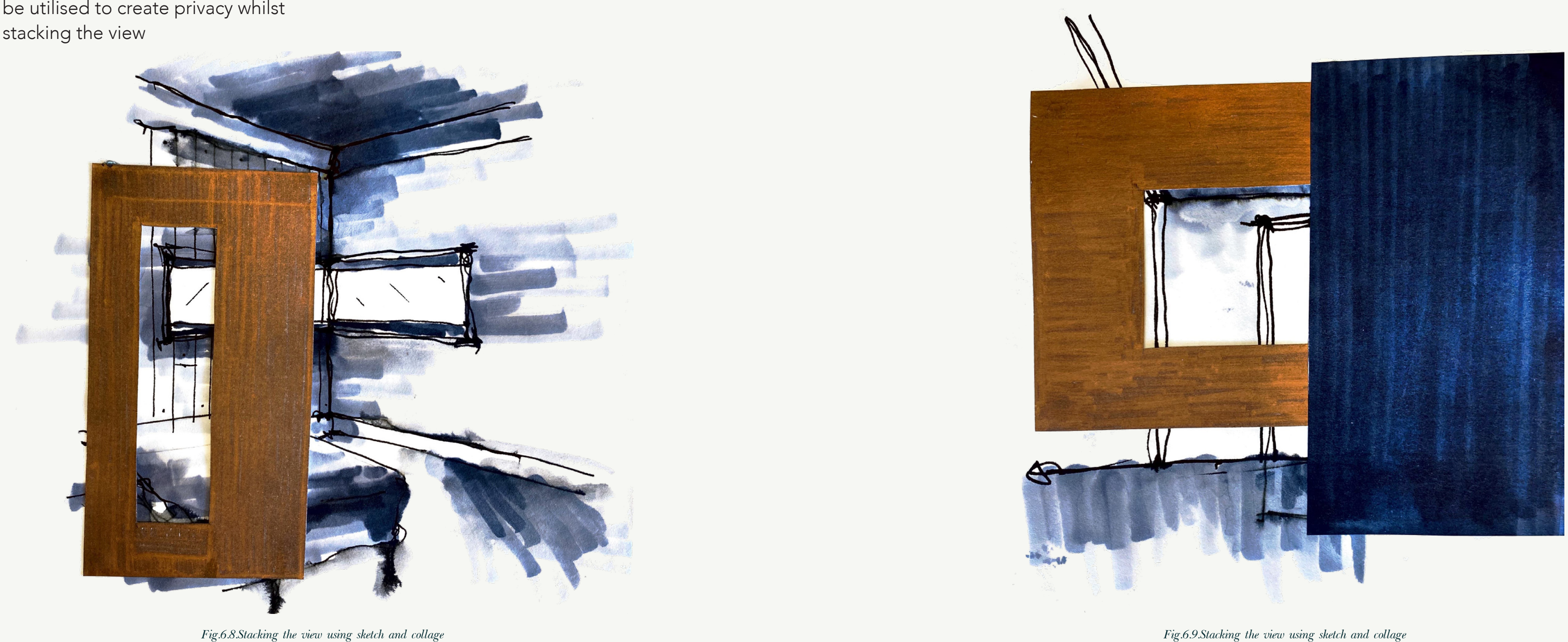
6.2.6. Iteration 5

Experimenting with stacking the view

through physical modelling shows

how viewports can be created using

both wall elements and tectonics
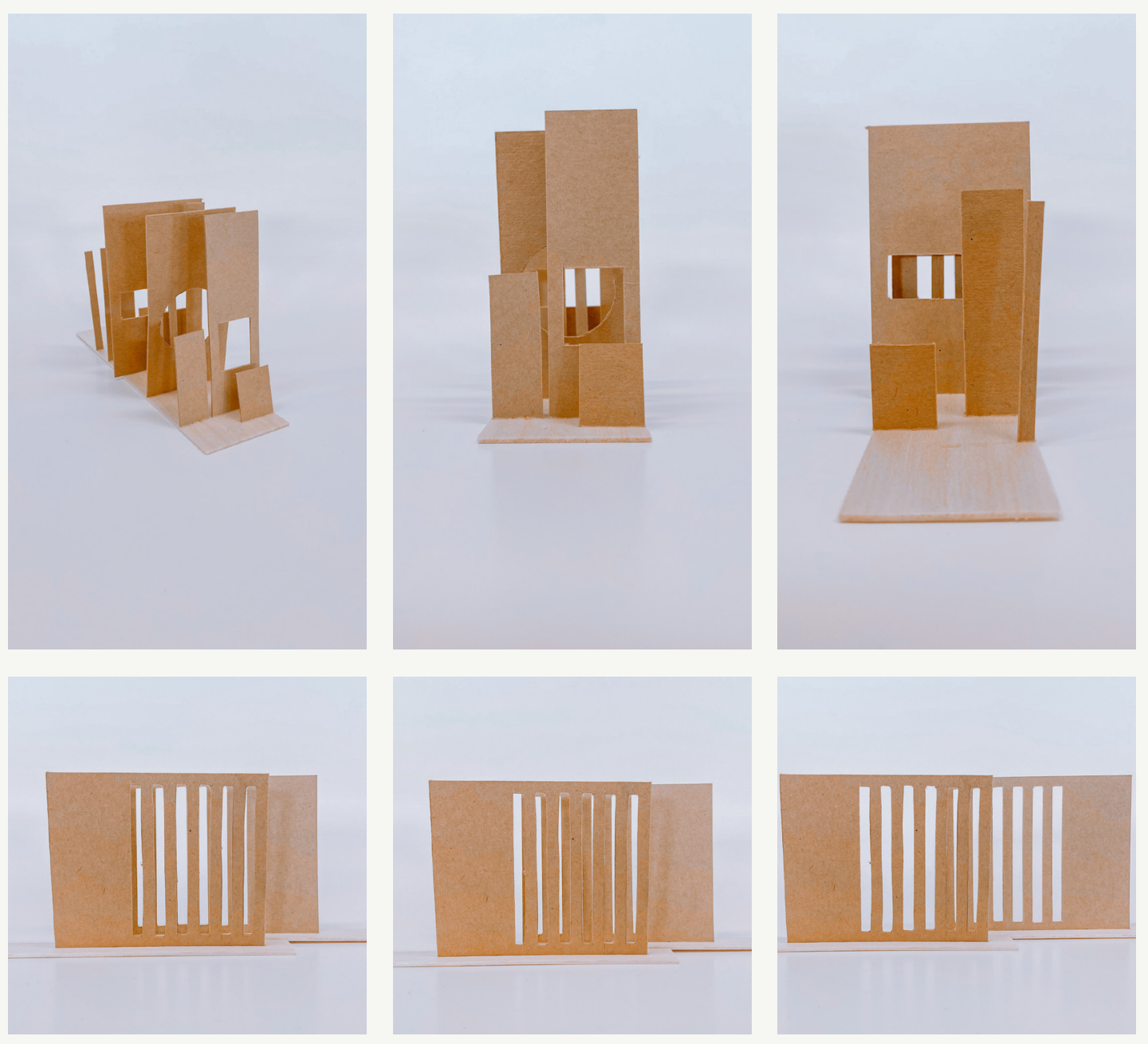

Fig.6.10.Stacking the view experiments with models
6.2.7. Iteration 6

Stacking the view through separate

volumes was less successful than

through walls and tectonics.
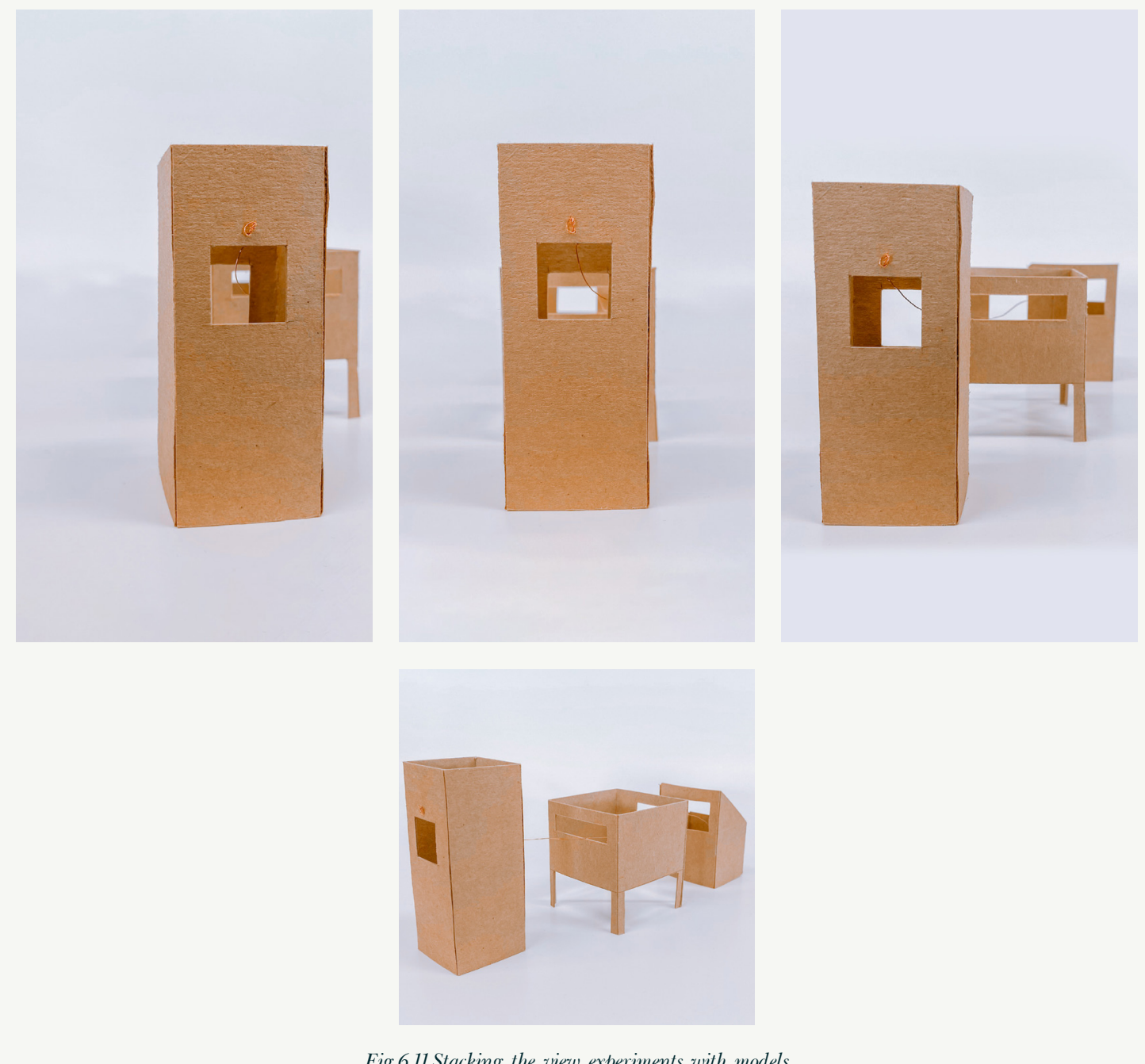


\subsubsection{Iteration 7}

Experimenting with stacking the view

both vertically and horizontally by

stacking spaces, analysing how this

might affect privacy of space

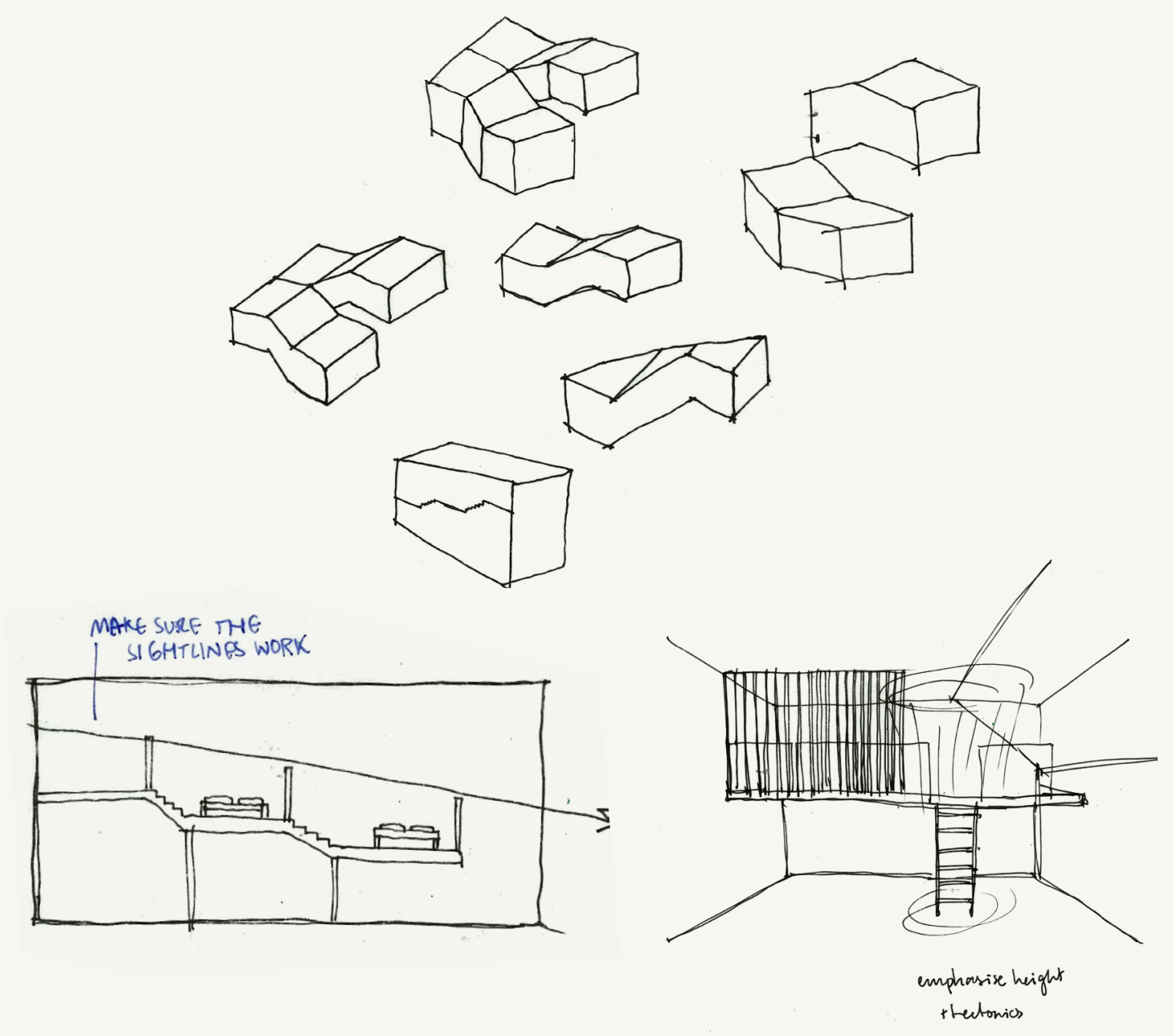

Fig.6.12.Stacking the view vertically

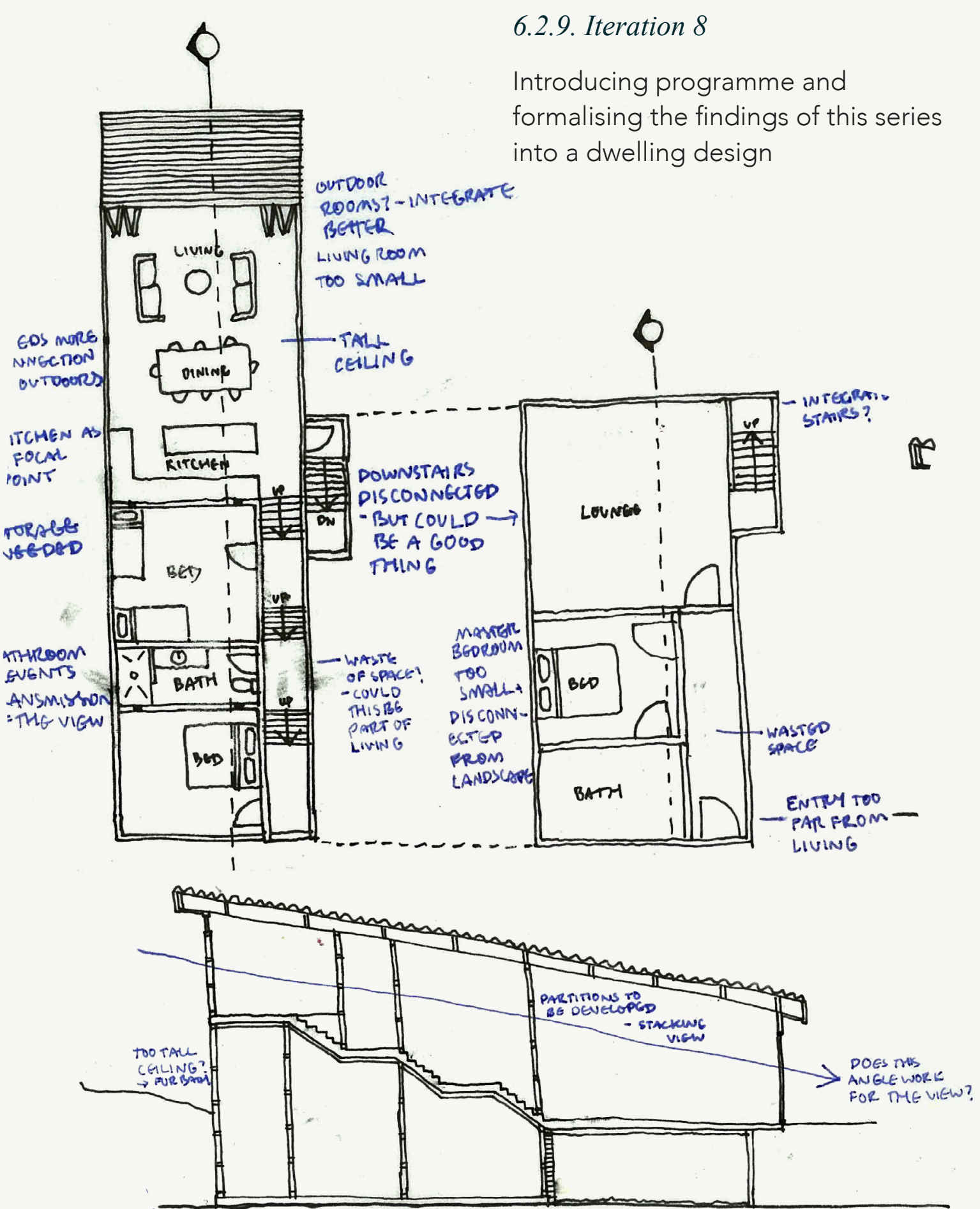

Fig.6.13.Introducing programm 


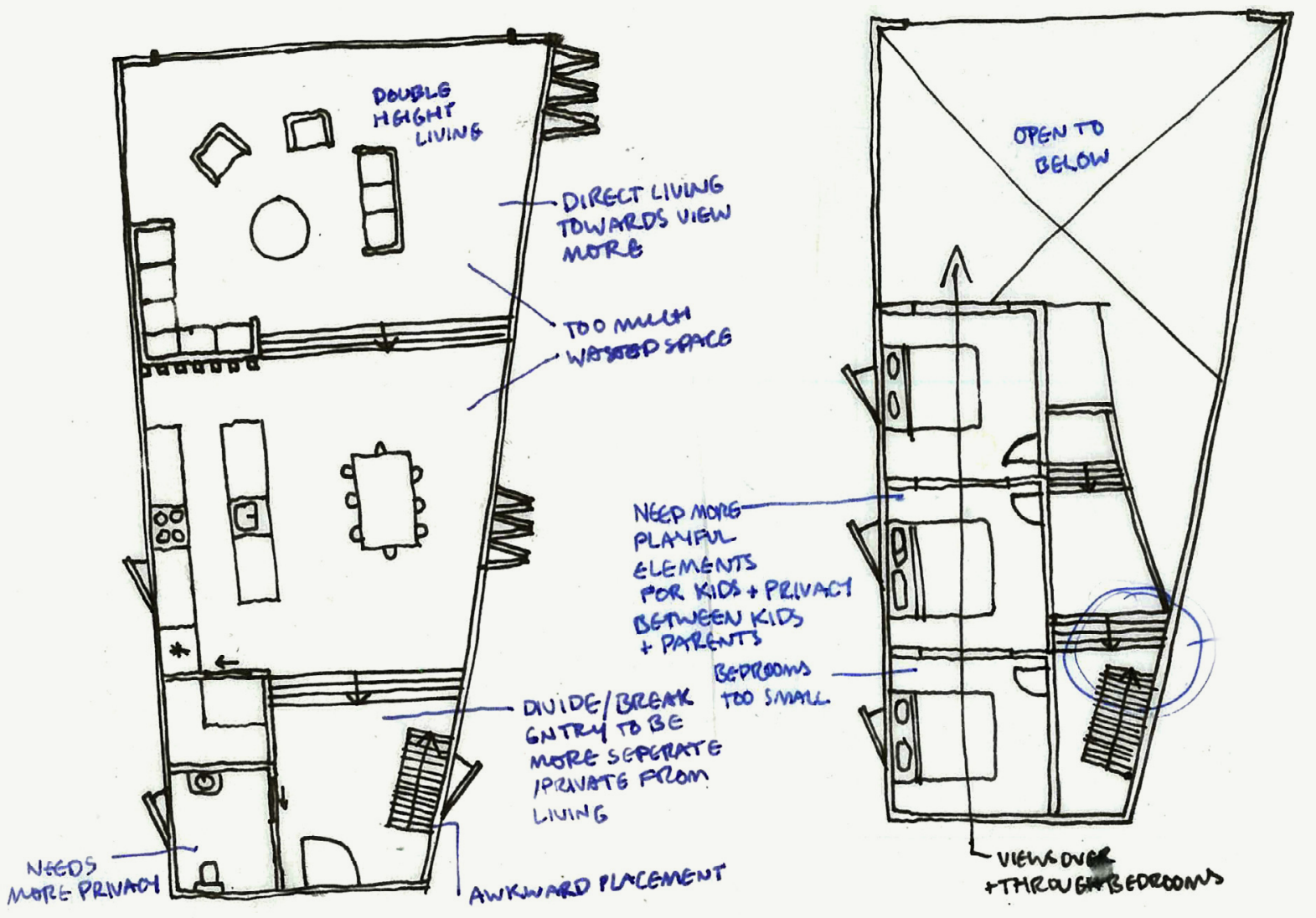

Fig.6.14.Introducing programme
6.2.10. Reflection

This series explores how space can be stacked to connect multiple spaces within the dwelling to the landscape to reduce glass usage.

Sketches informed how the view could be stacked using different design elements, such as walls, furniture or massing.

Aligning openings in walls creates viewports and allows the view to permeate through multiple spaces in the building. However, one issue that was observed was the lack of privacy these spaces can have. Viewports could resolve this issue by providing glimpses through spaces to the view by incorporating concealing elements such as semitransparent walls and tectonic elements. By positioning the view port carefully, certain parts of the room can be obscured, while the view is still transmitted into the room beyond. Placing stacked spaces both vertically and horizontally reduced the amount of glazing needed while maintaining privacy.

However, another issue that was observed was sound. Traditional space dividers like walls or glass offer sound insulation between rooms, and residents might still later use glass to adjust the partitions to elimate issues with noise. 


\subsection{POSITIVE AND NEGATIVE SPACE}

\subsubsection{Purpose of the series}

This series explored how positive and negative space can be arranged to reduce overall need for interior space, thus resulting in lower glass usage. Massing elements combined with tectonic elements allowed for an iterative series through sketch. This then developed into a series of physical models, followed by the introduction of programme using more formalised sketch iterations. The series will evaluate the need for interior space, and analyse whether some spaces can be created outdoors, resulting in lower glass usage. The series aims to:

Poetically: Create a threshold between the interior and exterior environment, allowing and encouraging users to experience a greater connection with the

landscape, instead of perceiving it through glass. It also aims to use indoor and outdoor space to divide space more effectively, allowing stacking of the view to be achieved more easily (section 6.2).

Scientifically: Reduce glass usage by creating outdoor living spaces. In addition, it will decrease the amount of material overall to

reduce impact on the environment, as well as providing a smaller building envelope, which decreases

the thermal requirements of the building.

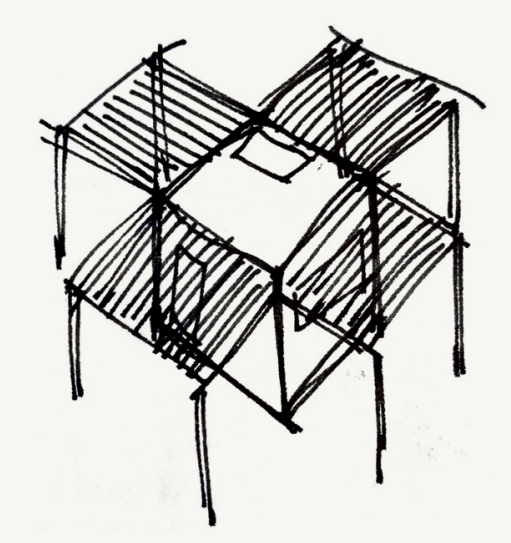

Fig.6.15.Concept of positive and negative space 


\subsubsection{Iteration 1}

Sketching massing and tectonic

elements to devide positive and

negative space on the site in plan
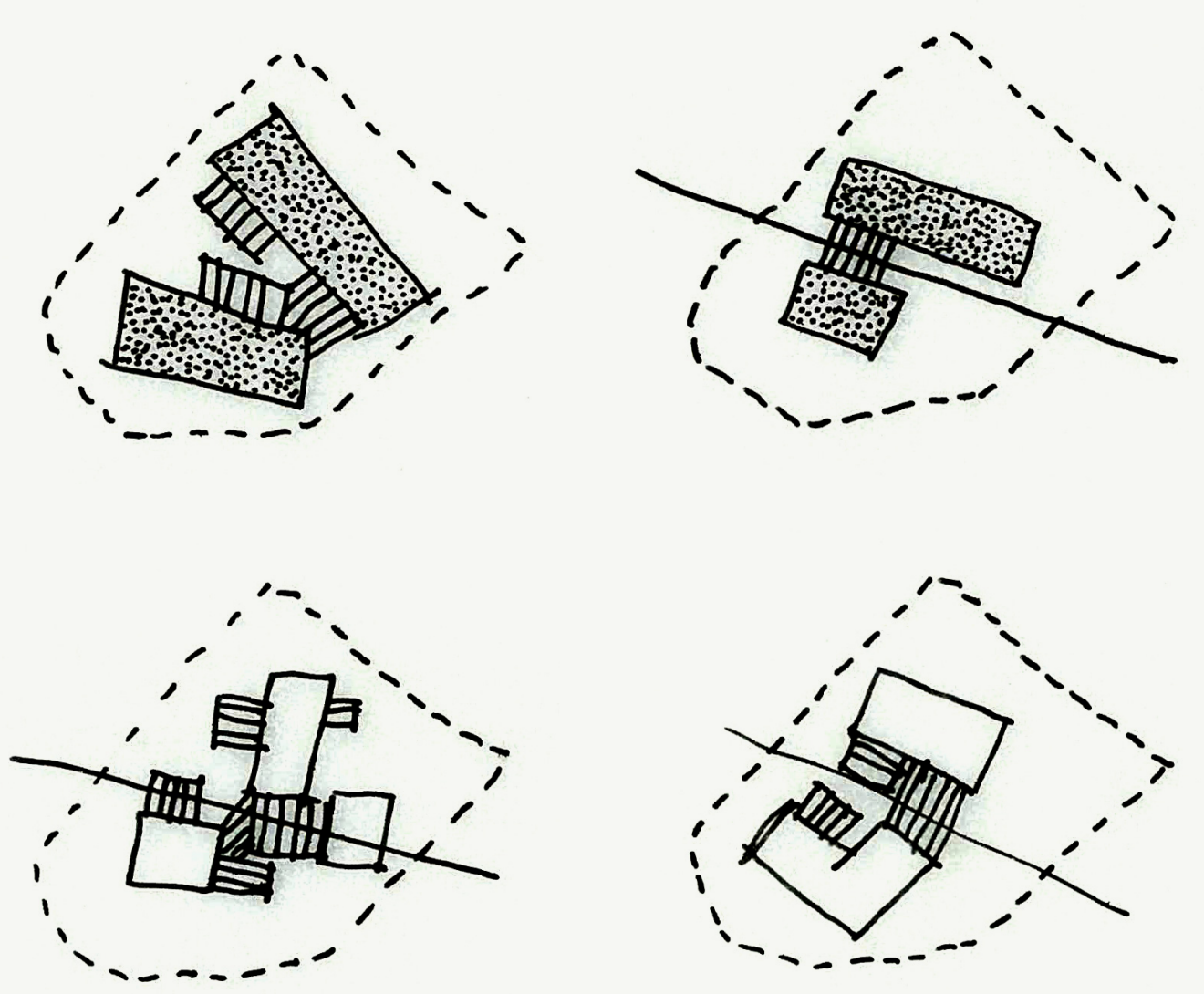

6.3.3. Iteration 2

Experimenting with how the threshold

between positive and negative space

can be achieved through tectonic and

volumetric elements

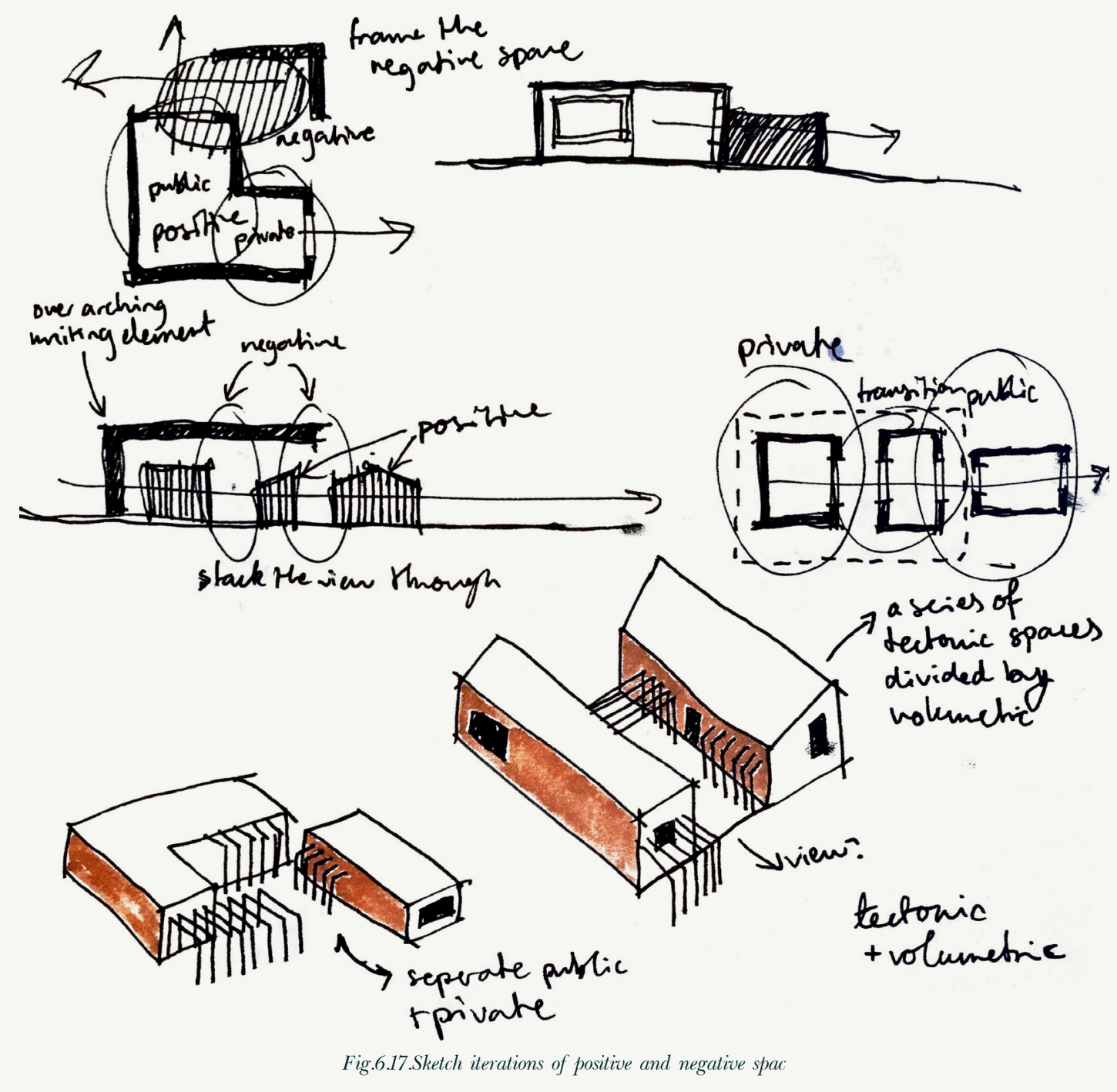




\subsubsection{Iteration 3}

Developing previous ideas of tectonic elements to contain the outdoor and volumetric elements three room space within the dwelling to

dimensional, using materiality to

define the threshold and volumetric

make it a viable sheltered living
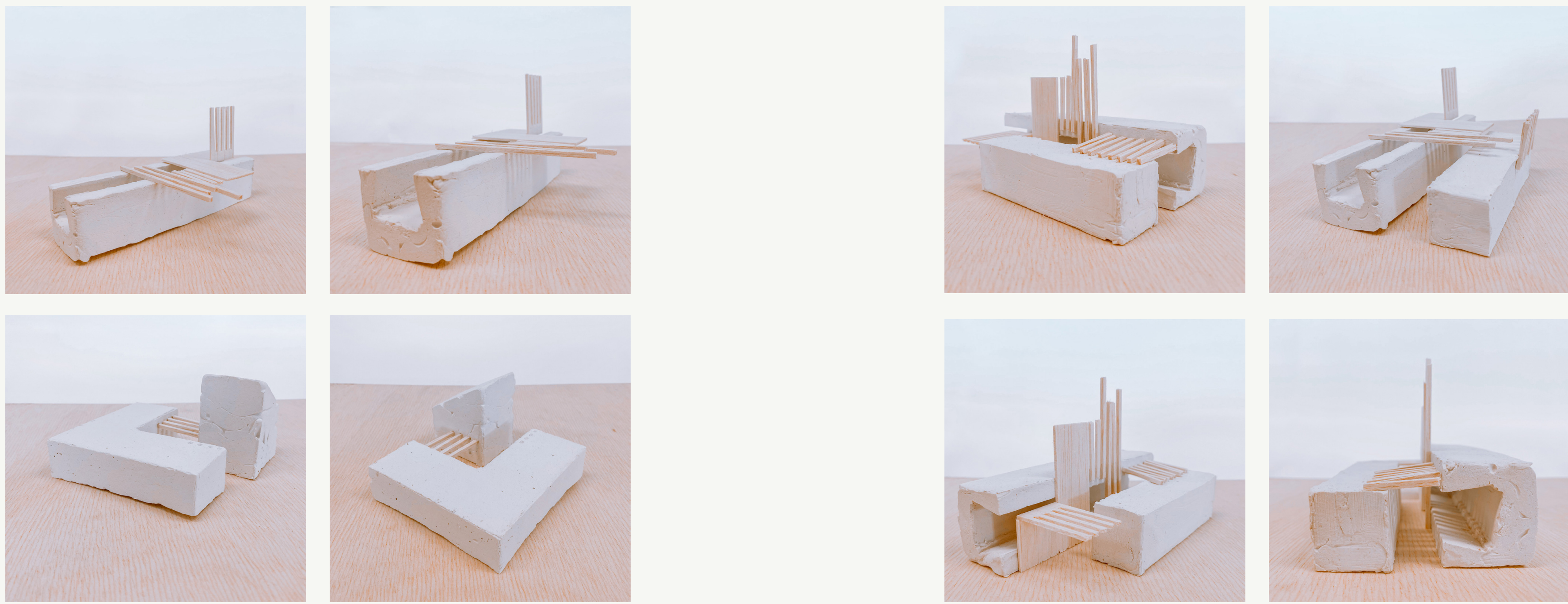

Fig.618.Shetch model iterations of positive and negative space
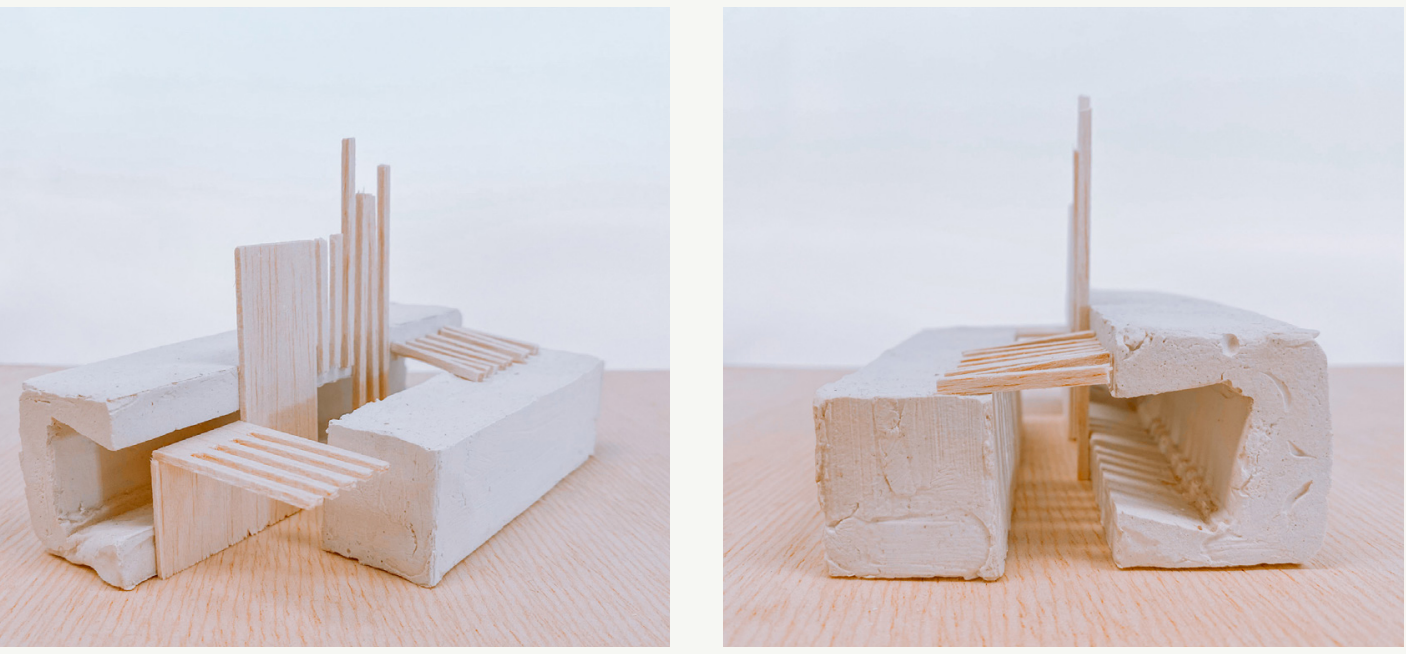

Fig.6.619.Sketch model iterations of positive and negative space 


\subsubsection{Iteration 4}

Central breezeway creates ideal

outdoor rooms using clearly defined

positive and negative space and

offers protection from the elements

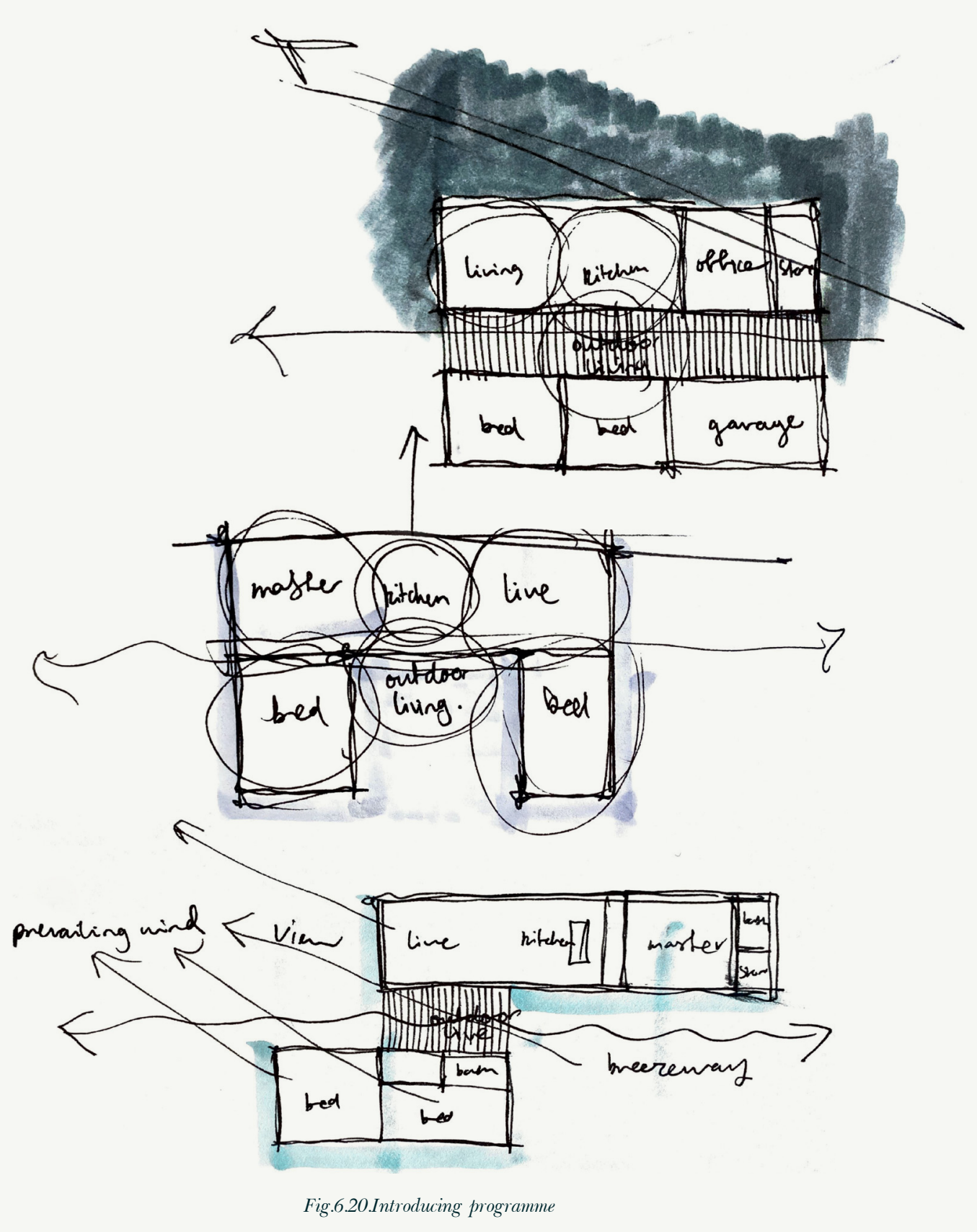

6.3.6. Iteration 5

An $\mathrm{H}$-shaped dwelling provides a

ideal scenario for negative space

contained within the dwelling. In

this instance it can be used to divide

public and private space. However

this form would have significant

thermal issues: more rectangular

forms are preferred.

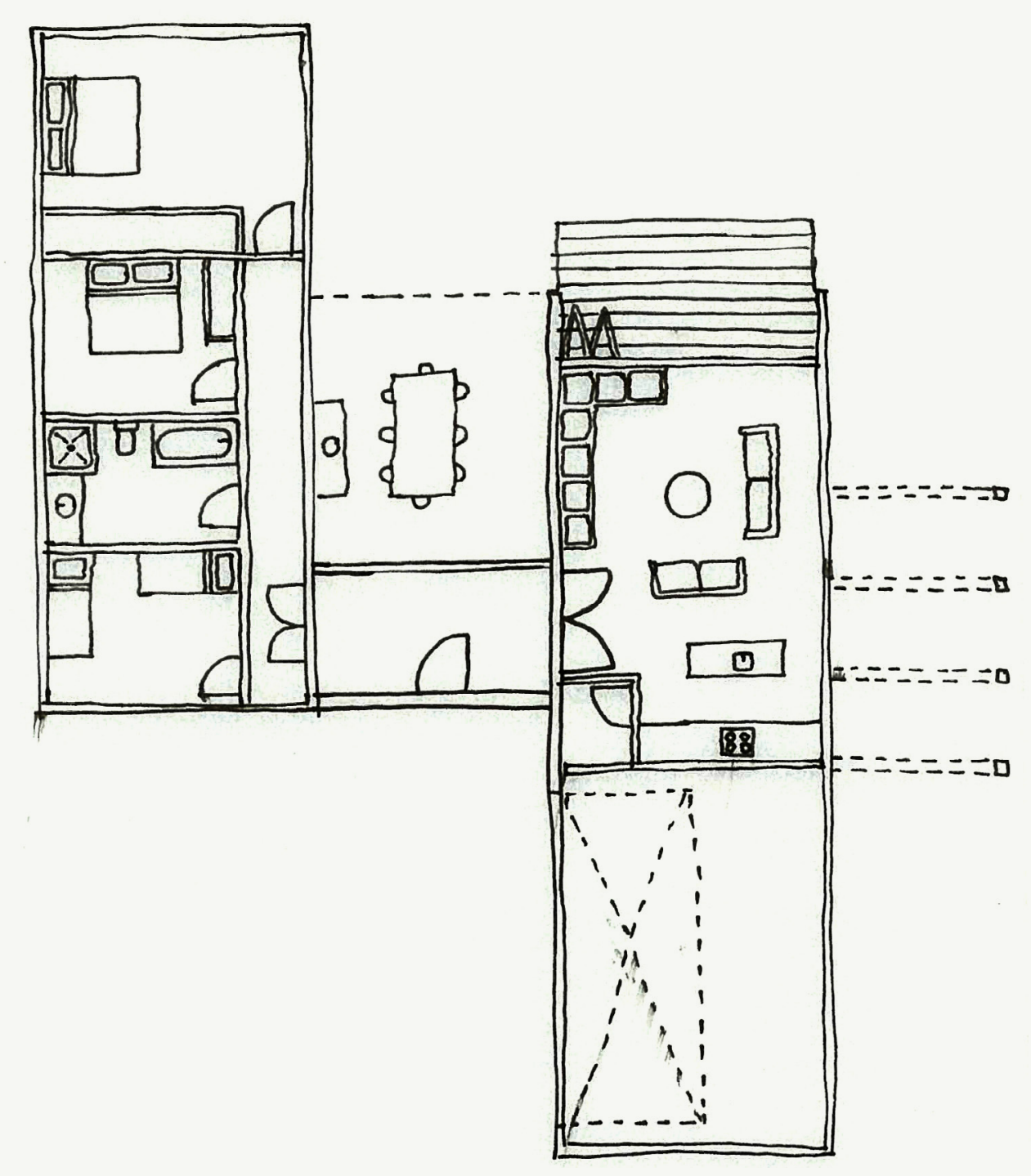

Fig.6.21.Introducing program 


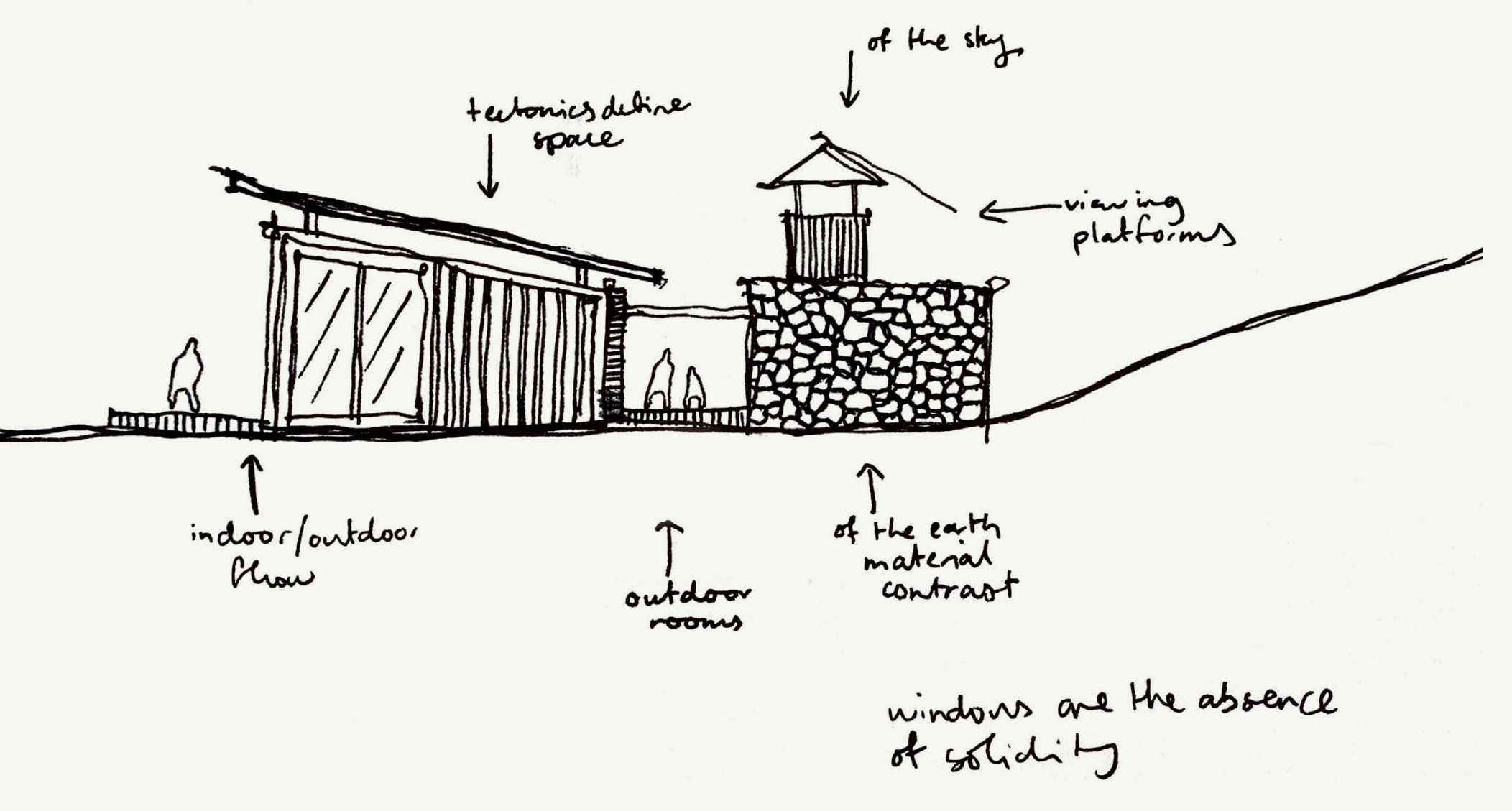

\subsubsection{Iteration 6}

An L-shaped dwelling provides ideal protection from prevailing weather from the Northwest, and is more successful thermally. However, the view is restricted to only indoor

living spaces and makes the outdoor negative space a less desirable space

to inhabit, also due it to receiving little sunlight.

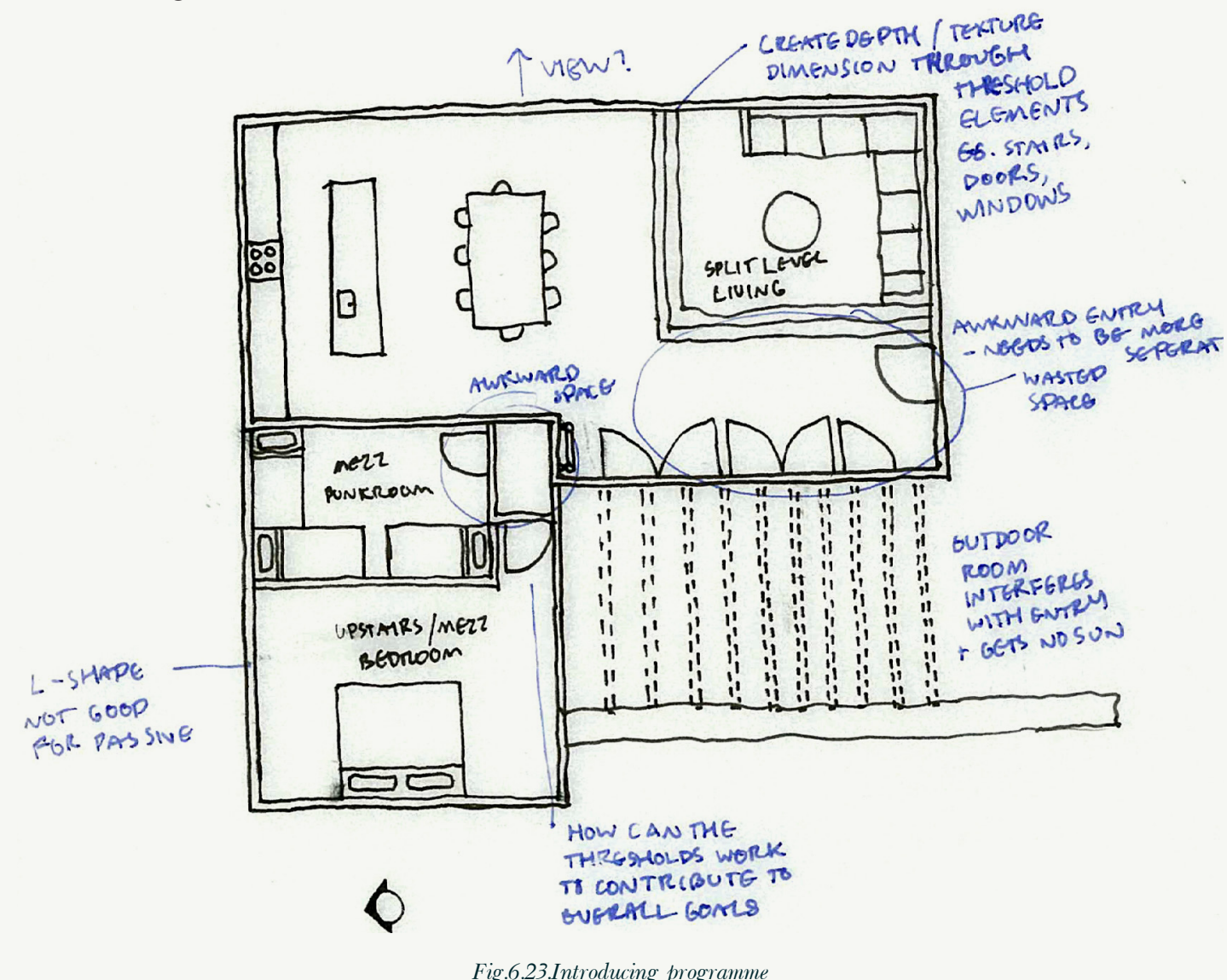




\subsubsection{Iteration 7}

Combining stacked spaces (section 6.2) with positive and negative space. A tapered form accentuates and draws the user toward the view at the end of the building, which is

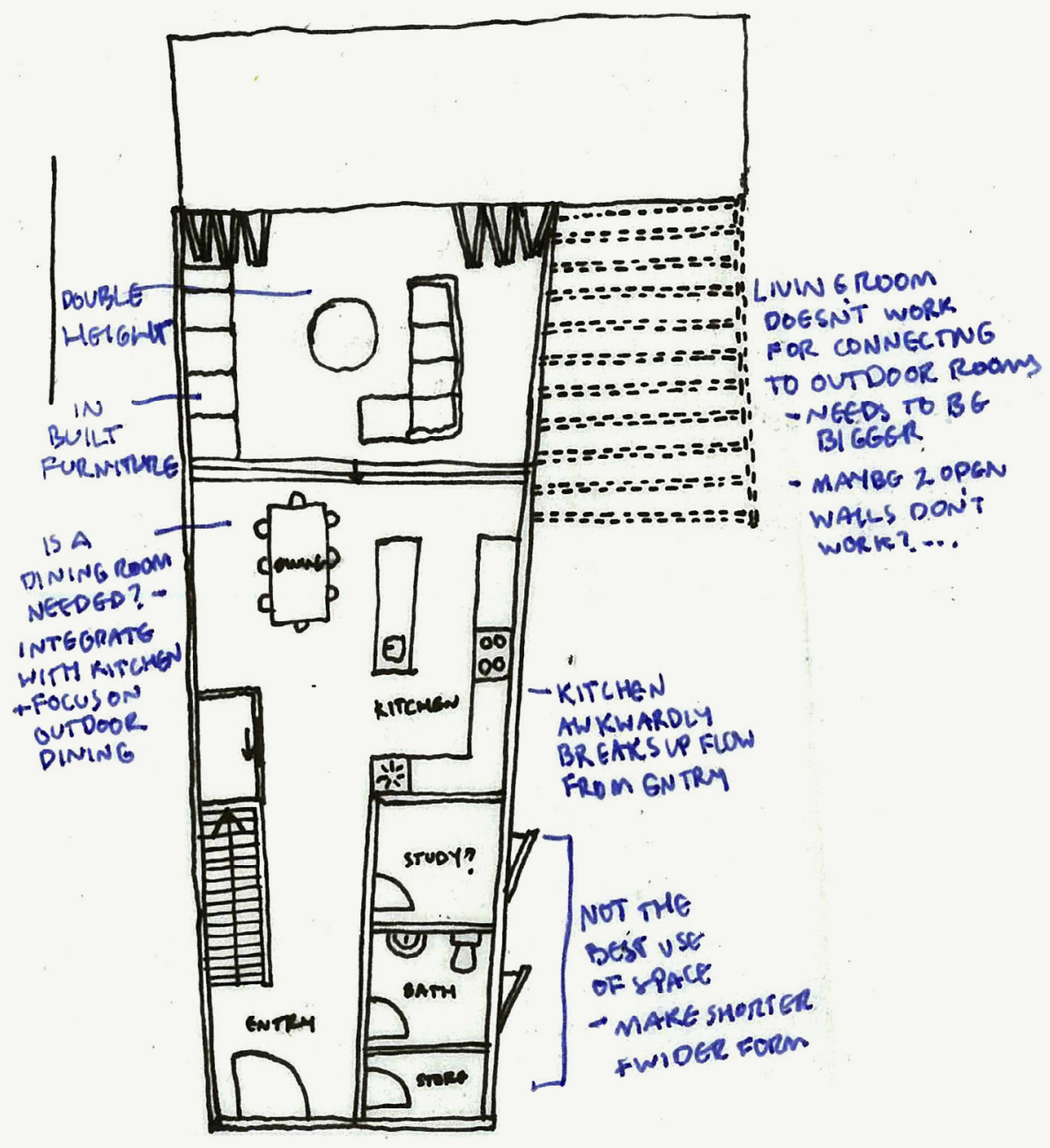

heightened by the placement of an outdoor room at this end, where it is both sheltered and directed toward the view.

Fig.6.24.Introducing programm
6.3.9. Iteration 8

Understanding best placement of positive and negative space to convey the view. In succession from iteration 5 , the $\mathrm{H}$ house, this iteration used the hillside as the secondary 'positive' massing element to prevent thermal loss by retaining a rectangular form.

In addition this iteration explored how the spaces could be placed to effectively benefit from the view, using the negative and positive space as a starting point and then introducing programme. 


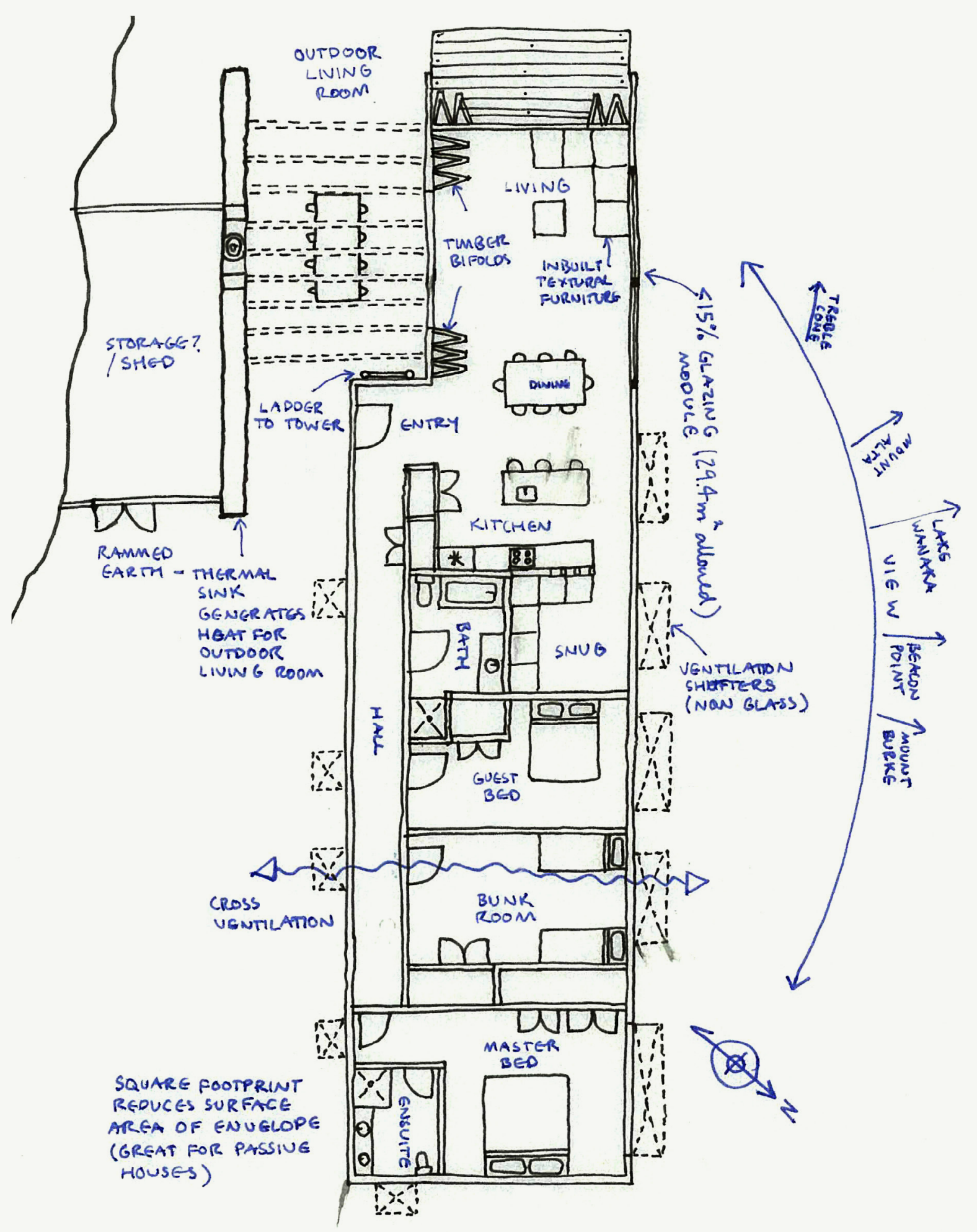

\subsubsection{Reflection}

This series explored how positive and negative space can be arranged to reduce overall need for interior space, thus resulting in lower glass usage.

The series demonstrated that site factors have a reasonable level of influence when it comes to creating outdoor rooms. Sun, wind and view each play a part when it comes to positioning and orientating outdoor rooms. The series attempted to position negative space where it would be sheltered from the wind but also receive sun and capture the view. These elements were essential for making an outdoor room liveable especially during winter months. The sketches demonstrated that negative space was best positioned between at least two positive space in order to provide these qualities.
Meanwhile, physical modelling exhibited how tectonic and

volumetric elements can be used to define both positive and negative space. It was important that negative space used structure to determine it as part of the living space, rather than simply outdoor space.

Additionally, it became clear later in this series that the introduction of programme to the design limited the possibilities of the architectural form. Going forward, design iterations that are not constrained by the building's programme could help achieve the 'architectural success' desired. This contributes to the idea that sustainability issues such as glass consumption could benefit from poetic design techniqes rather than exclusively scientific. 


\section{4. $M \cup L T I$ \\ FUNCTIONAL \\ SPACE}

This series explored how some spaces could be combined or carefully positioned in order to reduce overall floor area, which in turn reduces the amount of glazing required for the building.

The series began by separating space into their role, rather than the traditional programmatic spaces of a house: a place to live, bathe, eat and sleep. Removing the traditional programme of the building allows the design to be explored more poetically rather than scientifically (where scientific processes mean designing for the programme

alone). The series aims to explore

how poetic design of multifunctional spaces can reduce glass usage.

\section{Poetically the series aims to}

introduce the concepts of desired

living spaces in a non-traditional sense to understand how spatial arrangement can affect the

\section{placement of windows.}

Scientifically the series aims to reduce glass usage by combining traditional dwelling spaces to make better use of singular windows, and explore how these spaces can best be placed in relation to windows to receive adequate amounts of daylight.

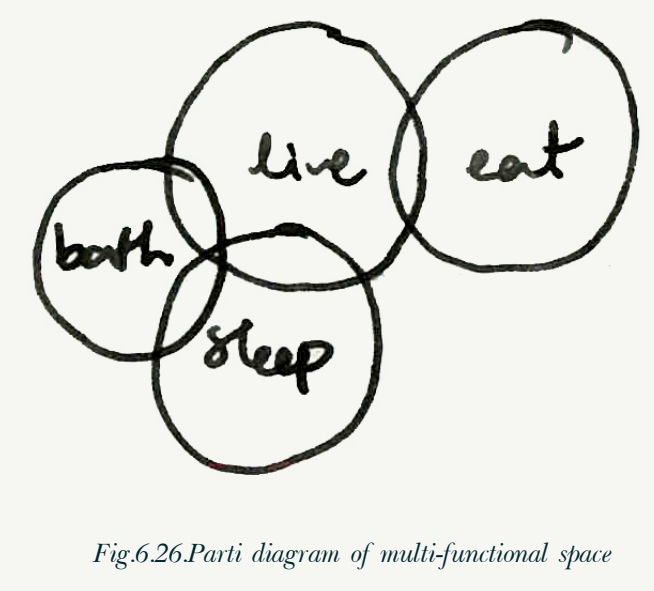




\subsubsection{Iteration 1}

Bubble diagrams of functional

spaces inform how the placement

of rooms within a square form

might work. Open plan living is

most successful at reducing glazing

required because of its ability to

connect all the main living spaces

into one.
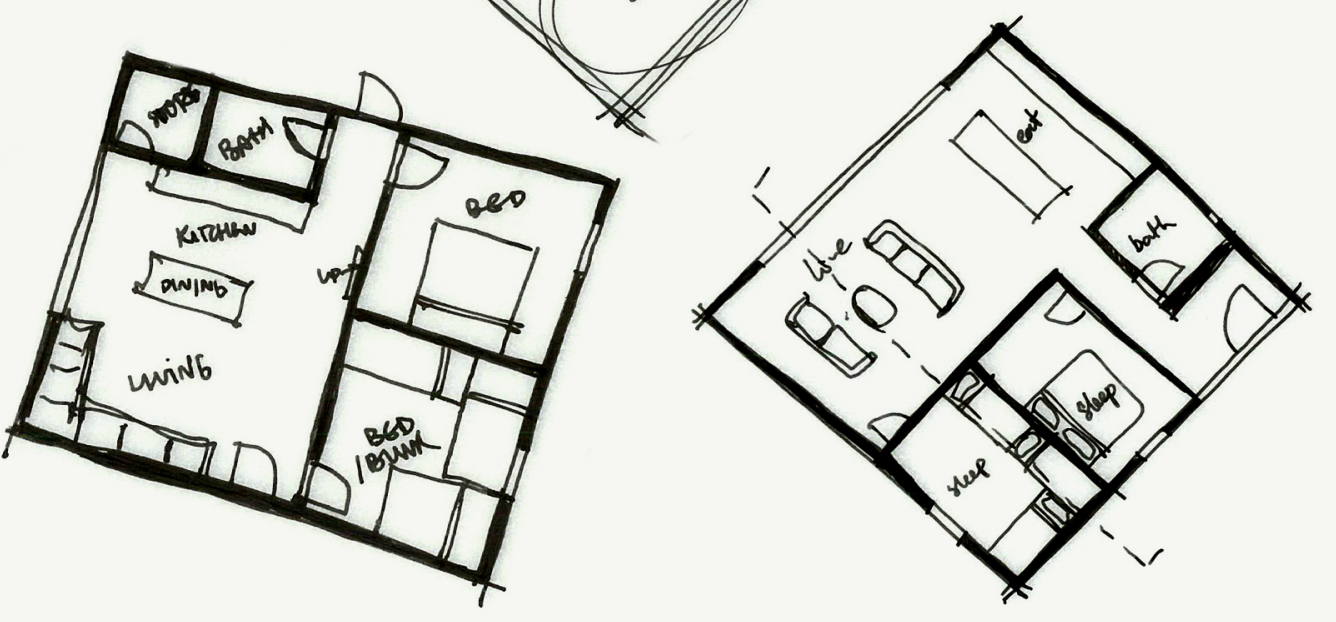

6.4.3. Iteration 2

Double height space with the

integration of a mezzanine floor

allows all spaces to benefit from one

large North-facing window
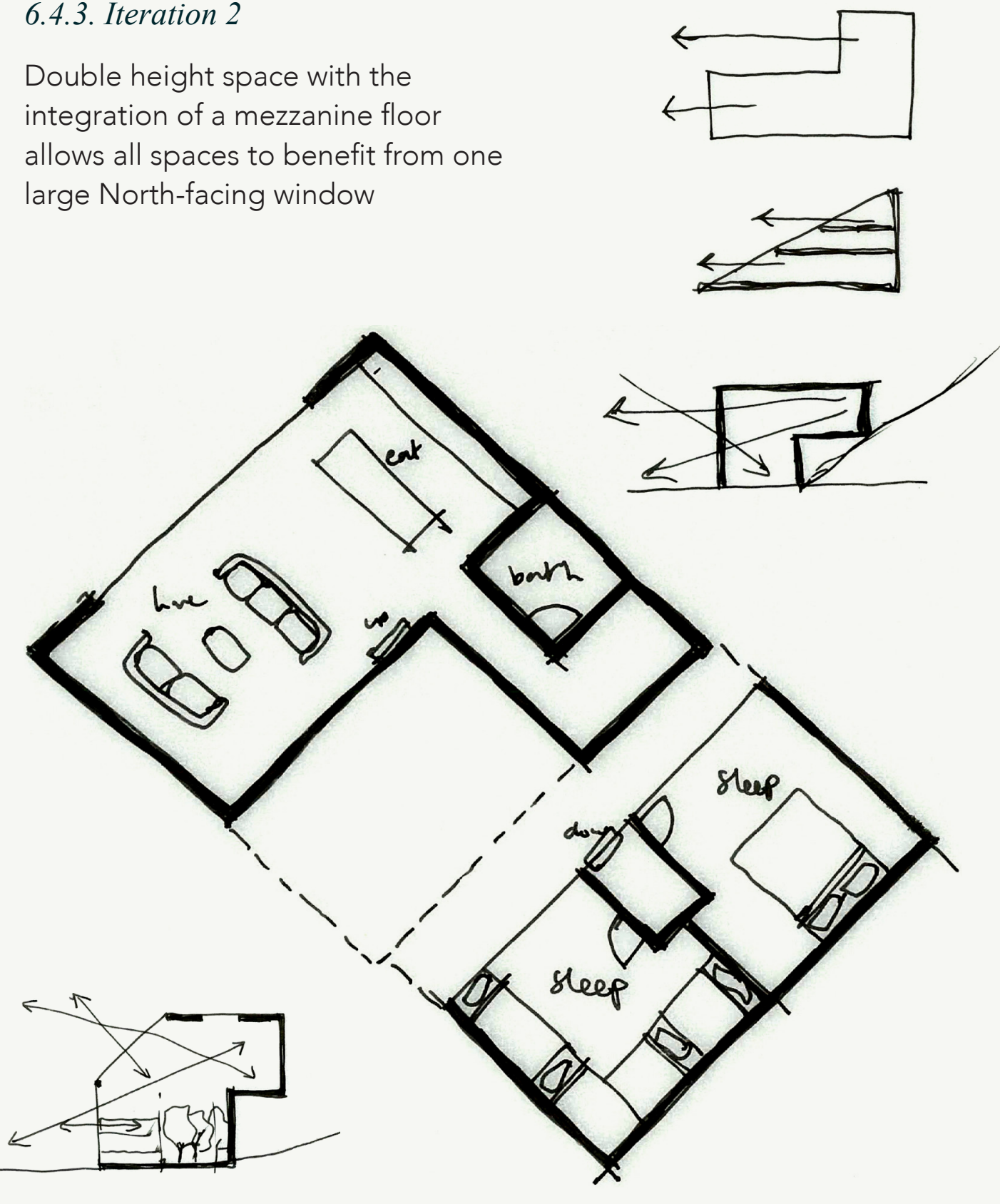

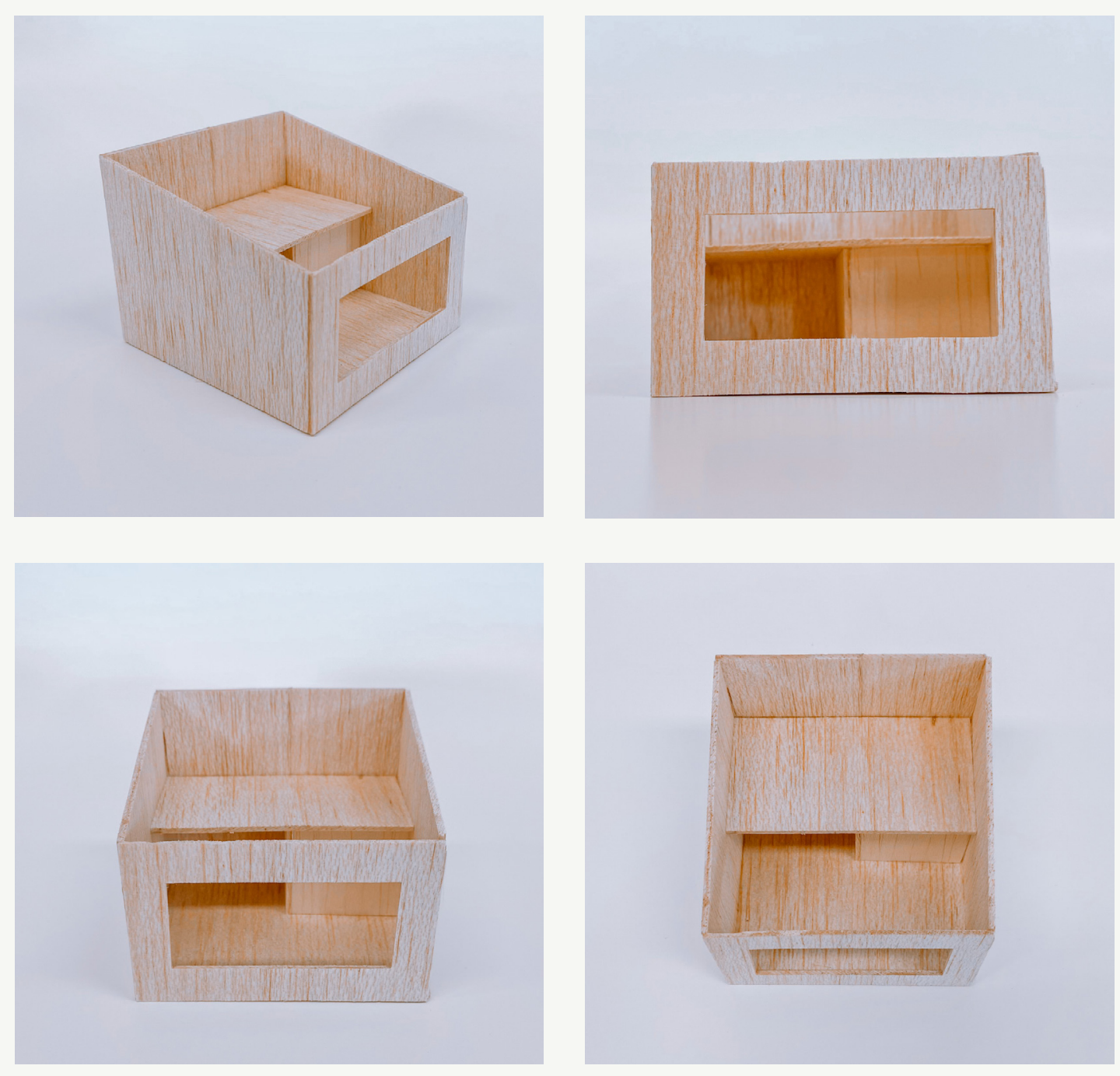

Fig.6.29.Employing a mezzanine floor allows multiple spaces to benefit from one window

\subsubsection{Reflection}

This series explored how spaces could be combined to reduce

the amount of glazing required in individual spaces.

Open plan living presented the best options for this by allowing multiple living spaces to benefit from one

large North-facing window.

One issue that was observed was how to provide light to more private or intimate spaces such as bedrooms while maintaining adequate lighting levels. A double height space with a mezzanine

floor was a successful solution to this: while the upstairs is less visible from the downstairs, it still receives daylight from the large window in the living area below.

It would be useful to experiment with lighting analysis of the space to gain a scientific understanding of daylighting levels in the space and whether or not it provides adequate lighting (see chapter 7). 
6.5.PUBLIC \& PRIVATE SPACE

This series explored how public and private spaces could be

designated, primarily through sketch and collage. The series questioned

whether glazing requirements could be reduced by defining public and private space.

Poetically the series aims to utilise thresholds between architectural space to divide public and private space. With the idea that private spaces such as bedrooms are more intimate and therefore need less light while public spaces like living rooms and kitchens need more light, the series aims to use the poetic concept of public and private space to reduce glass usage.

Space could be divided physically with elements such as walls but also metaphorically with the use of materials and patterns.

Scientifically the series aims to analyse which spaces require more light than others to determine the best routes for reducing glass where less light is required.

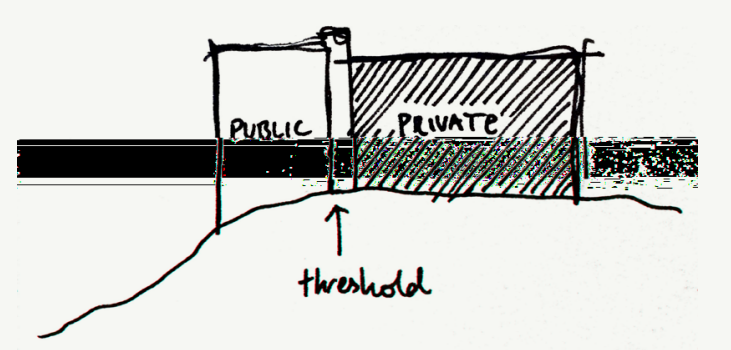

g.6.630.Parti diagram of public and private space 


\subsubsection{Iteration 1}

Overlapping public and private space results in a threshold between spaces. The essential indoors space derived from section 6.3 could be utilised as this threshold between the two typologies.

Materiality could be used to clearly define this threshold both on the interior and exterior. Similarly to positive and negative space

tectonics could be used to represent this transition zone.
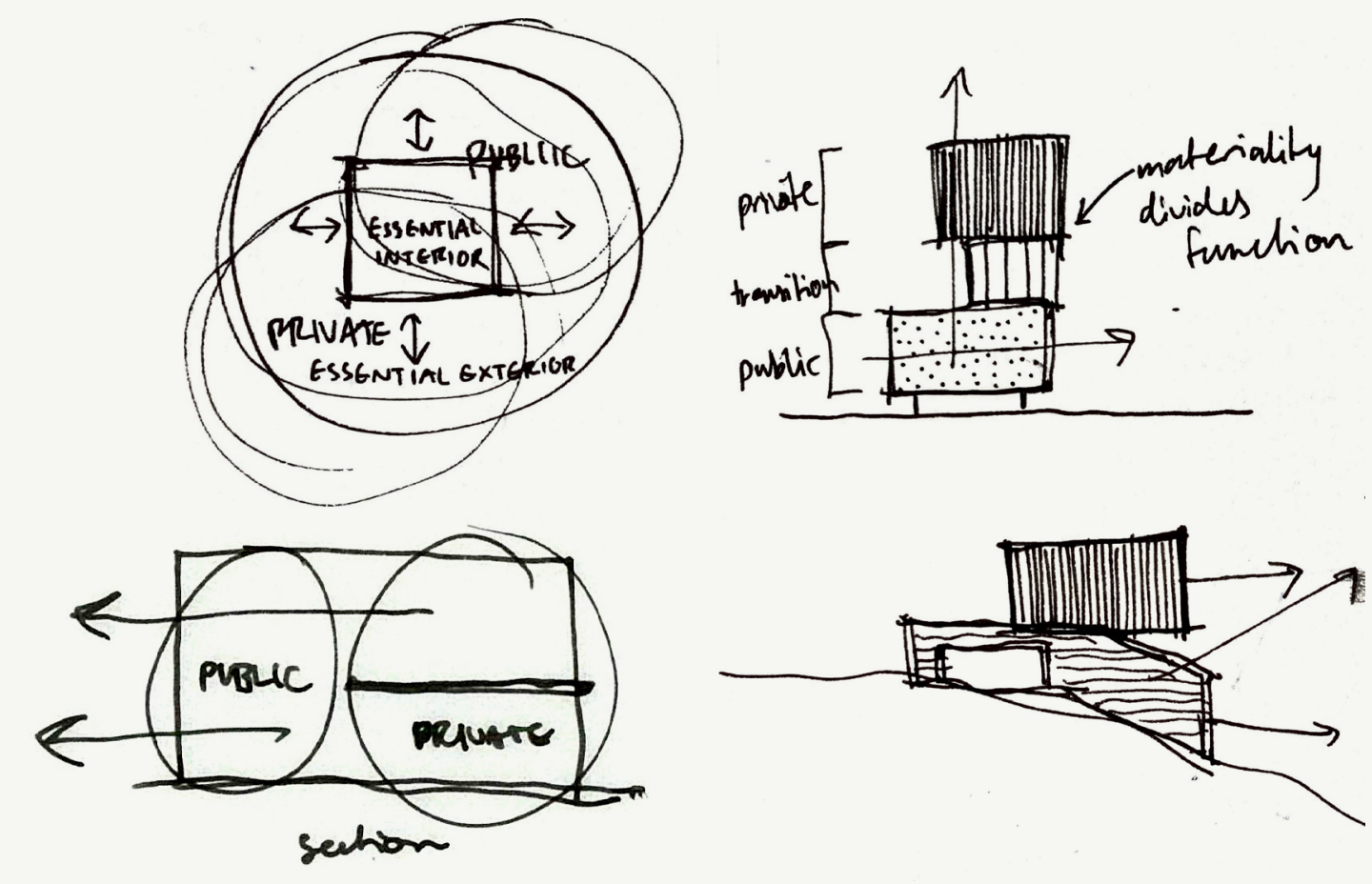

6.5.3. Iteration 2

Overlapping two central masses could separate public and private space and provide a transition zone, however forms such as these will be very inefficient for thermal performance.

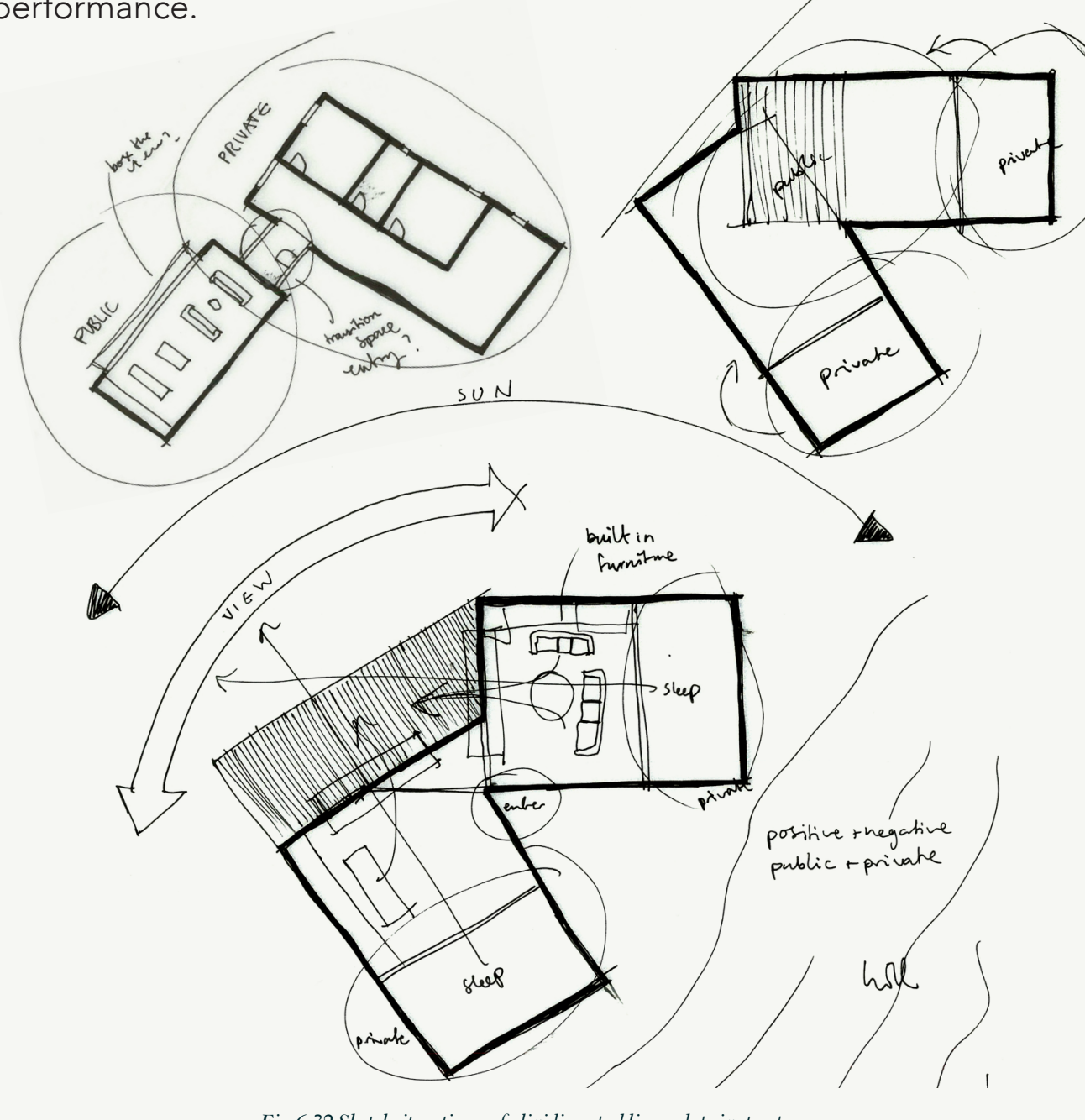

Fig.632.Sketch iterations of dividing public and private space 


\subsubsection{Iteration 3}

Collaging offered the ability to

understand how materiality could

be used to define public and private

space. Heavy, darker materials

represent private, more intimate

spaces where the view of the

landscape is less important, while

lighter materials such as glass and

timber provide a greater connection

to the landscape.

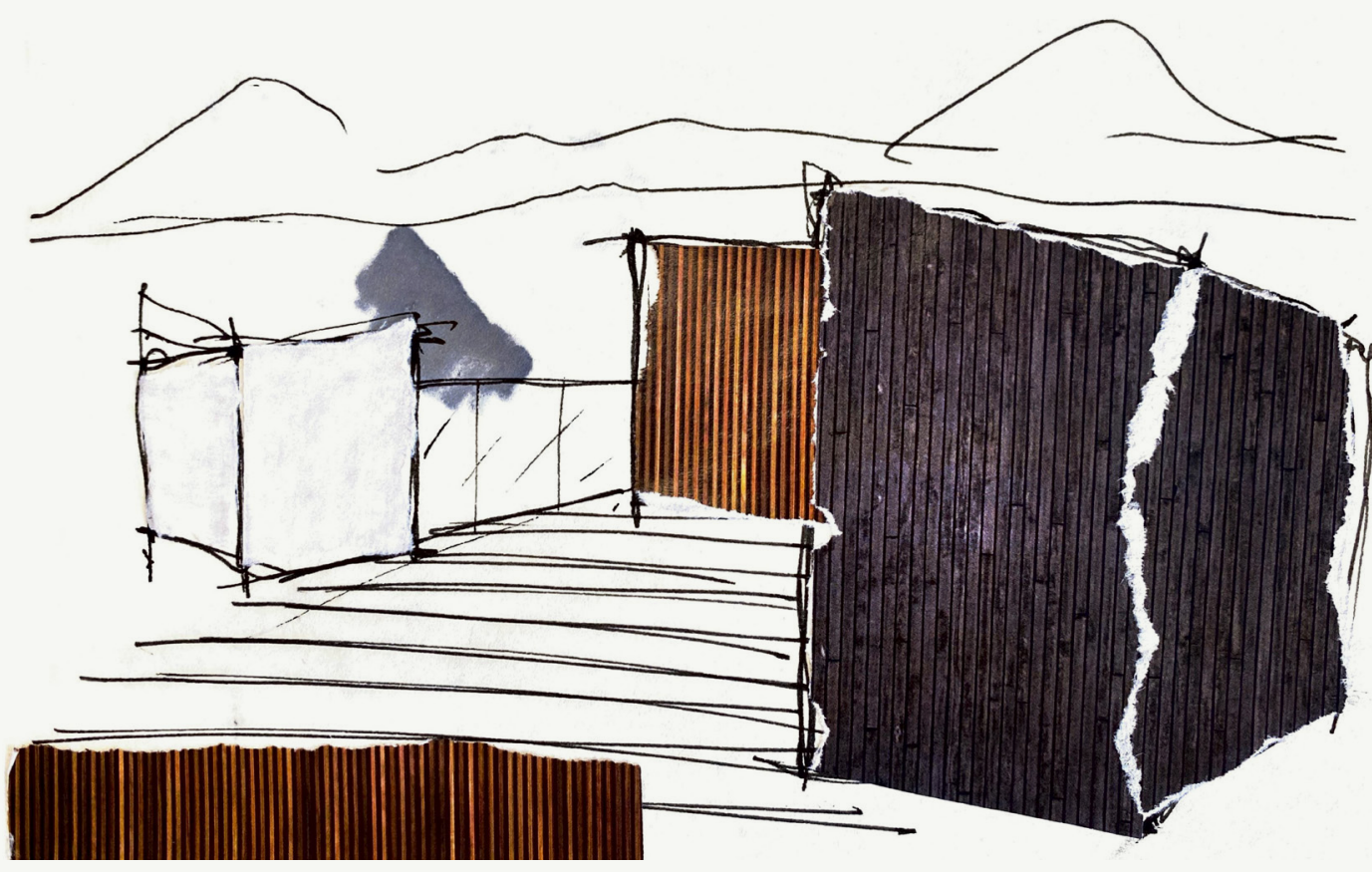

\subsubsection{Reflection}

Private spaces tend to be smaller and more intimate than public spaces, so often require less light and therefore smaller windows. Additionally, because they are often smaller, smaller windows are more suitable proportionally. As stated in the framework, the ideas of binary oppositions to create contrast between public and private spaces were explored. Collages were used to explore

how materiality could define public and private space. Private spaces were more successfully defined by solid materials such as stone and timber, while public spaces were better established using transparent glazing. This contrast in materials is important for determining window placement in a building and

ensures that the role of the space is equivalent with the window size and 


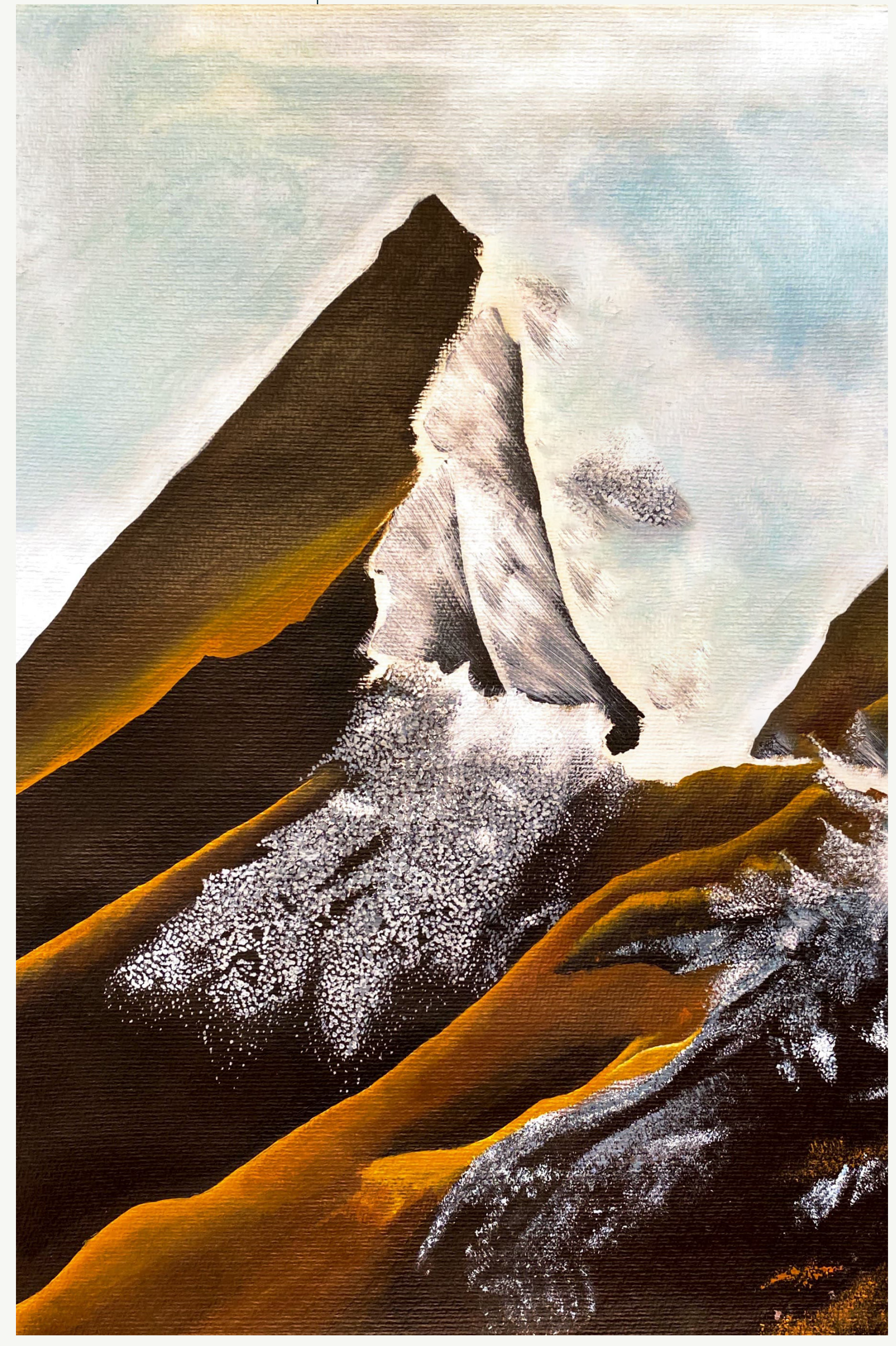




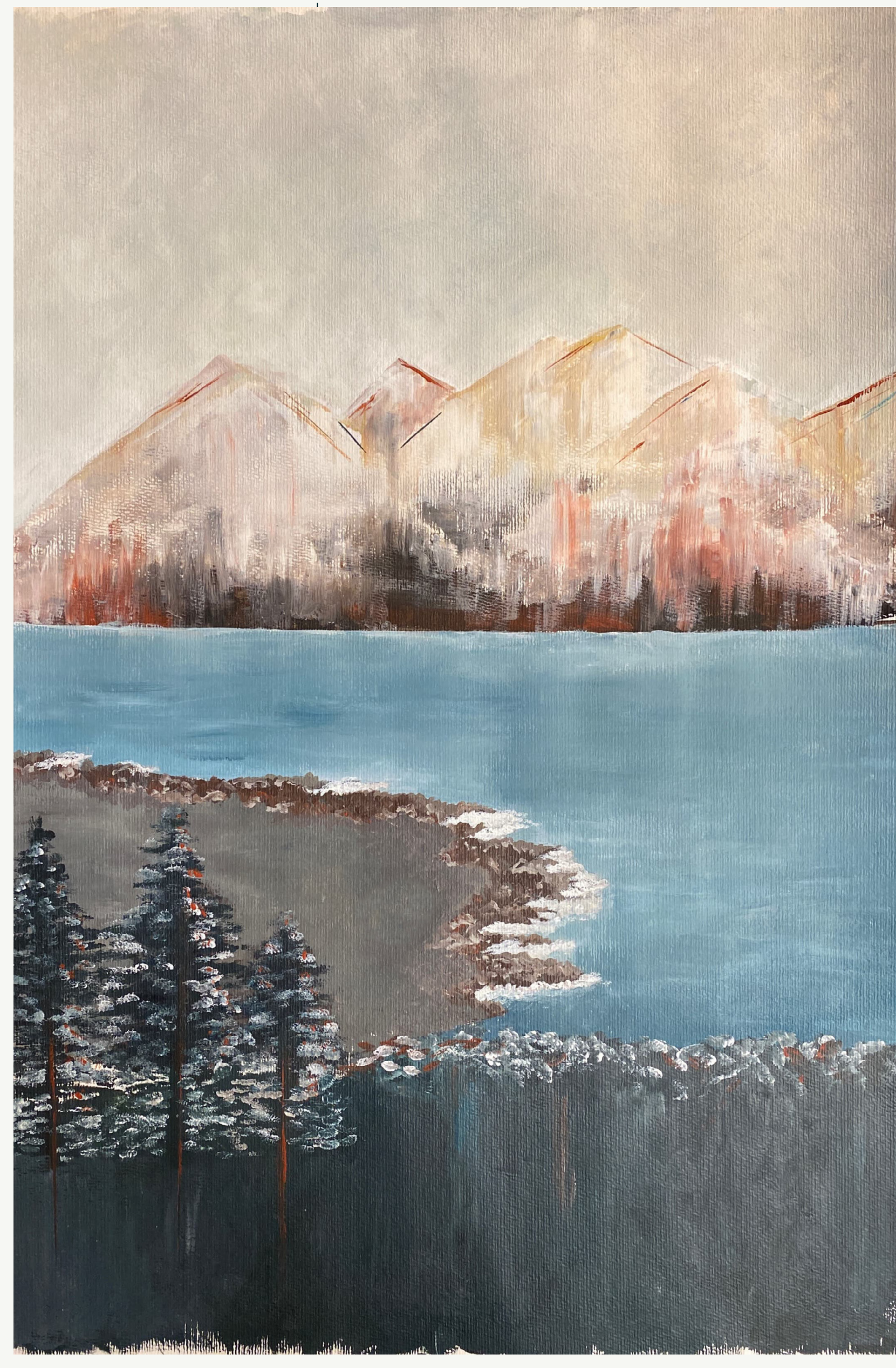

Fig.635.Painting of the view from Beacon's Point

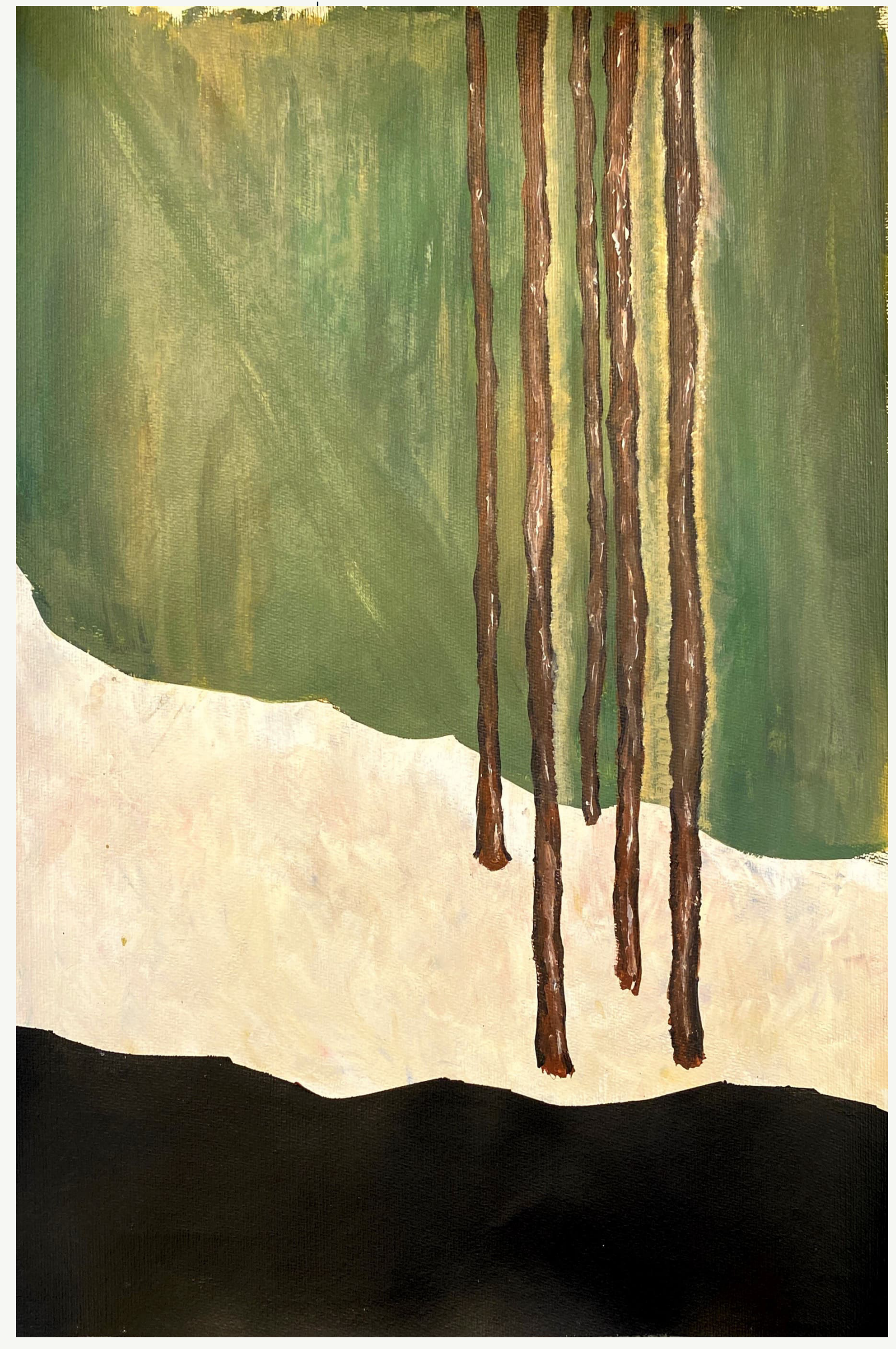

Fig.636.Detail painting of the Plantation 

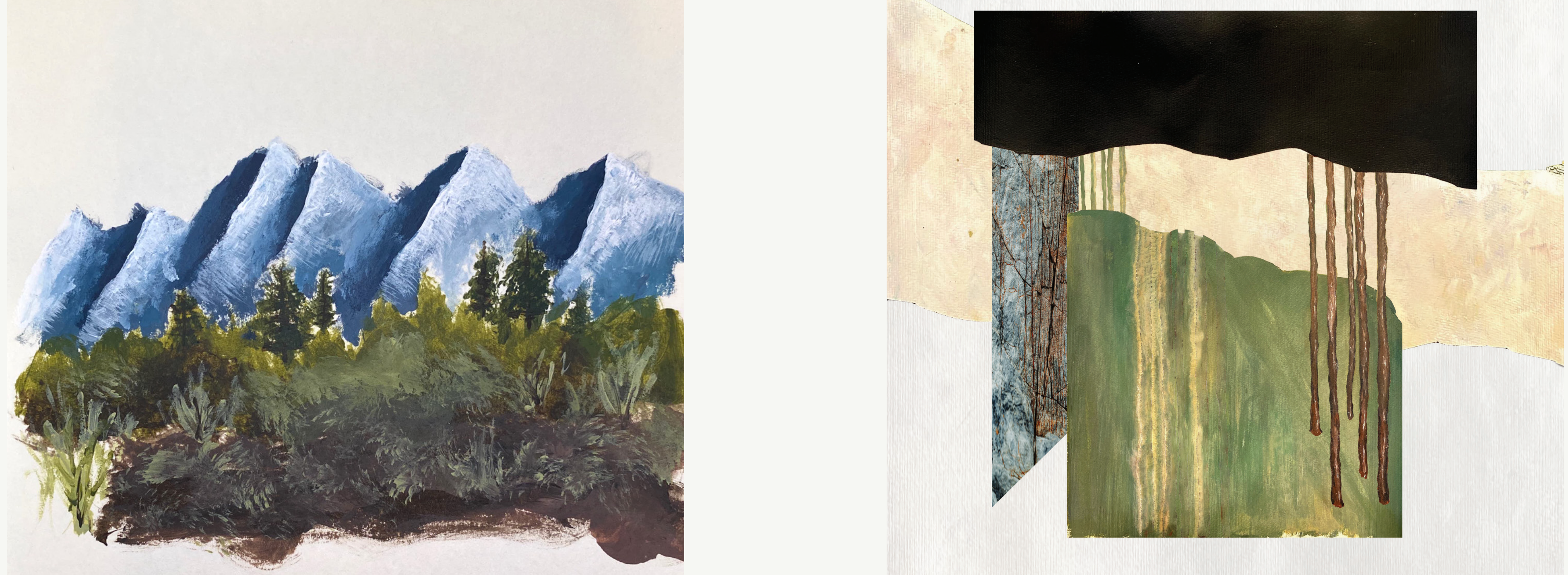

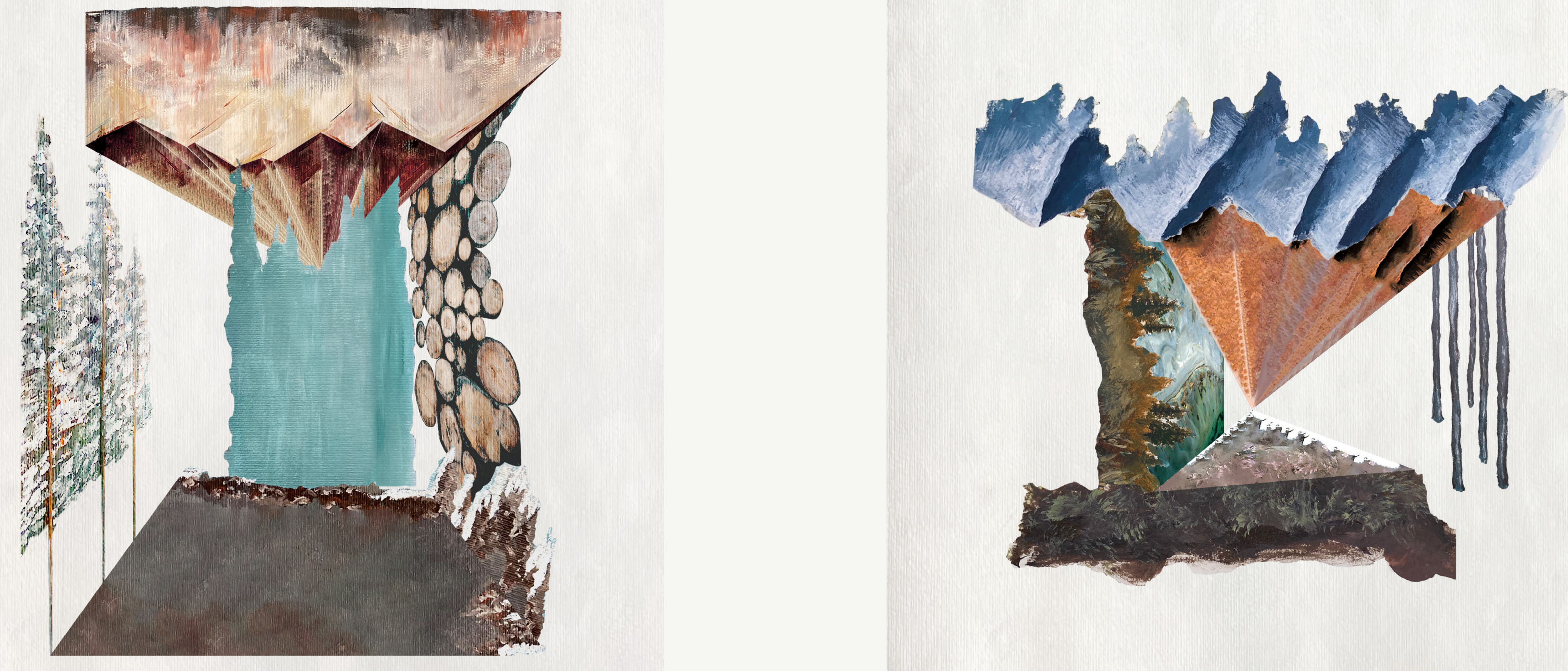


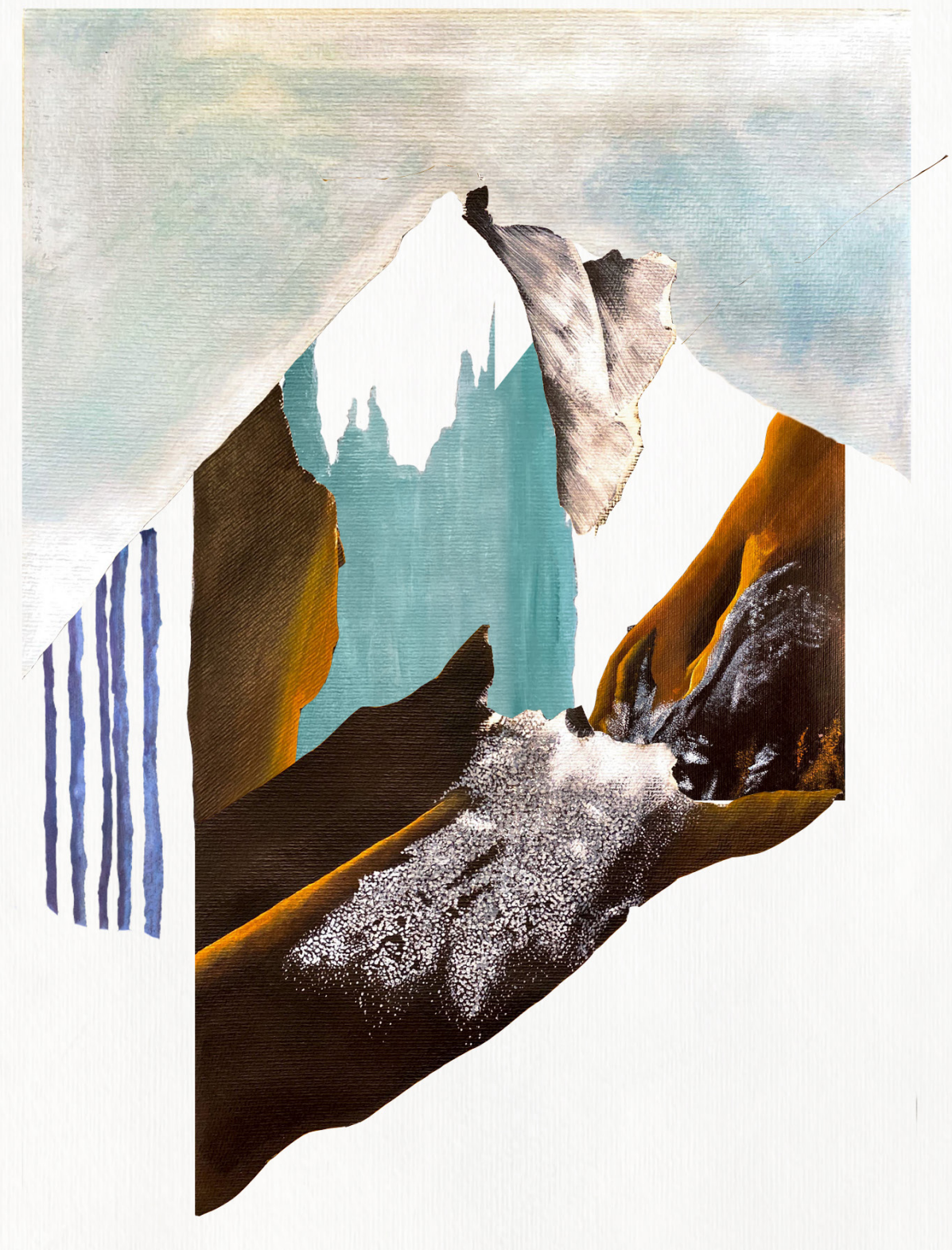

\subsubsection{Reflection}

This series of design iterations involved paintings of typical views New Zealanders desire in a home. The paintings were then "exploded" and rearranged to create spatial arrangements. The expressive techniques used helped to develop an understanding of how biomorphic forms of the landscape could be integrated into the design process. Large scale painting allowed for the creation of forms and textures generated from the landscape which would otherwise be difficult to achieve through traditional design techniques such as sketching and CAD modelling.

Horizontal and vertical lines were strong throughout the series. The horizontal and vertical could inform overall forms as well as composition of facades and interior elements as a way of connecting to nature and conveying 'the view' without the use of glazing.

Another aspect found from this series was its use of texture. Texture is abundant in nature, yet often lacking in contemporary minimalism architecture. Introducing texture to interior spaces could bring the aspect of the view into the design of the building itself, requiring less of the view to be transmitted through glazing. Alternatively, perhaps a lack of texture accentuates the view more, drawing users' attention towards the view, which could be an advantage for a space with only a very small window.

Overall the series was successful in bridging the ideas of poetic design seen in award-winning New Zealand architecture and the scientific aspect of reducing glass usage to solve a sustainability issue in the built environment. 


\subsection{FORMS AND MATERIALITY}

This series attempted for formalise forms, textures and patterns

explored through painting in section

6.3. It investigated through sketch

how materiality could be used in

the design to investigate how the facade would be impacted by the

effects of less glazing.

\section{Poetically the series aims}

understand how less glazing might affect the facade aesthetically. It also

aims to investigate how aspects of

nature could be incorporated into

the building through materiality

rather than providing the visual

connection with nature through

glazing. Forms typically found in the

New Zealand natural environment

were used to inspire such iterations,

as developed in section 7.2. The

development of an architectural language of materiality and textures would aid designers in representing nature in the design through means other than windows.

the series usows. 


\subsubsection{Iteration 2}

Explorations in the New Zealand landscape are often experienced in the form of a journey. This series looked at understanding how the architecture could create a similar journey through the 'landscape' to provide greater connection

with nature. Thresholds inspired

by the site between the lake, the
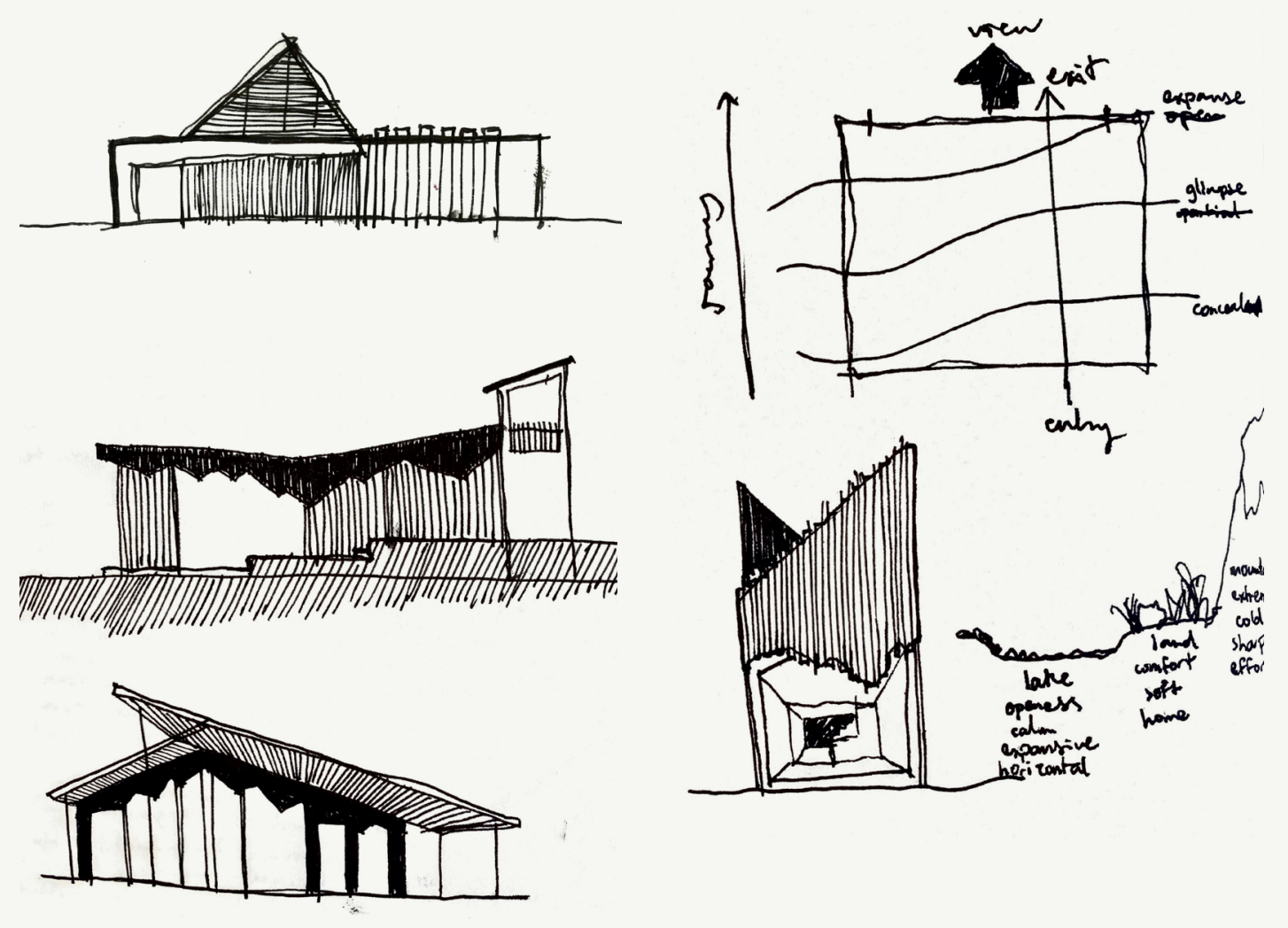

land and the mountains could be used to define interior space and accentuate the view found at the end of the journey.
6.7.4. Iteration 3

Materiality can contribute to

creating a journey through the space

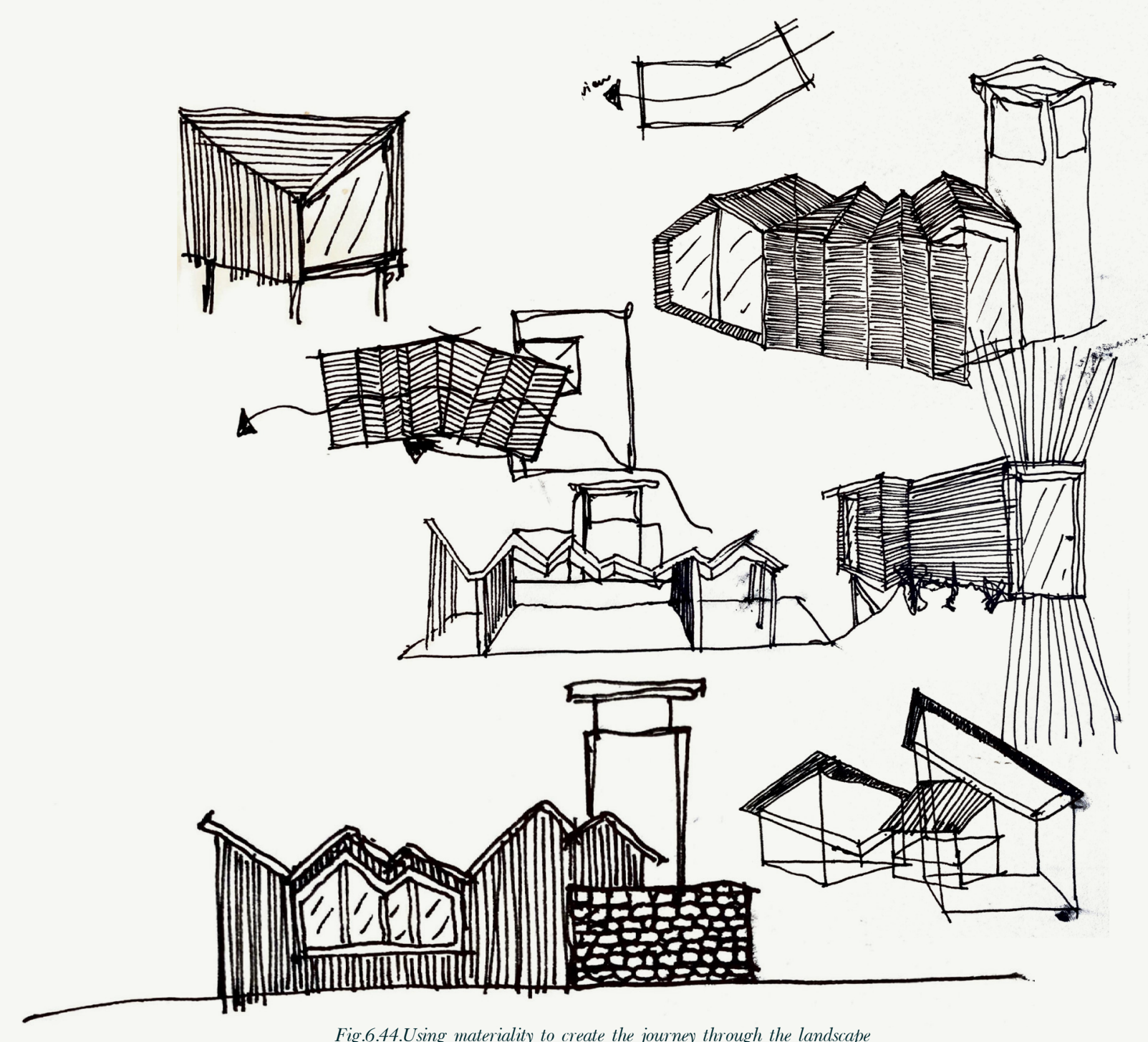




\subsubsection{Iteration 4}

\section{Developing an architectural}

language using materials found

in the landscape such as timber

and stone. This contributes to the

development of techniques for

designers to reduce glass usage by

representing the landscape through

materiality instead.
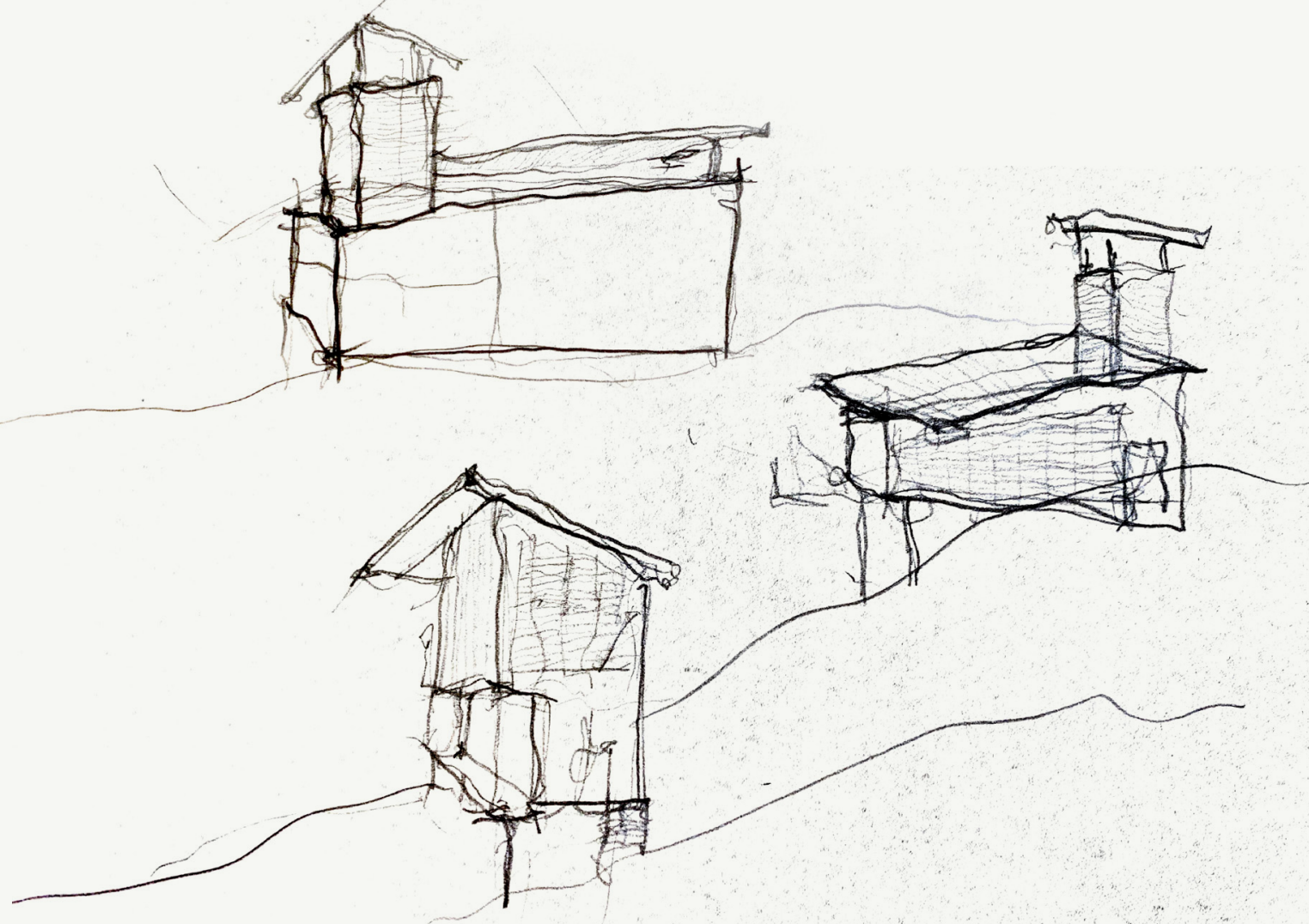

6.7.6. Iteration 5

This iteration introduced the mountainous diagonal forms into the facade. It was observed that having less glazing presents a

challenge for designers in terms of the facade. Glass is a simple material that creates a streamlined

look for the facade, yet creates stimulated interest through its transparency. This is a quality that is very difficult to achieve using other materials. Little or no glass makes simplicity difficult in terms of texture an issue which is experimented with in this iteration.
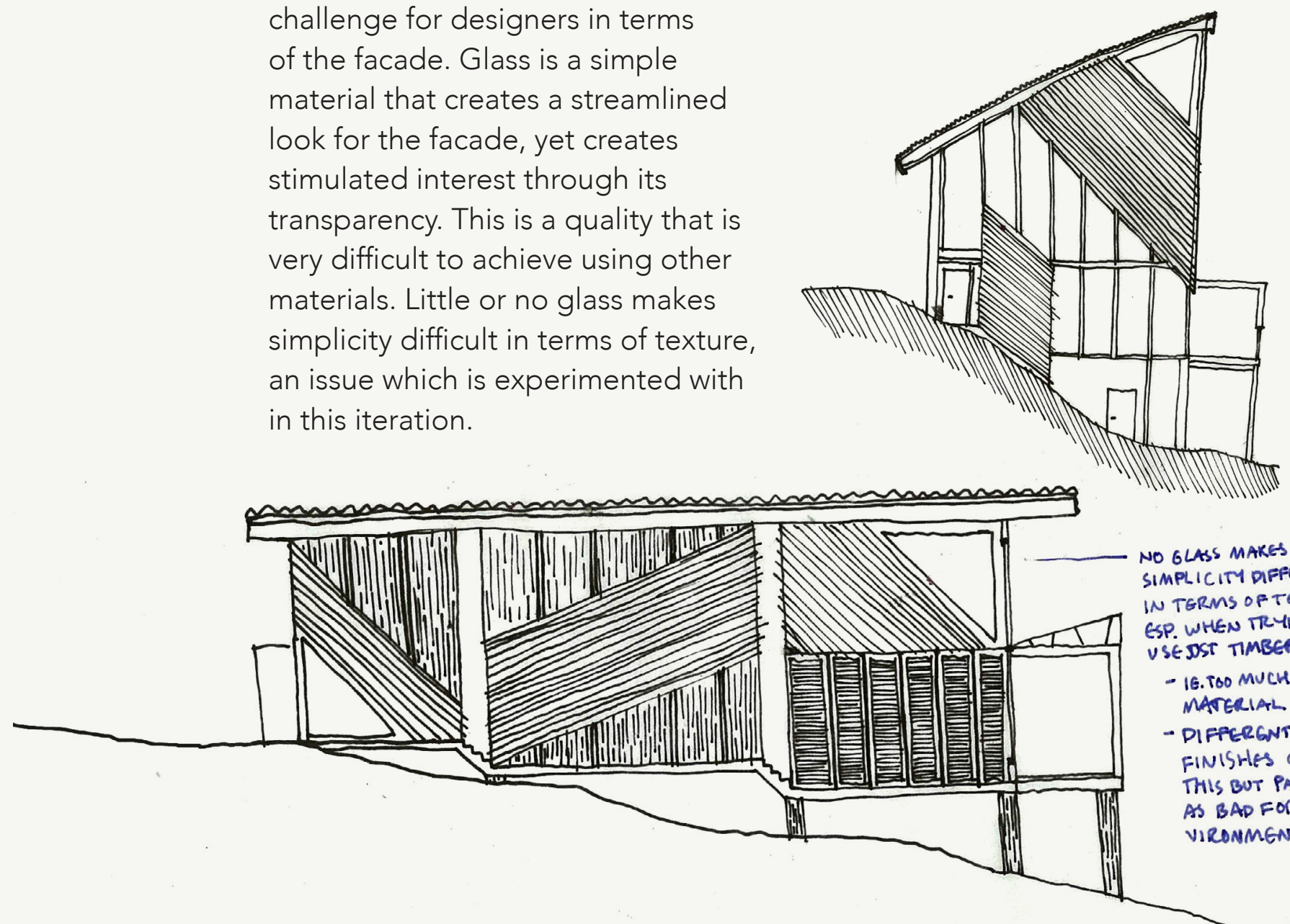
NO GLASS MAKES
SIMPLICITY DIFFICULE. TP. WHEN TRMING TO uSE BST TMBECR. - IE.TSO MULCH or - PIFFergans colours/ Finishles COULD Hel THIS BUT PAINT S S SON VIRONMENT 


\subsubsection{Iteration 5}

Contrasting materials can draw

the viewer's eye to the view of the

landscape instead, requiring smaller

windows to transmit the view.

This iteration showed that darker

materials accentuate the view more

successfully, and horizontal and

vertical lines in the facade direct

the viewer's eye towards a singular

window.

\subsubsection{Iteration 6}

As stated in section 6.7.5, less glazing presents the challenge of creating interest in the facade through other means. Incorporating site context into the overall form of the dwelling, such as the roofline informed by the mountainous

landscape here, could offer one solution to this issue.

- NZ house success often mearured by it ability to blend into the environonent trom the exterior - what is the best way to achiere this though least
amount of glass?

2 mon Euten viewing house

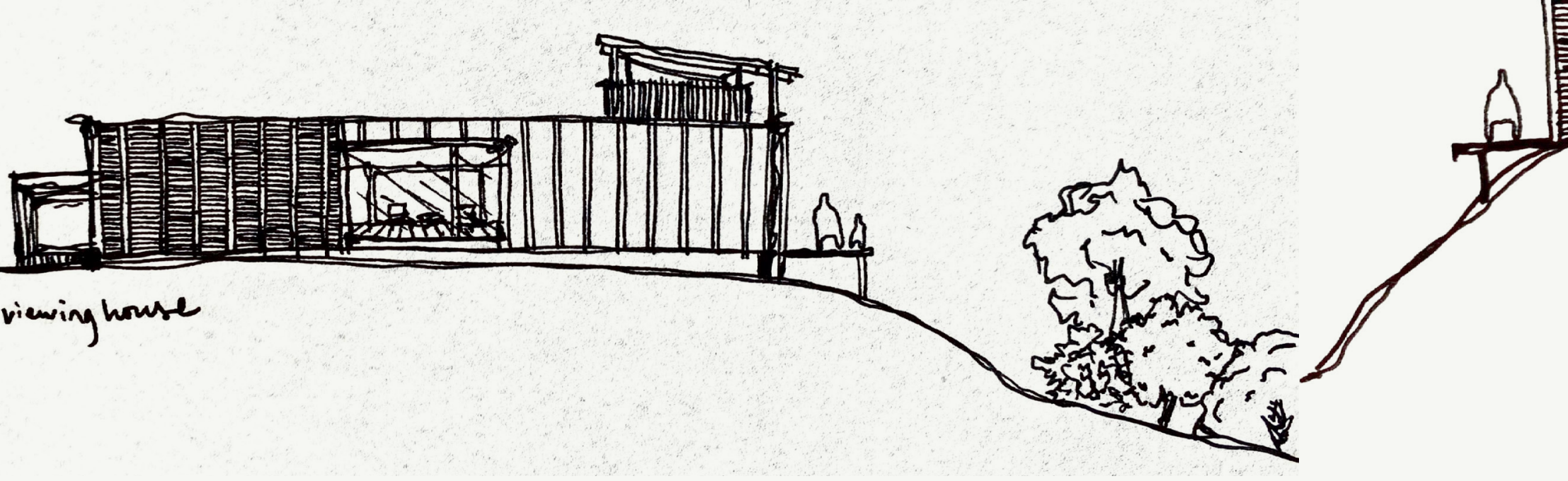

Fig.6.47. Shetch iterations of facade material options rer

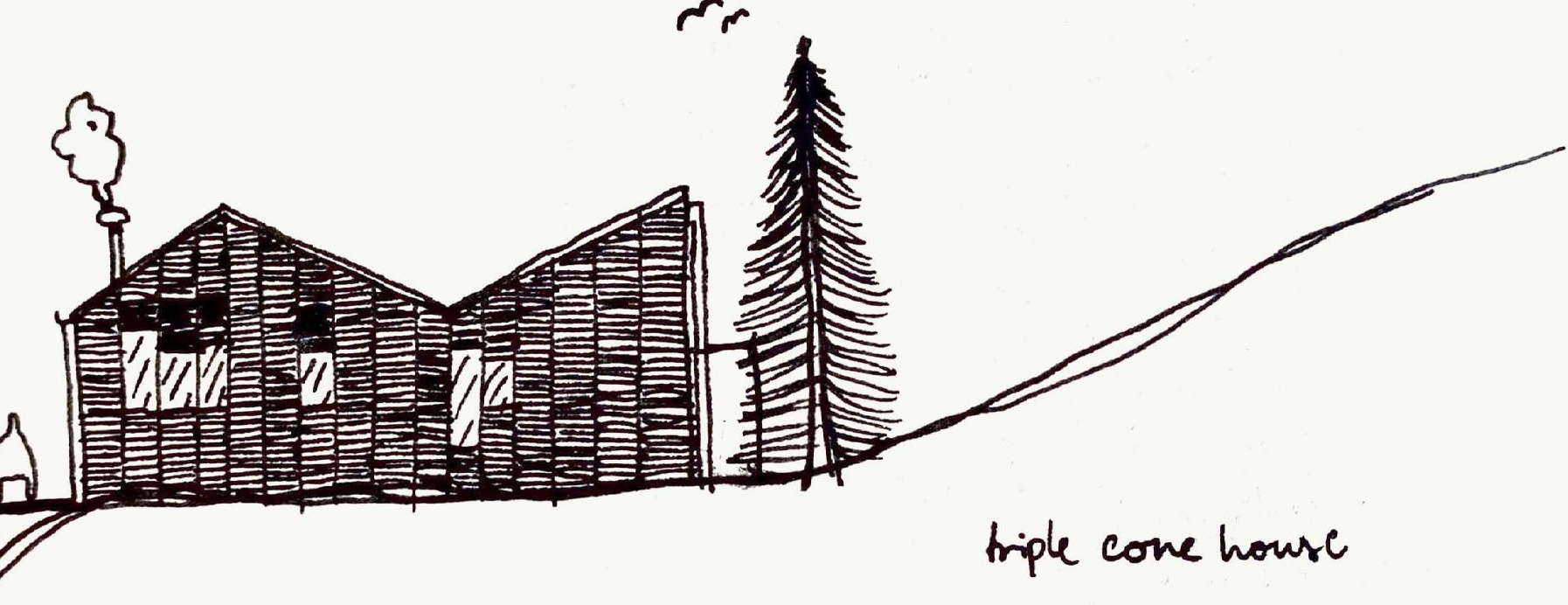

archectival success measmed by commection to culteral context. 


\subsubsection{Iteration 7}

Materiality can be used to define indoor and outdoor space (section 6.3). It can also contribute to the idea of creating a journey through

the space (section 6.7.2), where

heavy materials represent the

start of the journey on land and

lighter materials show the theshold

between land and water.

tectonicesdetine

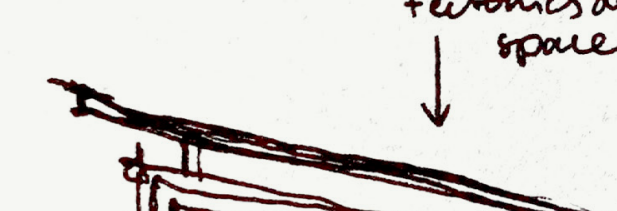
space

re

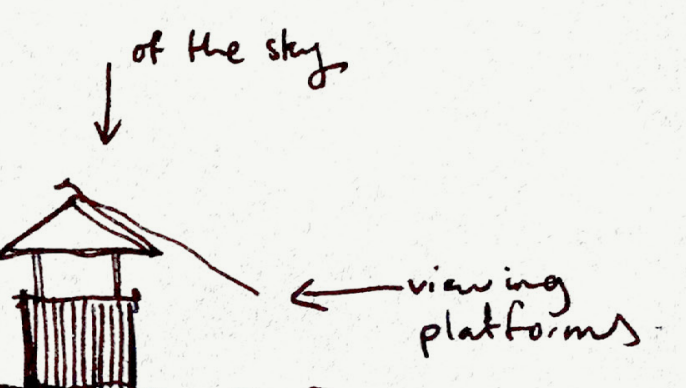

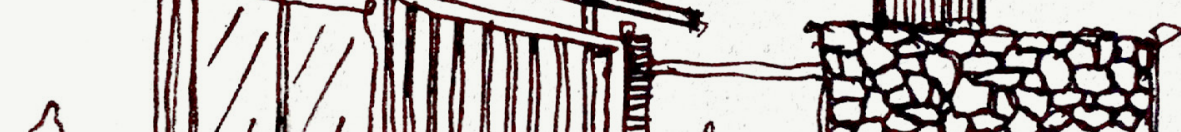

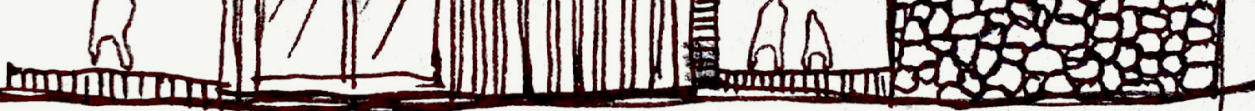

ridge houre

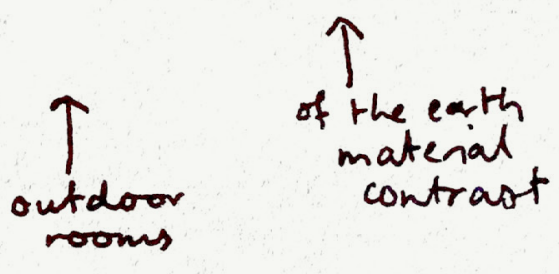

windous are the absence

of solidity
6.7.9. Iteration 8

Materiality can be used to express

the poetic values that are seen as

successful in contemporary New

Zealand residential architecture.

Materials can be used to tell as story

of the landscape, such as exposed

stone here reflecting Otago's

history of mining villages and

timber showing the quintessential

connection to nature.

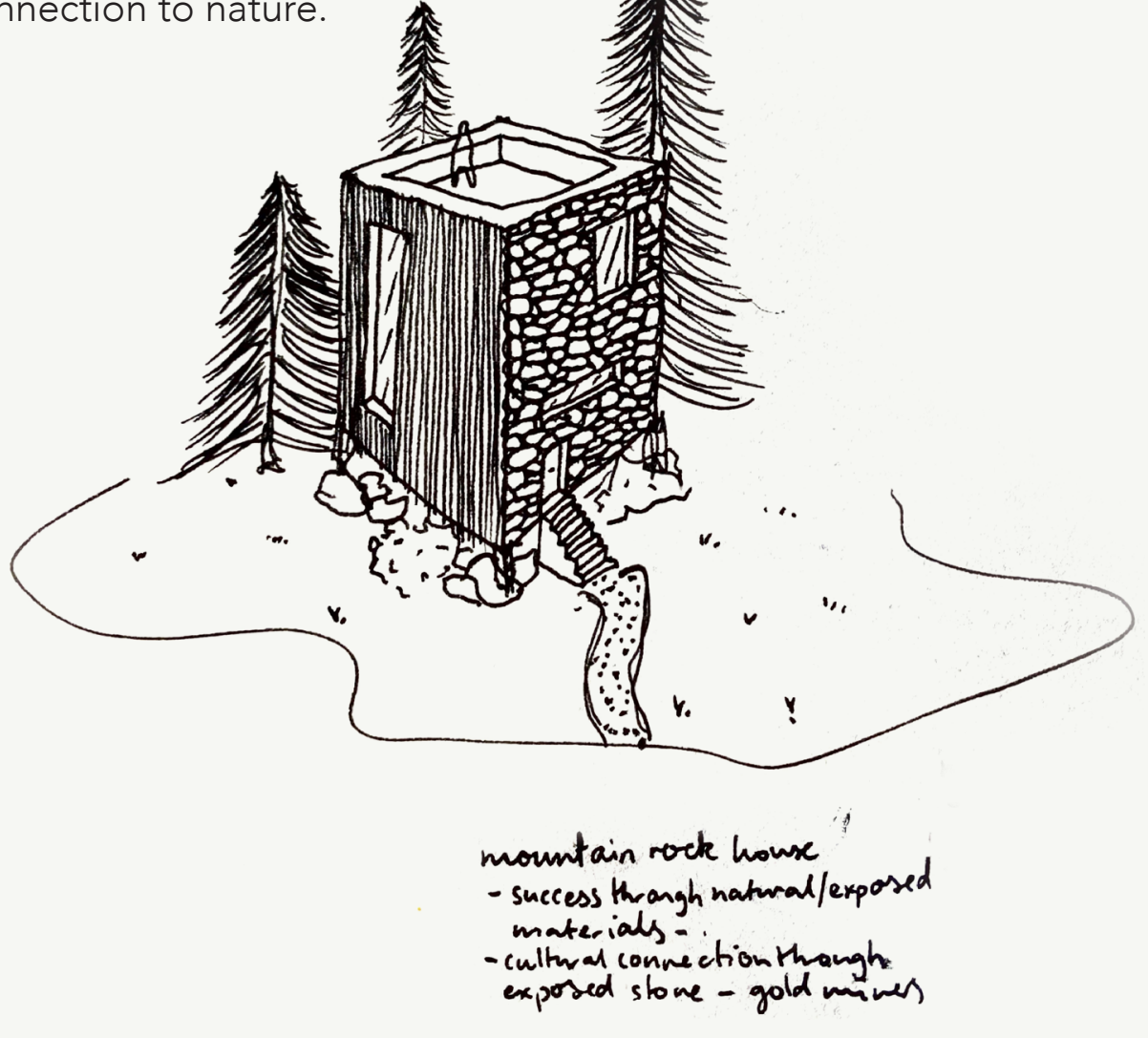

Fig.6.50.Sketch iterations of facade material options 


\subsubsection{Reflection}

Materiality is an important aspect of all architecture but a particularly essential consideration when designing with less glass. Natural materials can be employed in the dwelling's interior to provide an alternative connection with the landscape, rather than through glass.

Materiality can be used to create interest in the facade: elements of design that are often achieved through high usage of glass in the facade. However, one should be careful not to introduce too much complexity to the facade as it can result in patterns that are unsympathetic to the natural environment, and therefore not achieve the aim of incorporating the landscape through means other than windows.

\section{8. CRITICAL} REFLECTION

Poetic exploration of the site through expressive media such as painting allows for the creation of textural spatial designs and identification of common forms and patterns in the surrounding environment or landscape

Stacking views through the building creates view ports for the landscape o be seen from multiple points in the building, but must be carefully positioned and designed to protect the privacy of users

Postive and negative space reduces the need for interior space and therefore glazed area, but site elements should be incorporated to create 'outdoor rooms' (negative space) to reduce the need for complex building shapes (point 5).

Simple (rectangular) forms require less material as well as performing better passively/thermally. This is essential for upholding the purpose of the research for the wider context: the less material used, the less environmental impact.
A programmatic approach limits the possibilities of the design framework, so programme should be employed last and poetic and positional approaches should be prioritised. Therefore the framework should be revised to prioritise and place emphasis first of poetic techniques, then positional, and programmatic techniques should be employed much later in the design process

There are multiple solutions to designing a house with less glass. Some techniques identified in the framework may be suited to certain sites more than others. Therefore to determine a scientific outcome for the design research phase, the next step should be to take a generic

house design and apply the glazing threshold ratio of $<15 \%$. Following this, placement of windows and window sizings should be tested to determine which are the most affective for both conveying the view and providing sufficient light levels. 


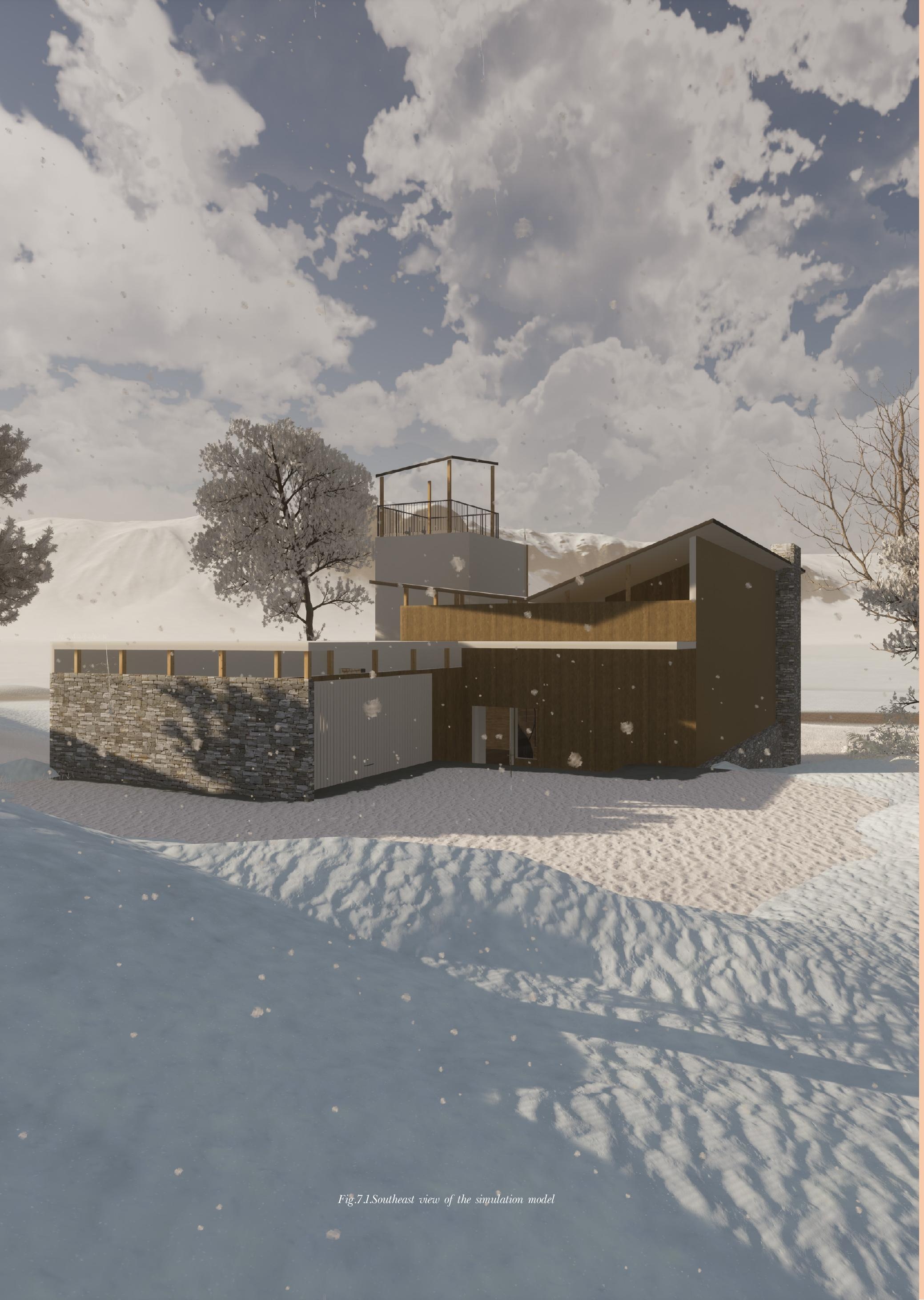

Chapter 7

\section{SIMULATION MODEL}

\author{
7.1.PURPOSE OF THE \\ SIMULATION \\ MODEL
}

As identified previously in section 6.8, there are multiple solutions to designing a house with less glass. Therefore, to determine a scientific outcome for the design research phase, the next design phase should determine design principles to capture the view and provide sufficient daylighting for a generic design. This chapter outlines the design of the testing model used. The testing model design is based on the explorations and conclusions found in Chapter 7. In particular, the iterations explored in section 6.4 found that a simple rectangular floor plan with a mezzanine floor was most successful at conveying the view from one window to multiple spaces (Fig.6.29). 
The issue of privacy needed to be addressed. Private spaces are necessary for a home to accommodate psychological comfort levels. The form identified

in Figure 6.29 showed two separate spaces, with one larger space being on the ground floor and a smaller space on the mezzanine floor. The smaller mezzanine floor was more suited to private space as smaller spaces are more intimate, and the mezzanine is less visible from the ground floor (compared to vice versa). Therefore, the larger ground space was more suitable as public space such as living and kitchen areas. However the mezzanine designated 'private' space was still relatively exposed to the downstairs public space. It was still necessary for the view to this space to be conveyed and for it to receive sufficient daylight. Tectonic elements were employed to provide privacy from the downstairs living area but still translate the view and daylight from the window, making the mezzanine a suitable master suite and study area. The back of the mezzanine would receive little light, making it a suitable placement for a second lounge or snug space.

Next, two secondary masses wer added to the original rectangular block to provide the additional parts typical of a New Zealand home: the garage and a tower element to provide extra sleeping areas.

The tower element resulted from the design framework concept of stationary vs. transitionary spaces to provide the stopping point from which the view can be admired most. The tower is visible from the approach to the building, insinuating a sense of longing for one to climb the tower and experience the view from it, an experience which is heightened by the effort of climbing the stairs to get to the top. The tower also introduces a sense of playfulness to the design, an aspect that is often commended in award-winning buildings in New Zealand.

From this, it was clear that the technique of introducing programme after the poetic and positional principles of the design was successful in placing spaces according to the light levels needed and the conveying of the view.

The next stage was to introduce the scientific parts of the design process that are commonly used in the industry for assessing the sustainability of a building. This would test whether poetic design aspects were successfully able to produce sustainable results longside the scientific aspects. For this thesis, this would be achieved through lighting analysis of the simulation model and assessing the effects of window sizing and placement on the lighting conditions. 


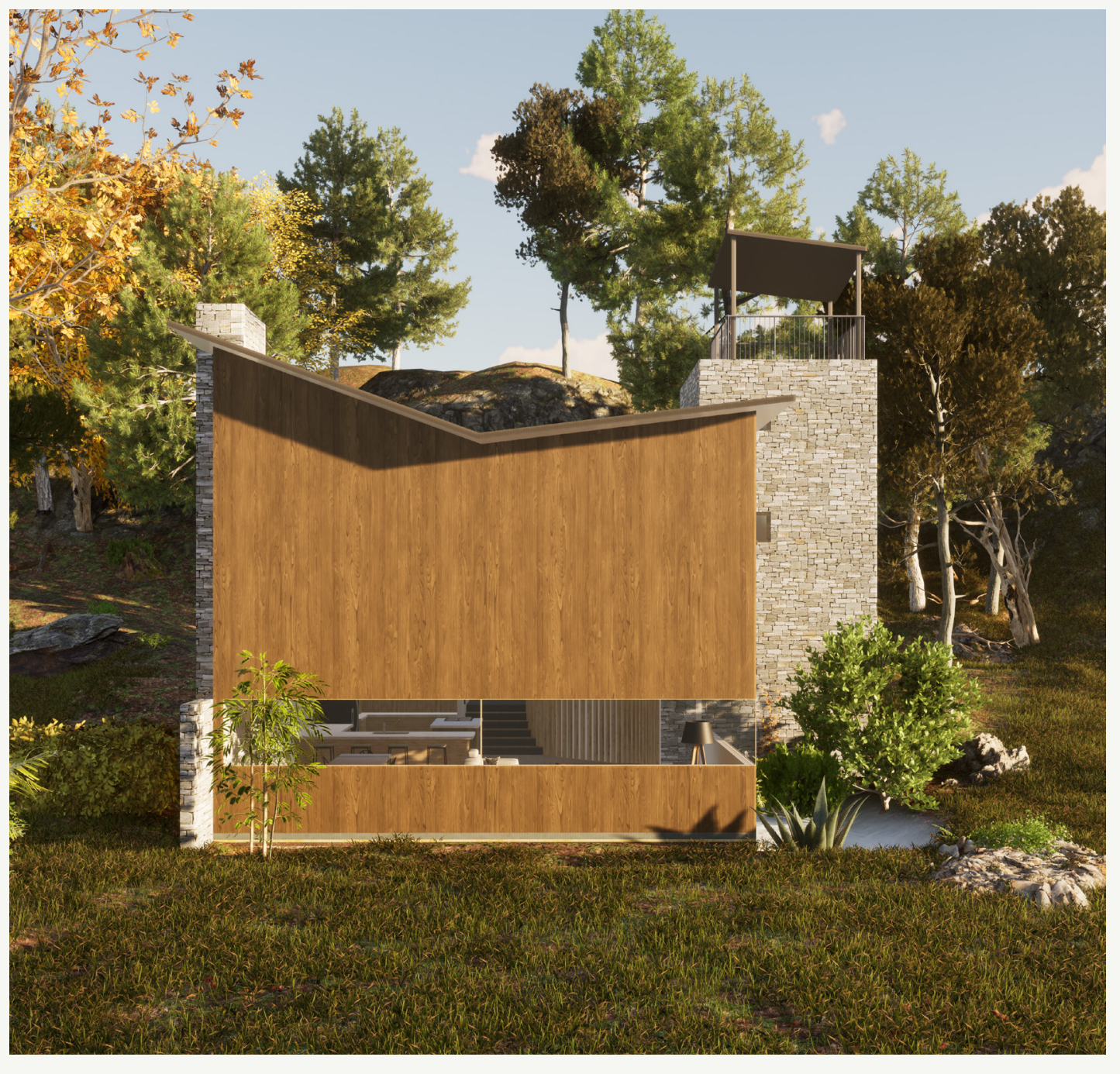

Fig.72.Northern facade of the simulation model (iteration 2)

\subsection{SOFTWARE}

$$
\text { SELECTION }
$$

The software used for lighting analysis is once again split into the ability to analyse the poetic and the the scientific aspects of lighting conditions. Twinmotion provided rendering that would accurately capture the poetic lighting

conditions of the space, but did not have the tools for providing scientific lighting analysis. LightStanza instead provided statistical data to be used for scientific analysis. The use of these two softwares combined gave the ability to analyse both the poetic and scientific lighting conditions.
7. 3. MODEL

LIM ITATIONS

The simulation model design is outlined in section 7.1. The purpose of the model is to provide analysis of lighting conditions and determine which glazing options are successful at staying within the $15 \%$ criteria for reducing glass usage. Therefore the model does not include accurate representations of window frames, structure or other aspects of design which are normally resolved in the detail design phase, as it is unlikely to have significant impact on the

ighting conditions analysed.

The simulation model includes a garage in each iteration for consistency with the analysis and glazing to floor area ratio extrapolated from chapter 3's glazing study. 


\subsection{ANALYSIS SPECIFICATIONS}

LightStanza offers the ability to input specifics of the site, location, time of day, and time of year. The conditions chosen for analysis were based upon their ability to demonstrate the most extreme conditions the dwelling would encounter over a year. This included conducting analyses at the winter and summer solstice (June 21st and December 22nd), and at every three hours during daylight hours (6am to 9pm).

However, LightStanza did not offer the ability to assess different weather conditions. Twinmotion provided the ability to analyse poetically the effect of weather on the lighting conditions.

The below symbols are included with each iteration to depict the described conditions. In addition, site conditions such as North direction and location were considered and set as control values that aligned with the Wanaka site.

$$
\text { E Time of day }
$$

I Summer solstice

㹻 Winter solstice

Y) Sunny

3 Overcast
7.5. GENERATING RESULTS

LightStanza uses illuminance grids to generate results for lighting analysis. The figures in this chapter are the raw data generated by the software. The grid is automatically placed by the software with grid points at every $1 \mathrm{~m}$, and the grid placed $1 \mathrm{~m}$ above each floor level.

The units are Lux $(\mid x)$, equal to one lumen per square metre. The colours are a visual representation of this number for each grid space (Fig.7.3).

\section{$300550800 \quad 3,000$}

\subsection{STUDY AIMS}

The aim of this study is to scientifically analyse the lighting evels for an iterative series of simulation models, where each iteration will attempt to improve upon the last. The aim is for the final iteration to provide adequate lux levels for each space as follows:

- 150-200lx for general household activity

- 300-500lx for focused activity eg. reading

- 800-1000lx for more concentrated activities eg. fine detailed sewing

(BRANZ,2013) 
7.7

SIMULATION $M O D E L$

$P L A N S$

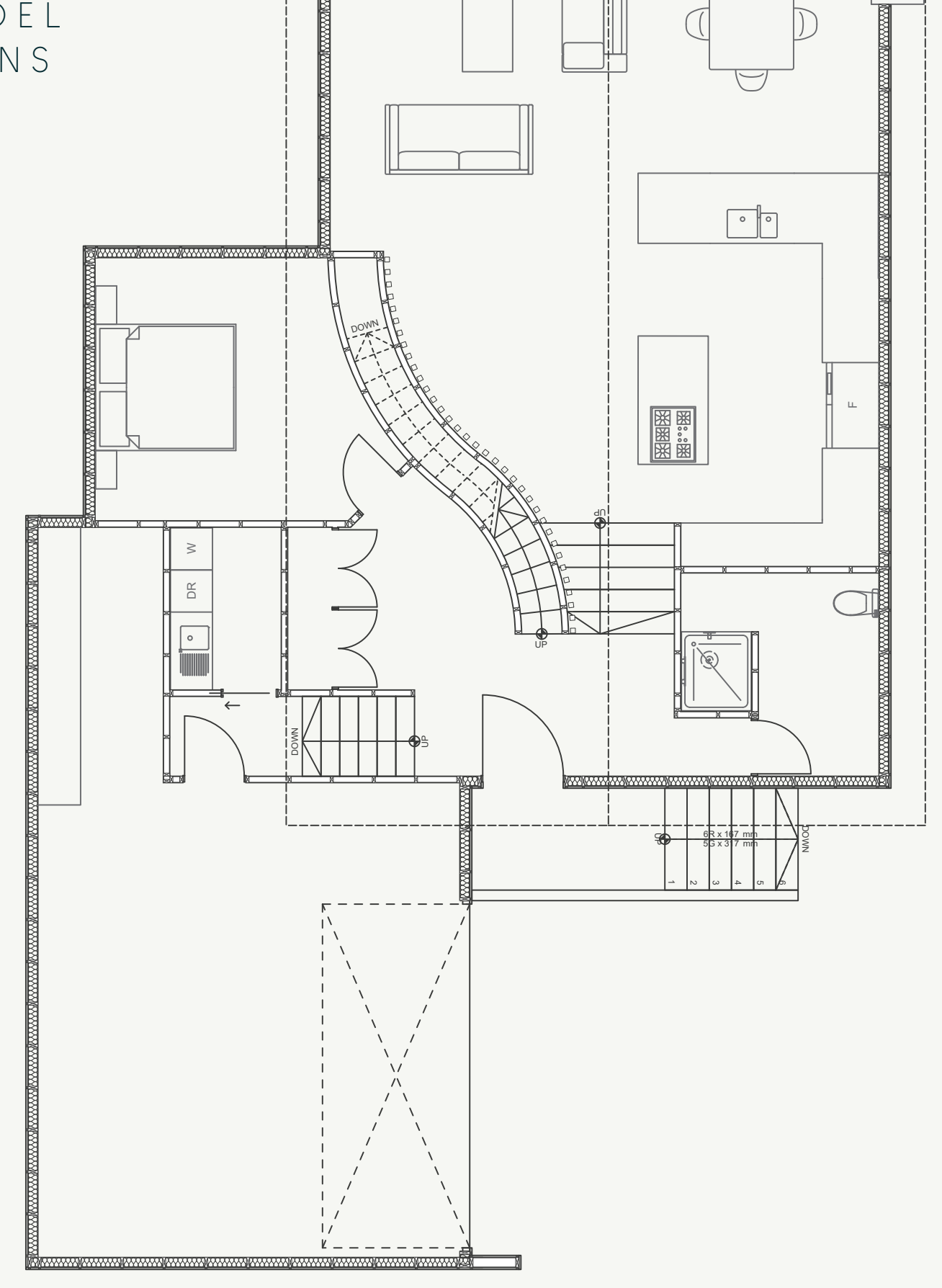

Fig.73.Ground floor plan of simulation model

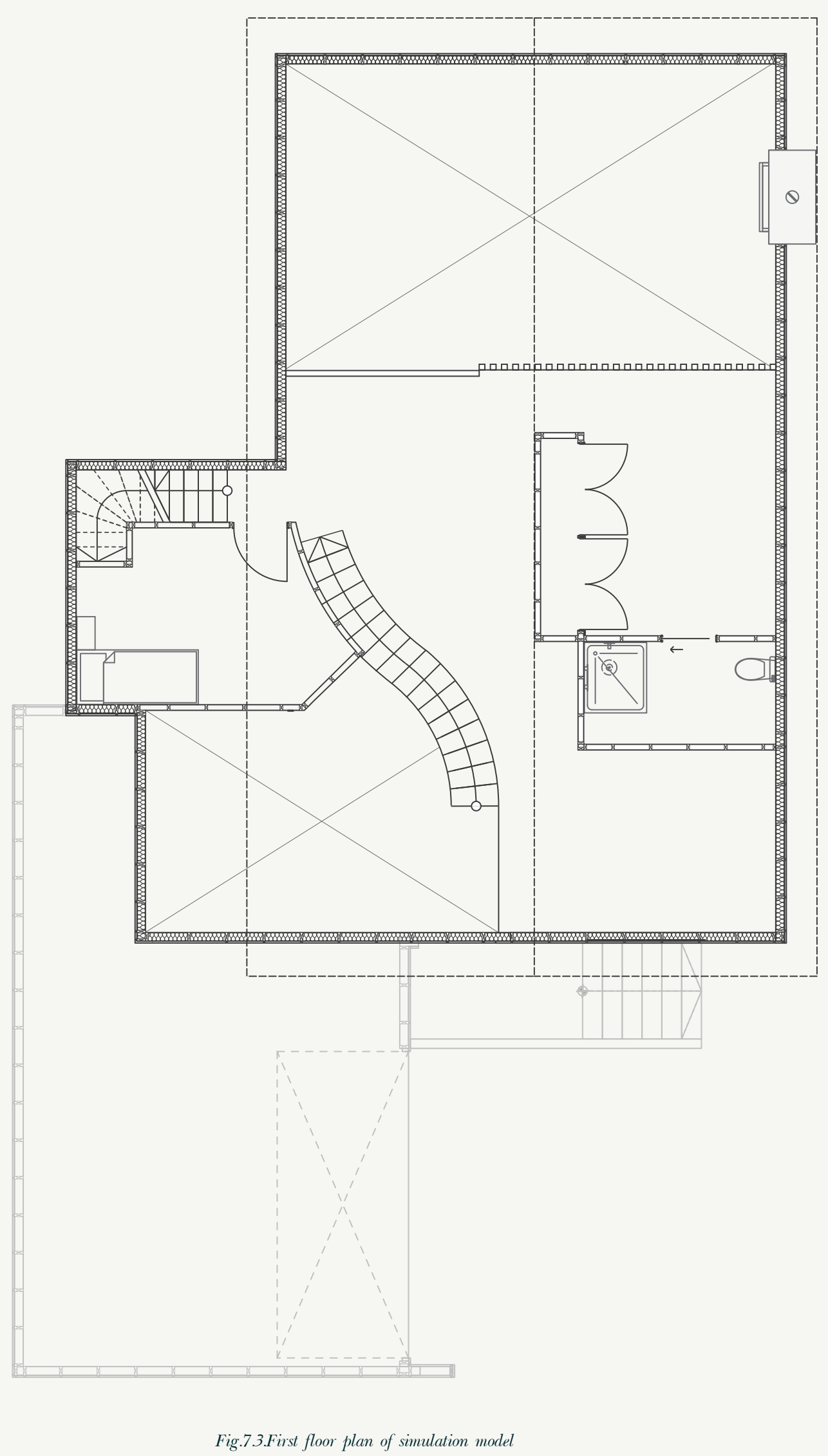




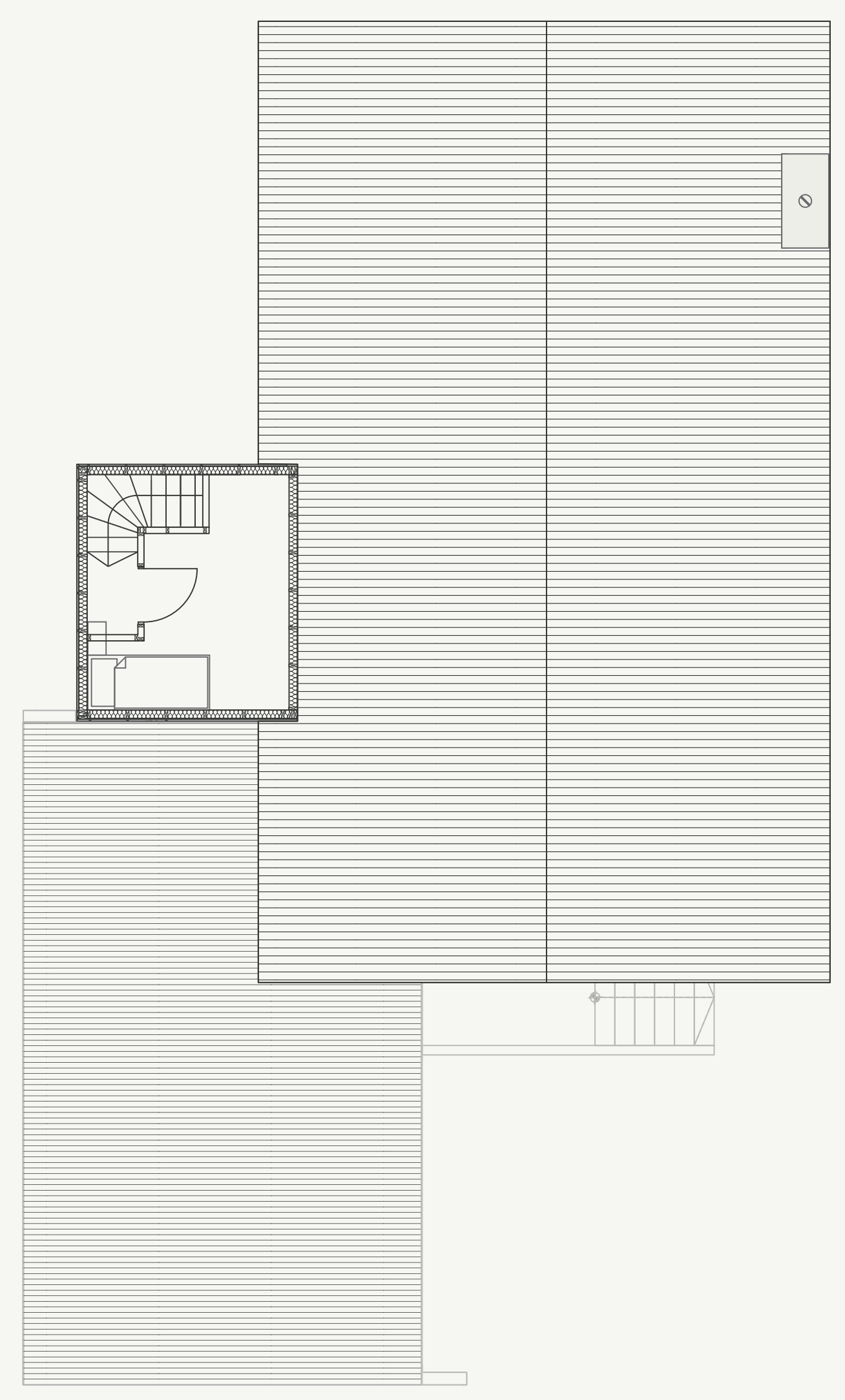

Fig.74.Second floor plan of simulation model 
7.8. ITERATION 1

\subsubsection{Model description}

This initial iteration provides lighting analysis for the simulation model

described in section 7.1. Daylight

is provided through one $3.4 \times 6.8 \mathrm{~m}$

window on the North facade, which

frames the best view in a simple

singular window.

Glazed area $=23.12 \mathrm{~m}^{2}$

$=9.3 \%$ building

footprint
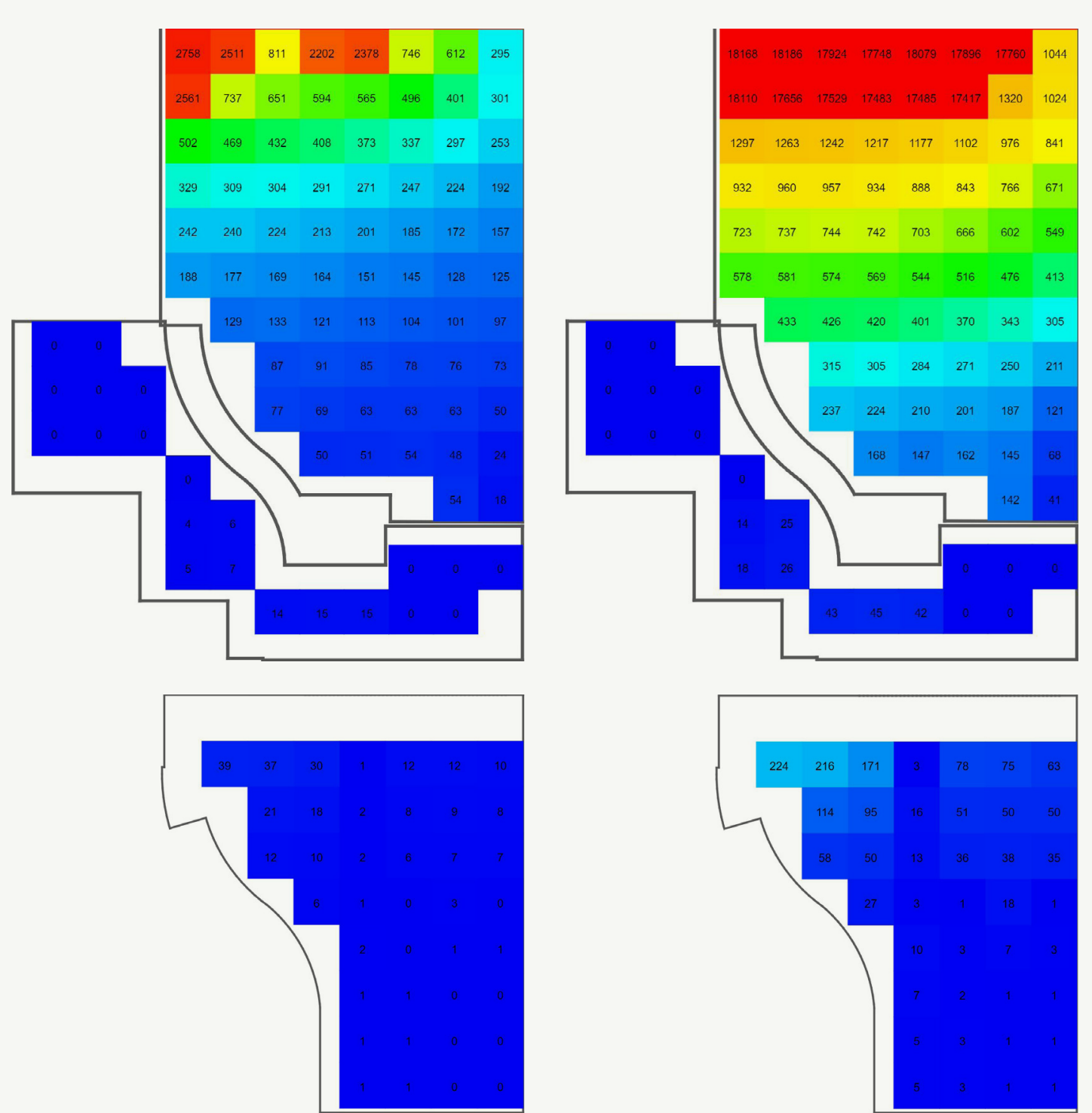

(1) 오 웅

(1) 오 웅

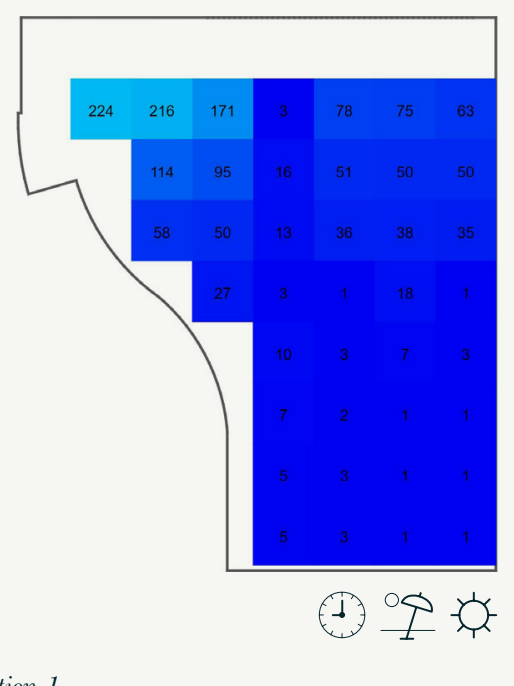



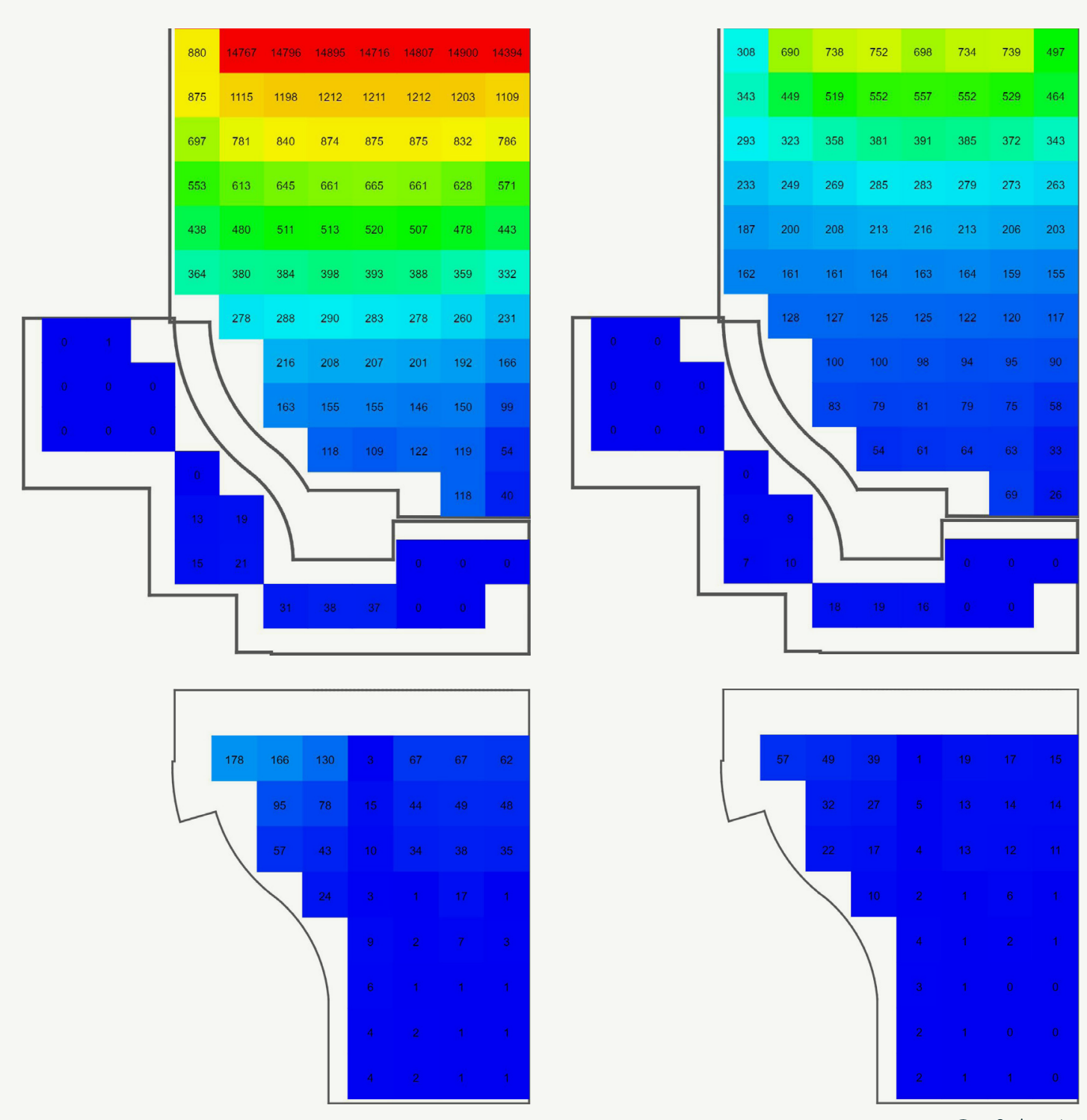

(1) 只果 Fig.7.6.Illuminance maps of iteration 1

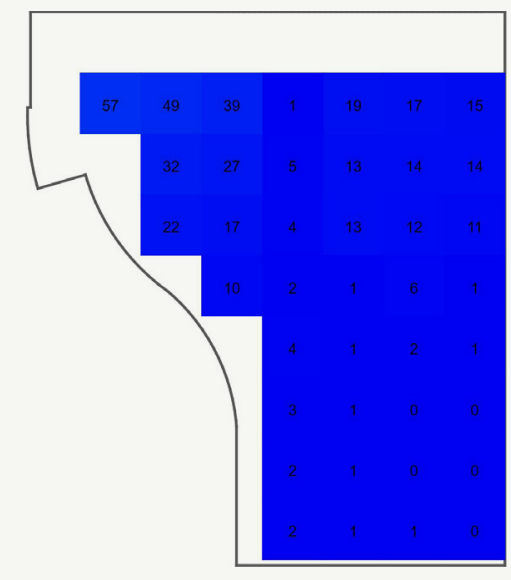

(4) 牛娕
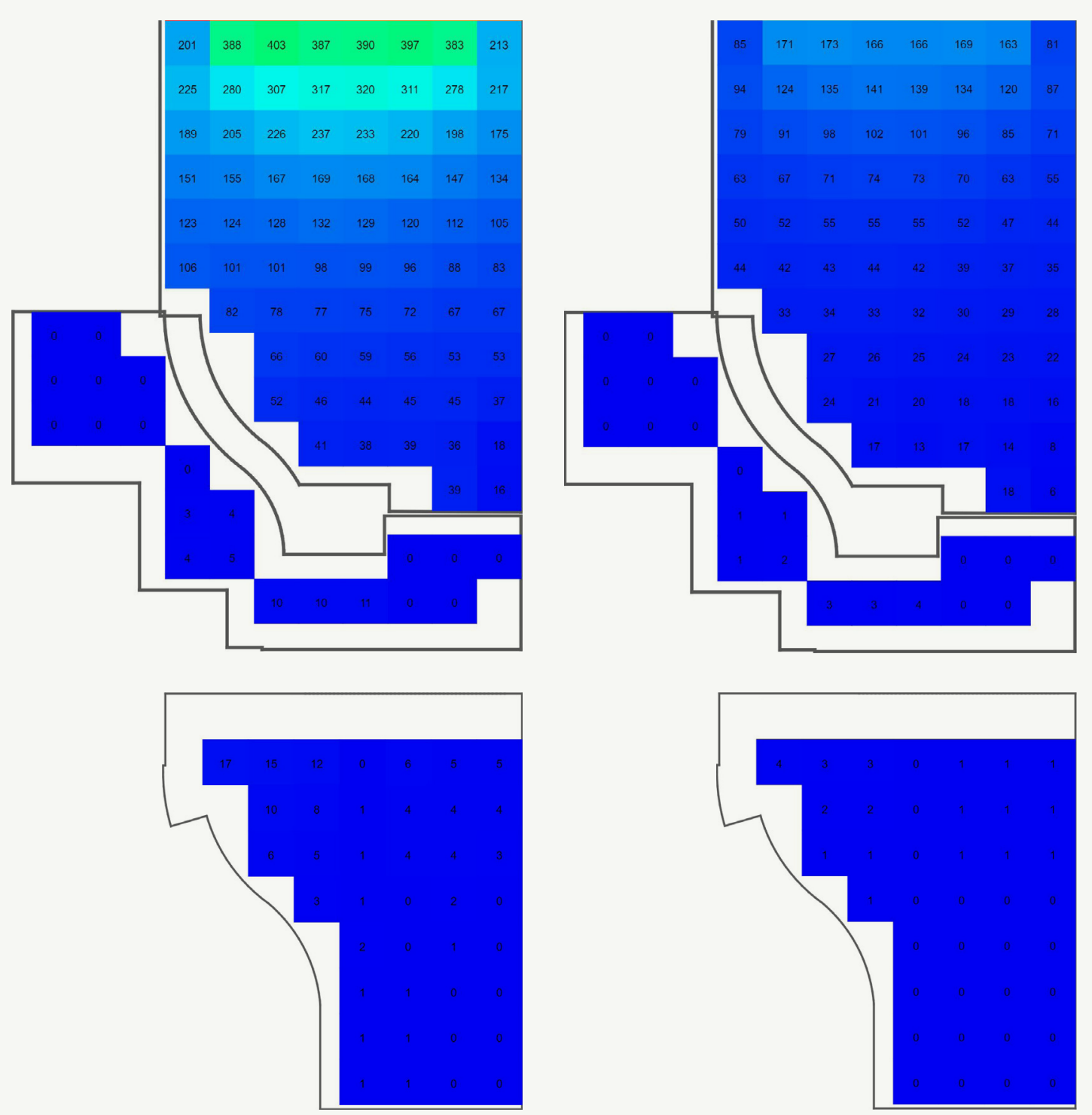

(1) 只 Fig.7.7. Illuminance maps of iteration 1

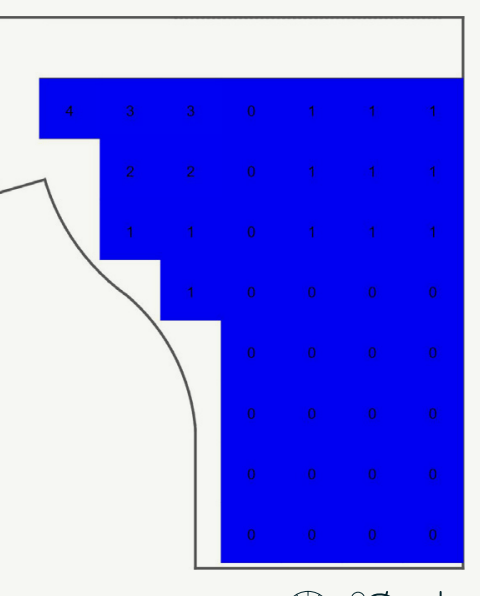

(1) 吅 

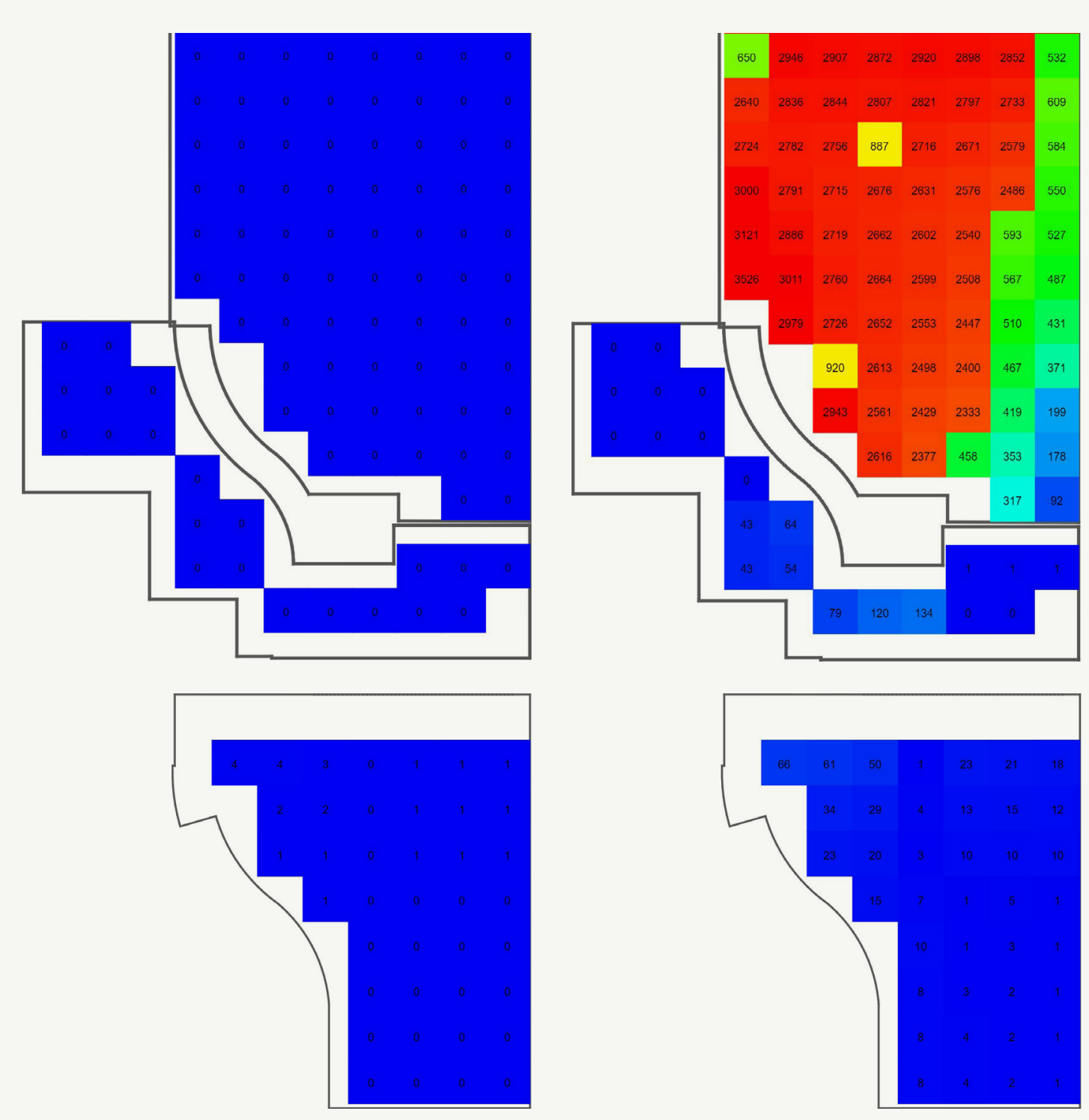

(1) 糔 Fig.7.8.Illuminance maps of iteration 1

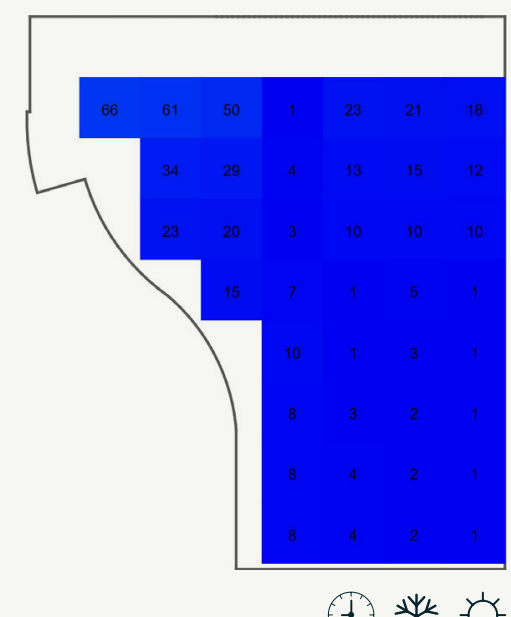

(1) 䊑
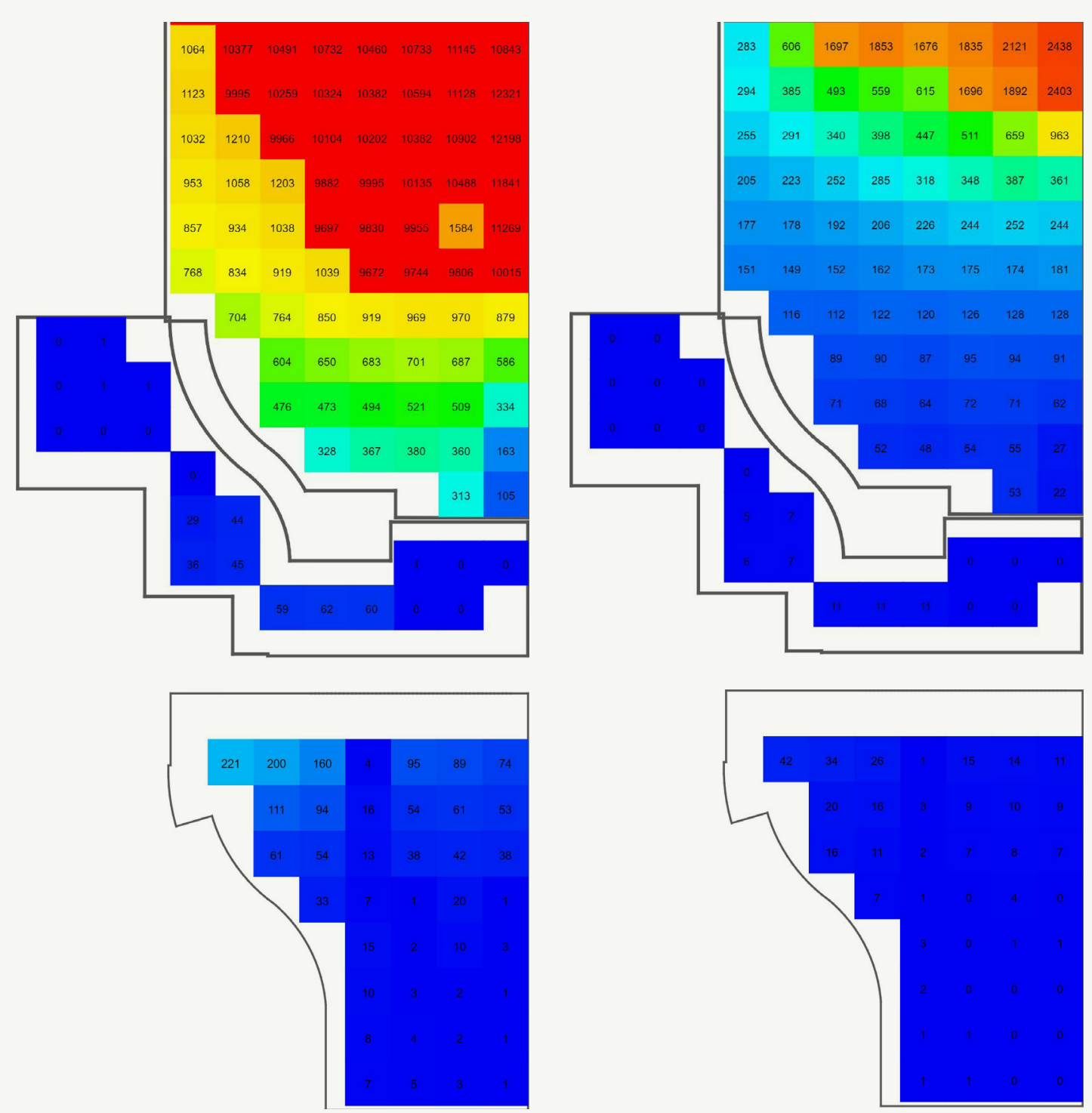

(1) 橉 Fig.79.1lluminance maps of iteration 1

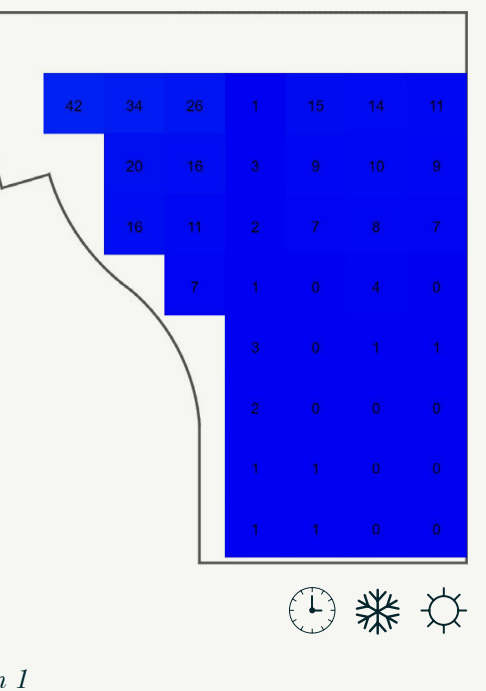



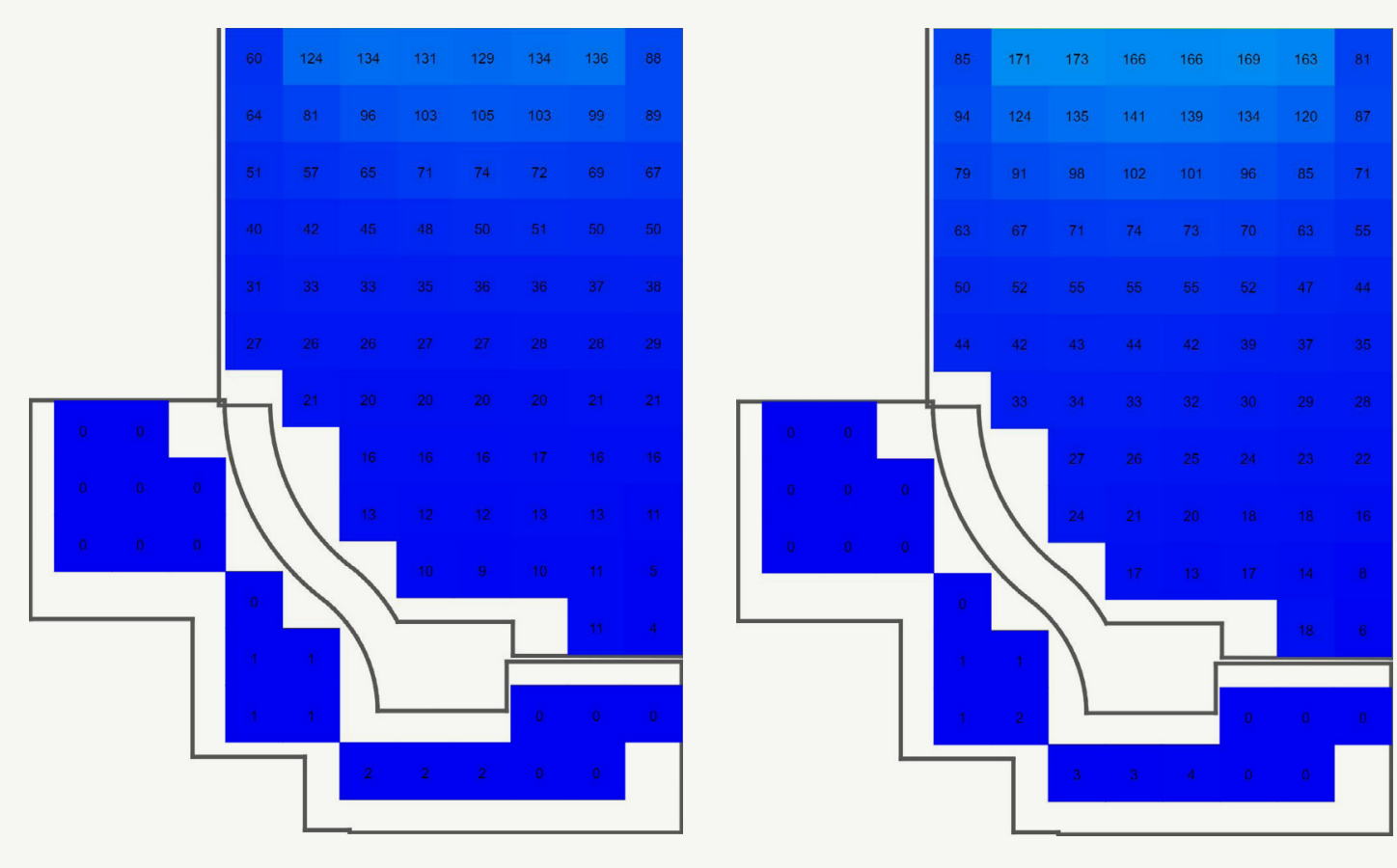

\subsubsection{Findings}

- Landscape windows on the ground floor do not provide adequate lighting to the mezzanine floor

- Lower sun height in winter resulted in higher than needed light levels in some areas, but not enough in others. More but smaller windows could distribute light more evenly throughout the space

- Placing one large window on the

(1) 燐 north facade does not allow light to permeate deep enough to the

southern parts of the dwelling

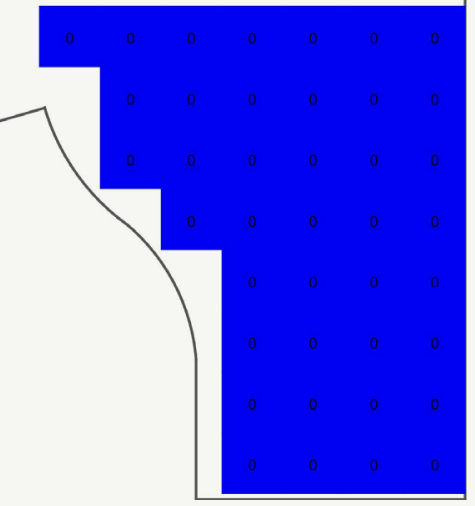


7.9. ITERATION 2

\subsubsection{Model description}

This iteration intended to build upon the issue found in the previous

iteration wherein the mezzanine

floor received hardly any light. The

previously horizontal window on

the Northern facade was rotated

to become a narrower by double

height window to attempt to

provide more adequate light to the

upper floor.

Glazed area $=18.7 \mathrm{~m}^{2}$

$=7.5 \%$ building

footprint
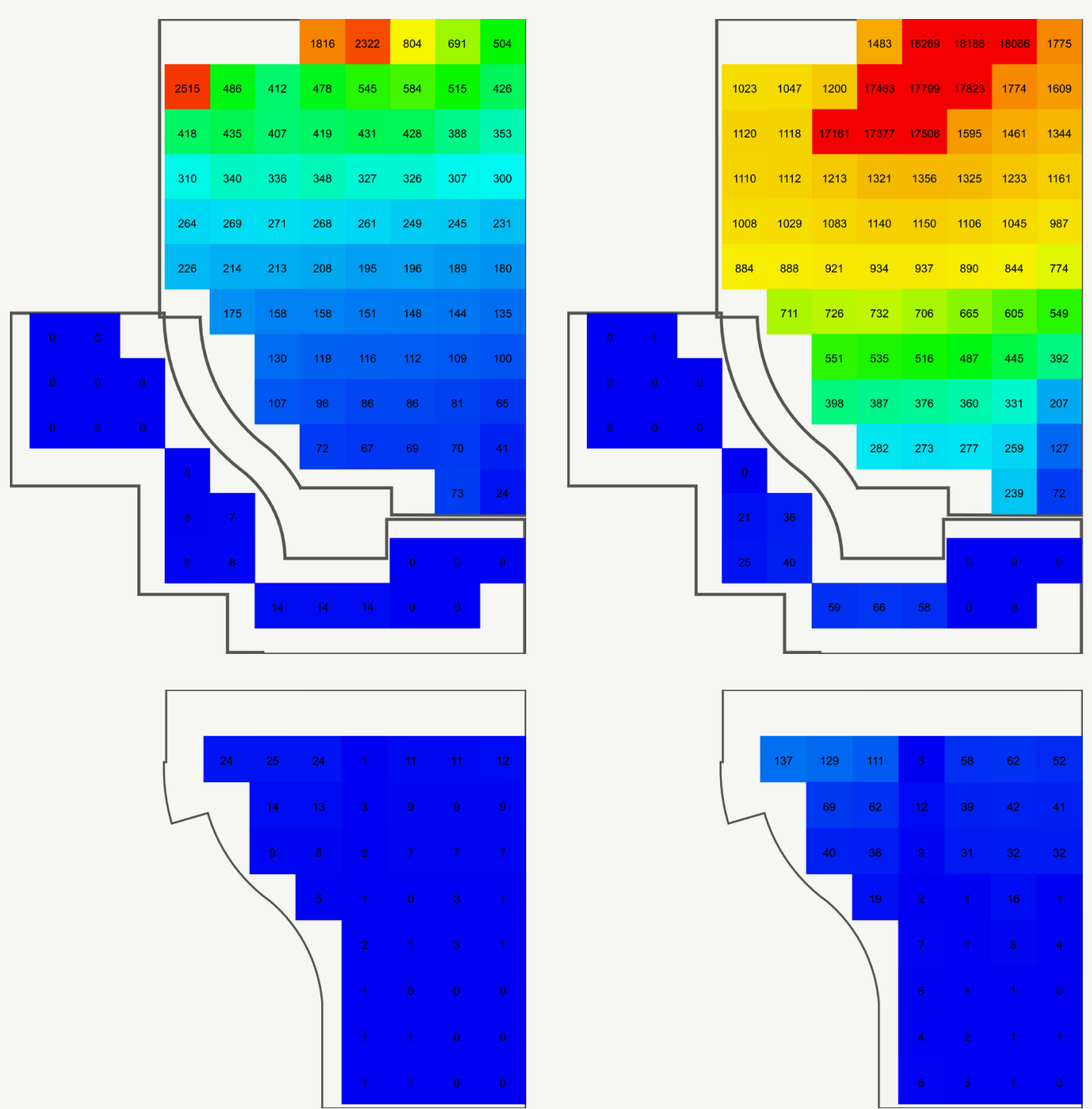

(1) 오

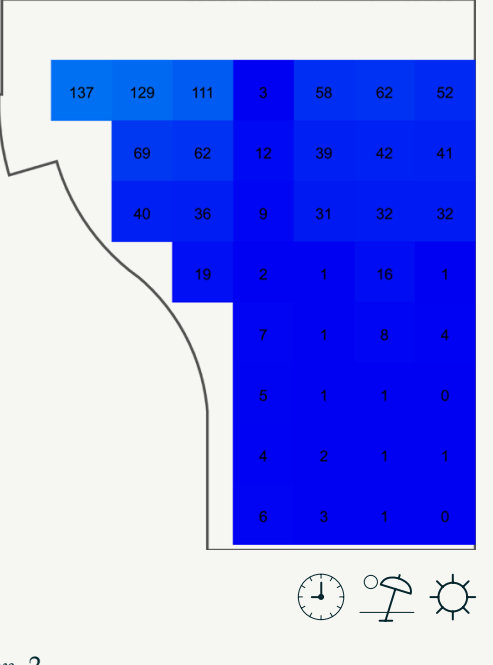



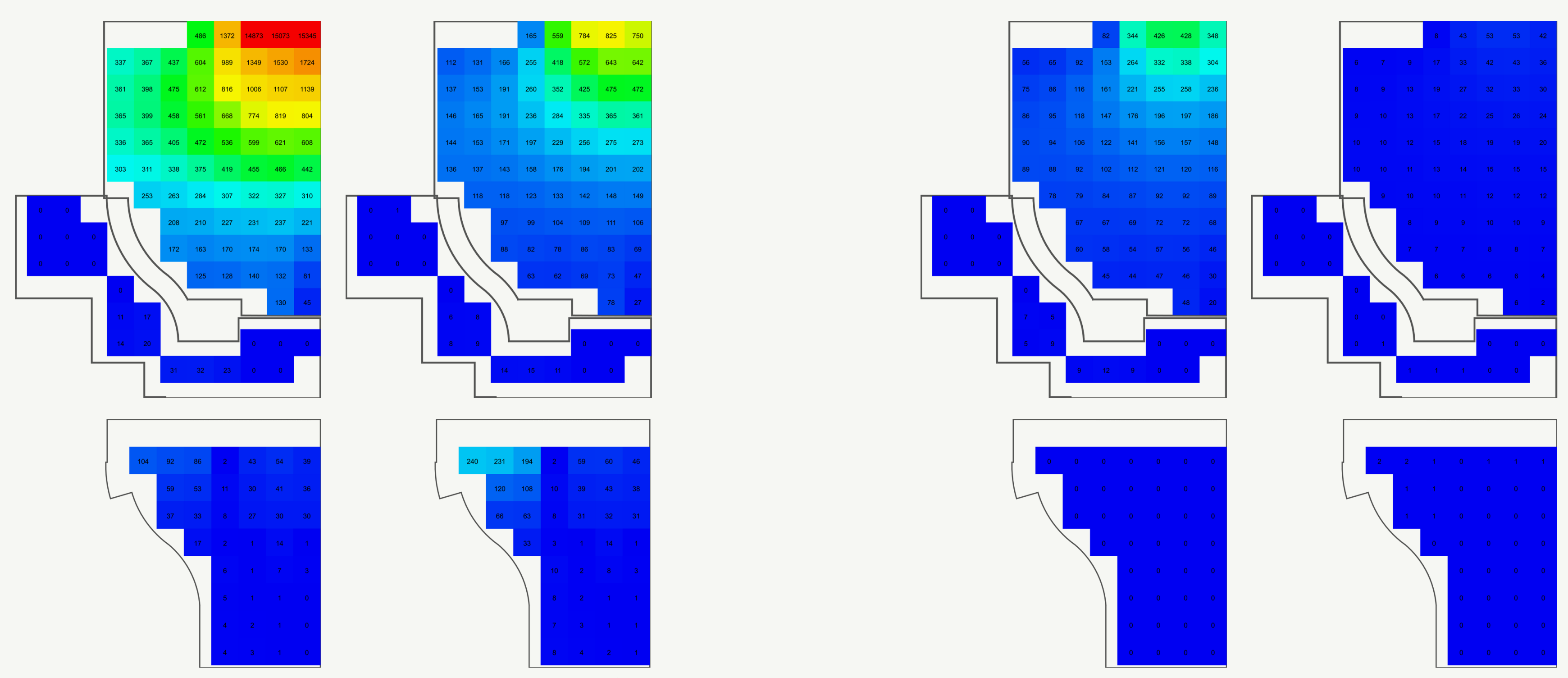

(1) 只里

(4) 哽

(1) 只

(4) 吅 Fig.7.73.Illuminance maps of iteration 2

政 

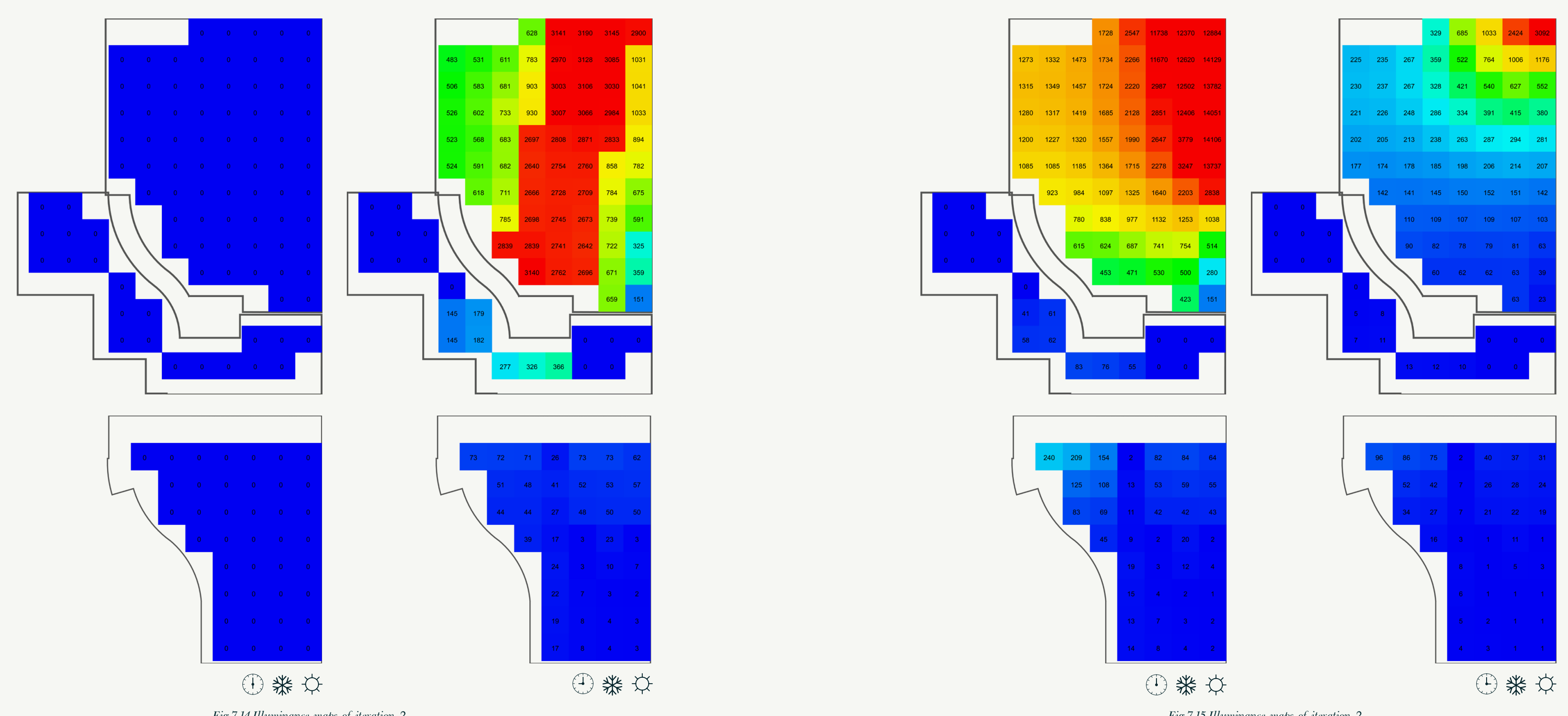

(1) 整洝

(b) 橉

(1) 橉 Fig.7.15.Illuminance maps of iteration 2 

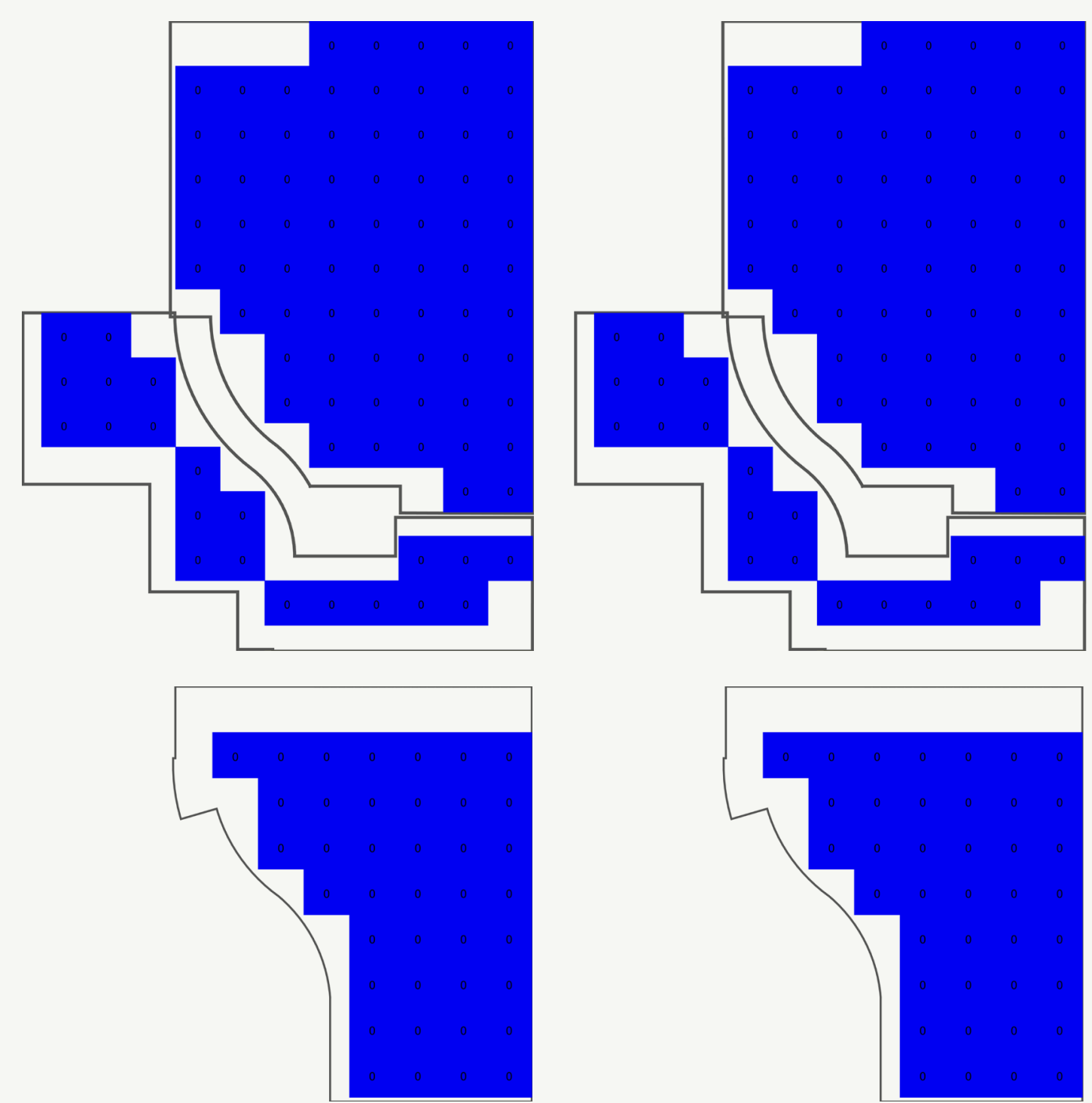

(1) 橉

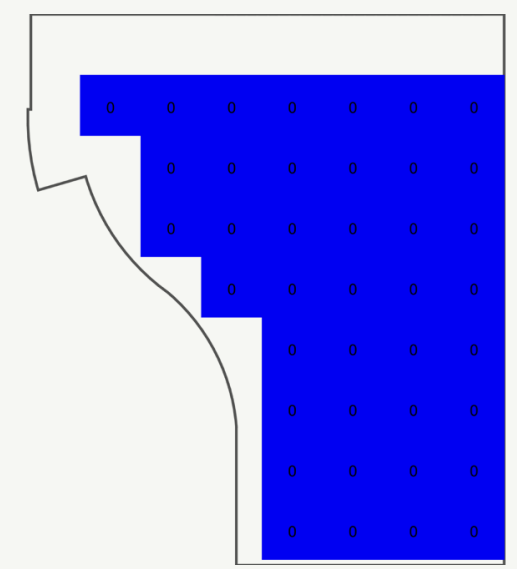

(4)

\subsubsection{Findings}

- Changing the horizontal window to a tall vertical window made little difference to achieving adequate lighting on the mezzanine floor

- The vertical window resulted in even more uneven distribution of light compared to the previous iteration

- However, it allowed light to penetrate deeper into the space slightly more effectively

- More alternatives are needed for providing adequate lighting to the mezzanine and even distribution of light throughout the building. 
7.10. ITERATION 3

\subsubsection{Model desciption}

This series utilised two narrower

double-height windows, one each

on the northern and western facades

in an attempt to bring more uniform

lighting to the space and better

lighting to the mezzanine floor.

Glazed area $=19.8 \mathrm{~m}^{2}$

$=7.9 \%$ building

footprint
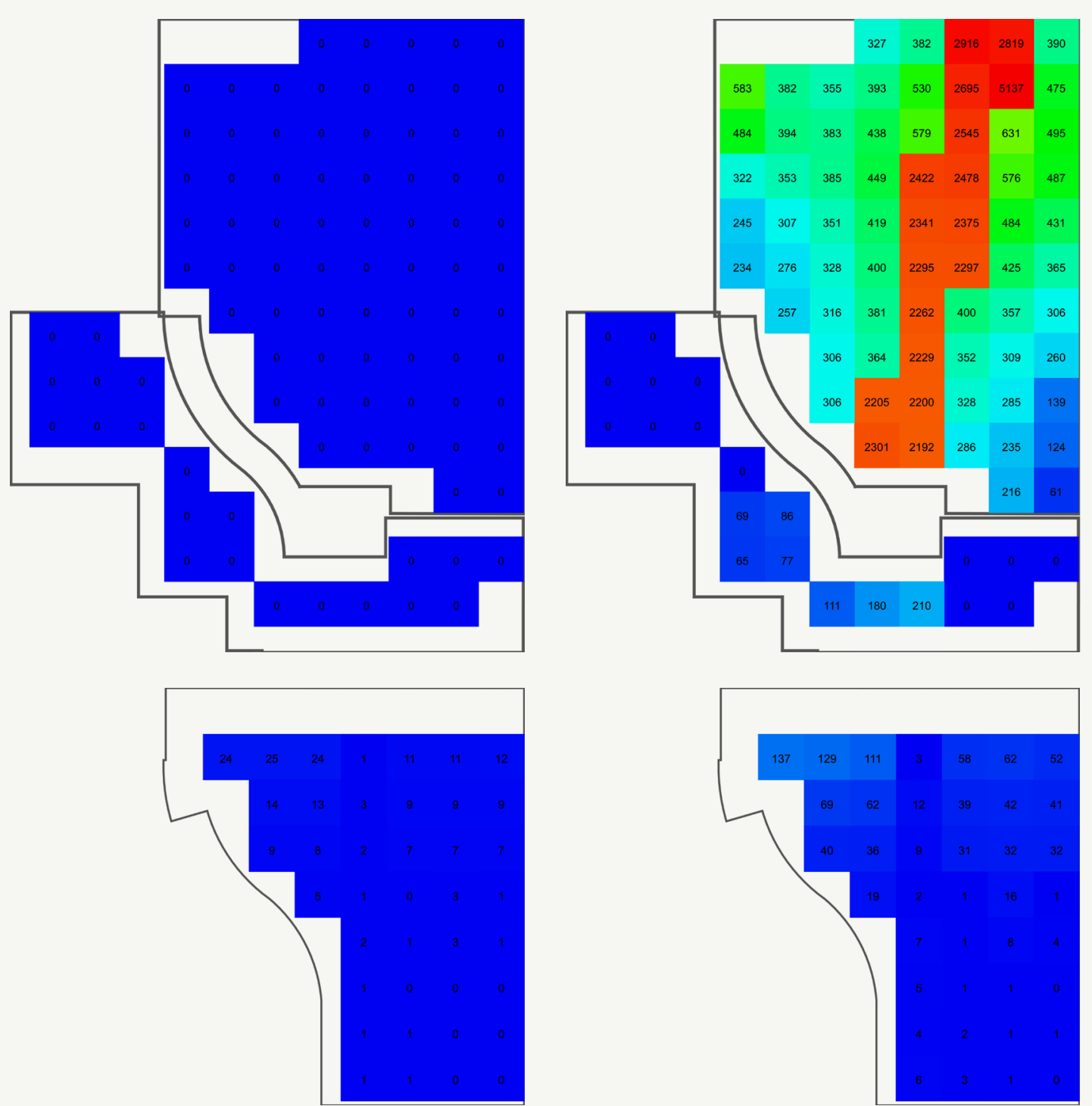

(1) 过 

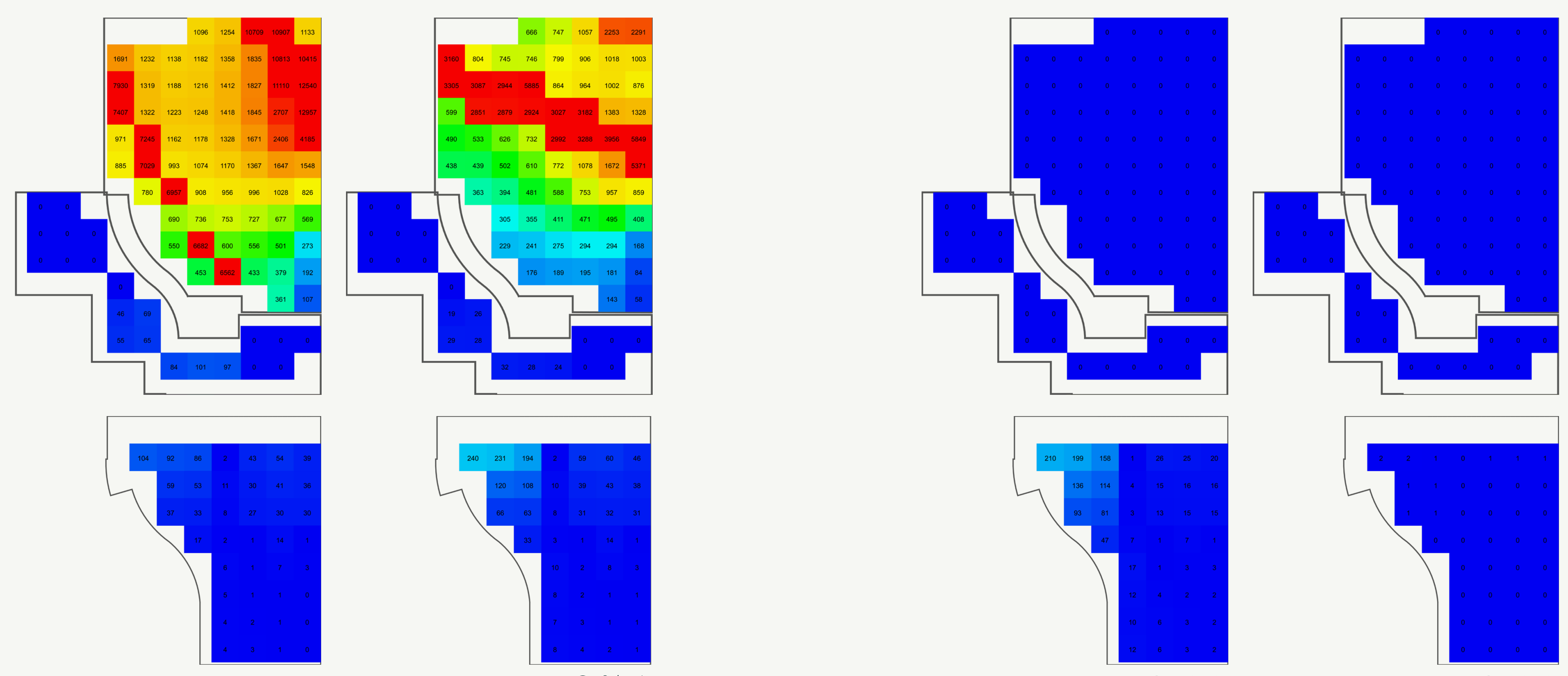

(1) 吅

(1) 只果

요 옹

(1) 只果 Fig.7.79.Illuminance maps of iteration 3 

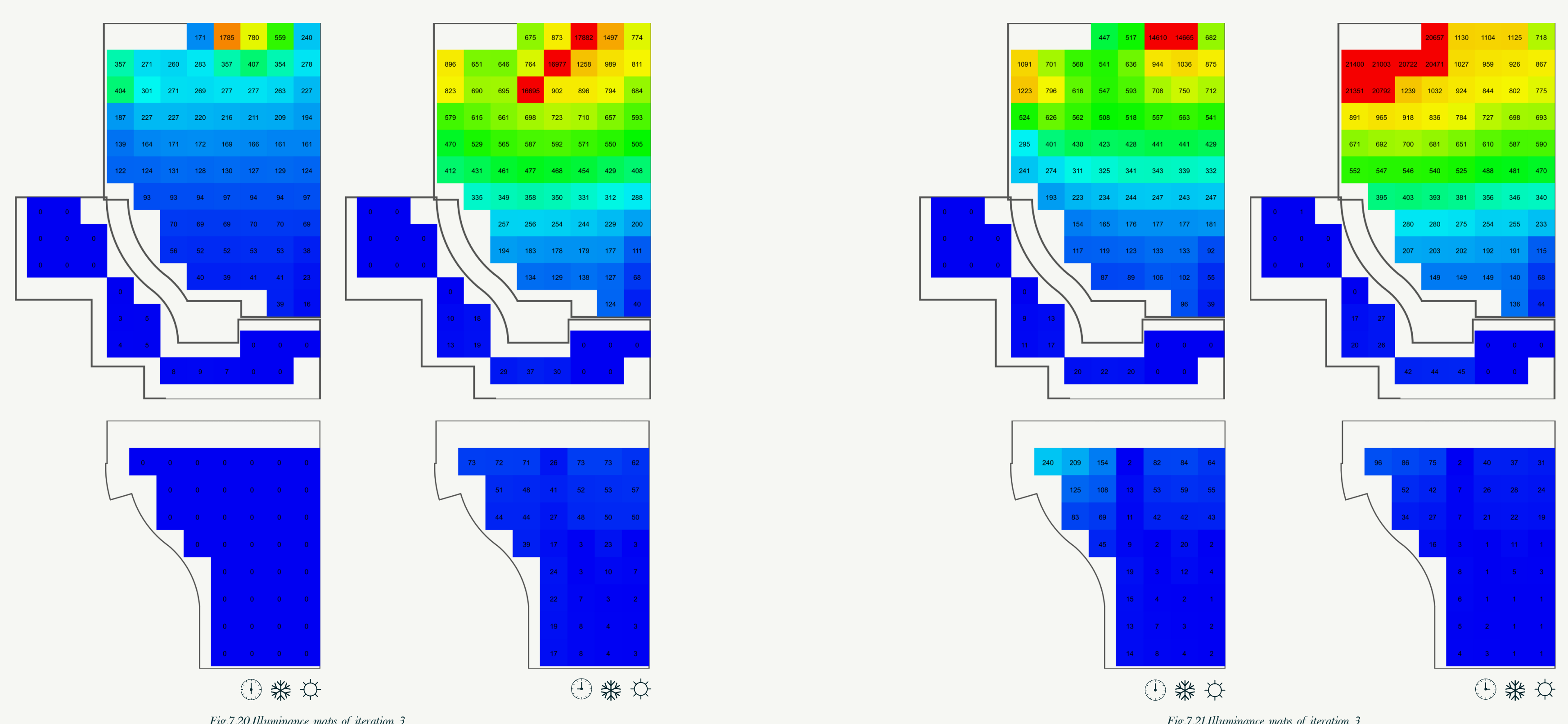

(1) 整访

(b) 橉

(1) 橉 Fig.7.720.Illuminance maps of iteration 3 Fig.721.1lluminance maps of iteration 3 

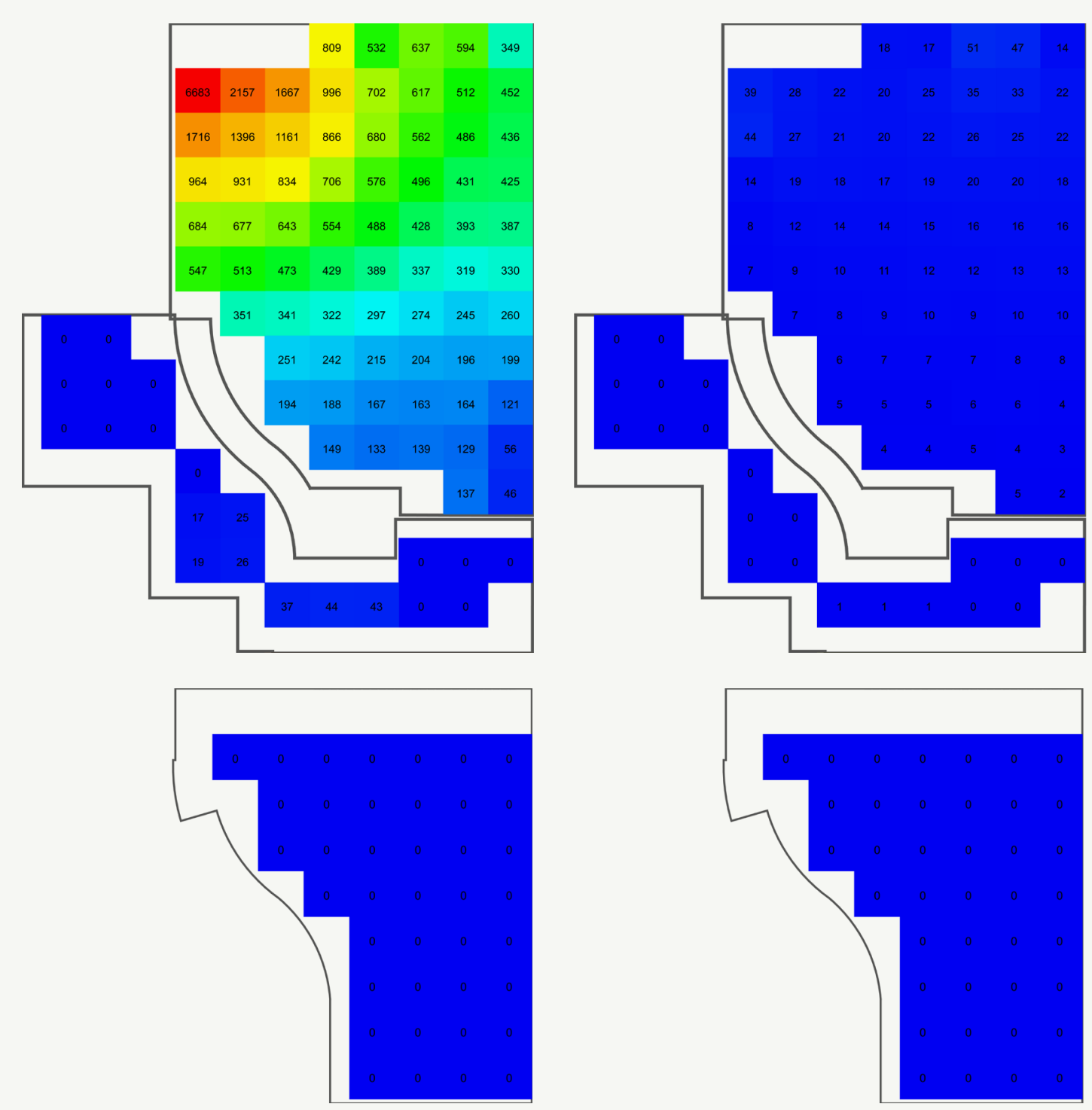

(1) 畨 Fig.7.72.Illuminance maps of iteration

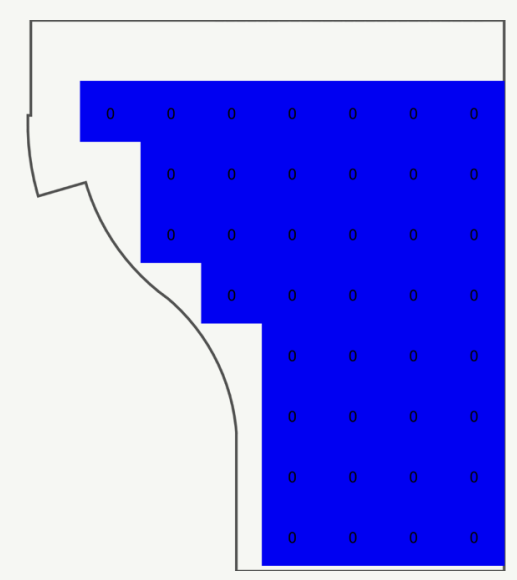

(1) 橉

\subsubsection{Findings}

- Narrow (1.8m wide) doubleheight windows create very variable lighting conditions at certain times of the day, where some areas are much too bright and others too dark, and could result in overheating

- However, placing windows on different facades appears to provide more uniform lighting across the space. This iteration could therefore be refined by changing the shape of the windows, rather than the placement

- Variable lighting conditions may in fact be desirable from a poetic perspective, by conveying patterns of nature through light (Browning et al., 2014). However these conditions need to be controlled carefully to prevent variations in lighting that are too extreme 
7.11.ITERATION 4

\subsubsection{Model desciption}

As double-height windows did not provide adequate lighting to

the mezzanine floor, this series

experimented with clerestory

windows to resolve this issue, while

maintaining the double height

window on the Northern facade to

provide the view. Because they are

higher up, clerestories can deliver

sunlight deeper into a living space

than normal glazing (Allen, 2017).

Glazed area $=29.9 \mathrm{~m}^{2}$

$=12.0 \%$ building

footprint
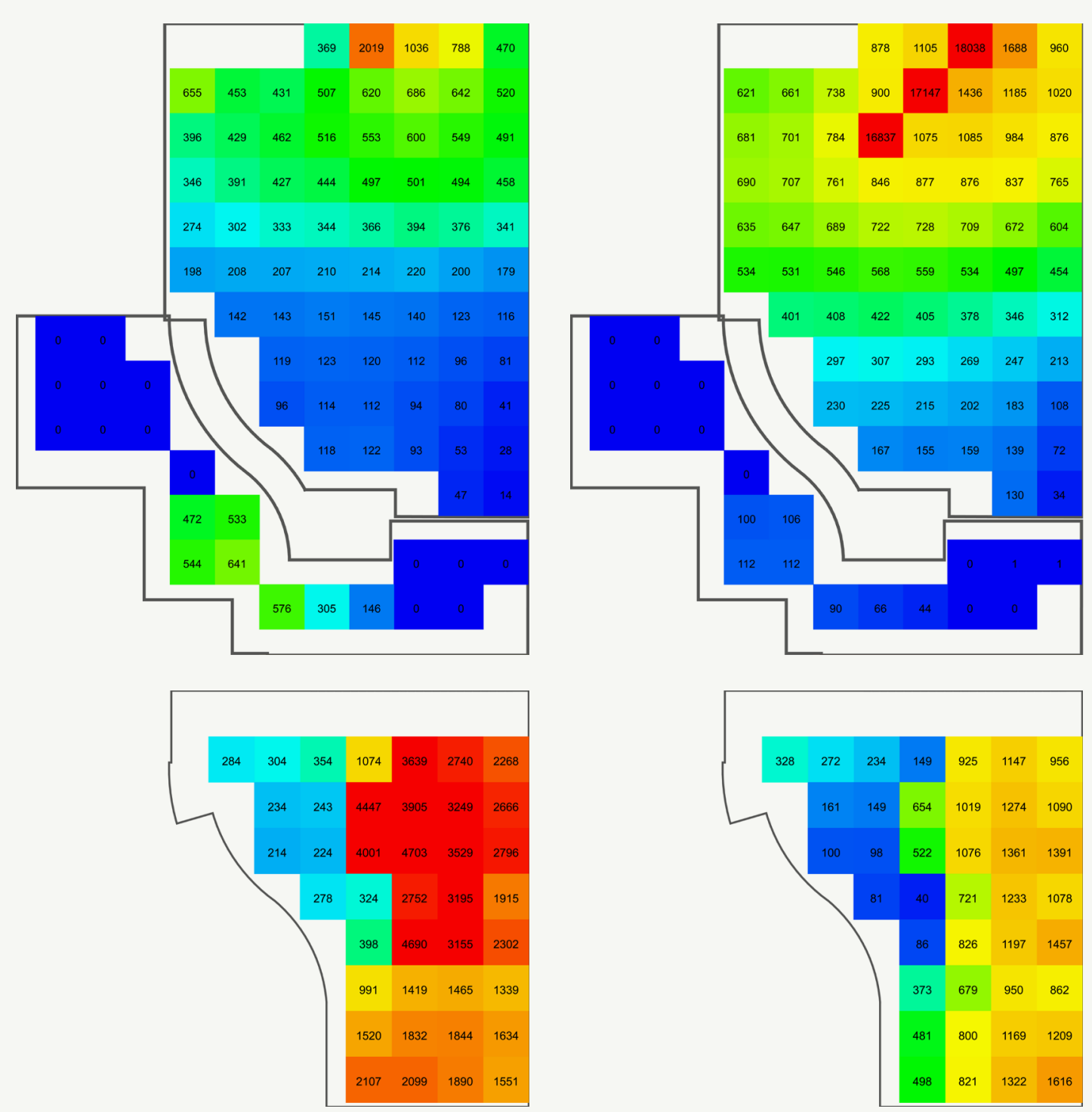

(1) 只 Fig.7.23.lluminance maps of iteration 4.

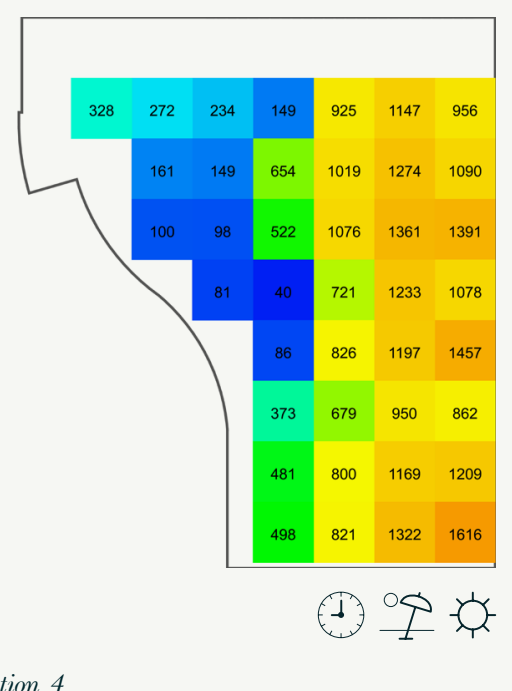



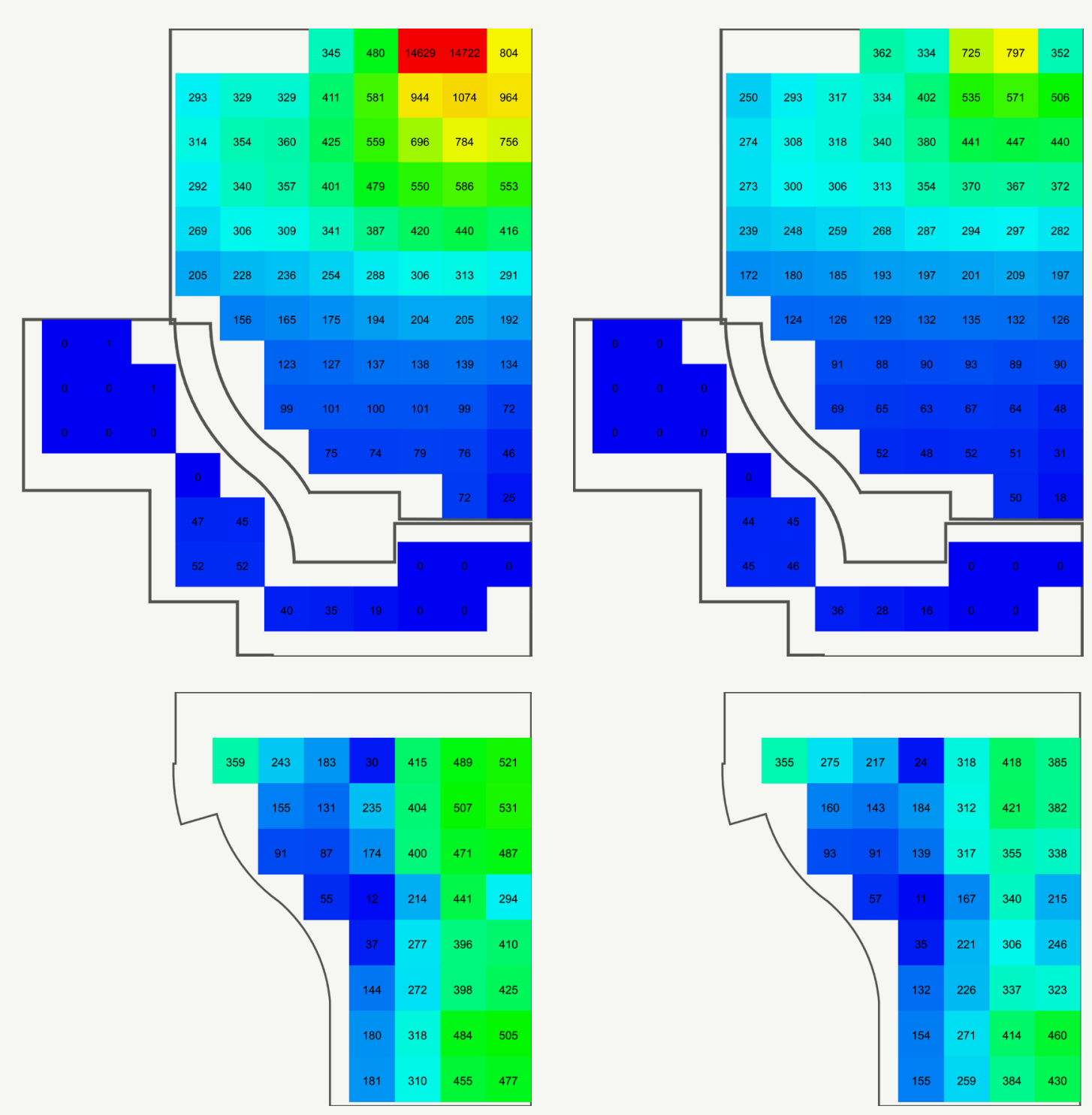

(1) 吅 Fig.724.Illuminance maps of iteration 4

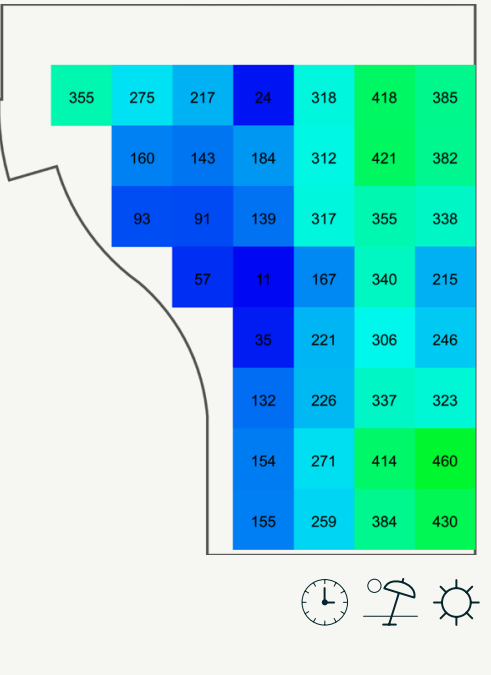

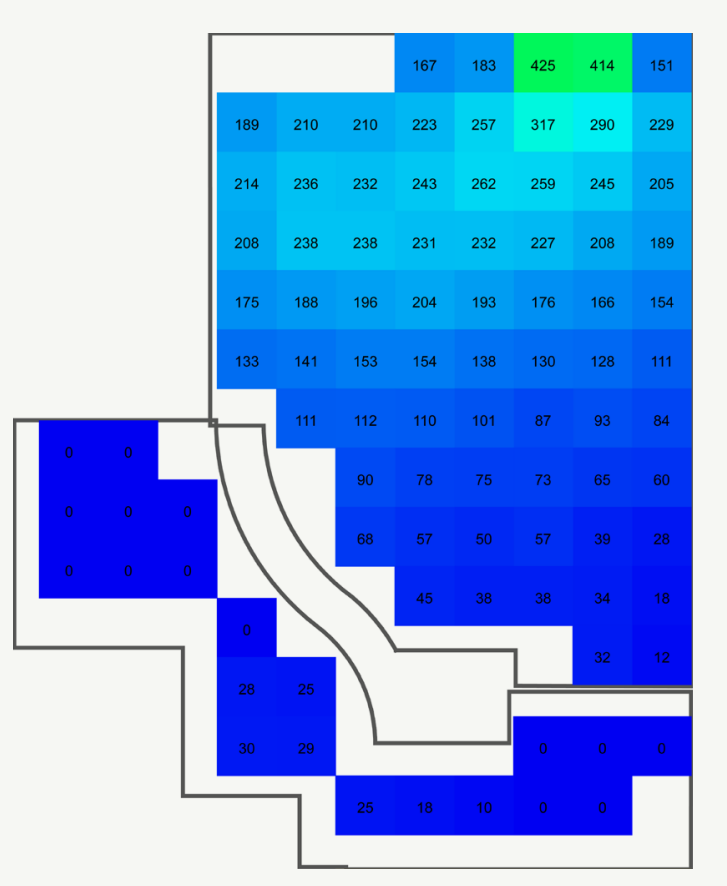

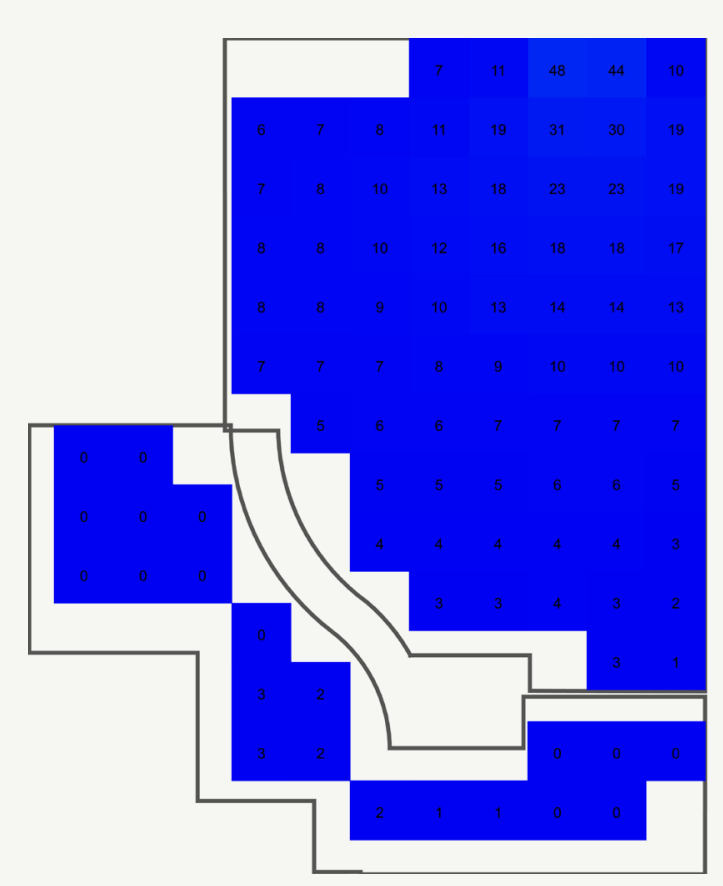

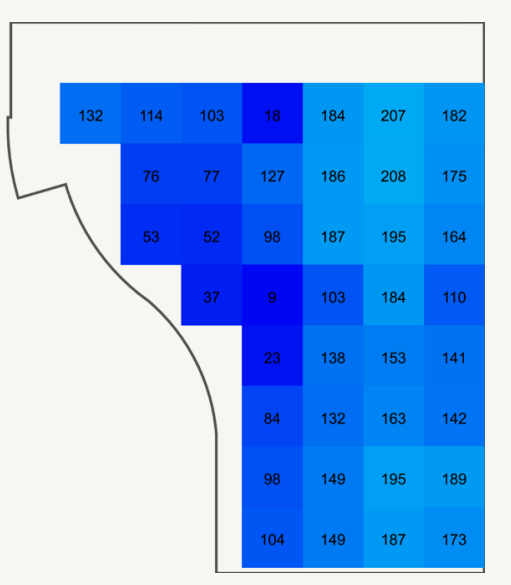

(1) 骂吕

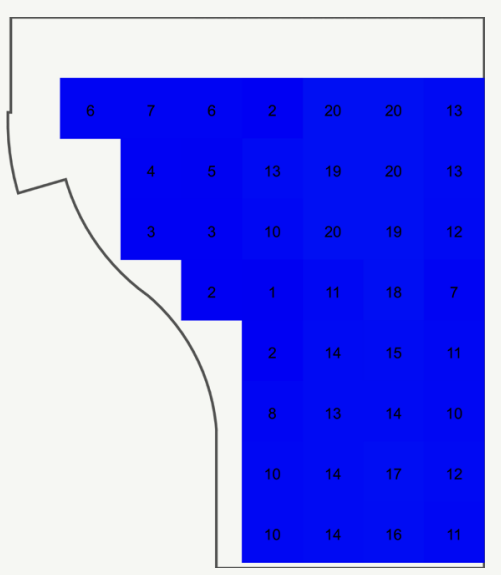

$\theta$ (1) 次 

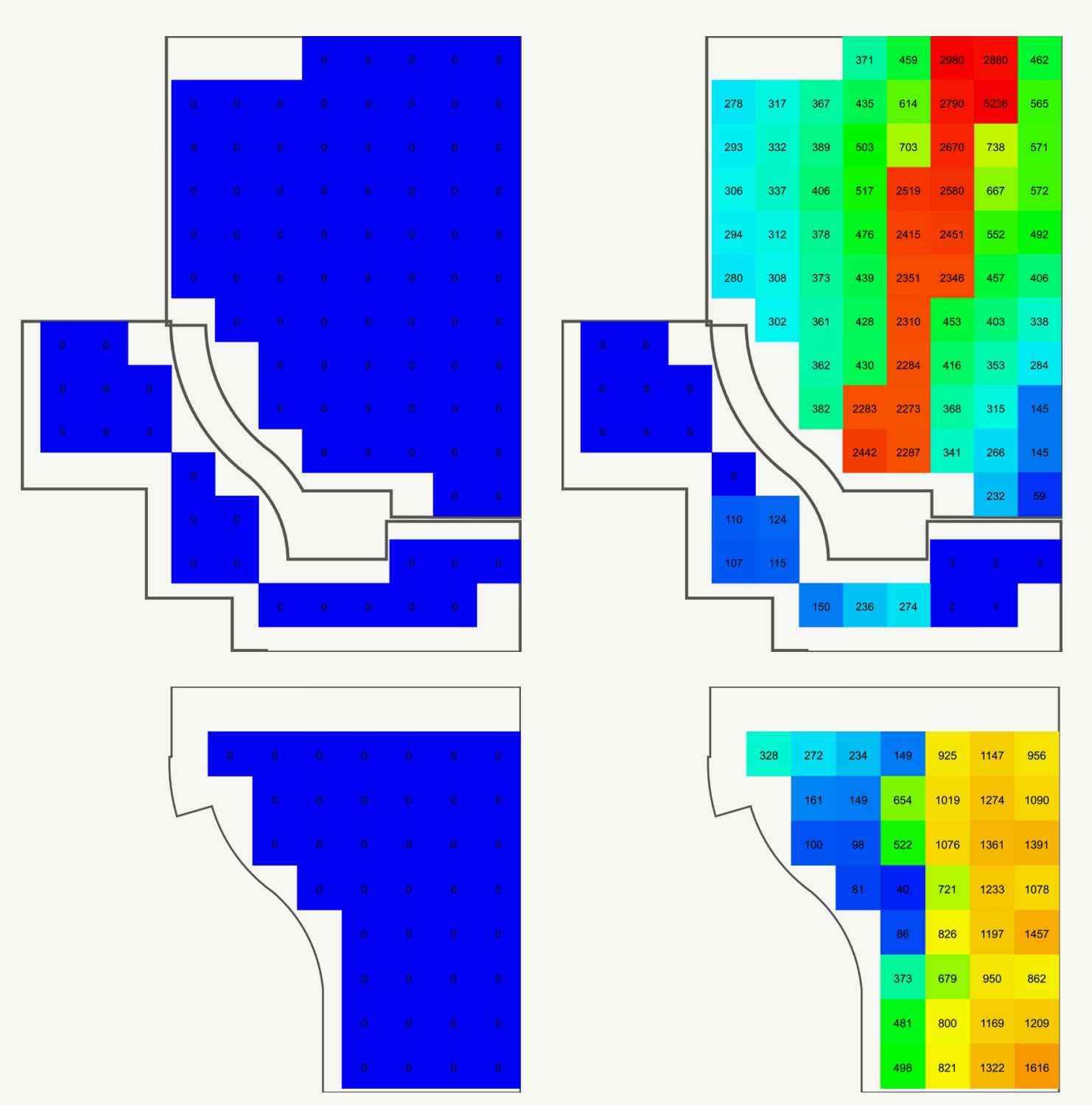

(1) 糔 Fig.7.726.Illuminance maps of iteration 4

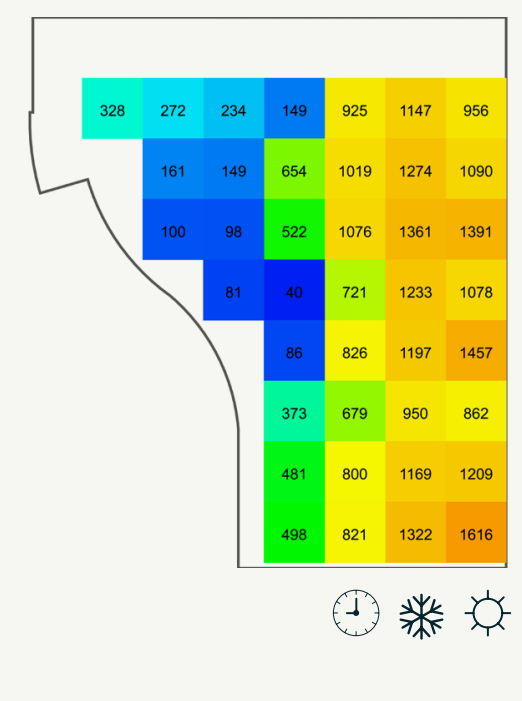

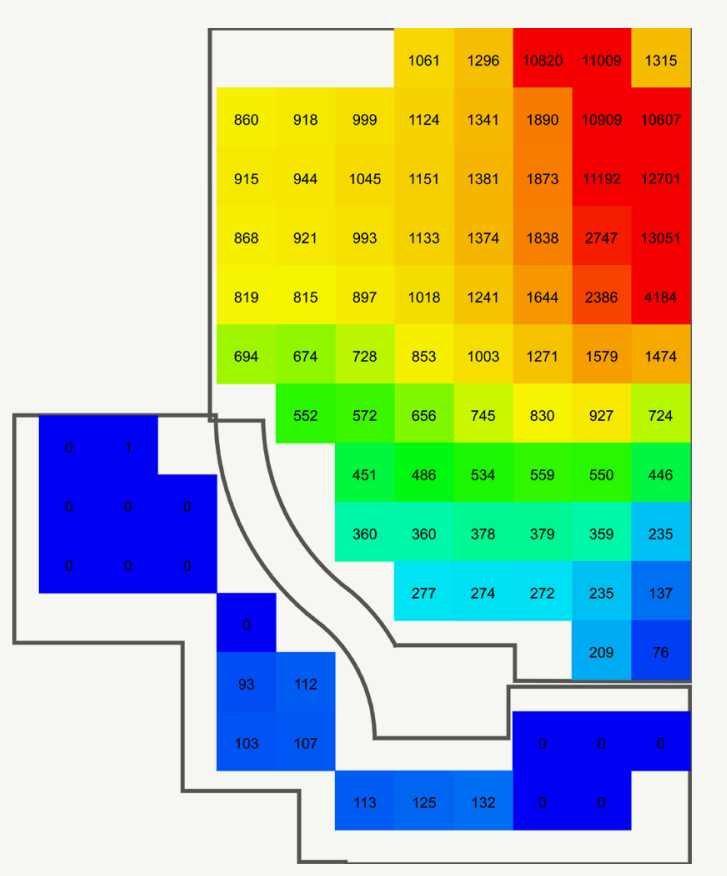
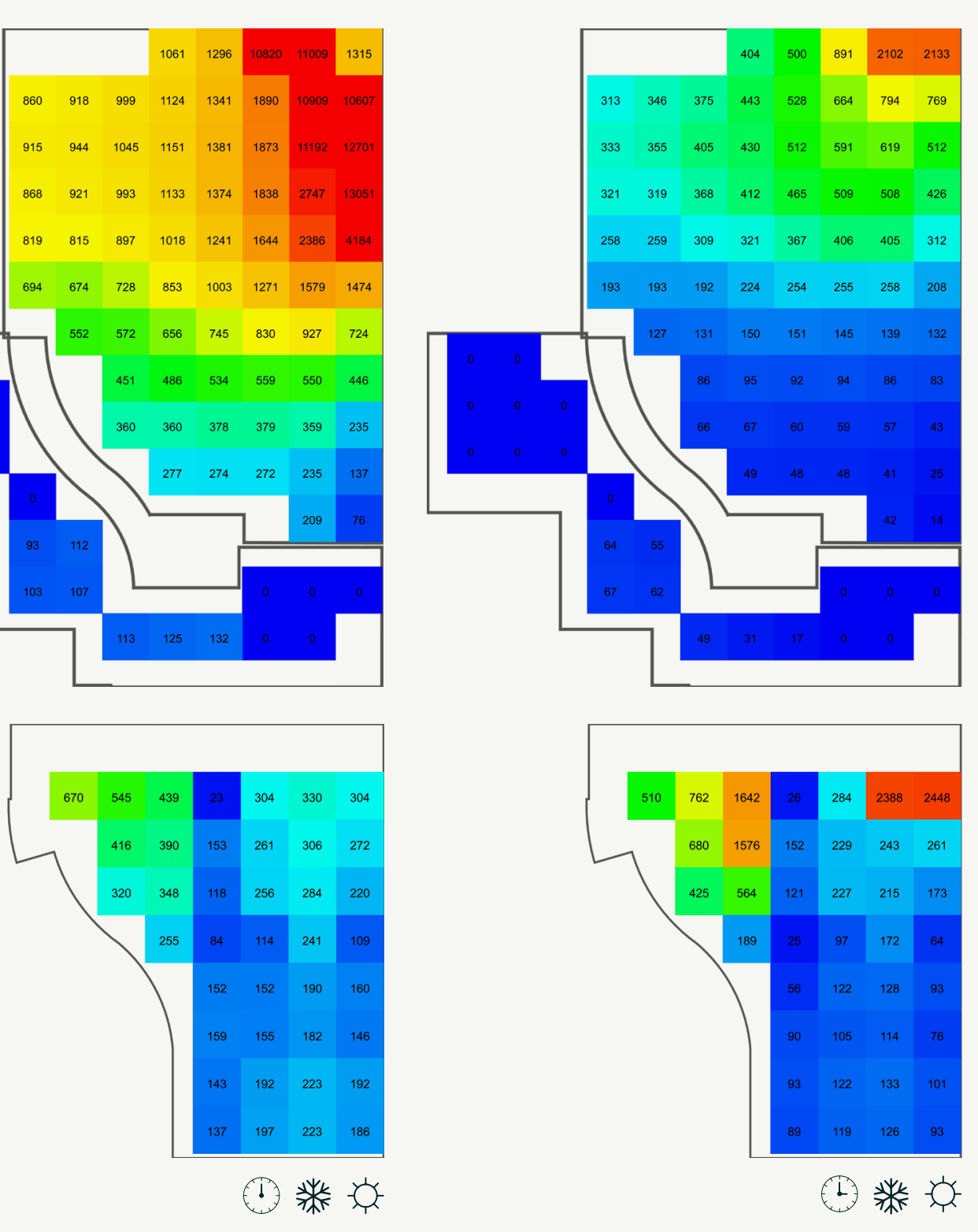

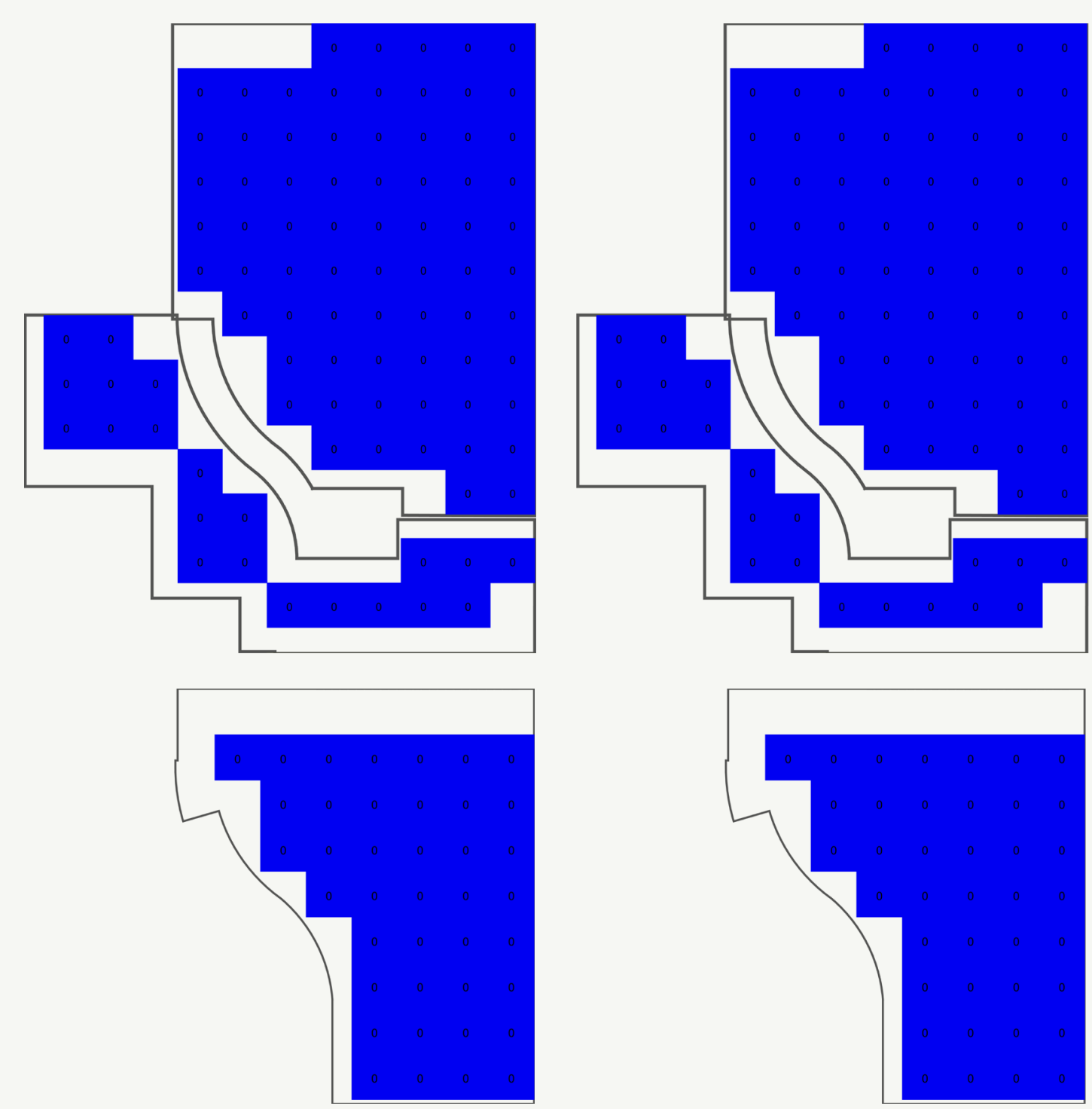

(1) 次 Fig.7.28.Illuminance maps of itortion 4

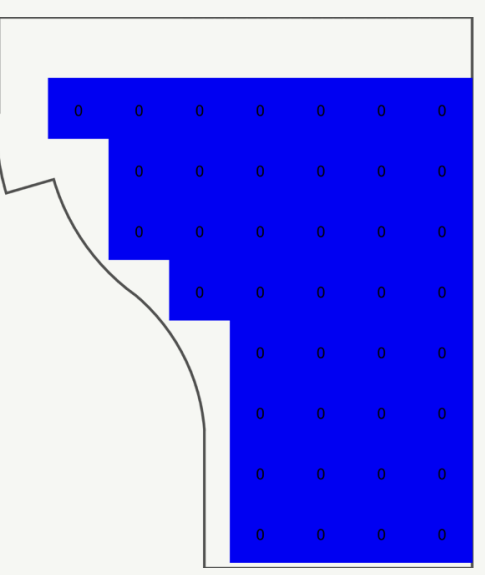

(1) 橉
7.9.2. Findings

- Clerestory windows are successful are providing sufficient lighting to upper floors

- Clerestories effectively transmit light deeper into the space, however more daylight is still needed in the back of the dwelling

- Clerestory windows provide more uniform lighting conditions across the space

- While they are successful are providing more adequate lighting for the dwelling, clerestory windows do not provide the desired connection to the landscape that traditionally placed windows do 
7.12. ITERATION 5

7.12.1. Model desciption

This series experimented with a combination of iterations 3 and

4 by implementing clerestory

windows alongside smaller windows

on multiple facades to frame the

view while maximising daylight to

permeate deeper into the dwelling.

Glazed area $=23.54 \mathrm{~m}^{2}$

$=9.5 \%$ building

footprint 

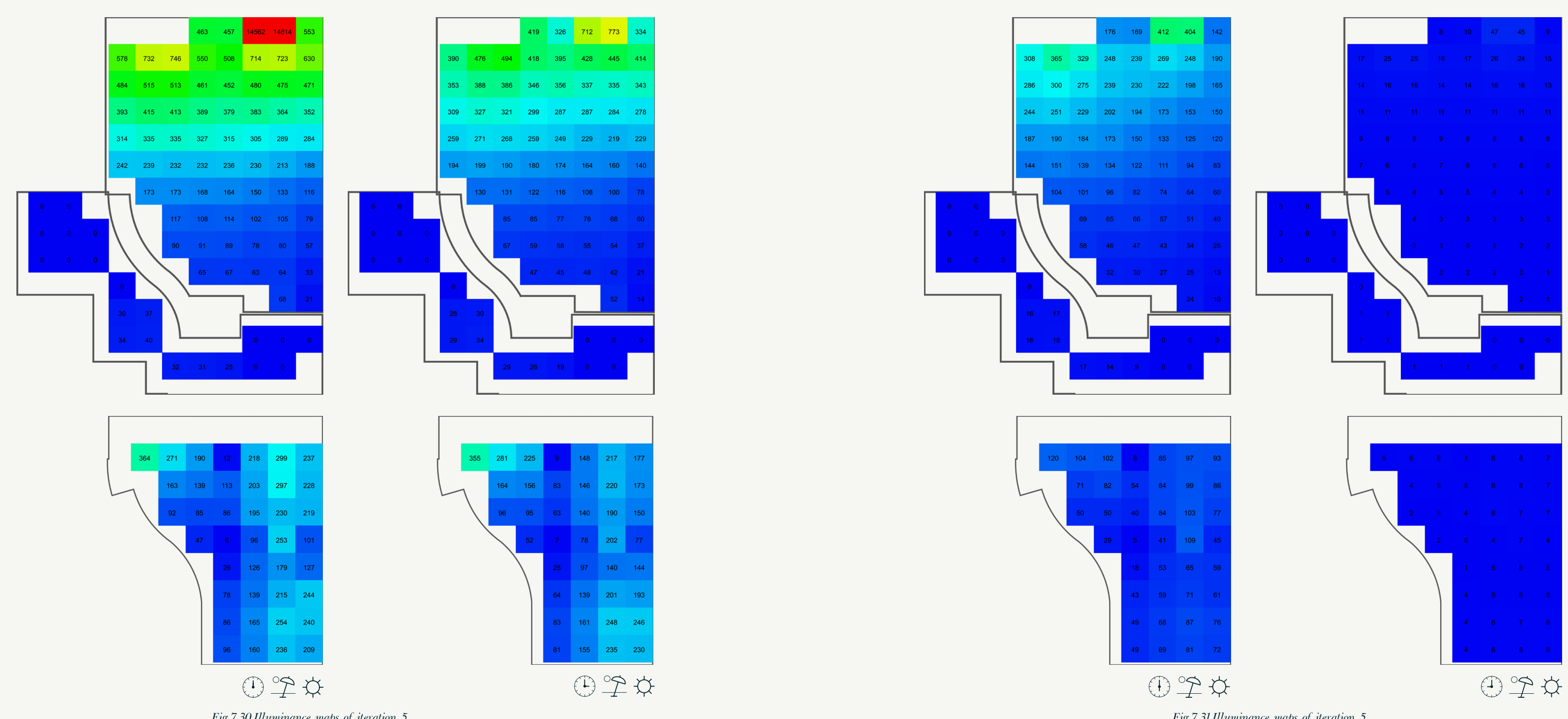

(1) 吅嫁

(1) 吅妨

(4) 吅好 

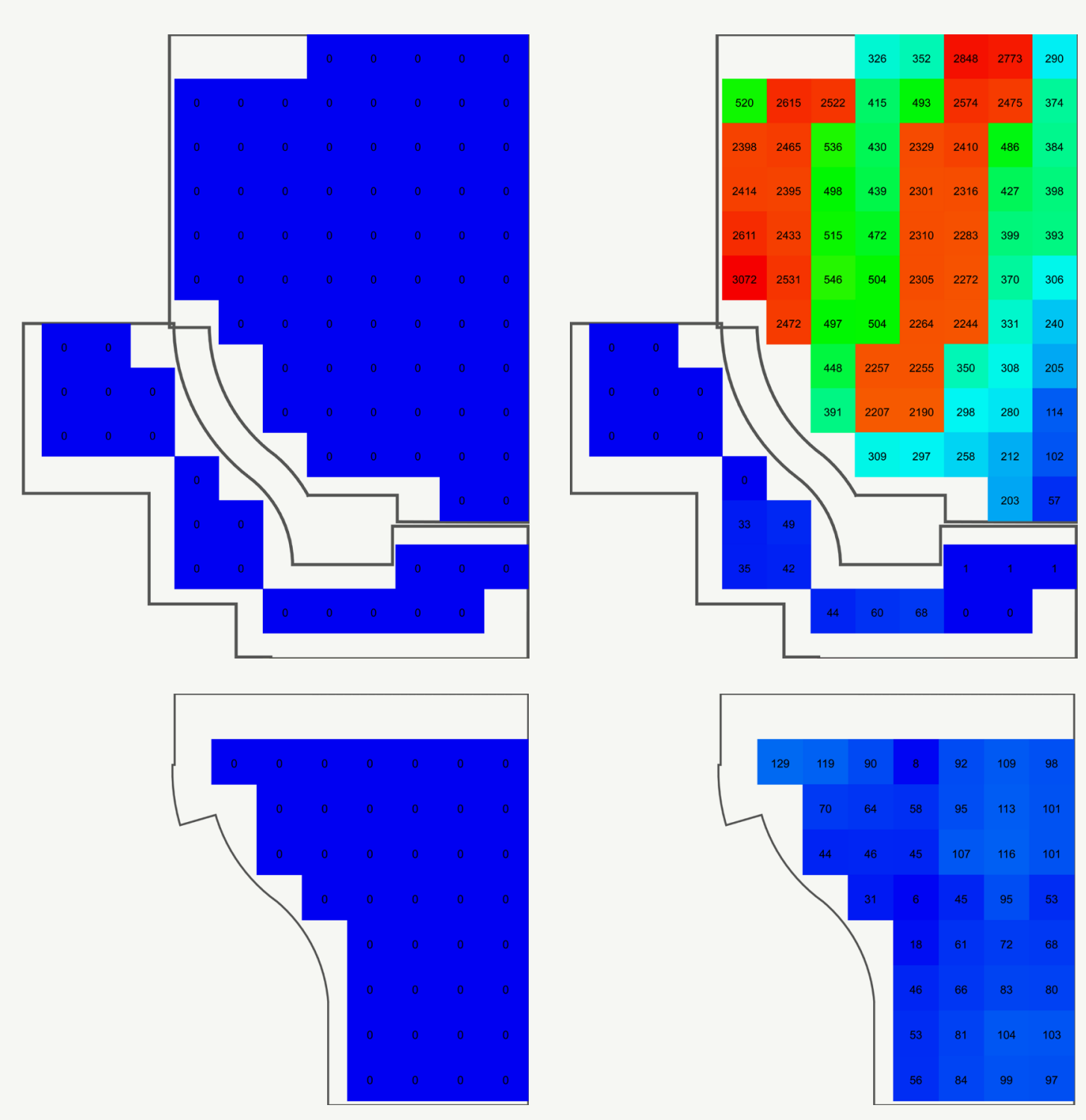

(1) 糔 Fig.732.Illuminance maps of iteration 5

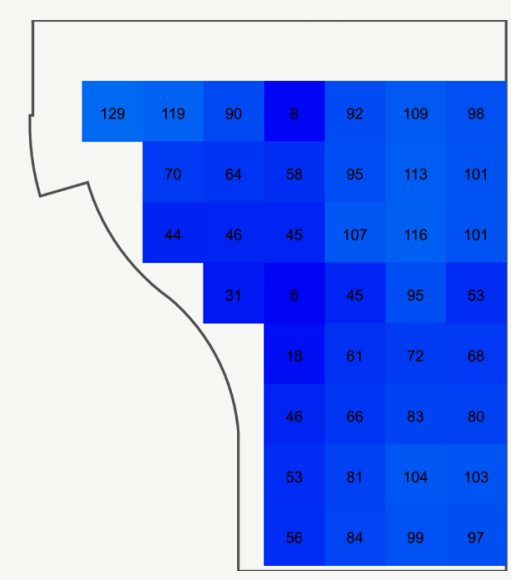

(1) 橉
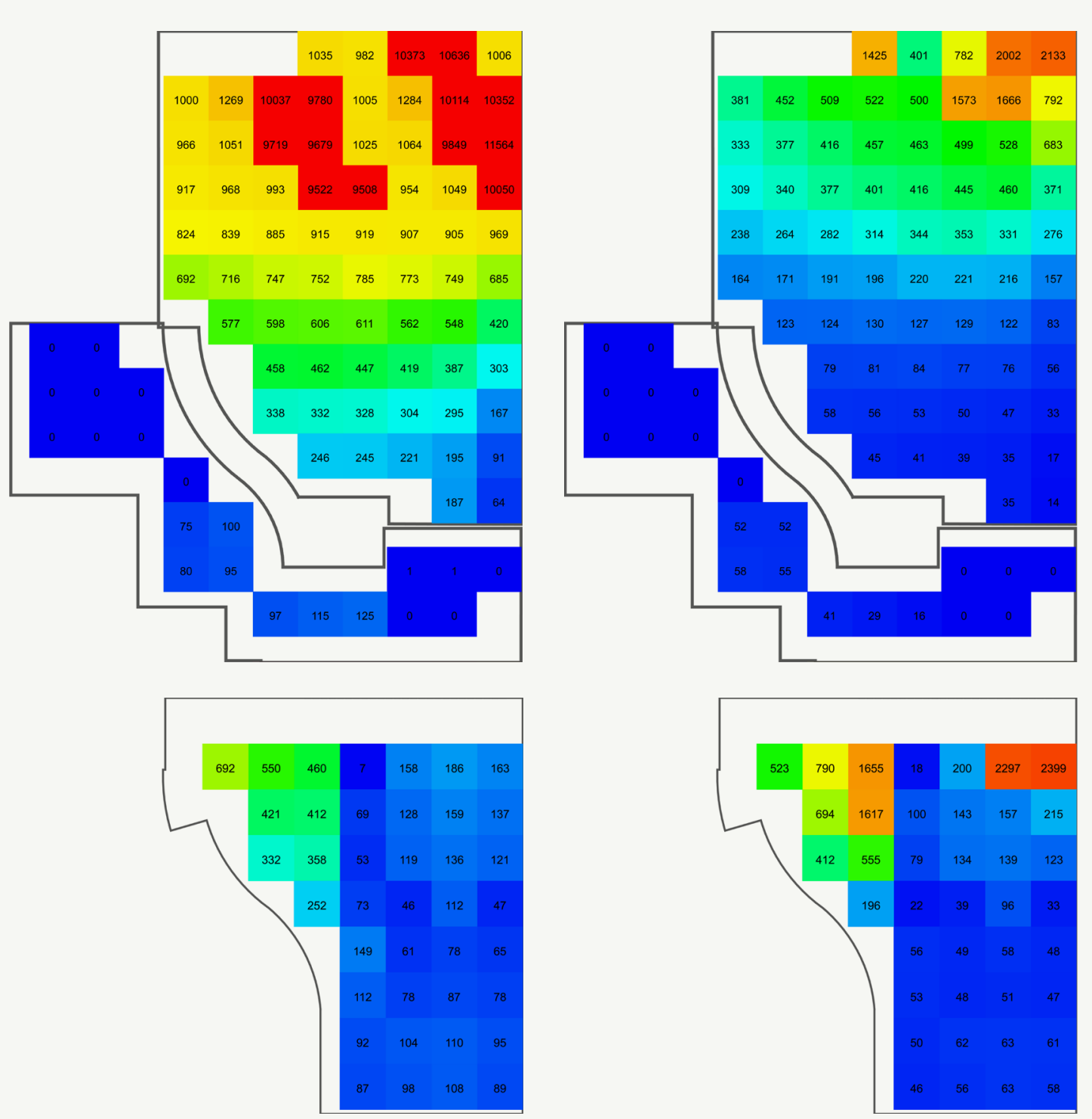

(1) 橉 Fig.733.lluminance maps of ieration 5

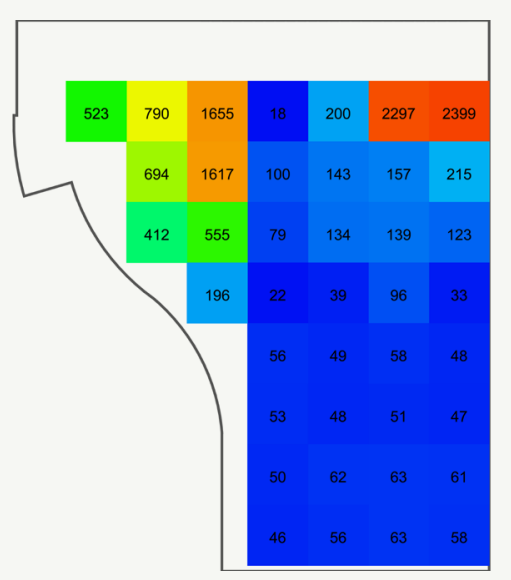

(1) 楼 

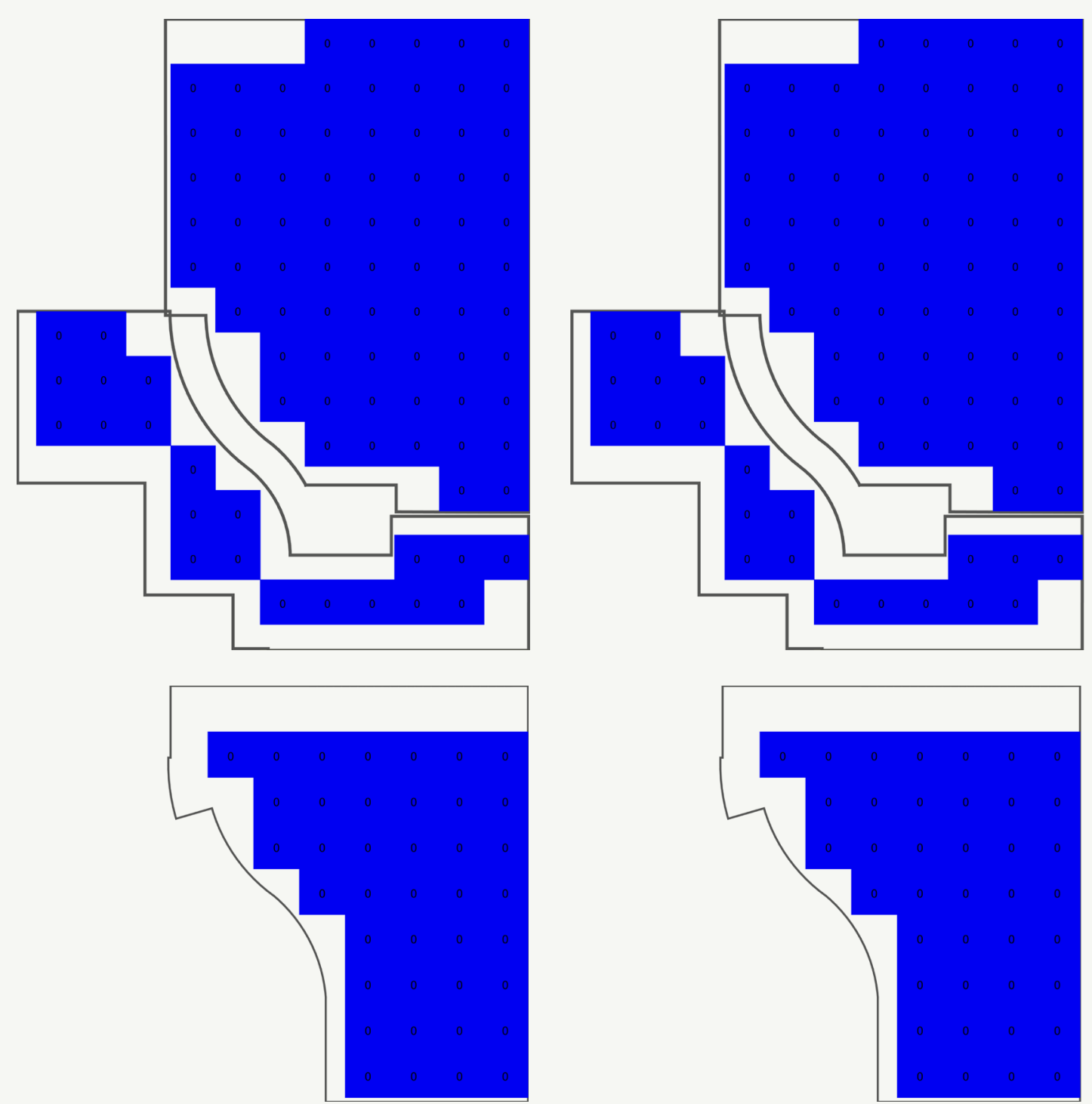

(1) 橉

(1) 料
7.10.2. Findings

- Smaller but multiple windows on more than one facade provide more evenly distributed lighting conditions, and provide more dynamic lighting conditions to replicate the effects of light in nature

- The combination of smaller windows on multiple facade and clerestory windows provides more adequate lighting

- Windows on the eastern facade are less effective at transmitting light to the interior than northern and western facades.

- Some windows are necessary on the southern facade to provide lighting to the back of the dwelling. This would provide the opportunity for cross-ventilation, which would prevent the overheating that is often associated with large windows used to frame the view

in contemporary residentia architecture (Kwok, 2018)

- Placing spaces that need less light, such as bathrooms, garages and lounge/snug spaces on the south side of the building would reduce the need for large windows on southern facades. 
7.13.ITERATION 6

\subsubsection{Model description}

This series extended upon

Corbusier's ideas of ribbon windows

in section 3.2.4, and experimented

with the possibility that poetically,

ribbon windows might create a more

invigorating connection with the

landscape and scientifically, might provide more even light distribution.

Glazed area $=35.93 \mathrm{~m}^{2}$

$=14.4 \%$ building

footprint
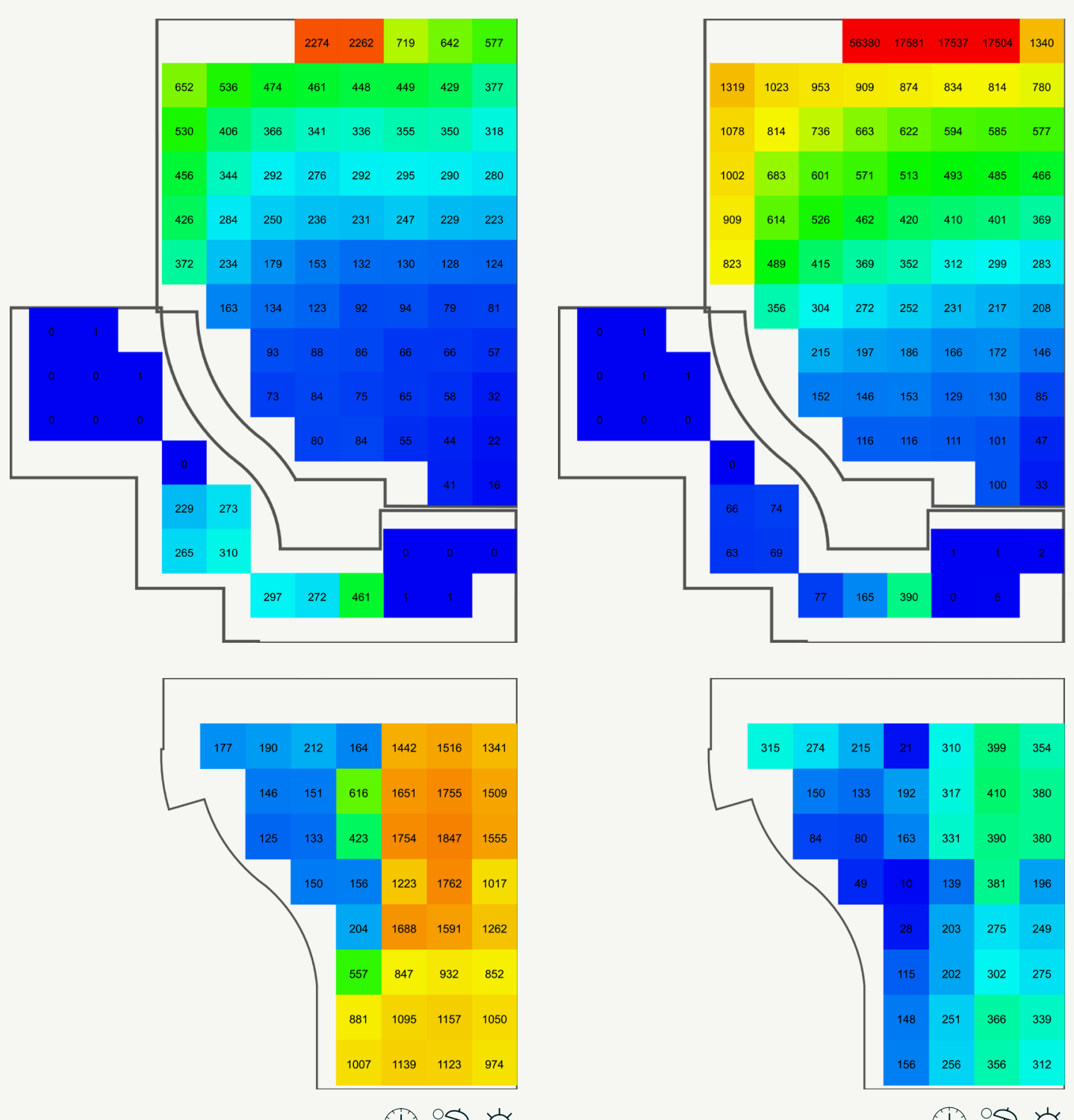

(1) 吅 Fig.735.Illuminance maps of iteration 6 

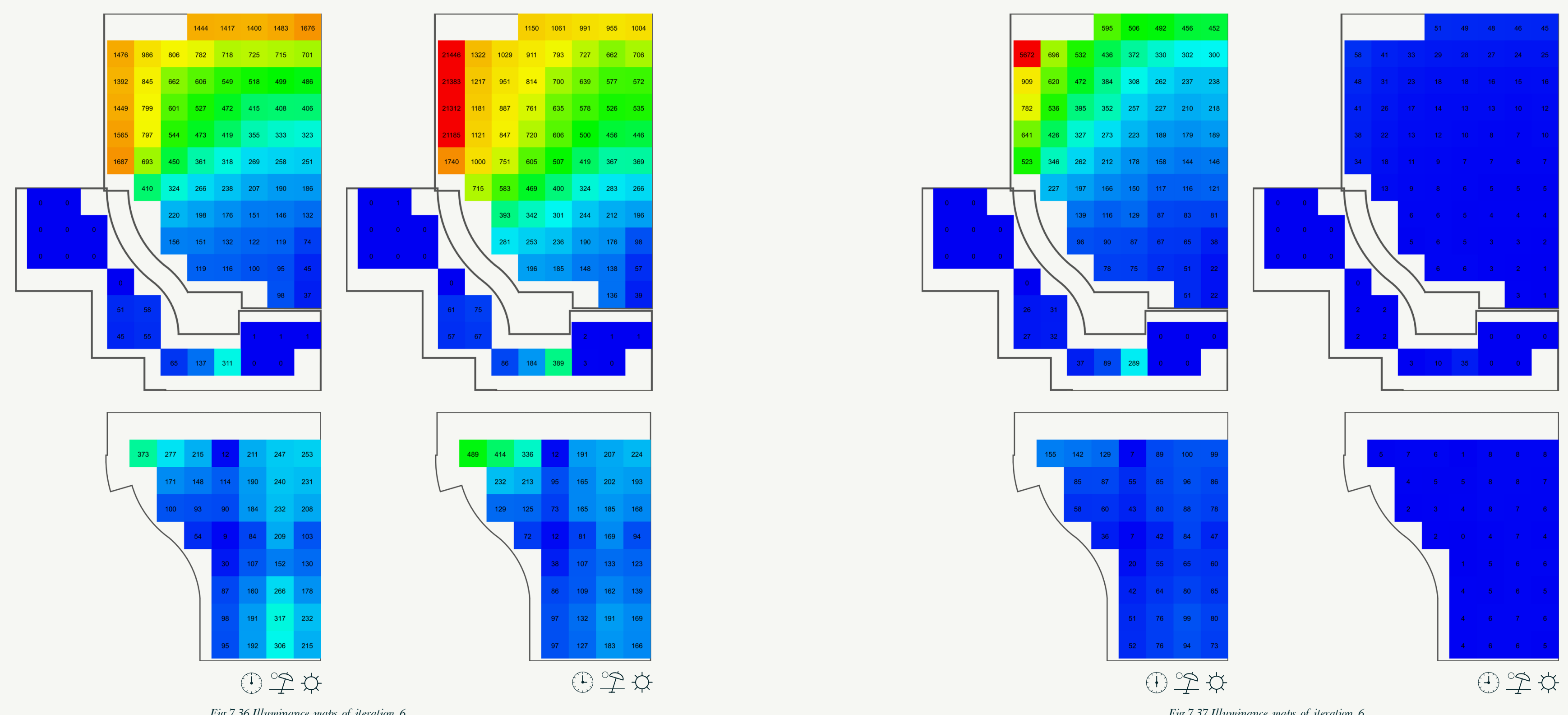

(1) 吅

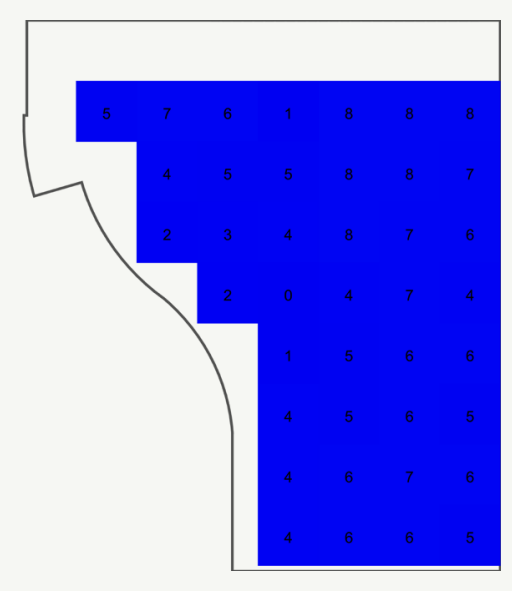

(1) 年

(1) 吅妏

Fig.737. Illu

(1) 只 

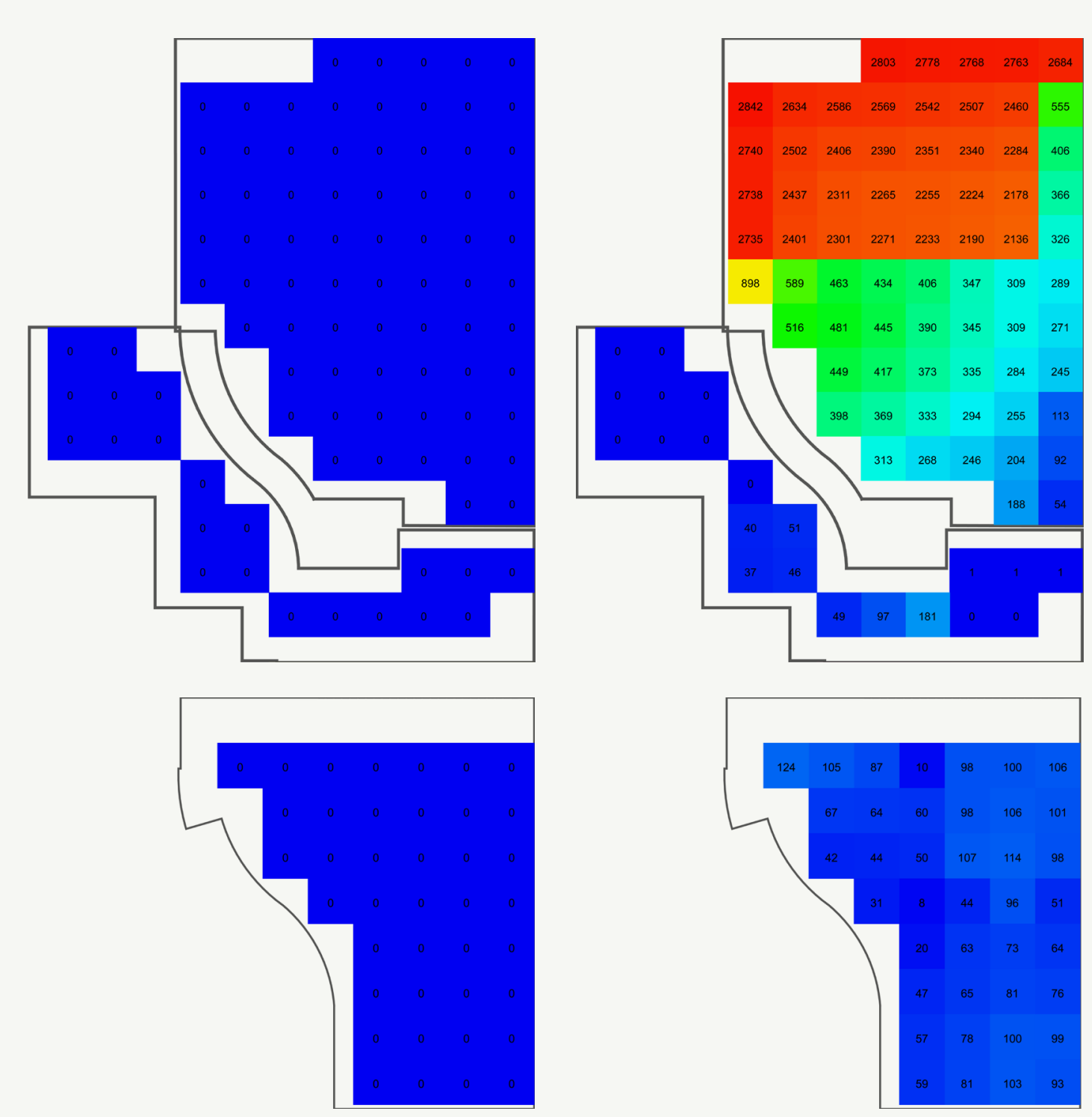

(1) 糔 Fig.738.Illuminance maps of iteration 6

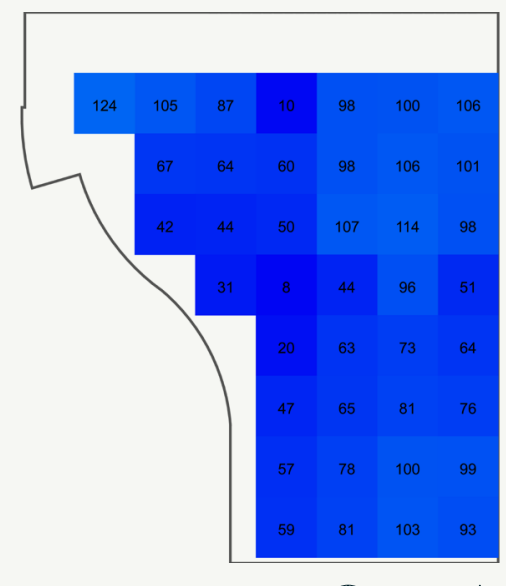

(1) 橉
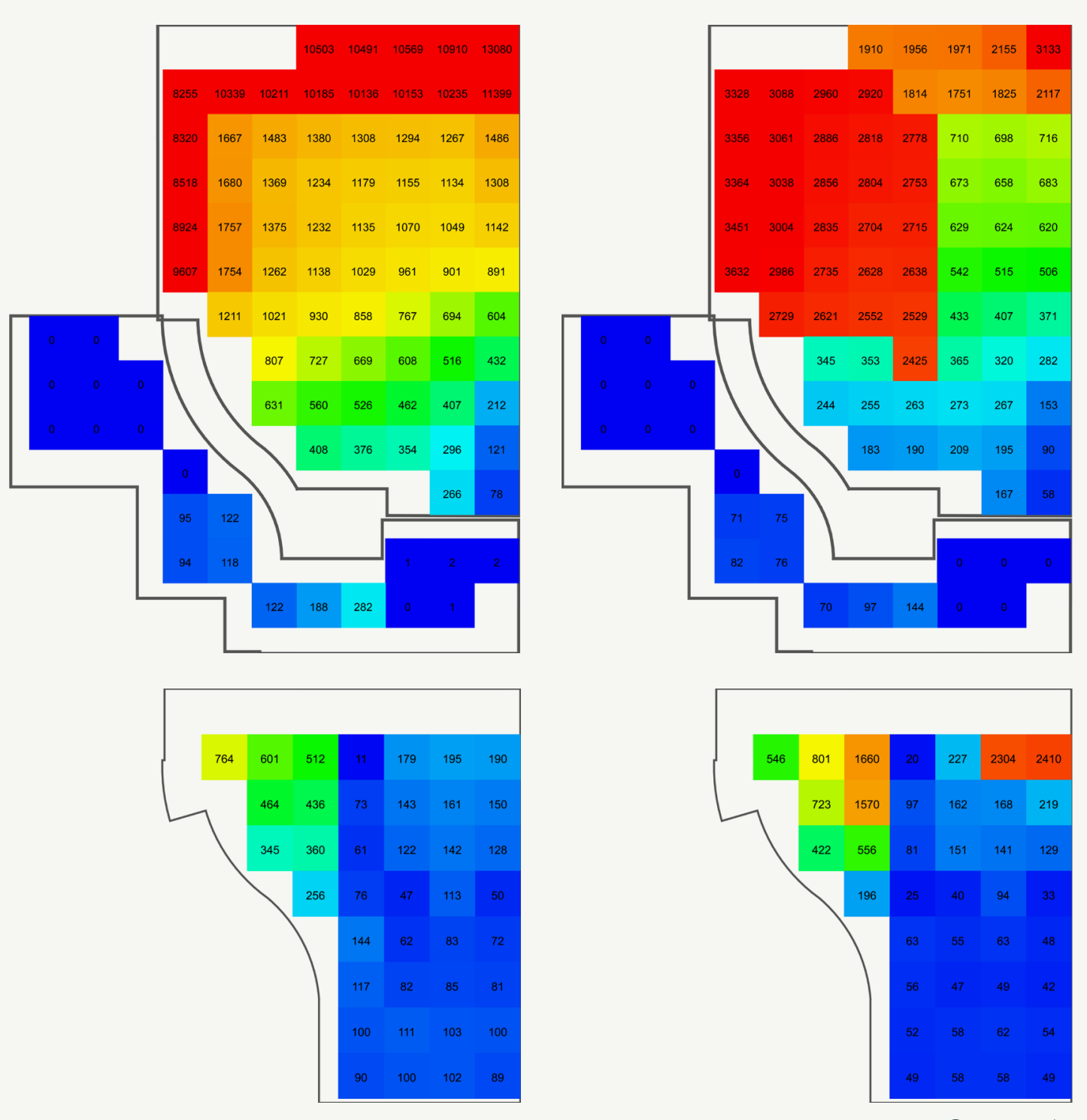

(1) 类 Fiig.739 Illuminance mats of iteration 6

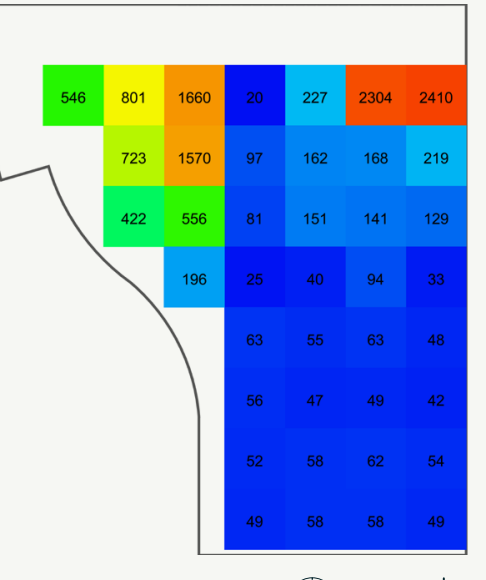

(4) 䊅 

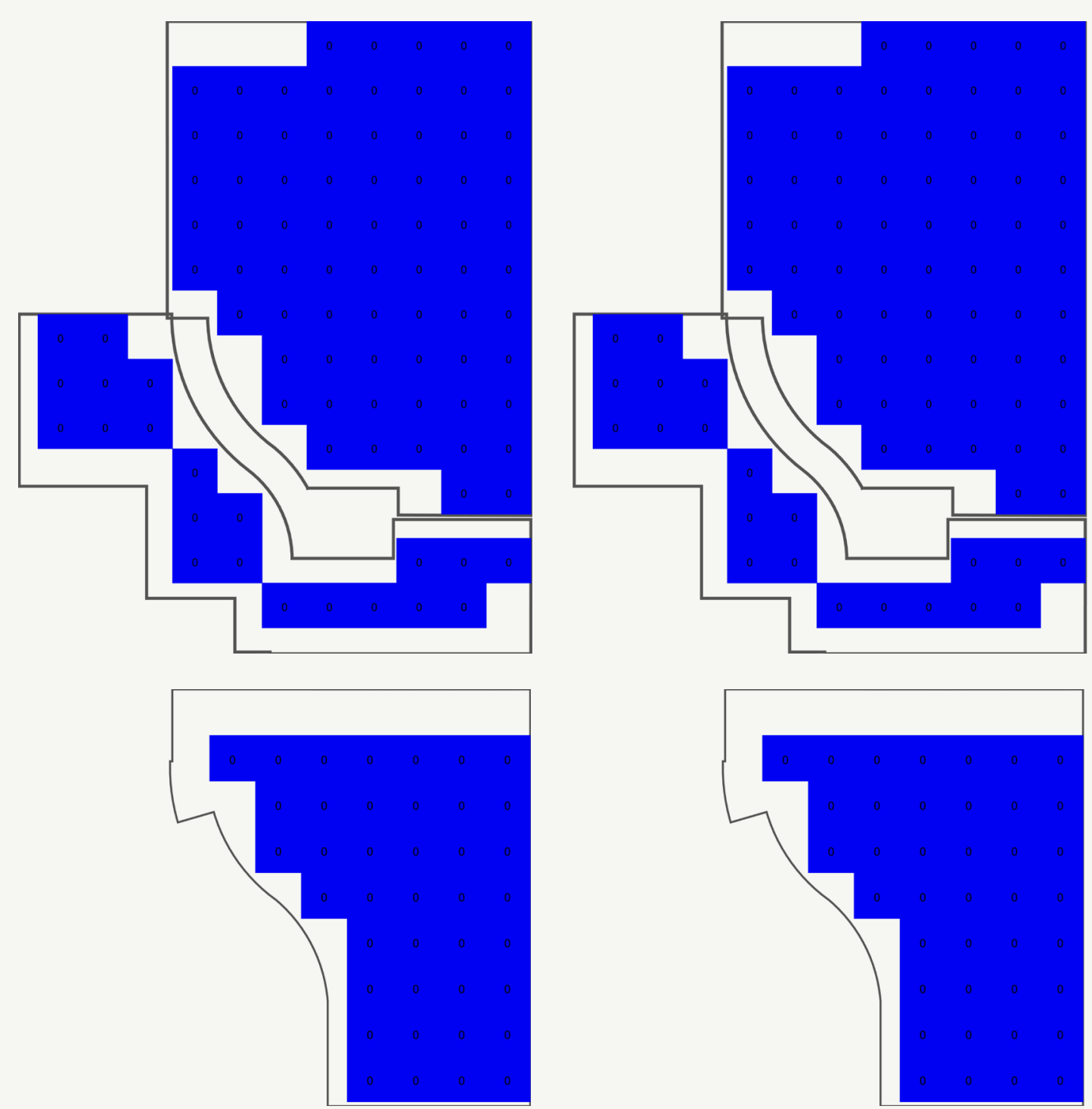

(1) 橉 rig.7.70.Illuminance maps of itumithn 6

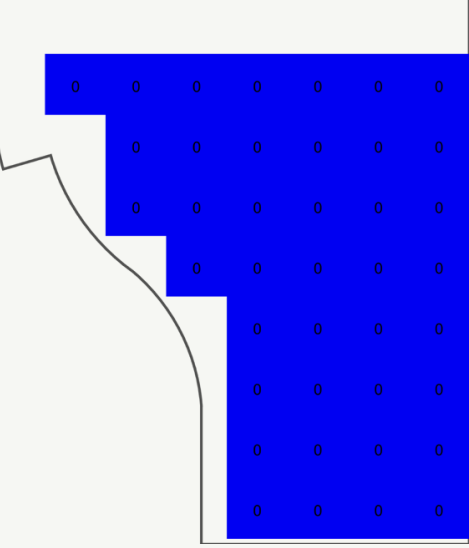

(3) 橉
7.11.2. Findings

- Ribbon windows create much more uniform lighting conditions across the space, while more successfully framing the view of the landscape with limited glass usage

- Ribbon windows have the ability to permeate light deeper into the space than other window typologies

- Ribbon window occasionally create extreme levels of

illuminance which could result in overheating, but very rarely in summer, and could be a benefit in winter to provide heating to the interior
- The combination of ribbon windows and clerestories

succesfully lit most areas of the dwelling during daylight hours, with the exception of the inner mezzanine during winter.

- Skylight could resolve the reoccuring issue of lighting the mezzanine during winter with minimal glass usage. 


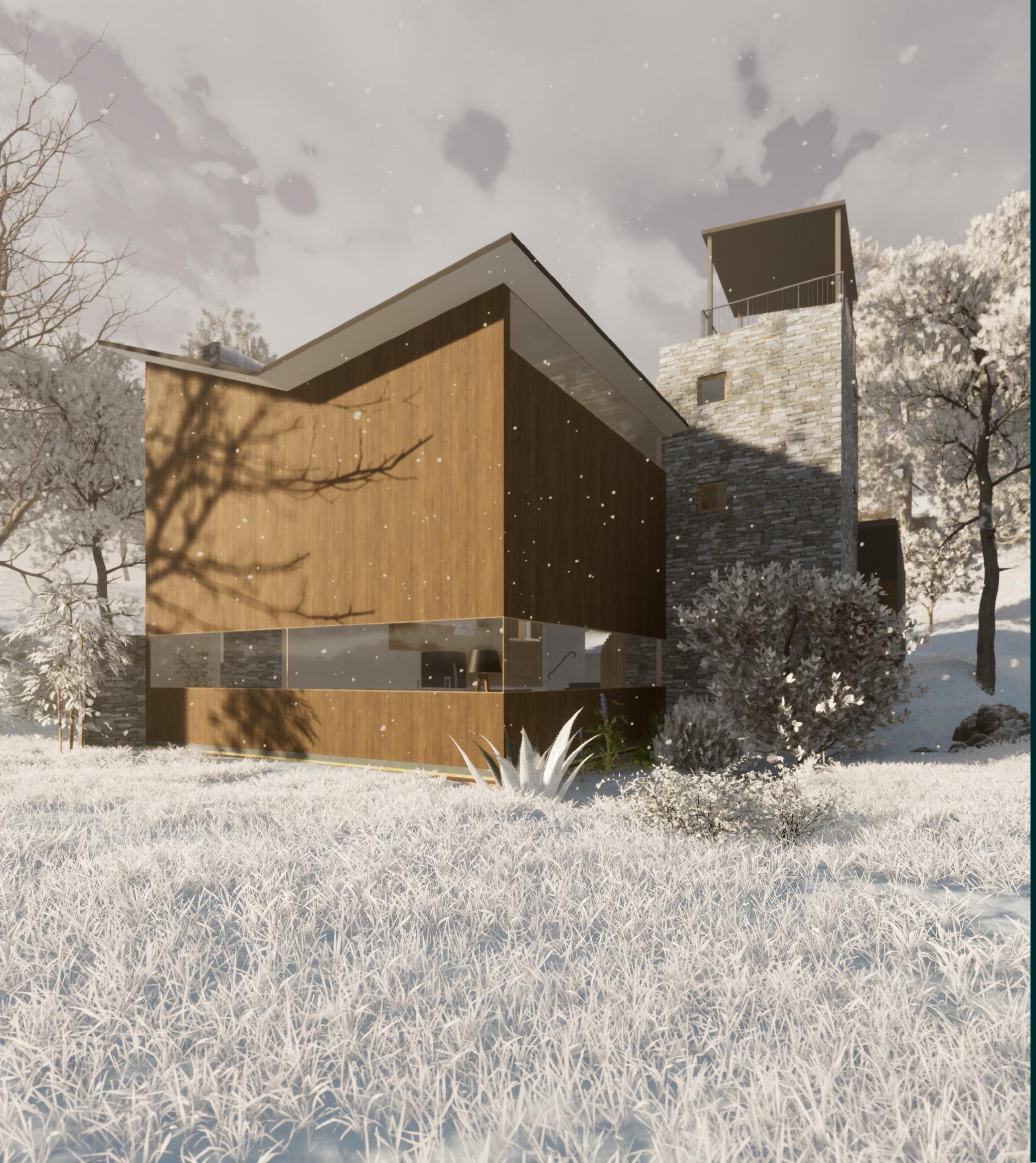

\subsection{LIGHTING RENDERING ANALYSIS}

7.14.1. Aim

This series aims to analyse the poetic effects of lighting conditions on the final iteration from section 7.13. Twinmotion was used to generate renders at certain times of day and year and under various weather conditions to analyse the poetic qualities of the space as affected by daylighting conditions. 


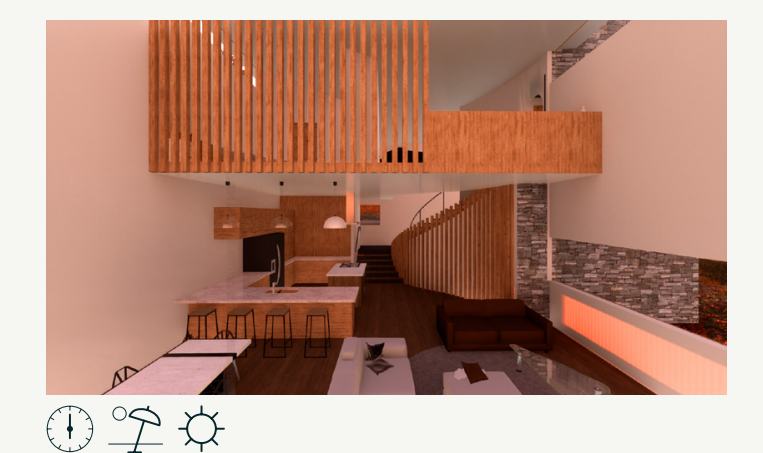

(1) 吅

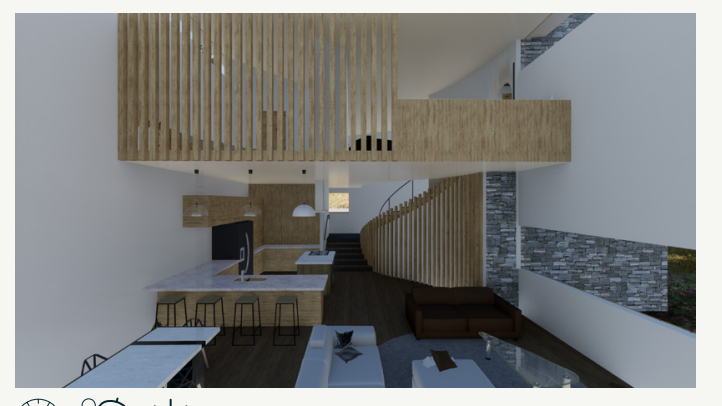

(1) 琼

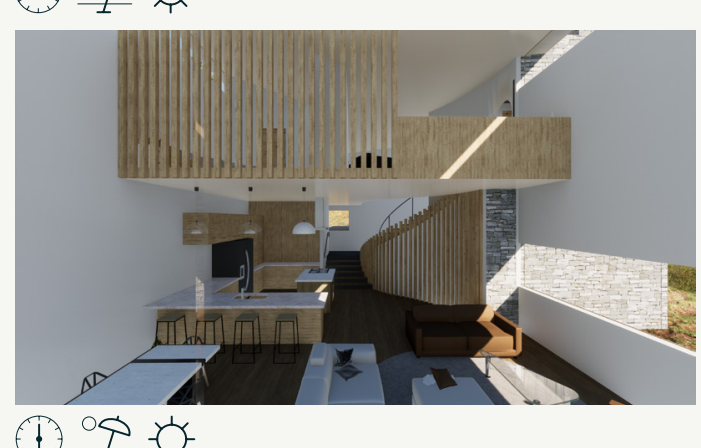

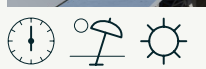

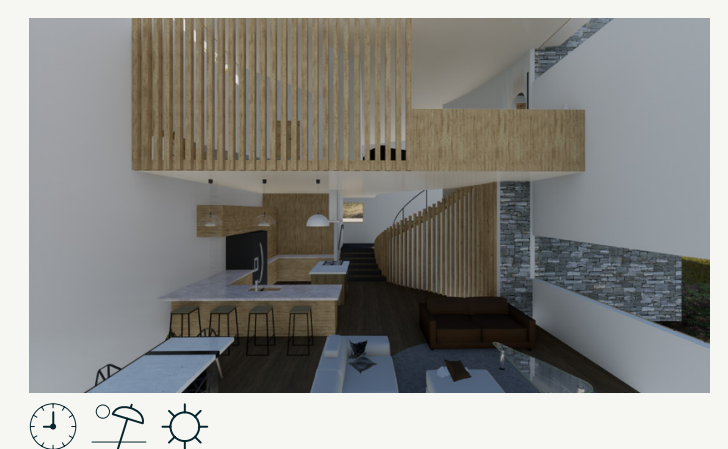

(1) 只
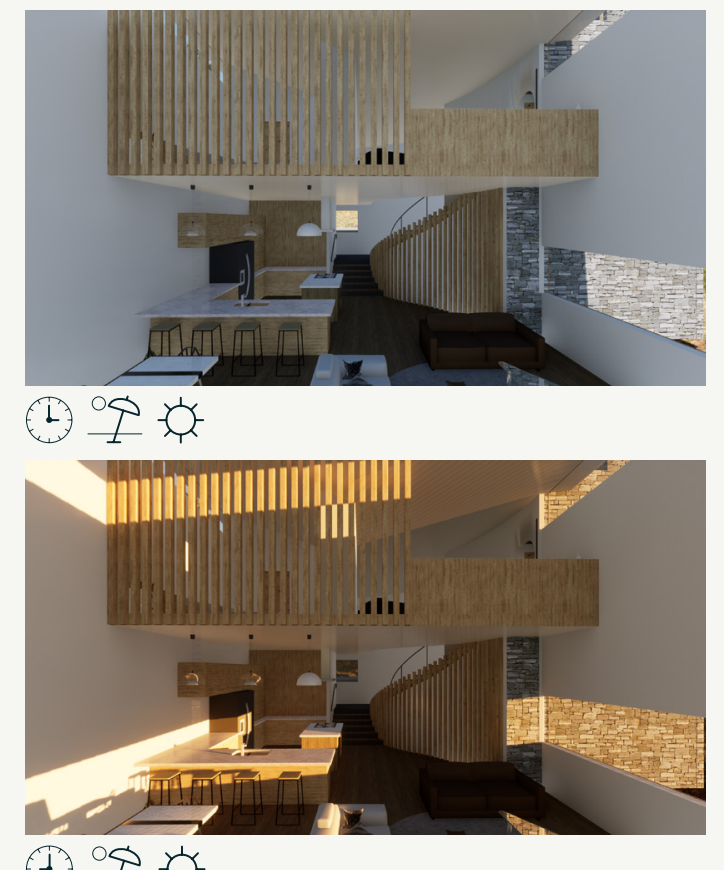

(4) ${ }^{\circ}$
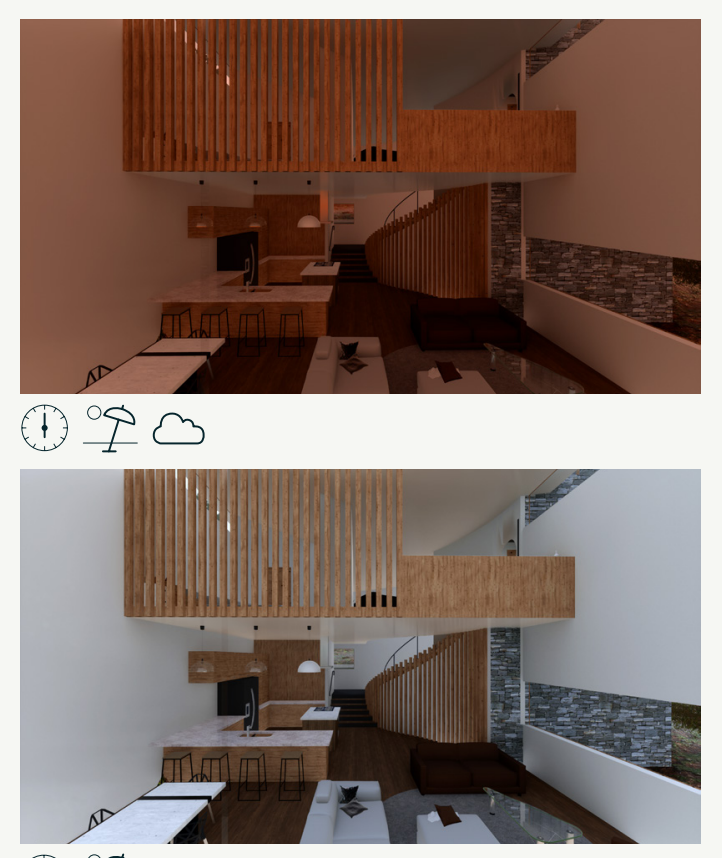

(b) ox
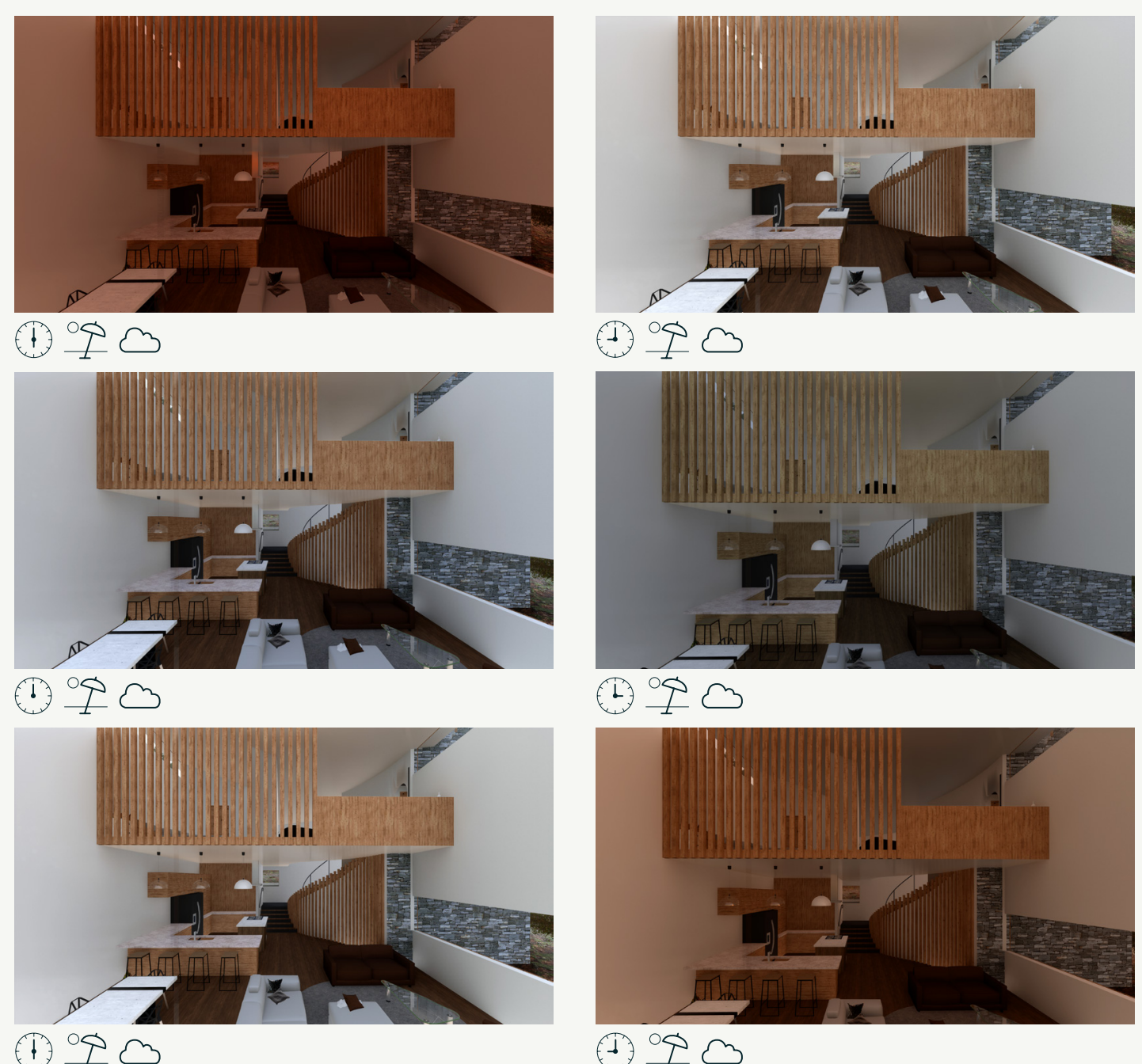

(1) ox

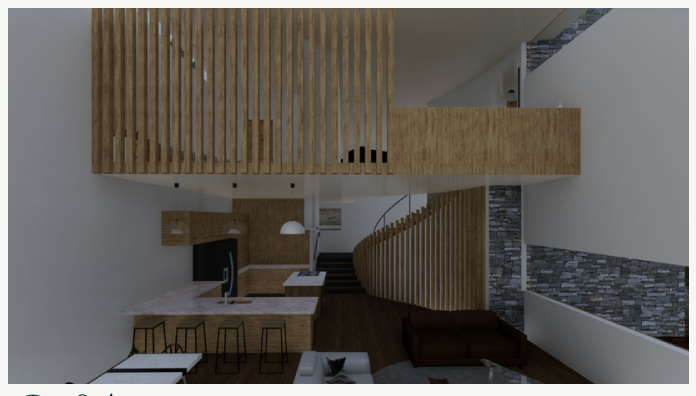

(1) 唡

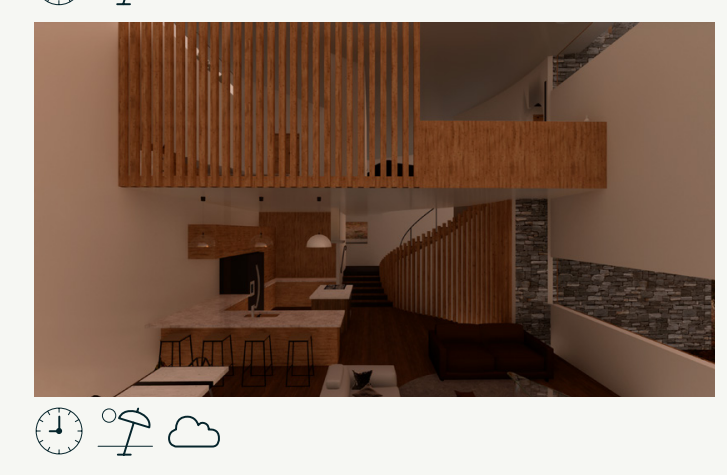

Fig.8I.Daylight renders of living room

Fig.82.Daylight renders of living room 


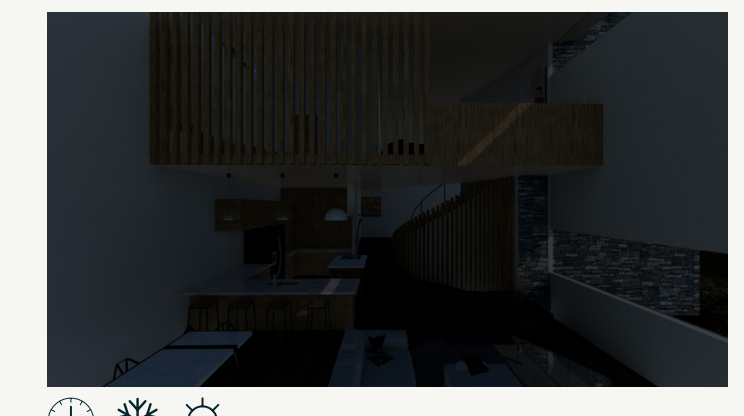

(1) 橉

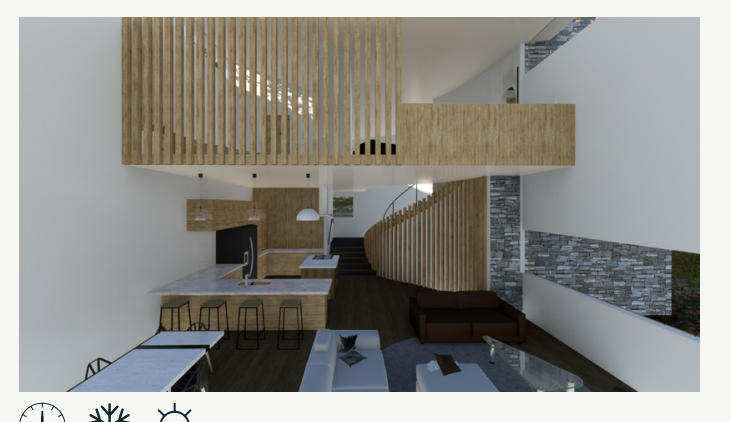

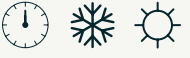

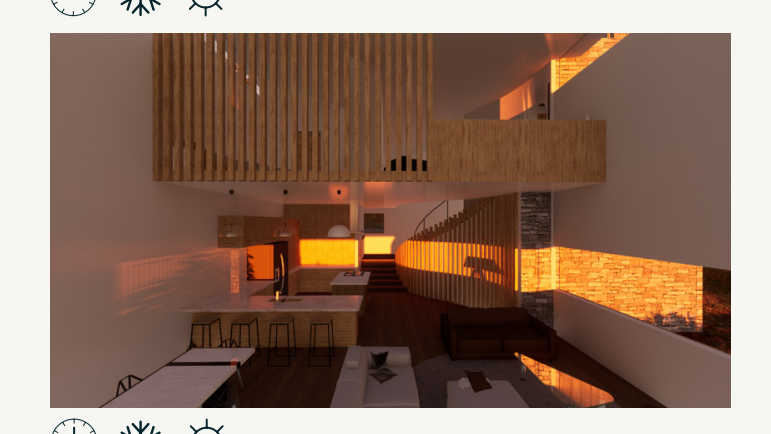

(1) 橉说

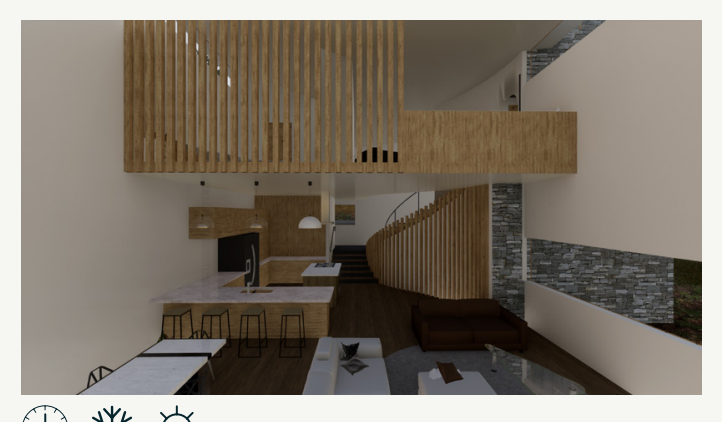

(1) 整

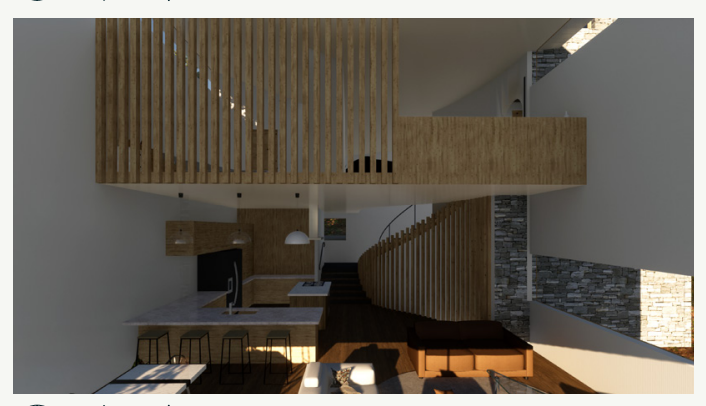

(1) 楼

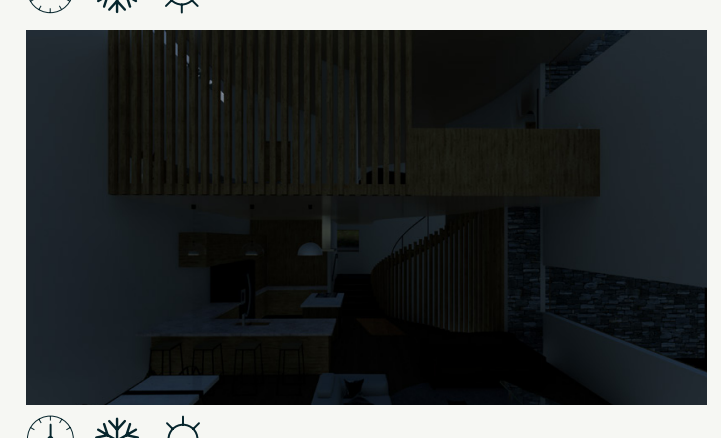

(9) 糔

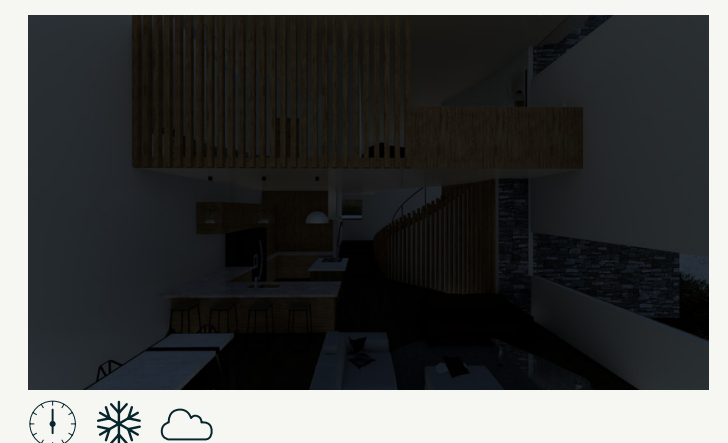

(1) 橉

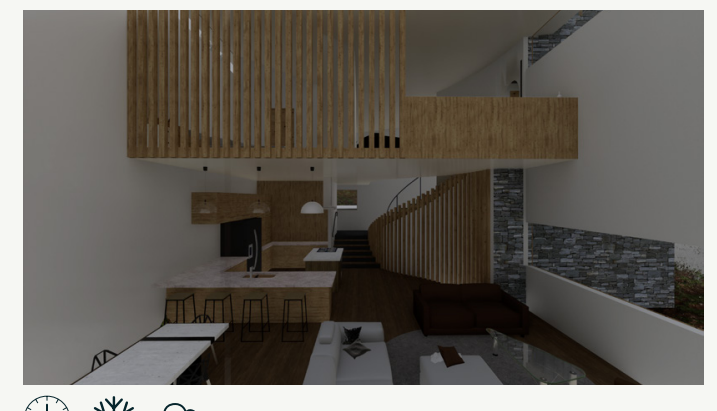

(1) 橉

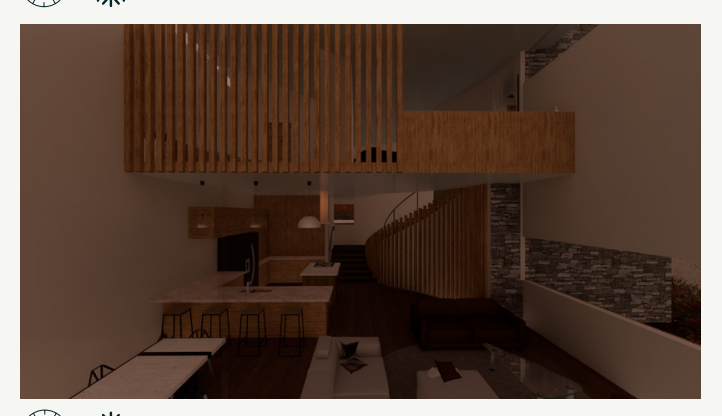

(1) 橉

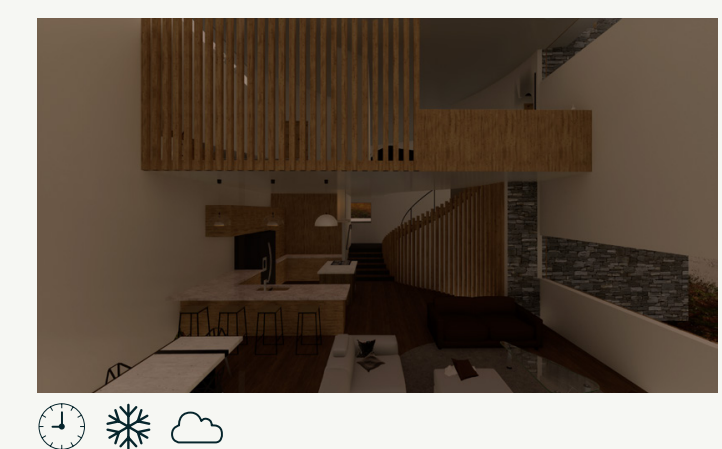

(1) 3

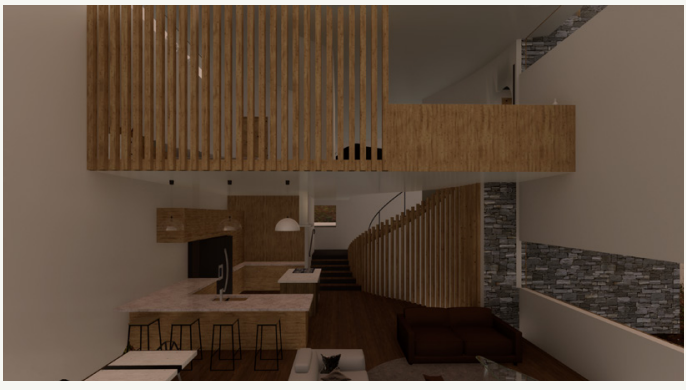

(1) 3

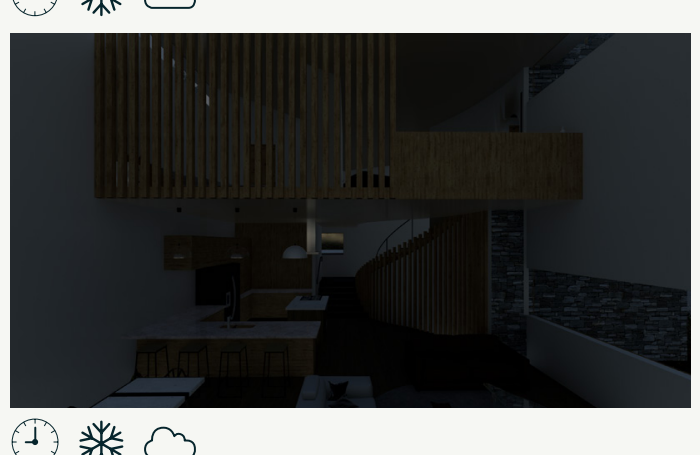

(4) 橉 Fig.83.Daylight renders of living room 

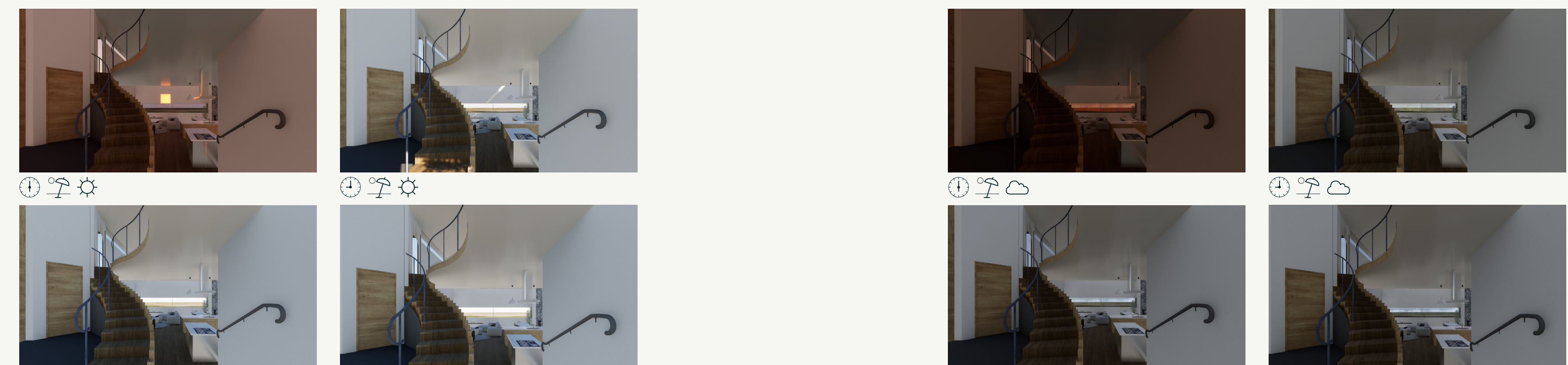

(1) 오
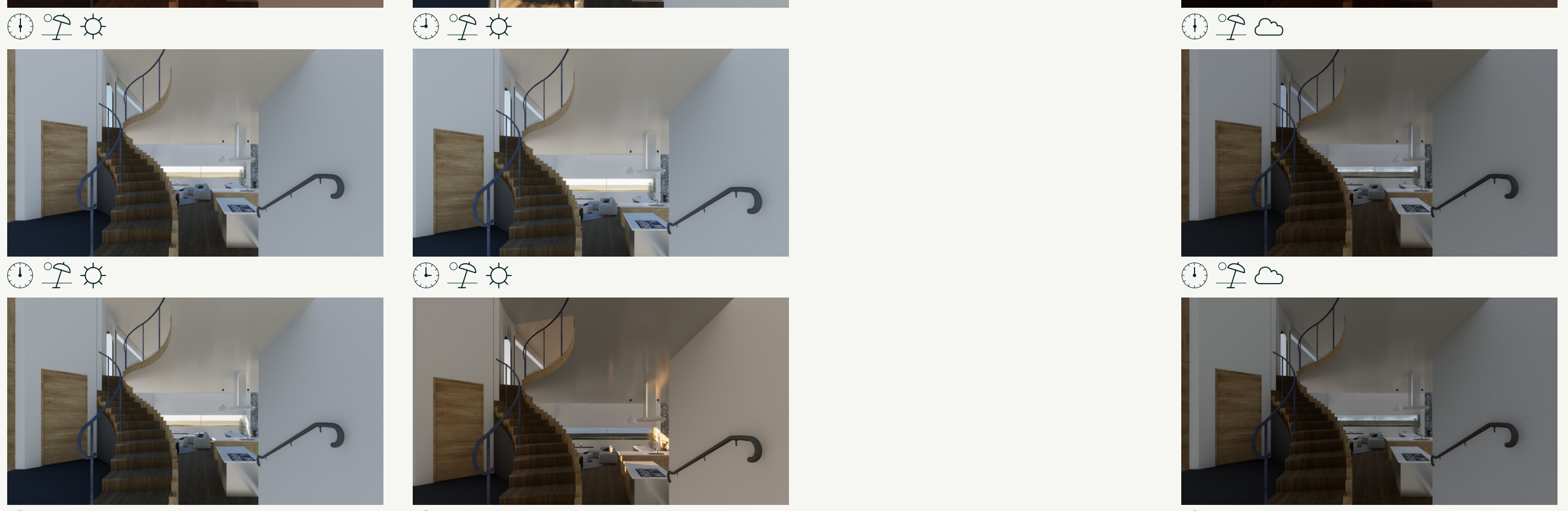

(1) 只果

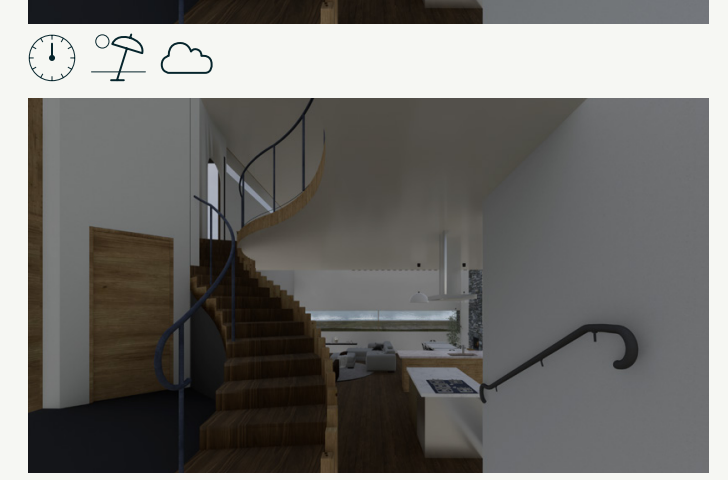

(1) 오요

(1) 오

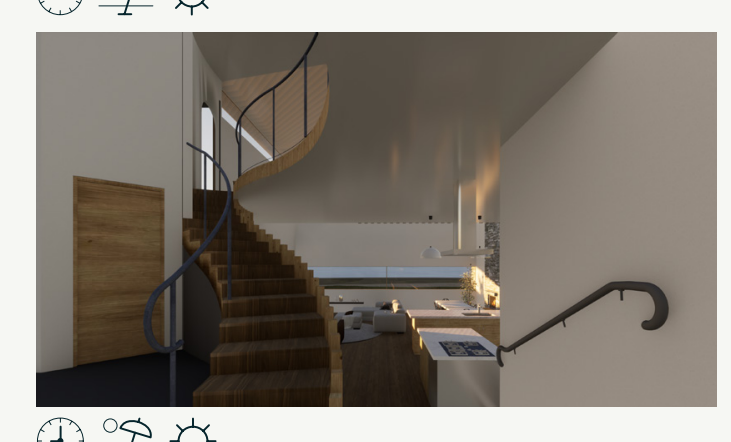

(1) 오 항

Fig.8.5.Dalight renders of entry

Figr.8.6Doylight renders of entry
(1) 오의

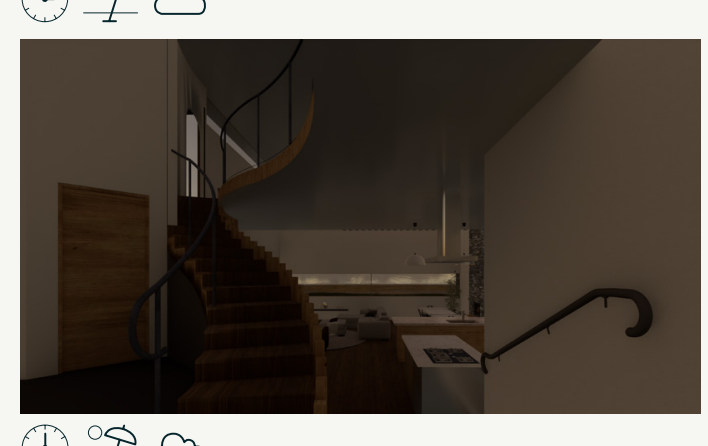

(1) 99

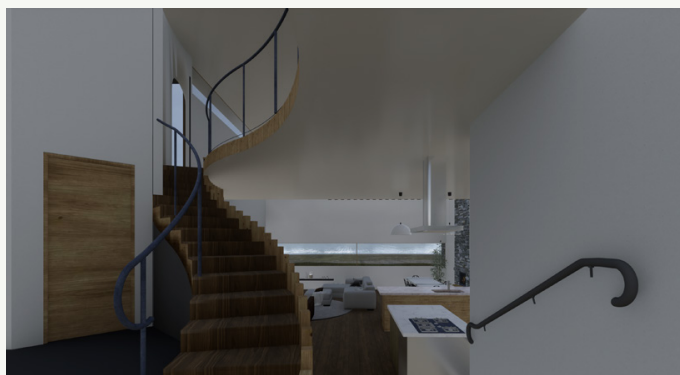



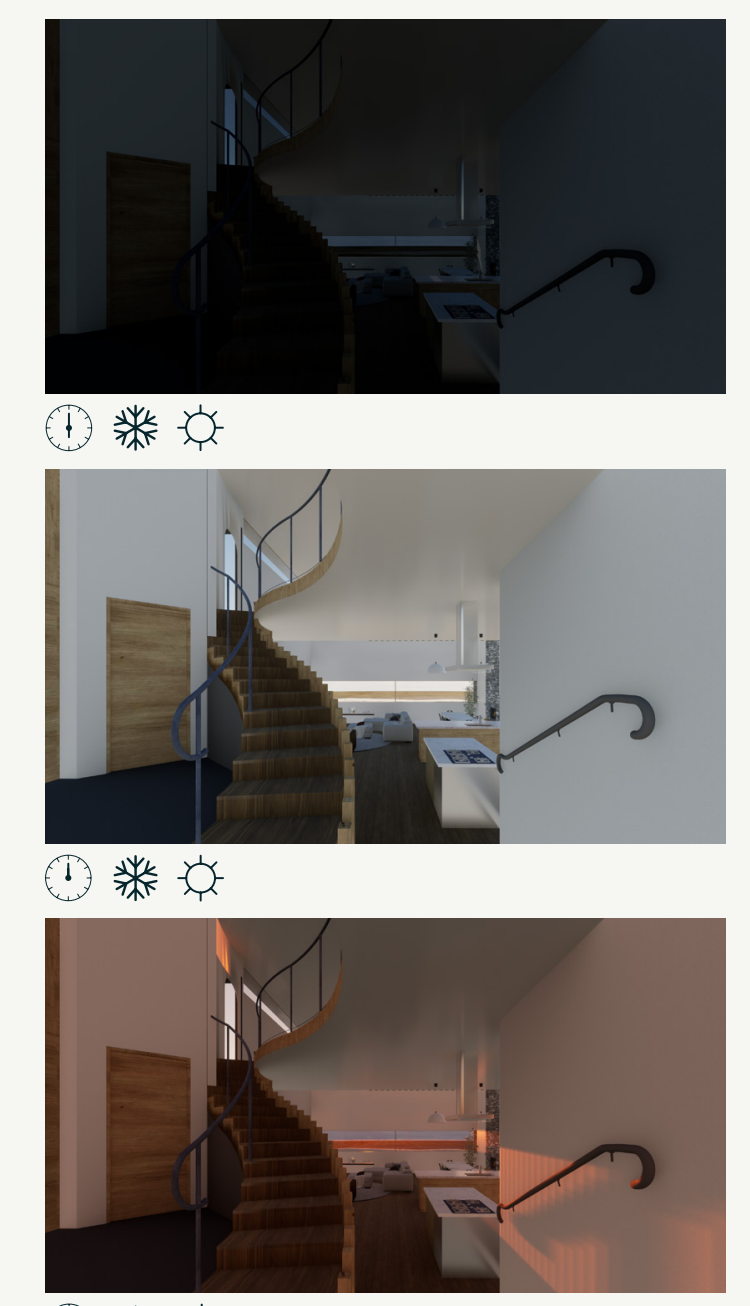

(1) 䊑

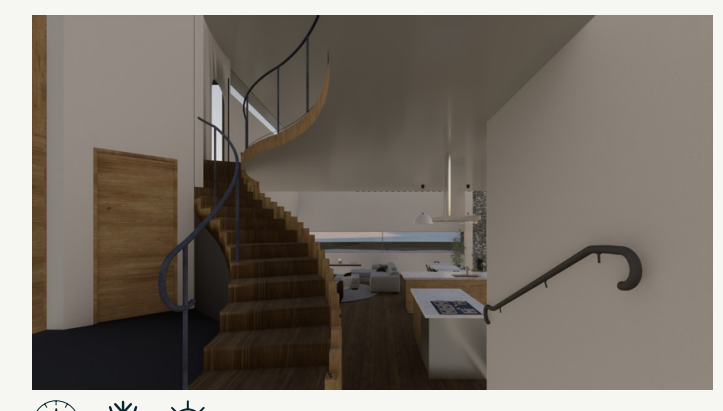

(4) 䊅
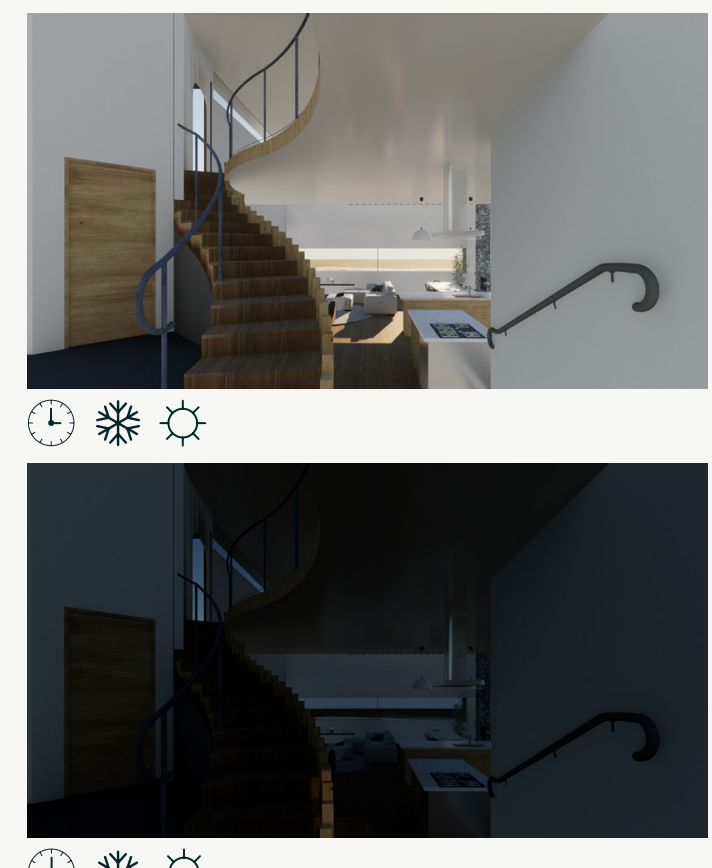

(9) 䊅

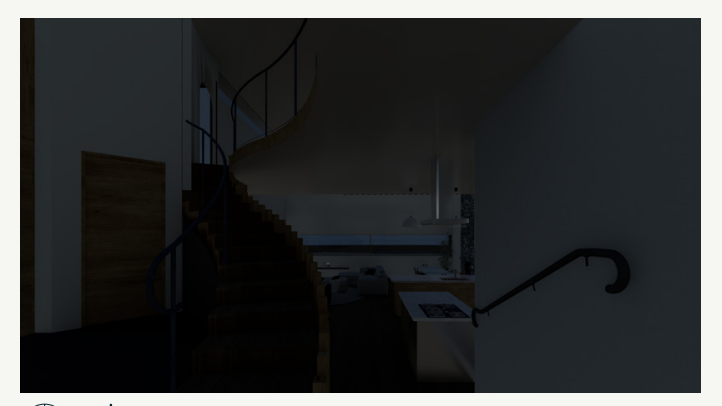

(1) 橉

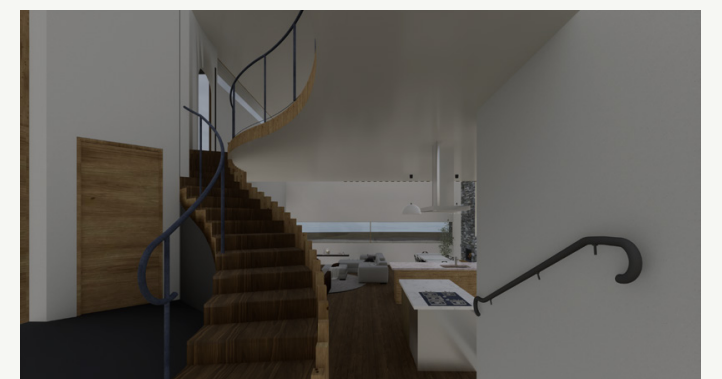

(1) 3

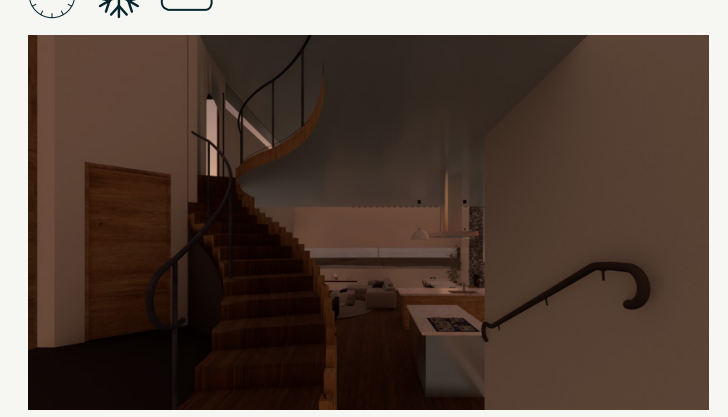

(1) 3

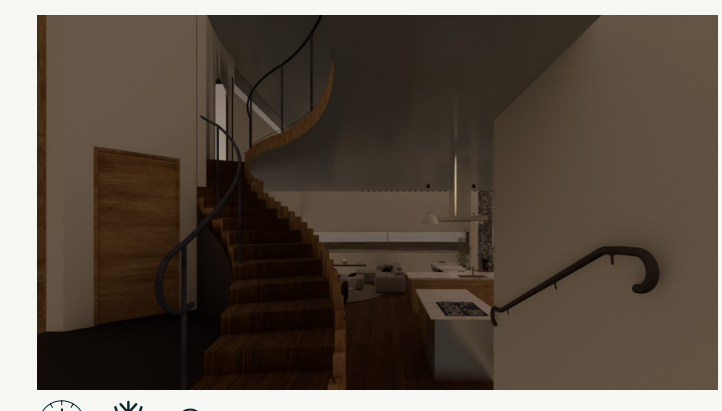

(1) 3

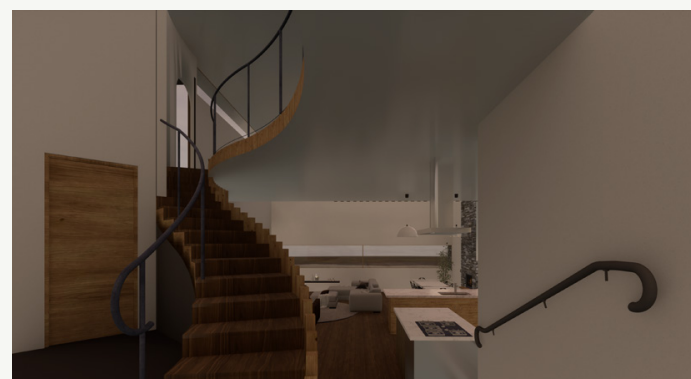

14 㭗 3

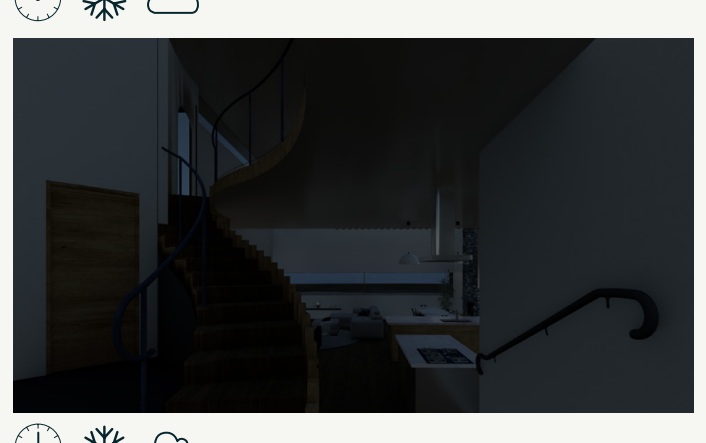

(1) 柴 Fig.87. Daylight renders of entry 

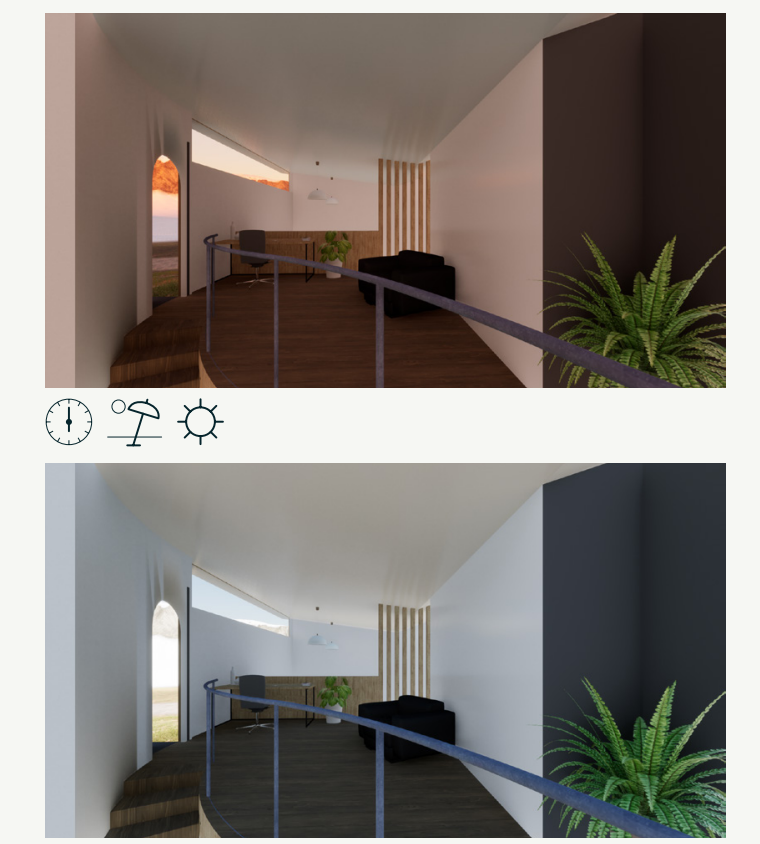

(1) 吅呚

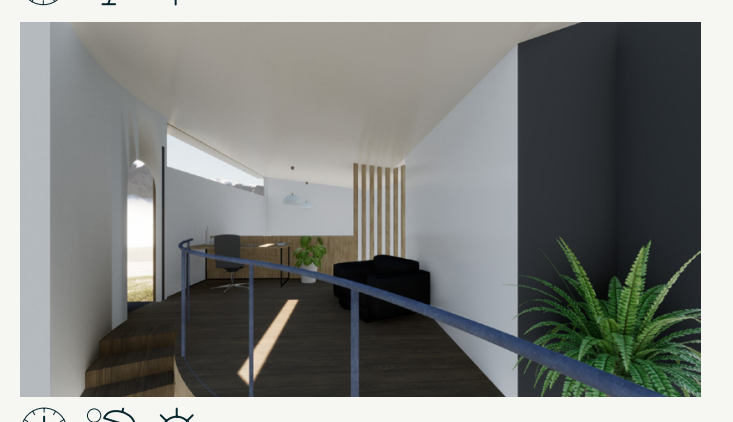

(1) 오

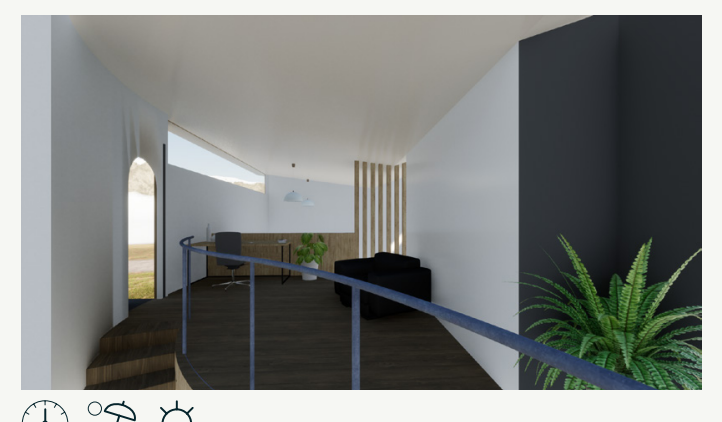

(4) 오엉

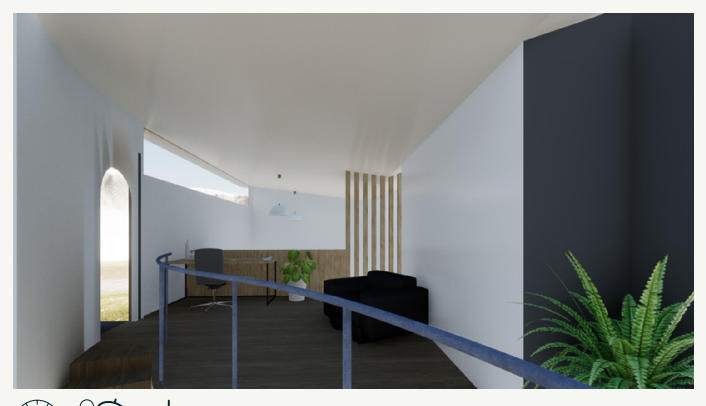

(1) 오엉

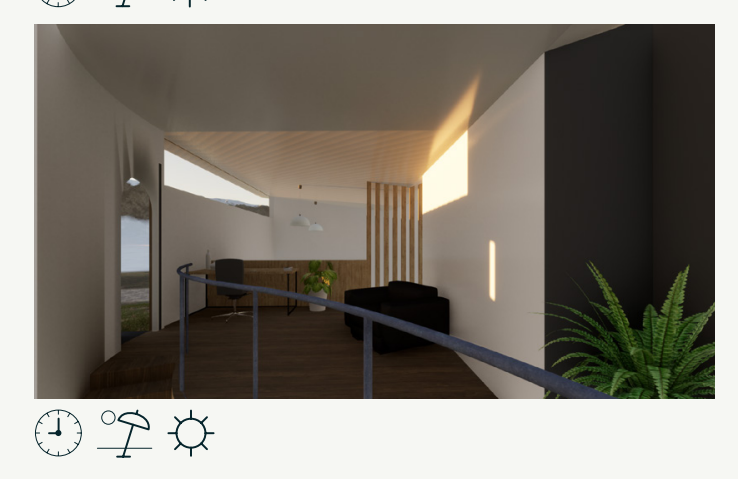

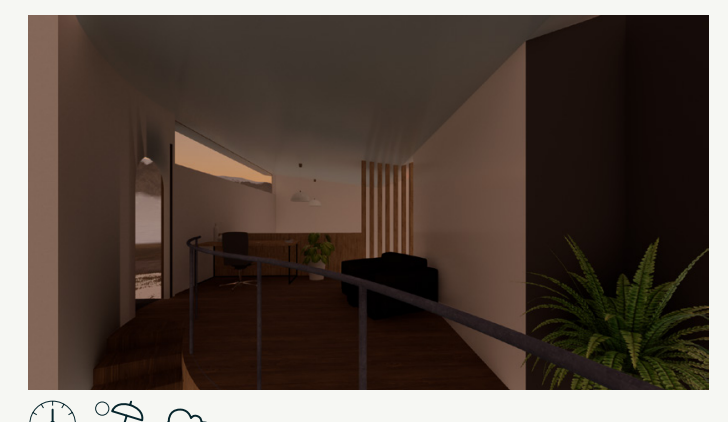

(1) 오의

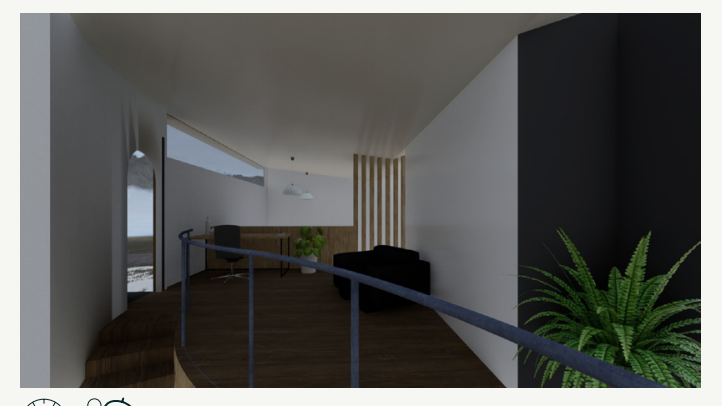

(1) 오의

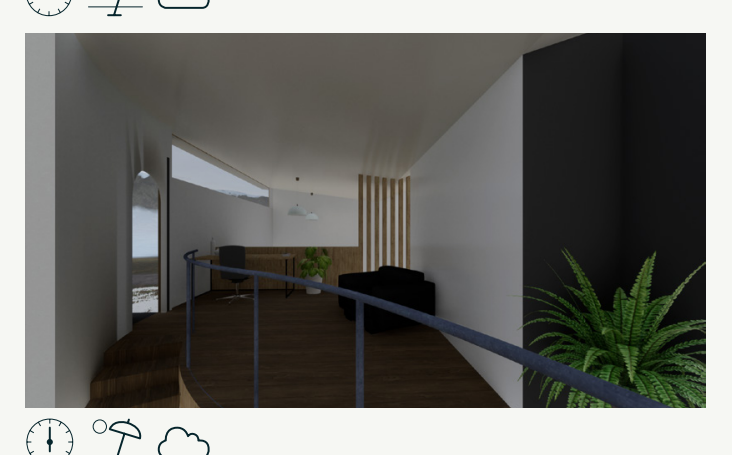

(1) 오의

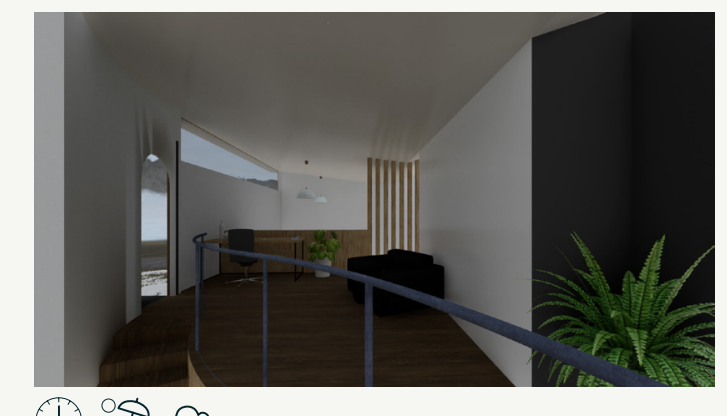

(4) 옹

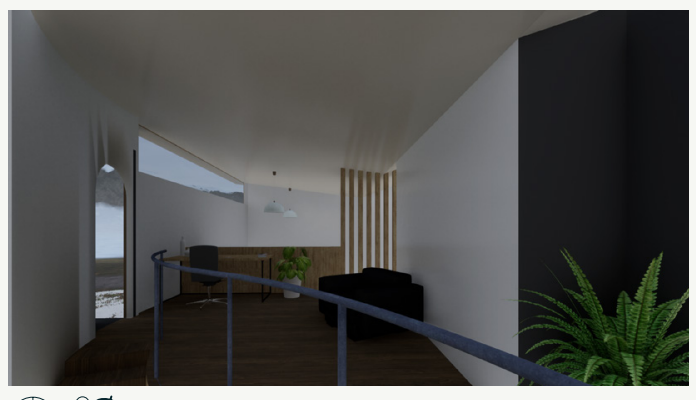

(1) 오의

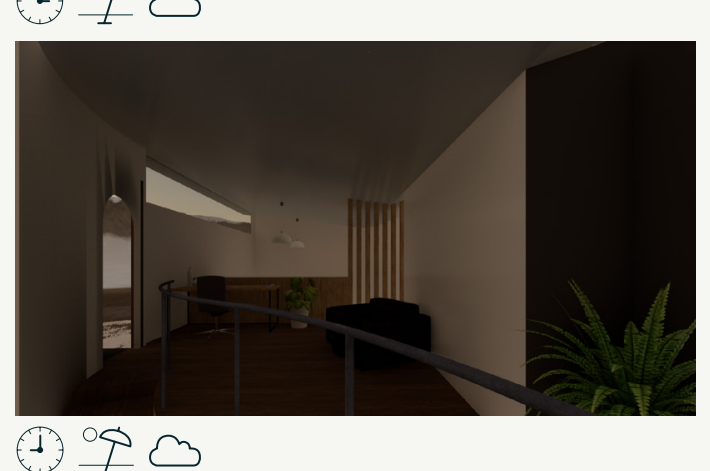

(1) 90 


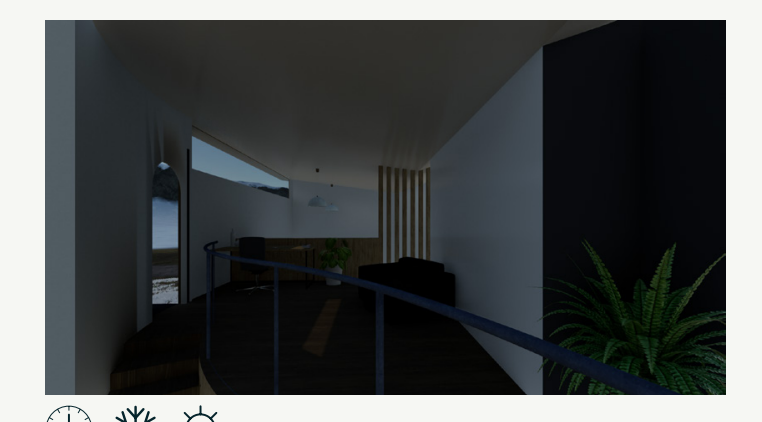

(1) 整识

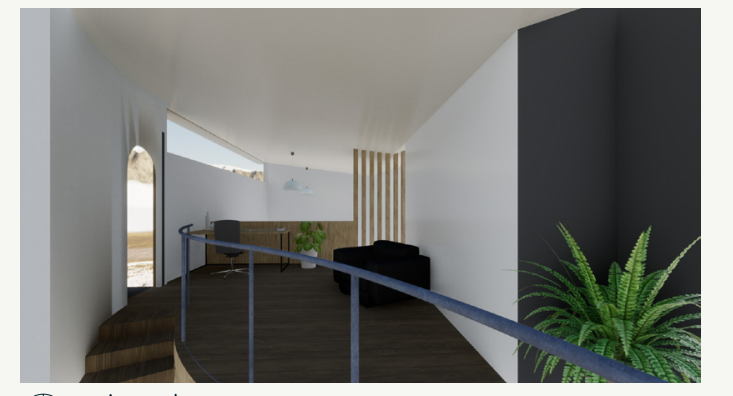

(1) 橉

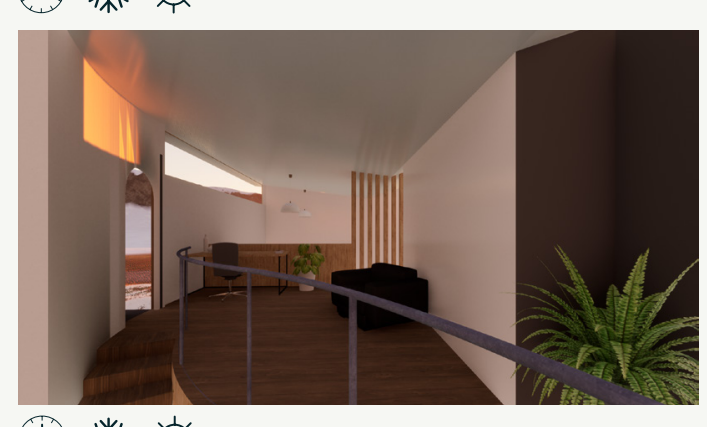

(1) 橉

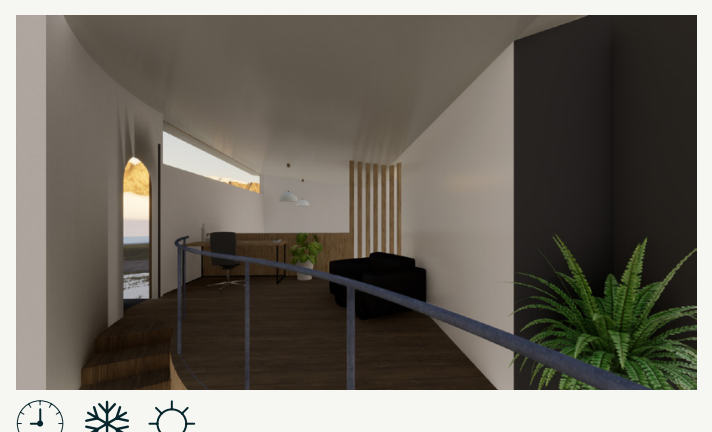

(1) 糔

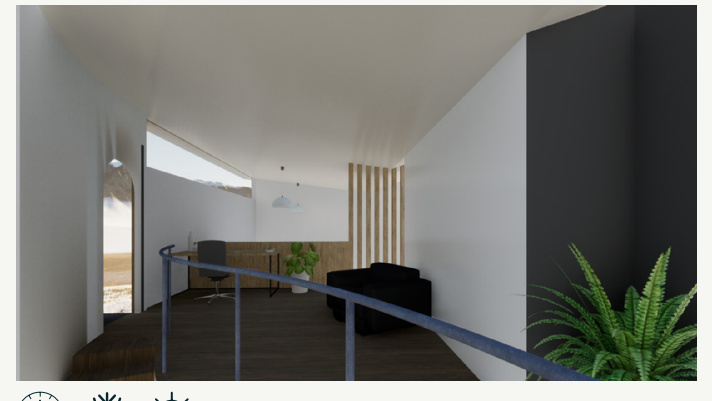

(1) 橉

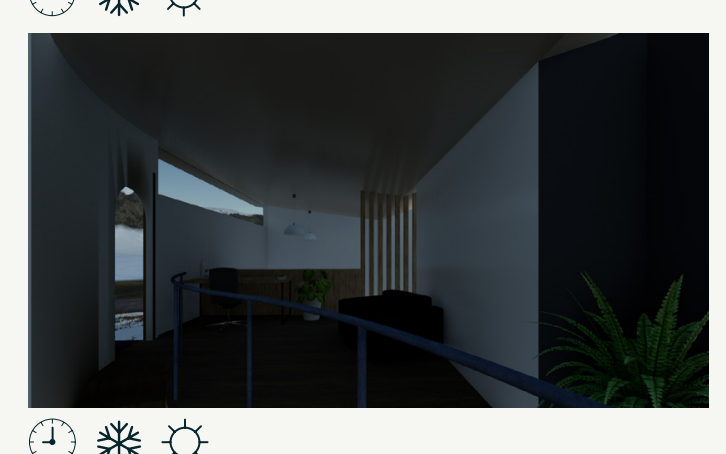

(9) 䊅

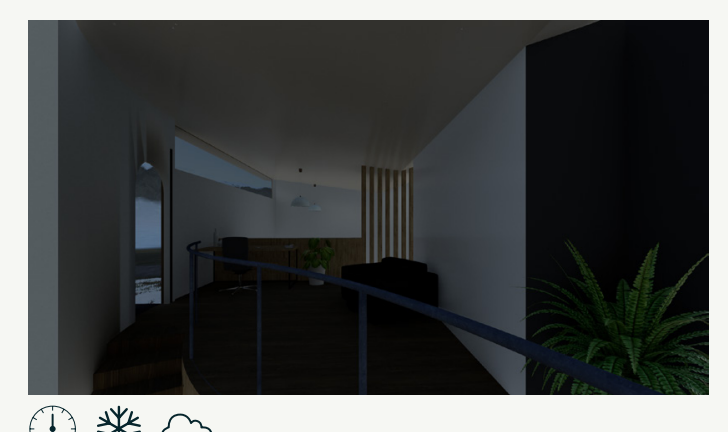

(1) 橉

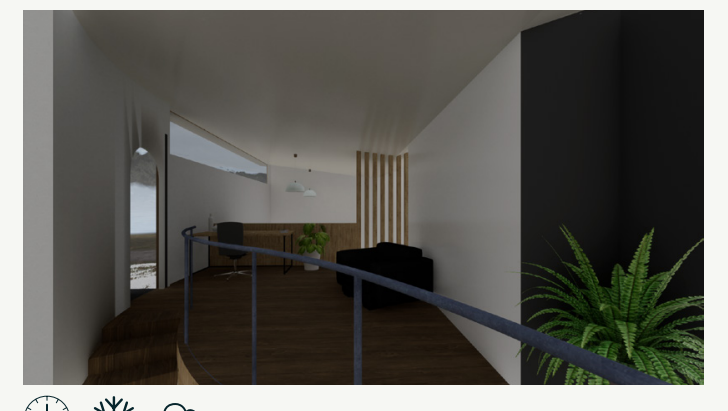

(1) 橉

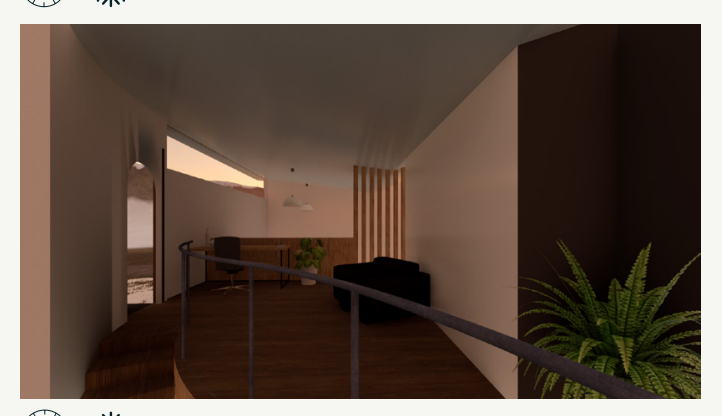

(1) 橉

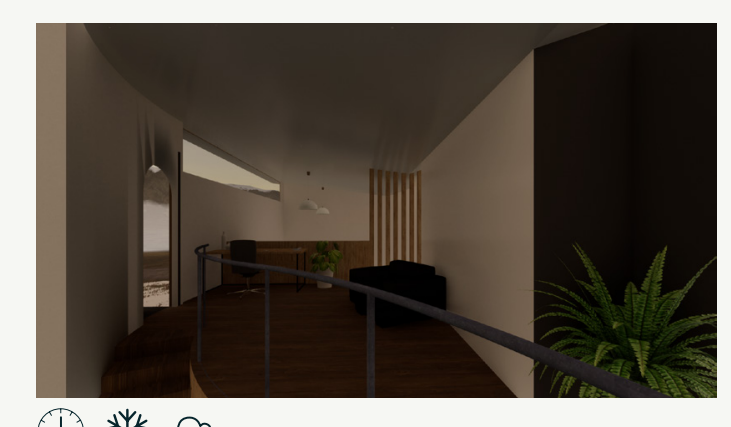

(4) 3

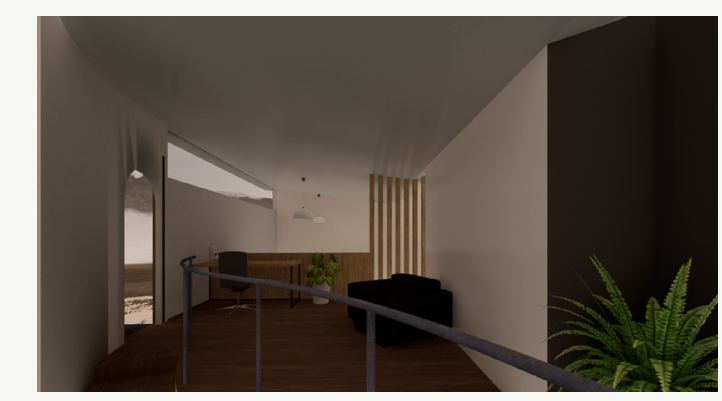

(1) 橉

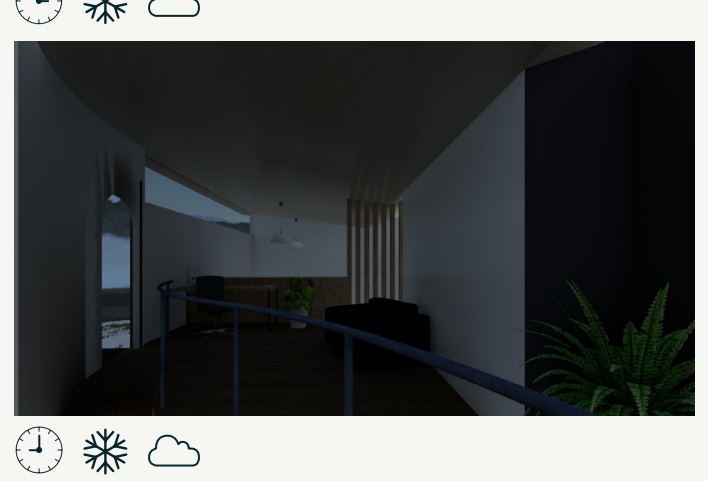

(1) 橉 


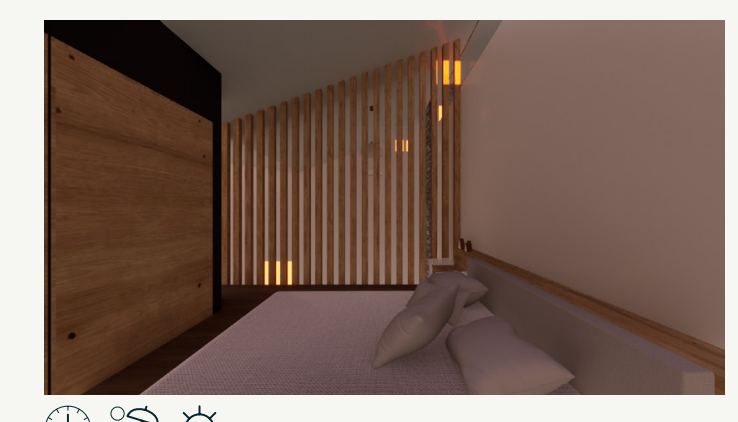

(1) 只谍

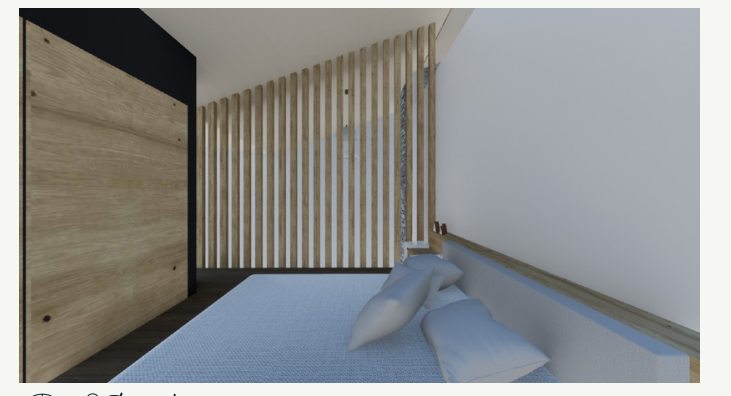

(b) 现

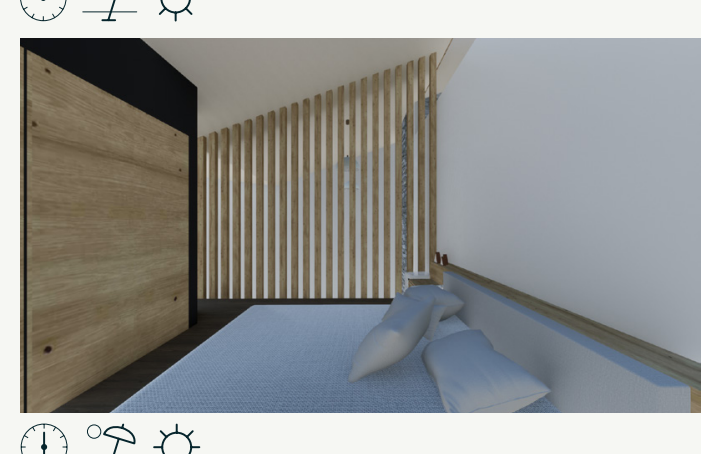

(1) 오

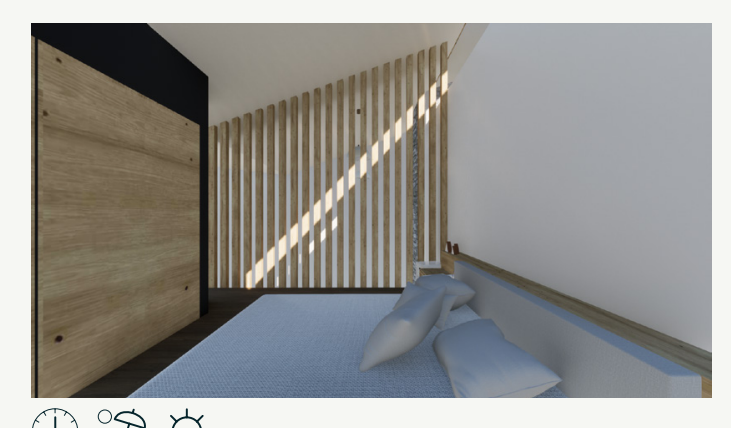

(4) 过

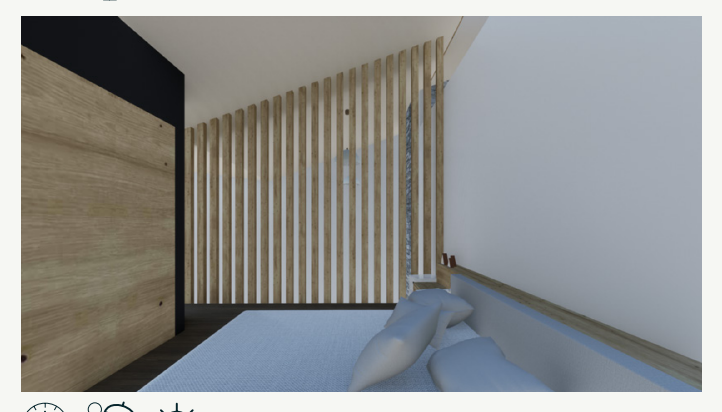

(1) 오엉

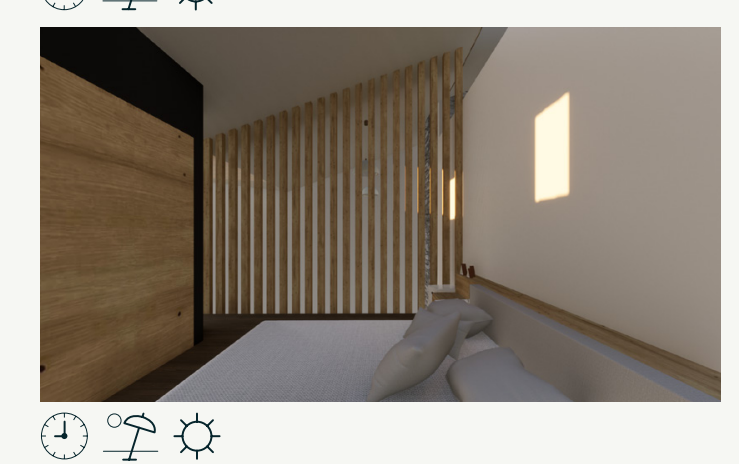

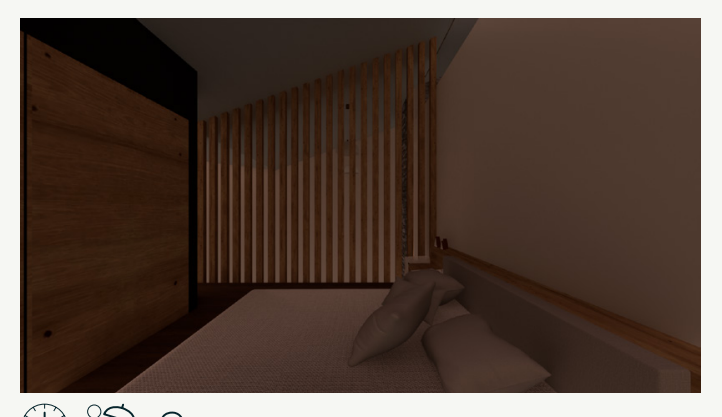

(1) 听

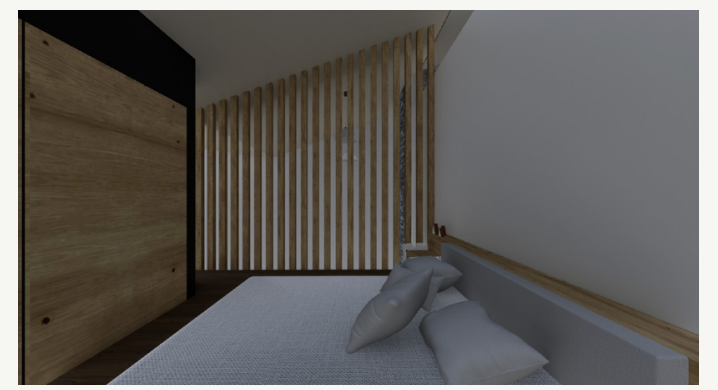

(1) 听

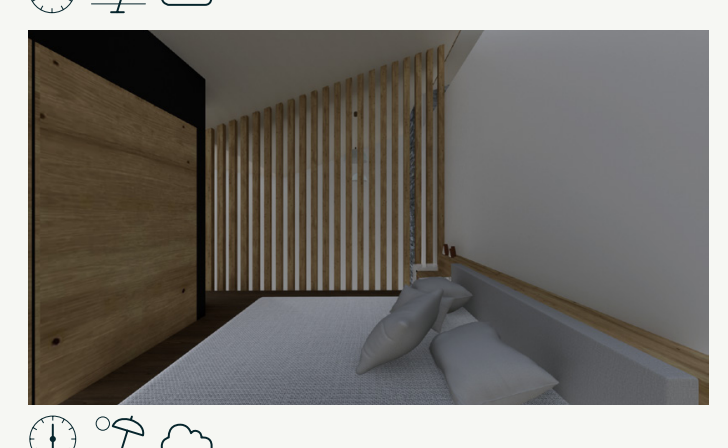

(1) 오의

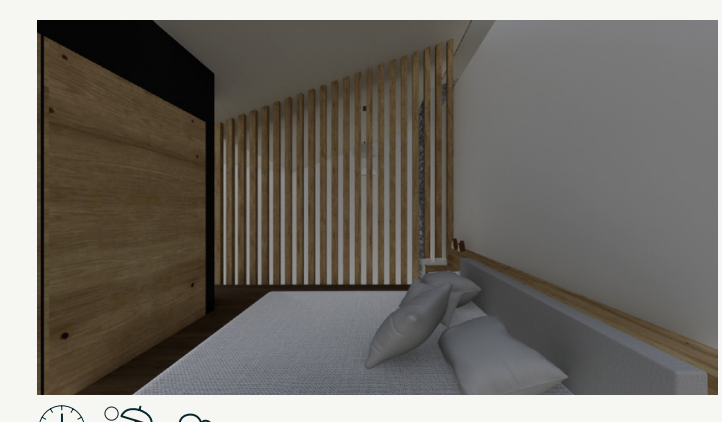

(4) 近 3

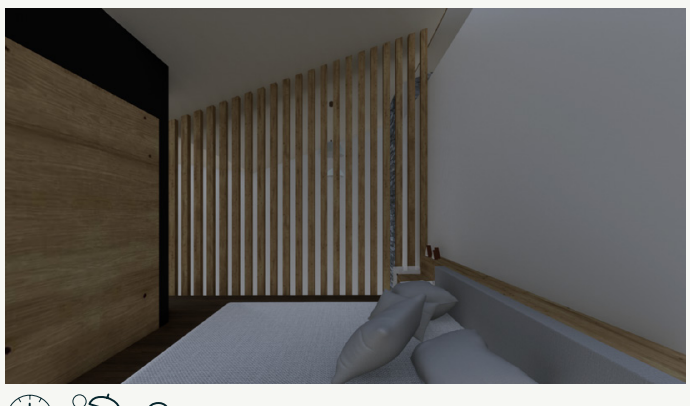

(1) 오의

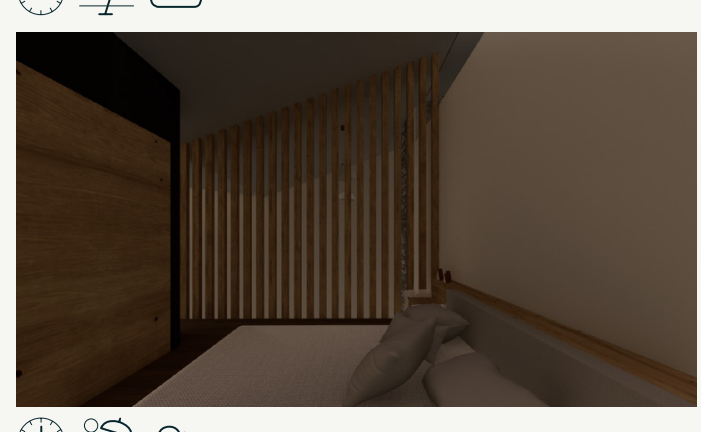

(3) 听 Fig.8.14.Daylight renders of mezzanine 

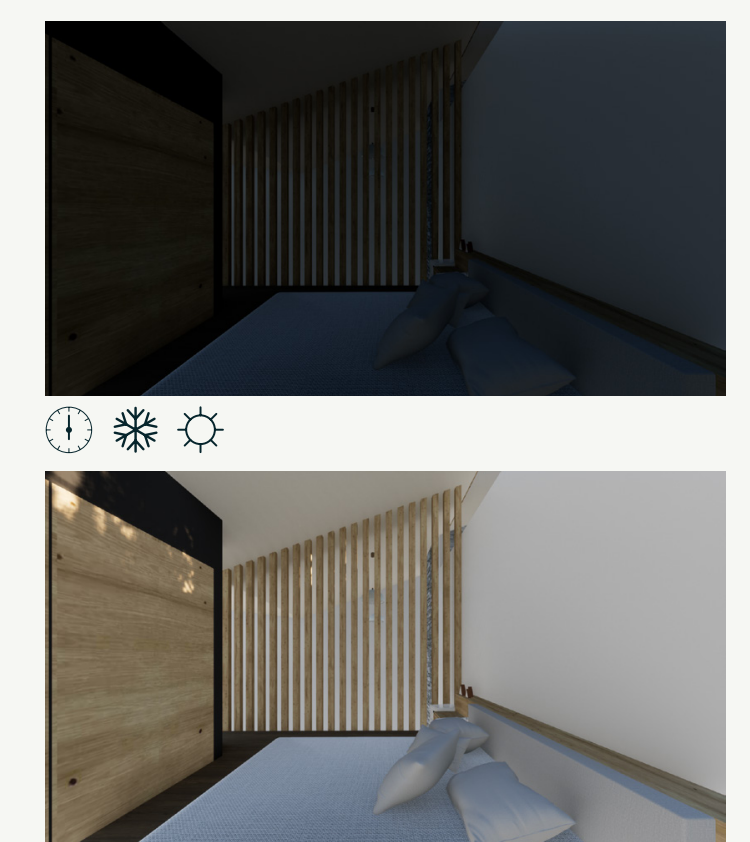

(1) 整

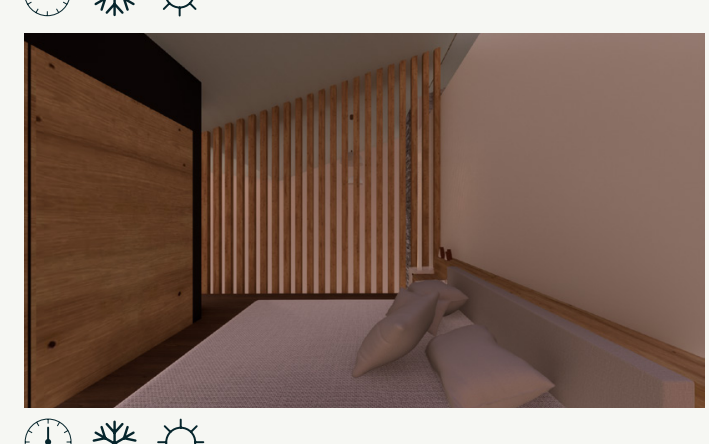

(1) 橉

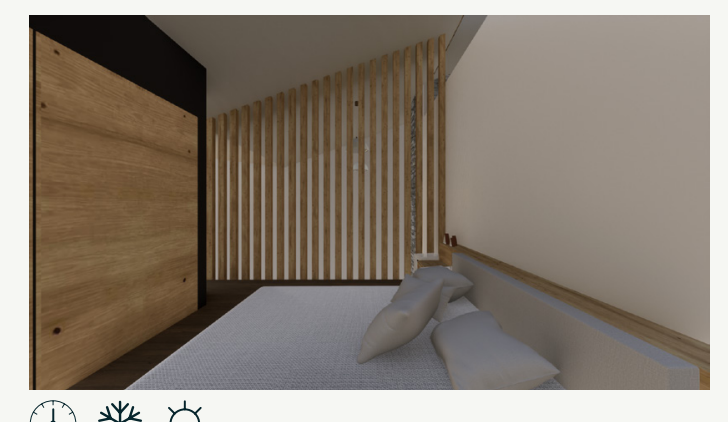

(1) 橉

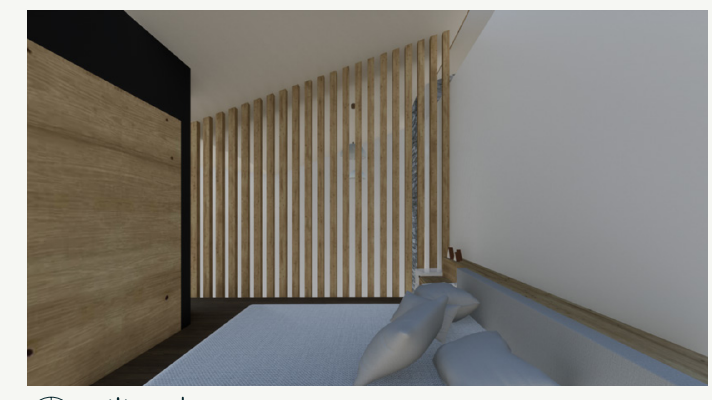

(1) 䅈

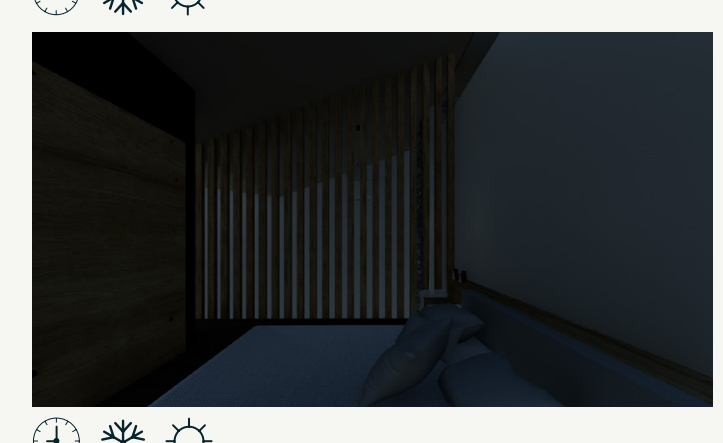

(1) 糔

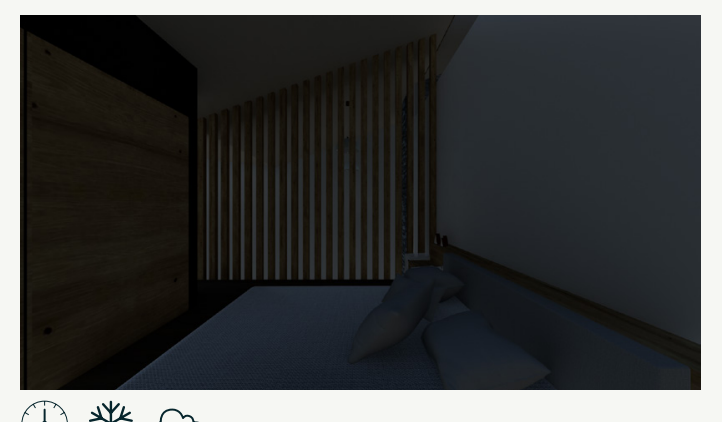

(1) 橉

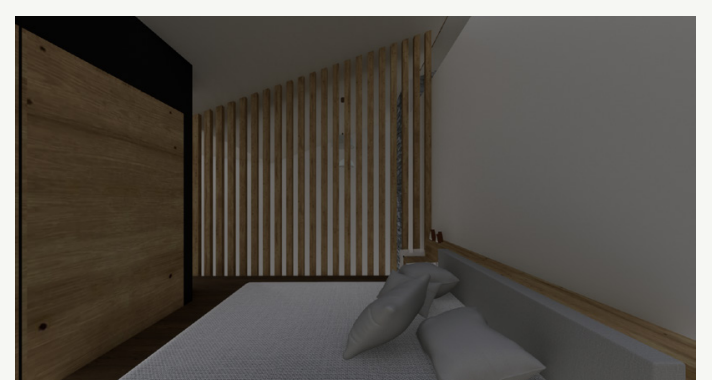

(1) 橉 3

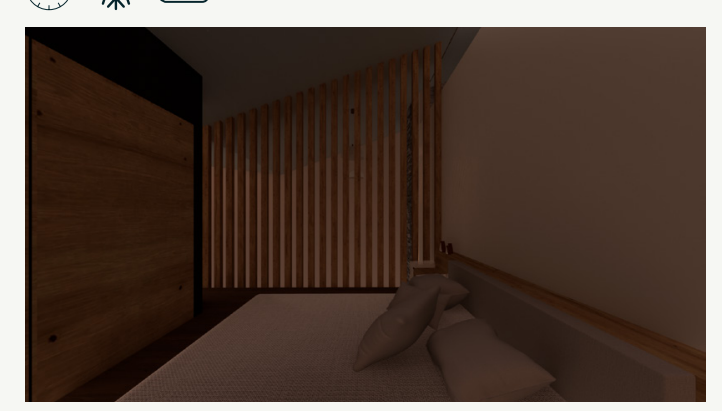

(1) 橉 3

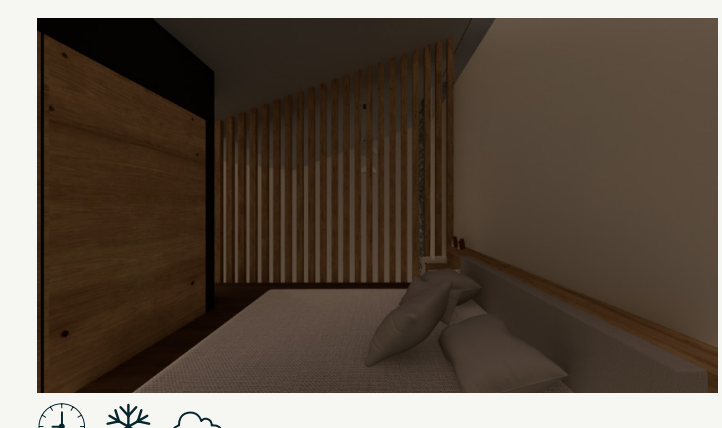

(4) 3

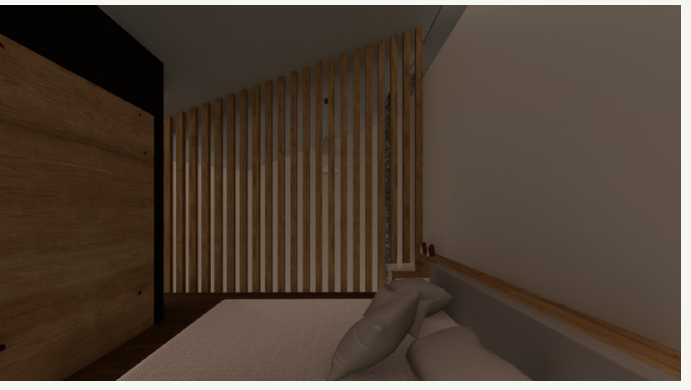

(1) 橉 3

Fig.8.15.Daylight renders of bedroom

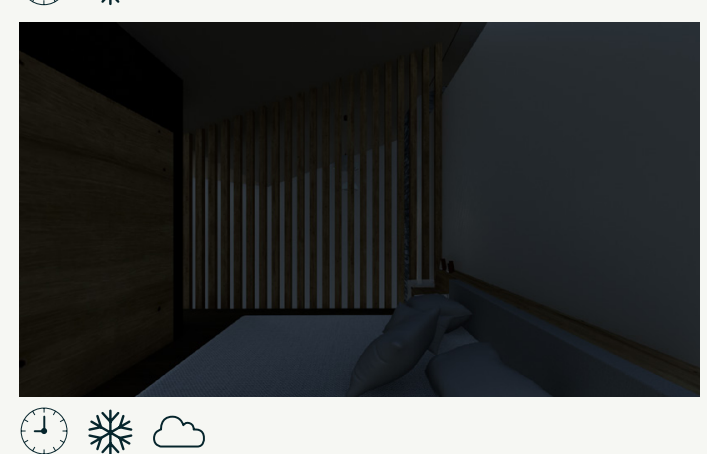




\subsubsection{Findings}

- Ribbon windows were more effective and translating

the view to the landscape than conventional windows.

Modernist attitudes towards the relationship between the interior and the exterior are therefore still relevant to achieving the poetic desires of contemporary residential architecture in New Zealand.

- Twinmotion successfully offered the ability to assess the effect of weather conditions on the lighting of the space.

- Iteration 7 provided adequate lighting to most spaces in overcast weather, as well as in sunlight as assessed in section 7.11. The addition of a skylight would likely add sufficient lighting to areas such as the mezzanine which were slightly

too dark during overcast weather.

- Ribbon windows had the effect of creating dynamic lighting conditions, enhanced by the tectonic elements of the space.

Dynamic lighting creates patterns caused by nature that change through the day and year, and therefore reduces the need for larger windows by incorporating aspects of the natura

environment into the architecture itself (Browning et al., 2014). This demonstrates that poetic design techniques can effectively be utilised to reduce glass usage.

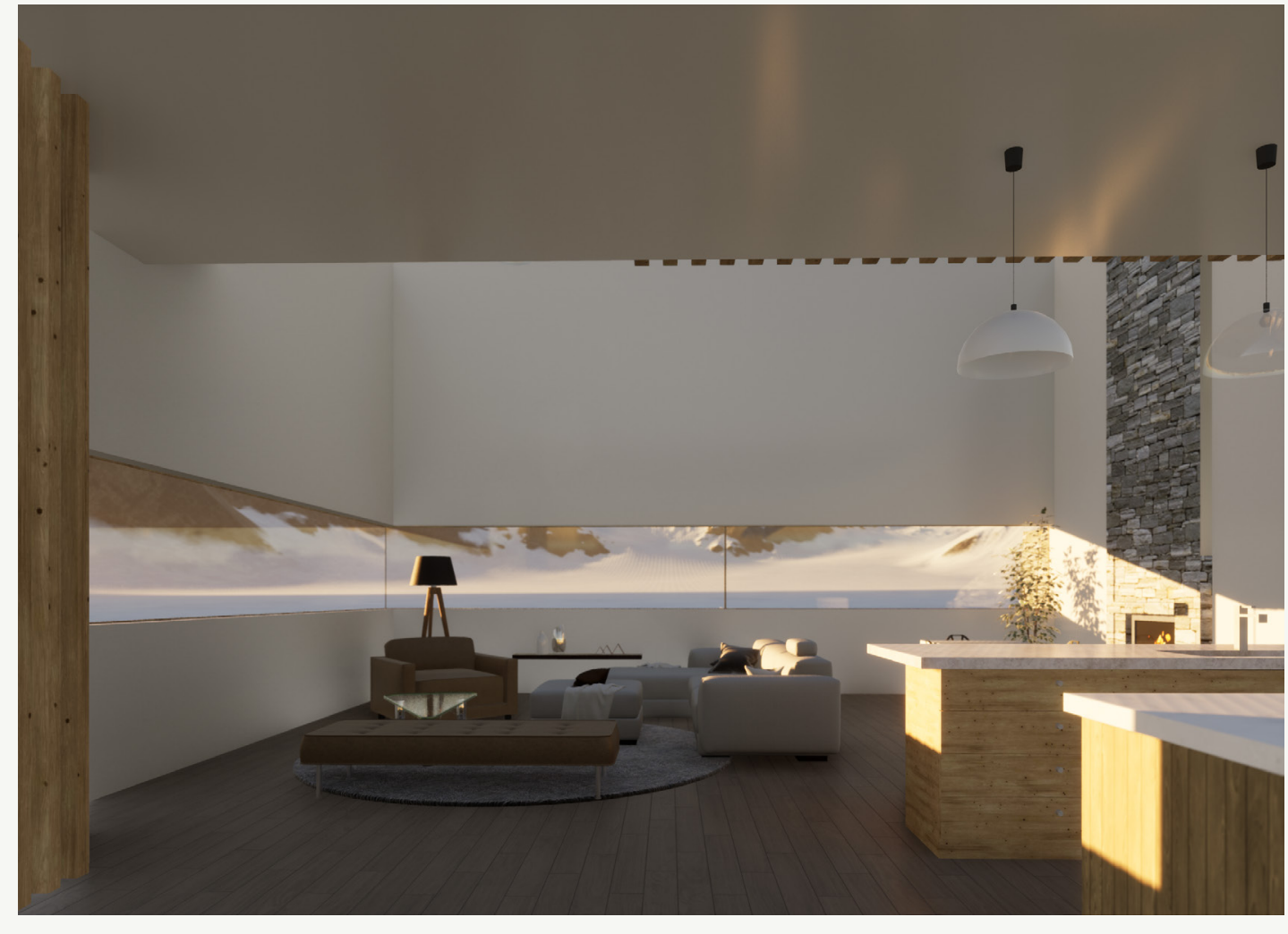

Fig.8.17. Interior vender of ribbon window and clerestory combination 


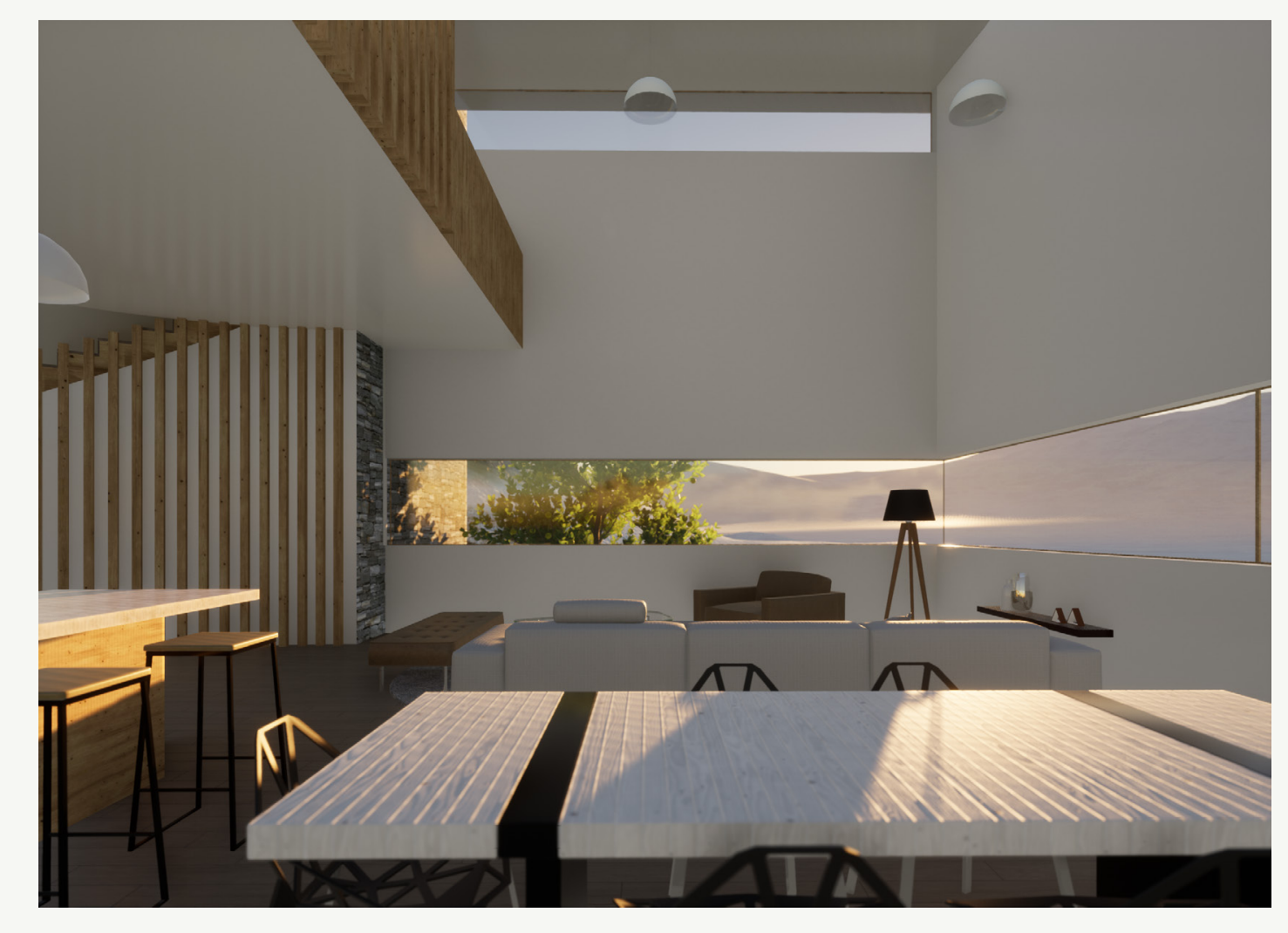

Fig.818. Interior render of ribbon window and clerestory combination 


\subsection{CRITICAL} REFLECTION

1. A combination of ribbon

windows and clerestories were most successful at reducing the amount of glass required while providing adequate lighting conditions assessed both scientifically and poetically.

2. Modernist attitudes towards glazing in contemporary residential architecture in New Zealand are still relevant today for achieving the poetic qualities of space found in award-winning dwellings, while restricted glazing ratios to less that $15 \%$ of the floor area.

3. A $15 \%$ floor area ratio is achievable in terms of its ability to provide adequate lighting conditions for an architecturally designed dwelling, and designers aspiring to create more sustainable houses should strive to achieve this ratio.

4. Selection of software is important for designers to analyse lighting conditions both poetically and scientifically to solve sustainability issues, and designers should not limit their analysis to one software package. LightStanza and Twinmotion were useful to quickly and efficiently analyse the many design iterations in terms of their daylighting, however LightStanza did not offer the ability to assess the effects of different weather conditions on the scientific daylighting analysis. To further confirm the results of this study lighting analysis using different software packages should be undertaken to better understand the integration of poetic and scientific daylighting effects and provide more accurate results.

5. Scientific analysis of daylighting does not adequately assess the poetic qualities of the space. While LightStanza provided lux level data to determine the success of the design by fitting within a quantifiable criteria, it did not offer the ability to understand poetic lighting conditions created through the materials, colours, tectonic structures and biomorphic forms of the building. These aspects can all contribute to reducing the glazing required to transmit the view of the landscape successfully into the interior of the dwelling by integrating site elements using different methods. Such aspects can only be understood using poetic analyses techniques and software such as in section 7.12 . 


\section{CONCLUSION}

\subsection{CONTRIBUTIONS TO DESIGN \\ RESEARCH}

This work contributed to a broad range of efforts to help combat sustainability issues in the construction industry. The specific focus was the global sand crisis, which appears to be more neglected in literature than other aspects of climate change issues, especially carbon emissions. The global sand crisis and the construction industry's reliance on materials manufactured from sand is a significant

contributing factor to unsustainable approaches to overexploitation of the planet.

This research contributes to increasing recognition of the importance to undertake research necessary to better understand

this gap in knowledge, and makes effort to contribute to addressing it. To date, most academic work related to sustainability appears focused on scientific knowledge and technological solutions, which does not adequately recognise the importance of the poetic aspects of architecture as a possible contributing factor to transitioning to a more sustainable future in the construction industry. In order to engage with this context, this thesis asked the question: Can poetic and scientific design processes be combined to produce more successful architectural outcomes for solving sustainability issues such as the global sand crisis?

Because of lack of recognition of this issue, methodologically, the work presents a reasonably pioneerings set of experiments to tackle this problem. A glazing analysis of case studies in Chapter 3 found that of award-winning houses in New Zealand, the majority had very high glass quantities compared to their passive house and standardspecification house counterparts. The results of this study suggest that there is a true gap between achieving the poetic aspects of dealised residential architecture and sufficiently sustainable dwellings. Moreover, it shows that perhaps desire to design poetically rather than pragmatically limits the ability create sustainable architecture. This finding presented a challenge: it called for investigation of how designers can utilise poetic

design processes to create more sustainable future with less glass for New Zealand residentia architecture.
For much of the analyses, the research split the role of glass in New Zealand residential architecture into two components: the need to provide adequate daylighting, and its ability to convey the country's most heroed possession: the landscape. Poetic design processes investigated in Chapter 6 resulted in an understanding of how nature can inform the architecture to reduce the reliance New Zealand residential architecture currently places on the view, which only windows can translate, and glass is the best material for these. Meanwhile, scientific aspects of the design explored in Chapter 7 showed how pragmatic design approaches could inform the space's poetic qualities by analysing daylighting through glazing positioning. Combining the two methods resulted in a framework that offered design principles for designing with 
less glass to produce successful architectural outcomes in one are of the broad subject of sustainable construction.

Therefore, research through design showed that designing poetically and sustainably is achievable by following specific design processes. In particular, identifying natural environment features (that may be site-specific) can reduce the need for more extensive of glass to translate the view poetically to the space's interior (section 6.2). The design process found that applying textures and biomorphic forms to the design found through expressive design techniques could achieve this idea. Defining positive and negative space to create outdoor living space significantly reduced the need to transpire the view through glazing from the interior. Meanwhile, designating public and private space induced the poetic notion of delivering more intimate space that required less glazing. Additionally, challenging the traditional house concept, where walls divide standard rooms, allowed for removing programmatic elements from the design. This resulted in forms that

focused on translating the view and provide sufficient daylight, as we as a reduction in the glazing levels required to translate that view.

\subsection{LIMITATIONS \& OPPORTUNITIES $F O R \quad F \cup R T H E R$ RESEARCH}

Initial research presented the issue of limited scholarship relating to solving sustainability problems through poetic means. The wide scope of this issue was made possible to explore in this thesis through the narrow context of how contemporary residential architecture in New Zealand can contribute to reducing the construction industry's impact on the global sand shortage. While a commercial scale building brief may have contributed to greater reduction of glass, it would have restricted the ability to understand the poetic nature of architecture in

ew Zealand and its relationship to the landscape, which is heightened through residential buildings.

Further research identifying the context of the problem on a commercial scale is needed to fully understand the implications for reducing glass in the construction industry; research which could not be undertaken as part of a Master's thesis.

More analytical work to determine in greater detail the role of glass in
New Zealand architecture is need such as in Chapter 3, which could not be undertaken during Master's thesis. A larger sample size of case studies could have produced different findings if time allowed for a more extensive investigation.

Furthermore, a major aspec of poetic design in residential architecture is its impact on the inhabitants of the space, which may differ from person to person.

For example, reduced use of glass could identify more claustrophobic responses in the space, and subjective sense of lack of light. Studies involving people could help understand how much these issues are prevalent and how to resolve them, which would contribute to the poetic development of the design.

Another limitation is the software used to provide scientific results of 
the effect of reducing glass in the building. While LightStanza and

Twinmotion provided adequate results and gave the ability to compare iterative designs, results should be verified by using more than one software simulation system.

The research could be benefitted by further integration of poetic design techniques and daylighting analysis through a final design iteration that attempts to merge the poetic and scientific findings from Chapters 6 and 7 more effectively. In addition, testing of the design in an urban

context would contribute to solving the issue for a more pragmatic context.

Overall, this thesis that there are real challenges facing designers who aspire to design both poetically and sustainably. The design framework details design principles and techniques that could be employed by designers wishing to reduce the reliance on glass that is so often found in New Zealand's successful architecture. Unfortunately, in addition to the issues with sand discussed here, the construction industry is one of the largest contributors to many other environmental issues also. This thesis identified the possibilities of utilising poetic design processes alongside scientific analyses to design more sustainably. These techniques could therefore be applied to other aspects of

sustainability in the building industry in future research. 


\section{LIST OF ILLUSTRATIONS}

\section{All figures not attributed are author's own}

Fig.1. Hardy, 2017, unsplash.com/photos/PP8Escz15d8

Fig.2. Corso, 2019, unsplash.com/photos/zIUIM_lyTNE

Fig.3. Heck et al., 2020, science.sciencemag.org/content/367/6478/638.4

Fig.4. Reynolds, 2018, archdaily.com/922306/lindis-lodge-architecture-workshop.

Fig.5. Cheshire Architects. 2019, https://www.nzia.co.nz/awards/local/ award-detail/8319

Fig.1.1. De Cactus, 2020, unsplash.com/photos/TObdTU0kO_U)

Fig.1.4. Author's graph, data from Schandl et al., 2018

Fig.1.5. Author's graph, data from Schandl et al., 2018

Fig.1.6. Author's graph, data from Schandl et al., 2018

Fig.2.1 Olsen, 2018, https://unsplash.com/photos/Gs1mJmK2ixc

Fig.2.2. Jolley, 2020, unsplash.com/photos/duRvSyVp2jA/info)

Fig.2.3. Author's graph, data from Miatto et al., 2017

Fig.2.5. Welland, 2010
Fig.2.6. Reed, 2017, http://www.rachelclarareed.com/

Fig.2.7. Zapata, 2020, stuff.co.nz/environment/climate-news/122231911/ street-of-port-waikato-houses-could-be-washed-away-in-decadeserosion-map-predicts

Fig.2.8. Xinhua, 2017, thejbsgroup78. medium.com/sand-mining-part-2-thestory-of-a-conflict-mineral-f8efc676b40

Fig.3.1. Wilson, 2017, fearonhay.com/alpine-terrace-house

Fig.3.2. Myrabella, 2011, en.wikipedia.org/wiki/Hall_of_Mirrors

Fig3.3. Loudon, n.d., commons.wikimedia.org/wiki/File:Greenhouse_John Claudius_Loudon_1818.png

Fig.3.4. United Nations, 2005, flickr.com/photos/un_photo/5812674972; Boucher, 1971, domusweb.it/en/buildings/farnsworth-house.html

Fig.3.5. Stoller, n.d., news.getty.edu/seagram-phyllis-lambert.htm; Eames, n.d., news.wfsu.org/2019-08-05/charles-and-ray-eames-made-lifebetter-by-design-their-home-was-no-exception

Fig.3.8. Meiring, 2010, herbstarchitects.co.nz/projects/timms-bach

Fig.3.9. Herbst, 2016, herbstarchitects.co.nz/projects/k-valley-house

Fig.3.10. Scowan, 2018, daa.co.nz/projects/st-marks-lane/

Fig.3.11. Reynolds, 2008, fearonhay.com/mountain-retreat)

Fig.3.12. Warren \& Mahoney, 2014, warrenandmahoney.com/portfolio/ closeburn-station-house

Fig.3.13. Devitt, 2018, eliskalewisarchitects.com/black-peak-house 
Fig.3.15. Wilson (2017) fearonhay.com/alpine-terrace-house

Fig.3.16. Reynolds (2018) architectureworkshop.co.nz/projects/ahuriri-valley-lindis-lodge-ahuriri-valley/

Fig.4.1. Reynolds (2008) fearonhay.com/mountain-retreat

Fig.4.2. Meiring (2010) herbstarchitects.co.nz/projects/timms-bach

Fig.4.3. Devitt (2018) www.rafemaclean.co.nz/kowhai-house

Fig.4.7. Herbst (2016) herbstarchitects.co.nz/projects/k-valley-house

Fig.4.8. Wilson (2017) fearonhay.com/alpine-terrace-house

Fig.4.9. Devitt (2018) eliskalewisarchitects.com/black-peak-house

Fig.4.10. Reynolds (2018) architectureworkshop.co.nz/projects/ahuriri-valley-lindis-lodge-ahuriri-valley/

Fig.5.4. Reynolds, 2018 www.archdaily.com/922306/lindis-lodge-architecture-workshop

Fig.5.5. Left: Author's own, Right: Patrick (2020) unsplash.com/photos/ oC5OWF3XrxO

\section{BIBLIOGRAPHY}

Abdulali, Sumaira. 2018. 'Illegal Sand Mining and Sand Mafia in India'. Geneva, October 11. https://www.youtube.com/ watch?v=Tm9Dvpqr3KM

Alden, Andrew. 2017. 'About Sand'. Reference Site. ThoughtCo. (blog). 17 March 2017. https://www.thoughtco.com/all-about-sand-1441192.

Allen, Eric. 2017. 'See How Clerestory Windows Can Transform a Room'. Architectural Digest, 16 January 2017. https://www. architecturaldigest.com/gallery/clerestory-windows-transform-a-room.

Alter, Lloyd. 2019. 'All-Glass Buildings Are an Aesthetic, as Well as a Thermal Crime'. Treehugger (blog). 1 April 2019. https://www.

treehugger.com/green-architecture/all-glass-buildings-are-aesthetic-well-thermal-crime.html.

Architecture Workshop. 2019. 'Lindis Lodge | Ahuriri Valley'. Architecture Workshop (blog). 2019. https://architectureworkshop.co.nz/ projects/ahuriri-valley-lindis-lodge-ahuriri-valley/.

AtelierNL. n.d. 'The Abundance \& Scarcity of Sand Symposium'. Presented at the The Abundance and Scarcity of Sand, The Netherlands. https://ateliernl.com/lectures/the-abundance-and-scarcity-of-sand.

Awaaz Foundation, and Bombay Natural History Society. n.d. 'Application for Inclusion of Sand Mining in the Agenda of the Convention of Biodiversity, a New and Emerging Issue Relating to the Conservation and Sustainable Use of Biodiversity'. Convention on Biological Diversity. 
Barreneche, Raul A. 2006. Pacific Modern. Rizzoli.

Behrens, Arno, Stefan Giljum, Jan Kovanda, and Samuel Niza. 2007. 'The Material Basis of the Global Economy: Worldwide Patterns of Natural Resource Extraction and Their Implications for Sustainable Resource Use Policies'. Ecological Economies 64 (2): 444-53. https://doi.org/Elsevier.

Beiser, Vince. 2016. 'The World's Disappearing Sand'. The New York Times, 23 June 2016, New York Edition edition.

Beiser, Vince. 2017. 'Sand Mining: The Global Environmental Crisis You've Probably Never Heard of'. The Guardian, 27 February 2017, sec. Cities. https://www.theguardian.com/cities/2017/feb/27/sand-mining-global-environmental-crisis-never-heard.

Beiser, Vince. 2018. The World in a Grain: The Story of Sand \& How It Transformed Civilisation. Penguin.

Berglund, Lars, Qiliang Fu, Shun Yu, Min Yan, and Yuanyuan Li. 2016. 'Optically Transparent Wood from a Nanoporous Cellulosic Template: Combining Functional and Structural Performance' Biomacromolecules 17 (4): 1358-64.

BRANZ. 2013. 'Appropriate Lighting Levels'. Level: The Authority on Sustainable Building (blog). 30 November 2013. http://www.level. org.nz/energy/lighting-design/appropriate-lighting-levels/\#: :text=New\%20Zealand\%20Building\%20Code\%20clause, when\%20 the\%20room\%20is\%20inhabited.

Brower, Richard. 2000. 'To Reach a Star: The Creativity of Vincent van Gogh'. High Ability Studies 11 (2): 179-208.

Browning, William, Catherine Ryan, and Joseph Clancy. 2014a. '14 Patterns of Biophilic Design'. Terrapin Bright Green. http://www. terrapinbrightgreen.com/wp-content/uploads/2014/04/14-Patterns-of-Biophilic-Design-Terrapin-2014e.pdf.
Building Research Institute. 1957. Windows and Glass in the Exterior of Buildings. 478. Washington D.C.: National Academy of Sciences National Research Council.

Castro, Joseph. 2013. 'What Is Sand?' Live Science (blog). 28 May 2013. https://www.livescience.com/34748-what-is-sand-beach-sand.html

Chellaney, Brahma. 2019. 'We Have Truly Lost Our Way When Our Rivers Can No Longer Find the Oceans'. The National News, 20 May 2019.

Connolly, Peter, Maibritt Pedersen Zari, and Mark Southcombe. 2020. Ecologies Design: Transforming Architecture, Landscape and Urbanism. Routledge.

Constable, Harriet. 2017. 'How the Demand for Sand Is Killing Rivers'. BBC News, 2 September 2017. https://www.bbc.com/news/ magazine-41123284.

Değirmenci, Nurhayat, Arin Yilmaz, Peng Zhang, and Yuwei Ma. 2011. 'Effective Utilization of Waste Glass as Cementitious Powder and Construction Sand in Mortar'. Indian Journal of Engineering and Materials Science 18 (4): 303-8.

Delestrac, Denis. 2013. Sand Wars. Documentary. La Compagnie des Taxi-Brousse. https://www.cie-taxibrousse.com/en/film/ sand-wars-2/\#play.

Dumiak, Michael. 2019. 'Shortage of Sand May Slow Growth'. Engineering News-Record 283 (2): 8.

Elkadi, Hisham. 2006. Cultures of Glass Architecture. United Kingdom: Ashgate Publishing Ltd.

Filho, Gilberto M. Amado, Joel C. Creed, Leonardo R. Andrade, and Wofgang C. Pfeiffer. 2004. 'Metal Accumulation by Halodule Wrightii Populations'. Aquatic Botany 80 (4): 241-51. 
Fimrite, Peter. 2017. 'Ignoring State Threats, Firm Keeps Sucking Sand from Monterey Bay'. San Francisco Chronicle, 3 March 2017. https://www. sfchronicle.com/science/article/lgnoring-state-threats-firm-keepssucking-sand-10973856.php.

Fraser, Matthew W., Jessie Short, Gary Kendrick, Dianne McLean, John Keesing, Maria Byrne, M. Julian Caley, et al. 2017. 'Effects of Dredging on Critical Ecological Processes for Marine Invertebrates, Seagrasses and Macroalgae, and the Potential for Management with Environmental Windows Using Western Australia as a Case Study'. Ecological Indicators 78 (July): 229-42.

Freedonia. 2016. 'World Construction Aggregates: Industry Study with Forecasts for 2019 \& 2024'. Freedonia. https://www.freedoniagroup. com/industry-study/world-construction-aggregates-3389.htm.

Freestone, lan. 1991. 'Looking into Glass'. In Science and the Past, 37-55. University of Toronto Press.

Fumbuka, Caroline Ponsian. 2017. 'Sand Mining and Its Impact on Ecosystem Chance: A Conceptual Framework'. Delhi Business Review 18 (2): 59-73.

Gabbatiss, Josh. 2017. 'Sand Mafias and Vanishing Islands: How the World Is Dealing with the Global Sand Shortage'. The Independent, 6 December 2017. https://www.independent.co.uk/news/long_reads/ sand-shortage-world-how-deal-solve-issue-raw-materials-suppliesglass-electronics-concrete-production-a8093721.html.

Gavriletea, Marius Dan. n.d. 'Environmental Impacts of Sand Exploitation. Analysis of Sand Market'. Sustainability 9 (7): 1118.
Gifford. 2020. 'Creating a Sustainable Sand Industry Requires Greater Regulation - Here's Why'. World Finance, 15 April 2020. https:// www.worldfinance.com/featured/creating-a-sustainable-sand-industry-requires-greater-regulation-heres-why\#: :text=ln\%20 2004\%2C\%20when\%20work\%20began,cubic\%20metres\%20of\%20 sand\%20to.

Global Footprints Network. 2019. 'Past Earth Overshoot Days'. Earth Overshoot Day (blog). 2019. https://www.overshootday.org/about/.

Global Witness. 2010. 'Shifting Sand: How Singapore's Demand for Cambodian Sand Threatens Ecosystems and Undermines Good Governance'. London: Global Witness. https://www. globalwitness. org/en/archive/shifting-sand-how-singapores-demand-cambodian-sand-threatens-ecosystems-and-undermines-good/.

Gonzalez, Sarah. n.d. 'Peak Sand'.Mp3. Planet Money. https://www.npr.org/ sections/money/2018/07/13/628894815/episode-853-peak-sand.

Guzowski, Mary. 2018. The Art of Architectural Daylighting. 1st ed. London: Laurence King Publishing.

Haenecour, Pierre, Xuchao Zhao, Christine Floss, Yangting Lin, and Ernst Zinner. 2013. 'First Laboratory Observation of Silica Grains from Core Collapse Supernovae'. Astrophysical Journal Letters 768 (1) 1-5. https://doi.org/10.1088/2041-8205/768/1/L17.

Hall, Matthew. 2020. '6 Things You Need to Know about Sand Mining'. Mining Technology (blog). 7 May 2020. https://www. mining-technology.com/features/six-things-sand-mining/.

Hollingsworth, James. 2016. 'Glass Weight Calculator - How to Calculate the Weight of Glass'. Glass Domain (blog). 2016. https:// glassdomain.co.uk/blog/glass-weight-calculator/. 
Jones, Katy. 2018. 'The Future of Sand Mining in NZ'. Stuff.Co.Nz, 7 June 2018. https://www.stuff.co.nz/national/104065329/the-future-ofsand-mining-in-nz.

Kaltenbach, Frank. 2004. Transluscent Materials. Detail Praxis. Munich Birkhauser.

Kharas, Homi. 2010. 'The Emerging Middle Class in Developing Countries'. OECD Development Centre Working Papers, no. 285 (January): 1, $4-52$

Kharas, Homi. 2017. 'The Unprecedented Global Expansion of the Middle Class'. Brookings Institution Global Economy and Development Program. https://www.brookings.edu/wp-content/uploads/2017/02/ global_20170228_global-middle-class.pdf.

Krause, Jochen Christian, Markus Diesing, and Gunther Arlt. 2010. 'The Physical and Biological Impact of Sand Extraction: A Case Study of the Western Baltic Sea'. Journal of Coastal Research SI (51): 215-26

Krausmann, Fridolin, Dominik Wiedenhofer, Christian Lauk, Willi Haas, Hiroki Tanikawa, Tomer Fishman, Alessio Miatto, Heinz Schandl, and Helmut Haberl. 2017. 'Global Socioeconomic Material Stocks Rise 23-Fold over the 20th Century and Require Half of Annual Resource Use'. Proceedings of the National Academy of Sciences of the United States of America 114 (8): 1880-85.

Kumar, Anil M. 2013. 'Illegal Sand Mining and Transportation Made Cognizable Offense'. Times of India, 21 November 2013, sec. City: Bengaluru. https://timesofindia.indiatimes.com/city/bengaluru/ Illegal-sand-mining-and-transportation-made-cognizable-offense/articleshow/26163777.cms\#: :text=BANGALORE\%3A\%20 The\%20Karnataka\%20cabinet\%20on, illegally\%20mined\%20or\%20 transported\%20sand.
Kwok, Alison G. 2018. The Green Studio Handbook: Environmental Strategies for Schematic Design. Third edition. New York: Routledge.

Lai, Xijan, David Shankman, Claire Huber, Herve Yesou, Qun Huang, and Jiahu Jiang. 2014. 'Sand Mining and Increasing Poyang Lake's Discharge Ability: A Reassessment of Causes for Lake Decline in China'. Journal of Hydrology 519 (B): 1698-1706.

Loughran, Patrick. 2003. Falling Glass: Problems and Solutions in Contemporary Architecture. Basel, Switzerland: Birkhauser.

Lutter, Stephan, Giljum Stafan, Burcu Gozet, Mirko Lieber, and Jakob Gutsch/hofer. 2020. Domestic Extraction of a Country by Material Groups. Material Flow Analysis Portal. Vienna, Austria: Vienna University of Economics and Business Institute for Ecological Economics. http://www.materialflows.net/visualisation-centre

Mazumder, Muhammed Khairujjaman, Freeman Boro, Badruzzaman Barbhuiya, and Utsab Singha. 2014. 'A Study of the Winter Congregation Sites of the Gangetic River Dolphin in Southern Assam, India, with Reference to Conservation'. Global Ecology and Conservation 2 (December): 359-66

MBIE. 2019. 'Responsibly Delivering Value: A Minerals and Petroleum Resource Strategy for Aotearoa New Zealand 2019-2029'. Ministry of Business, Innovation and Employment. https://www.mbie.govt. $\mathrm{nz} /$ dmsdocument/7148-responsibly-delivering-value-a-minerals-and-petroleum-strategy-for-aotearoa-new-zealand-2019-2029,

MBIE, 2020. 'Annual Minerals Industry Statistics and Survey'. Ministry of Business, Innovation \& Employment: New Zealand Petroleum and Minerals. https://www.nzpam.govt.nz/nz-industry/nz-minerals/ minerals-statistics/industry-statistics/. 
McKay, Bill. 2016. 'The Story up Til Now'. Koha: An Offering of New Zealand Architecture and Design, 2016.

McLintock, A. H. 1966. 'Towards an Indigenous Architecture-"'Space, Light, and Nature"'. In An Encyclopaedia of New Zealand. Vol. 1. http:// www.TeAra.govt.nz/en/1966/architecture/page-7.

Merritt, Richard W., Edward D. Walker, Pamela L.C. Small, John R. Wallace, Paul D. R. Johnson, M. Eric Benbow, and Daniel A. Boakye. 2010 'Ecology and Transmission of Buruli Ulcer Disease: A Systematic Review'. PLoS Neglected Tropical Diseases 4 (12): e911. https://doi. org/doi:10.1371/journal.pntd.0000911.

Miatto, Alessio, Heinz Schandl, Tomer Fishman, and Hiroki Tanikawa. 2017. 'Global Patterns and Trends for Non-Metallic Minerals Used for Construction'. Journal of Industrial Ecology 21 (4): 924-37. https:// doi.org/10.1111/jiec.12471.

Mikadze, Kirsten. 2018. 'The Global Sand Crisis and Its Link to Urbanisation'. Municipal World 128 (6): 41-42.

Munda, Sanjay, P.R. Sindhi, Vinay Chandwani, Ravindra Nagar, and Vinay Agrawal. 2016. 'Crushed Rock Sand: An Economical and Ecological Alternative to Natural Sand to Optimize Concrete Mix'. Perspectives in Science 8 (September): 345-47. https://doi. org/10.1016/j.pisc.2016.04.070.

Narvydas, Artuiras. 2014. 'Trends of Sustainable Residential Architecture' Rigas Tehniskas Universitates Zinatniskie Raksti 9: 33. https://doi. org/10.7250/aup.2014.005.

Nelson, Tim. 2017. 'How a Worldwide Sand Shortage Could Devastate the Design World', 11 October 2017. https://www.architecturaldigest. $\mathrm{com} /$ story/how-a-worldwide-sand-shortage-could-devastate-thedesign-world.
Neumann, Frank, and Manfred Curbach. 2018. 'Thermal Treatment of Desert Sand to Produce Construction Material.' In MATEC Web of Conferences. Vol. 149. Les Ulis, France: EDP Sciences. https://doi. org/10.1051/matecconf/201814901030.

Newton, Gregg. 2018. 'Gone with the Wind: Storms Deepen Florida's Beach Sand Crunch'. Reuters, 16 February 2018, sec. Environment. https://www.reuters.com/article/us-florida-storm-beaches/ gone-with-the-wind-storms-deepen-floridas-beach-sand-crunchdUSKCN1G00W4.

NIWA. 2010. 'Summer Series 8: The Science of Sand'. National Institute of Water and Atmosphere (blog). 2010. https://niwa.co.nz/ news-and-publications/media-centre/summer-series/summer-series-8-the-science-of-sand.

NOAA. 2020. 'How Does Sand Form?' National Ocean Service: National Oceanic and Atmospheric Administration (blog). 12 April 2020 https://oceanservice.noaa.gov/facts/sand.html.

O'Dwyer, Ellen. 2020. 'Street of Port Waikato Houses Could Be Washed Away in Decades, Erosion Map Predicts'. Stuff.Co.Nz, 26 July 2020 https://www.stuff.co.nz/environment/climate-news/122231911/ street-of-port-waikato-houses-could-be-washed-away-in-decadeserosion-map-predicts.

Ong, Boon Lay. 2013. Beyond Environmental Comfort. London; New York: Taylor \& Francis Group

Owen, David. 2017. 'The World Is Running out of Sand'. The New Yorker, 29 May 2017. https://www.newyorker.com/magazine/2017/05/29/theworld-is-running-out-of-sand. 
Padmalal, D, and K Maya. 2014. Sand Mining: Environmental Impacts and Selected Case Studies. Dordrecht, Netherlands: Springer

Peduzzi, Pascal. 2014. 'Sand, Rarer than One Thinks'. Environmental Development 11 (July): 208-18. https://doi.org/10.1016/j. envolev.2014.04.001.

Peduzzi, Pascal. 2016. The Insatiable Demand for Sand. Multimedia. Geneva. https://unepgrid.ch/en/resource/2CFA9705.

Peduzzi, Pascal. 2020. 'Head in the Sand'. Land Journal, January, 10-11. Peters, Sascha. 2011. Material Revolution: Sustainable and Multi-Purpose Materials for Design and Architecture. Basel, Switzerland: Birkhauser $\mathrm{GmbH}$.

Petrović, Emina Kristina. 2017. 'An Overview of Health Hazards from Materials: Application of Principles'. In Materials for a Healthy, Ecological and Sustainable Built Environment, 203-36. Duxford: Woodhead Publishing.

Rayasam, Renuka. n.d. 'The Global Construction Boom Has Created Huge Demand for Sand - Even in Cities Surrounded by the Coarse Commodity.' BBC Worklife, sec. Personal Finance. https://www.bbc. com/worklife/article/20160502-even-desert-city-dubai-imports-itssand-this-is-why.

Rege, Aunshul. 2016. 'Not Biting the Dust: Using a Tripartite Model of Organized Crime to Examine India's Sand Mafia'. Internationa Journal of Comparative and Applied Criminal Justice 40 (2): 101-21. https://doi.org/10.1080/01924036.2015.1082486.

Rockström, Johan, Will Steffen, Kevin Noone, Åsa Persson, F. Stuart III Chapin, Eric Lambin, Timothy M. Lenton, et al. 2009. 'Planetary Boundaries: Exploring the Safe Operating Space for Humanity'. Ecology and Society 14 (2): 302.
Roos, Dave. 2017. 'Sand Is in Such High Demand, People Are Stealing Tons of It'. HowStuffWorks. Com (blog). 6 March 2017. https://science. howstuffworks.com/environmental/conservation/issues/sand-issuch-high-demand-people-are-stealing-tons-it.htm.

Salvaggio, Francesco. 2015. Dubai Skyline from the Desert. Photograph. https://www.istockphoto.com/photo/dubai-skyline-from-the-desertgm501364568-81291781.

Schandl, Heinz, Marina Fischer-Kowalski, James West, Stefan Giljum, Monika Dittrich, Nina Eisenmenger, Arne Geschke, et al. 2018. 'Global Material Flows and Resource Productivity: 40 Years of Evidence'. Journal of Industrial Ecology 22 (4): 827-38

Schandl, Heinz, and Jim West. 2010. 'Resource Use and Resource Efficiency in the Asia-Pacific Region'. Global Envrionmental Change 20 (4): 636-47.

Scharf, Caleb. 2013. 'An Exploding Star, a Grain of Sand, and an Origin Story'. The New Yorker, 9 May 2013, sec. Annals of Technology. https://www.newyorker.com/tech/annals-of-technology/an-exploding-star-a-grain-of-sand-and-an-origin-story.

Scheerbart, Paul. 2014. Glass! Love!! Perpetual Motion!!! : A Paul Scheerbart Reader. New York, New York: Christine Burgin.

Slavid, Ruth. 2019. Extreme Architecture: Building for Challenging Environments. 1st ed. London: Laurence King Publishing

Smil, Vaclav. 2014. Making the Modern World: Materials \& Dematerialisation. United Kingdom: John Wiley \& Sons Ltd. Standards New Zealand. 2016. 'NZS 4223.1:2008 Glazing in Buildings'. Ministry of Business, Innovation and Employment 
Swanson, Ana. 2015. 'How China Used More Cement in 3 Years than the U.S. Did in the Entire 20th Century'. The Washington Post, 25 March 2015, sec. Economic Policy. https://www.washingtonpost.com/news/ wonk/wp/2015/03/24/how-china-used-more-cement-in-3-yearsthan-the-u-s-did-in-the-entire-20th-century/.

Torres, Aurora, Jodi Brandt, Kristen Lear, and Jianguo Liu. 2017. 'A Looming Tragedy of the Sand Commons'. Science 357 (6355): 970-71.

Torres, Aurora, Jianguo Liu, Jodi Brandt, and Kristen Lear. 2017. 'The World Is Facing a Global Sand Crisis'. The Conversation, 8 September 2017. https://theconversation.com/the-world-is-facing-a-globalsand-crisis-83557.

Trenchard, Tommy. 2013. Sand-Mining Threatens Homes and Livelihoods in Sierra Leone. Photograph. https://www.thenewhumanitarian.org/ news/2013/02/01/sand-mining-threatens-homes-and-livelihoods-sierra-leone.

Tweedie, Neil. 2018. 'Is the World Running out of Sand? The Truth behind Stolen Beaches and Dredged Islands'. The Guardian, 1 July 2018, sec. Environment. https://www.theguardian.com/global/2018/jul/01/ riddle-of-the-sands-the-truth-behind-stolen-beaches-and-dredgedislands.

UNEP. 2016. Global Material Flows and Resource Productivity: Assessment Report for the UNEP International Resource Panel. UNESCO.

UNEP. 2019. 'Sand and Sustainability: Finding New Solutions for Environmental Governance of Global Sand Resources'. Geneva, Switzerland: United Nations Environment Programme. https:// wedocs.unep.org/bitstream/handle/20.500.11822/28163/SandSust. pdf? sequence $=1$ \&isAllowed $=y$.
United Nations. 2015. 'About the Sustainable Development Goals'. 2015. https://www.un.org/sustainabledevelopment/sustainable-development-goals/.

Wainwright, Oliver. 2018. 'Not the End of The World: The Return of Dubai's Ultimate Folly'. The Guardian, 13 February 2018, sec. The long read. https://www.theguardian.com/cities/2018/feb/13/not-end-theworld-return-dubai-ultimate-folly.

Welland, Michael. 2009. Sand: The Never-Ending Story. 1st ed. University of California Press. https://www.jstor.org/stable/10.1525/j.ctt24hst7.5.

Welland, Michael. 2010. 'Sand and Us'. Blog. Through the Sandglass (blog). 8 January 2010. https://throughthesandglass.typepad.com/ through_the_sandglass/sand_and_us/page/13/.

Weyler, Rex. 2017. 'Sand Depletion'. Organisation. Greenpeace (blog). 16 November 2017. greenpeace.org/international/story/19351/ sand-depletion/.

Wilson, Libby. 2019. 'Disappearing Port Waikato: Locals Demand Action as Erosion Threatens'. Stuff.Co.Nz, 6 October 2019. https://www. stuff.co.nz/environment/116350674/disappearing-port-waikato-locals-demand-action-as-erosion-threatens?cid=facebook.post\&fbclid=IwAR2TXphRnPwJHh0-jKkpW4zCshx9NHCk5w1OqSbFLXzTo9yRK_LhWdd_kIM.

Zapata, Dominco. 2020. Houses on the Sea Front at Port Waikato in 2019. Since Then, Green's House (Far Right) Has Been Demolished. Photograph. https://www.stuff.co.nz/environment/ climate-news/122231911/street-of-port-waikato-houses-could-bewashed-away-in-decades-erosion-map-predicts.

Zhang, Guoxue, Jianxia Song, Jiansen Yang, and Xiyuan Liu. 2006. 'Performance of Mortar and Concrete Made with a Fine Aggregate of Desert Sand'. Building and Environment 41 (11): 1478-81. https:// doi.org/doi.org/10.1016/j.buildenv.2005.05.033. 
Chapter 9

APPENDIX

Data of glass usage measured from the construction drawings of case studies from glazing study in Chapter 3. 
Herbst Architects - Timms Bach - Northland

\section{Window Number}

Bed 1 Door

Bining 1 Window
Bed 2 Window

Living

Total area $(\mathrm{m} 2)$

Tould double glazing area $(\mathrm{m} 2)$

Total glass volume (m3)

Total glass weight $(\mathrm{T})$

Total silica content - aka sand ( $k g)$

Total silica content - aka sand (T)

Total sand volume ( $\mathrm{m} 3$ )

Sand weight per sq $\mathrm{m}$ footprint $(\mathrm{kg})$

Sand volume per sq $m$ footprint $(\mathrm{cm}$

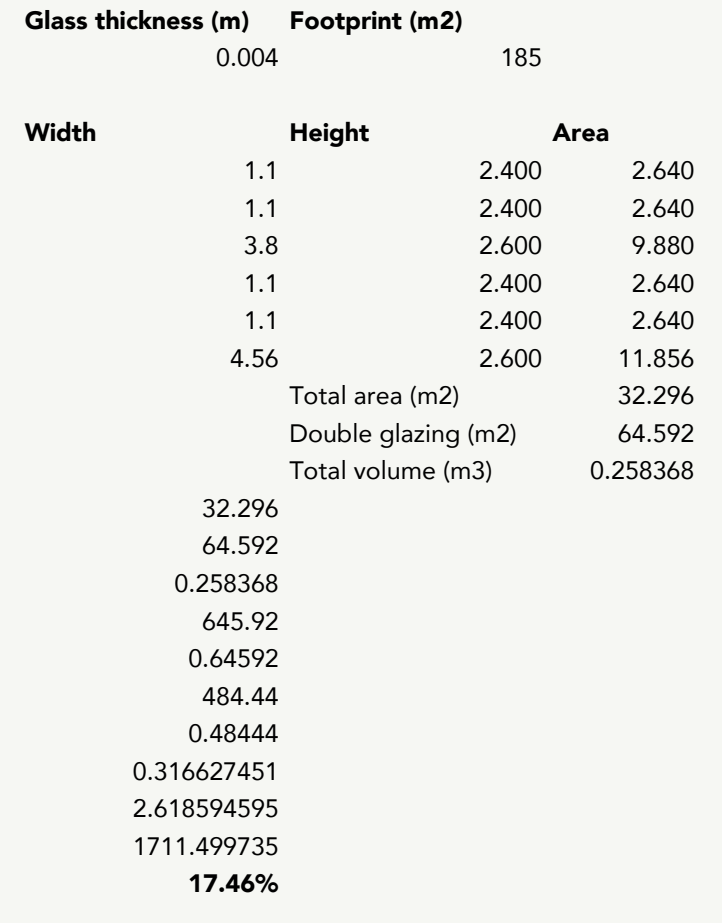

\begin{tabular}{|c|}
\hline Window Number \\
\hline $\begin{array}{l}\text { North } 1 \\
\text { N Number }\end{array}$ \\
\hline North 2 \\
\hline West 1 \\
\hline \multirow{2}{*}{$\begin{array}{l}\text { West } 2 \\
\text { West } 3\end{array}$} \\
\hline \\
\hline West 4 \\
\hline West 5 \\
\hline $\begin{array}{l}\text { West } 5 \\
\text { West } 6\end{array}$ \\
\hline 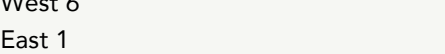 \\
\hline $\begin{array}{l}\text { East } 1 \\
\text { East } 2\end{array}$ \\
\hline \\
\hline East 3 \\
\hline East 5 \\
\hline North 1 \\
\hline North 2 \\
\hline North 3 \\
\hline North 4 \\
\hline Total area $(\mathrm{m} 2)$ \\
\hline \multirow{2}{*}{$\begin{array}{l}\text { Total double glazing area }(\mathrm{m} 2) \\
\text { Total glass volume }(\mathrm{m} 3)\end{array}$} \\
\hline \\
\hline \\
\hline $\begin{array}{l}\text { Total glass weight }(\mathrm{kg}) \\
\text { Total glass weight (T) }\end{array}$ \\
\hline Total silica content - aka sand (kg) \\
\hline Total silica content - aka sand (T) \\
\hline Total sand volume (m3) \\
\hline Sand weight per sq m footprint (kg) \\
\hline $\begin{array}{l}\text { Sand volume per sq } m \text { footprint }(\mathrm{cm} 3) \\
\text { Percent of footprint }\end{array}$ \\
\hline
\end{tabular}

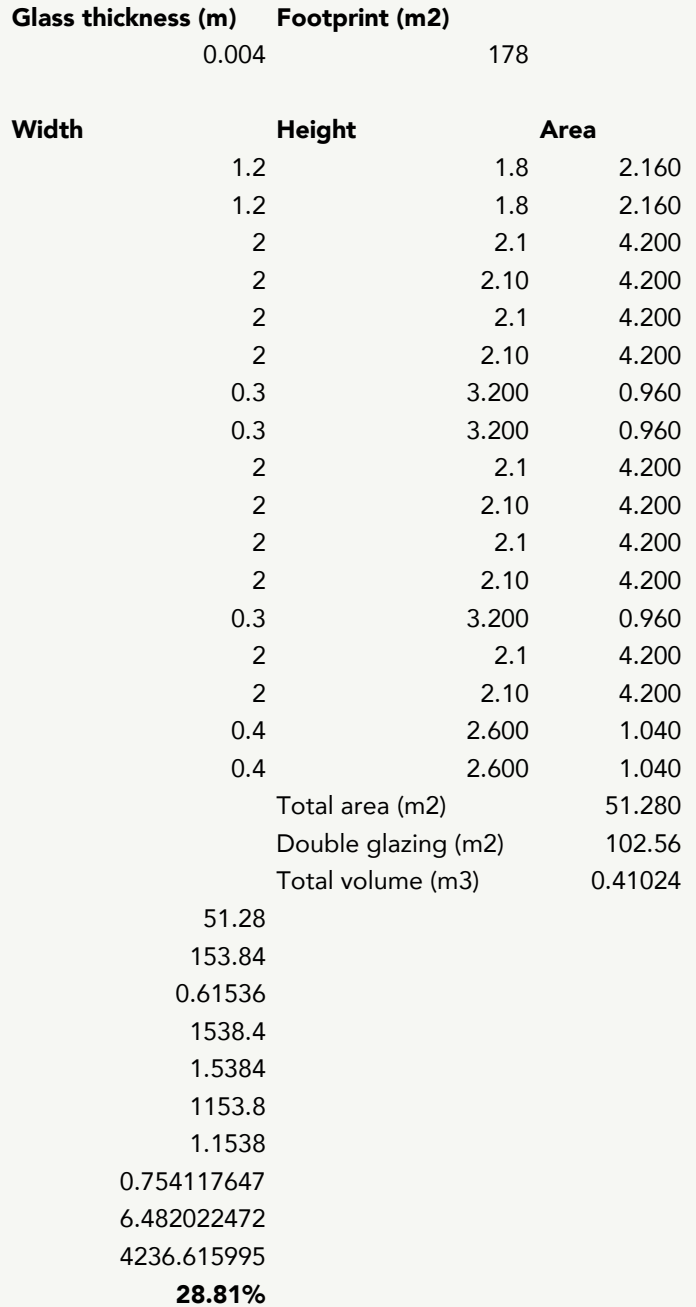




\begin{tabular}{|c|c|c|c|}
\hline \multirow{2}{*}{$\begin{array}{l}\text { Dorrington Atcheson - St Marks Lane - Queenstown } \\
\text { Window Number }\end{array}$} & $\begin{array}{r}\text { Glass thickness }(\mathbf{m}) \\
0.004\end{array}$ & \multicolumn{2}{|l|}{$\begin{array}{ll}\text { Footprint (m2) } & \\
282\end{array}$} \\
\hline & Width & Height & Area \\
\hline & 2.1 & 2.225 & \\
\hline w3 & 2.6 & 2.4 & 6.240 \\
\hline w4 & 0.89 & 2.4 & 2.136 \\
\hline w5 & 1.1125 & 2.400 & 2.670 \\
\hline w6 & 7.2 & 2.400 & 17.280 \\
\hline w7 & 1.2 & 2.400 & 2.880 \\
\hline w8 & 3.7 & 2.400 & 8.880 \\
\hline W9 & 1.998 & 2.400 & 4.795 \\
\hline W10 & 3.59 & 2.400 & 8.616 \\
\hline W11 & 1.16 & 1.938 & 2.248 \\
\hline W12 & 0.4 & 1.935 & 0.774 \\
\hline W13 & 2.33 & 1.550 & \\
\hline W14 & 2.33 & 1.550 & \\
\hline W15 & 1.2 & 1.938 & 2.326 \\
\hline w16 & 2.33 & 1.550 & 3.612 \\
\hline W17 & 0.495 & 1.935 & 0.958 \\
\hline W18 & 2.045 & 1.457 & 2.980 \\
\hline W19 & 1.67 & 1.2695 & \\
\hline w20 & & & 0.000 \\
\hline \multirow[t]{4}{*}{ w21 } & 3.795 & 1.182 & \\
\hline & & Total area (m2) & 84.895025 \\
\hline & & Double glazing (m2) & 169.79005 \\
\hline & & Total volume (m3) & 0.6791602 \\
\hline Total area (m2) & 84.895025 & & \\
\hline Total double glazing area (m2) & 254.685075 & & \\
\hline Total glass volume (m3) & 1.0187403 & & \\
\hline Total glass weight $(\mathrm{kg})$ & 2546.85075 & & \\
\hline Total glass weight $(T)$ & 2.54685075 & & \\
\hline Total silica content - aka sand (kg) & 1910.138063 & & \\
\hline Total silica content - aka sand (T) & 1.910138063 & & \\
\hline Total sand volume (m3) & 1.24845625 & & \\
\hline Sand weight per sq $\mathrm{m}$ footprint $(\mathrm{kg})$ & 6.773539229 & & \\
\hline Sand volume per sq $\mathrm{m}$ footprint $(\mathrm{cm} 3)$ & 4427.149823 2 ( & & \\
\hline Percent of footprint & $30.10 \%$ & & \\
\hline
\end{tabular}

Fearon Hay - Mountain Retreat - Closeburn Window Number

WG.01.A

WG.02.A

Total area (m2)

Total double glazing area ( $m 2$ )

Total glass volume ( $\mathrm{m} 3 \mathrm{3}$

Total glass weight $(\mathrm{kg})$
Total glass weight $(\mathrm{T})$

Total silica content - aka sand (kg)

Total silica content - aka sand (T)

Total sand volume ( $\mathrm{m} 3$ )

Sand volume per sq $\mathrm{m}$ footprint $(\mathrm{cm} 3)$

Percent of footprint
Glass thickness ( $m$ ) Footprint (m2)
0.004

Width

Heigh Are $\begin{array}{rr}1.600 & 12.682 \\ & 1.120\end{array}$ Double glazing (m2) $\quad 31.6954$ 31.6954 95.0862 0.3803448 950.862
0.950862
713.165 0.950862
713.1465
0.713465 0.7131465 0.466108824 7.131465

4661.088235 $31.70 \%$ 


\begin{tabular}{|c|c|c|c|}
\hline Warren \& Mahoney - Closeburn Station & \multicolumn{2}{|c|}{$\begin{array}{ll}\text { Glass thickness }(\mathbf{m}) & \text { Footprint (m2) } \\
0.004 & \end{array}$} & 458 \\
\hline Window Number & Width & Height & Area \\
\hline w4 & 2.94 & 2.510 & 7.379 \\
\hline W17 & 3.035 & 2.510 & 7.618 \\
\hline W18 & 2.51 & 7.425 & 18.637 \\
\hline w23a & 6.19 & 2.400 & \\
\hline w23b & 6.19 & 0.500 & 3.095 \\
\hline $\mathrm{w}_{23 c}$ & 6.19 & 0.250 & 1.548 \\
\hline D15 & 1.085 & 2.400 & 2.604 \\
\hline S24 & 0.9 & 1.200 & 1.080 \\
\hline S25 & 0.9 & 1.200 & 1.080 \\
\hline S26 & 1.2 & 1.200 & 1.440 \\
\hline W13 & 1.57 & 2.400 & 3.768 \\
\hline W15 & 1.445 & 2.400 & 3.468 \\
\hline W16 & 3.09 & 2.400 & 7.416 \\
\hline W19 & 2.4 & 2.980 & 7.152 \\
\hline W20 & 4.78 & 2.510 & 11.998 \\
\hline W21 & 3.64 & 2.510 & 9.136 \\
\hline W22 & 4.305 & 2.250 & 9.686 \\
\hline D14 & 2.01 & 2.400 & 4.824 \\
\hline W1 & 4.305 & 2.250 & 9.686 \\
\hline w2 & 1.845 & 2.400 & 4.428 \\
\hline w5 & 2.67 & 1.200 & 3.204 \\
\hline W6 & 1.905 & 2.510 & 4.782 \\
\hline W7 & 1.365 & 2.510 & 3.426 \\
\hline W12 & 0.685 & 2.400 & 1.644 \\
\hline D1 & 0.71 & 2.200 & 1.562 \\
\hline D3a & 0.48 & 2.400 & 1.152 \\
\hline D3b & 0.48 & 2.400 & 1.152 \\
\hline w3 & 2.94 & 2.510 & 7.379 \\
\hline W8a & 6.035 & 2.400 & 14.484 \\
\hline w8b & 6.035 & 0.500 & 3.018 \\
\hline W8c & 6.035 & 0.250 & 1.509 \\
\hline W9 & 1.755 & 2.510 & 4.405 \\
\hline W10 & 2.695 & 2.400 & 6.468 \\
\hline W11 & 2.695 & 2.400 & 6.468 \\
\hline W14 & 1.18 & 2.400 & 2.832 \\
\hline \multirow{4}{*}{ D13 } & \multirow{2}{*}{\multicolumn{2}{|c|}{ 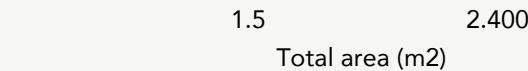 }} & 3.600 \\
\hline & & & 196.540 \\
\hline & & Double glazing (m2) & 393.08 \\
\hline & & 1.57232 \\
\hline Total area (m2) & \multirow{2}{*}{\multicolumn{2}{|c|}{$\begin{array}{l}196.54 \\
393.08\end{array}$}} & \\
\hline Total double glazing area (m2) & & & \\
\hline Total glass volume (m3) & \multicolumn{2}{|l|}{1.57232} & \\
\hline Total glass weight (kg) & \multicolumn{2}{|l|}{3930.8} & \\
\hline Total glass weight $(T)$ & \multicolumn{2}{|l|}{$\begin{array}{l}3930.8 \\
3.9308\end{array}$} & \\
\hline Total silica content - aka sand (kg) & \multicolumn{2}{|l|}{$\begin{array}{l}2948.1 \\
2908-1\end{array}$} & \\
\hline Total silica content - aka sand (T) & \multicolumn{2}{|l|}{2.9481} & \\
\hline Total sand volume (m3) & \multicolumn{2}{|l|}{1.926862745} & \\
\hline Sand weight per sq $\mathrm{m}$ footprint $(\mathrm{kg})$ & \multirow{2}{*}{\multicolumn{2}{|c|}{6.436899563}} & \\
\hline Sand volume per sq $\mathrm{m}$ footprint $(\mathrm{cm} 3)$ & \multirow{2}{*}{\multicolumn{2}{|c|}{$\begin{array}{r}4207.123898 \\
\mathbf{4 2 . 9 1 \%}\end{array}$}} & \\
\hline Percent of footprint & & & \\
\hline
\end{tabular}

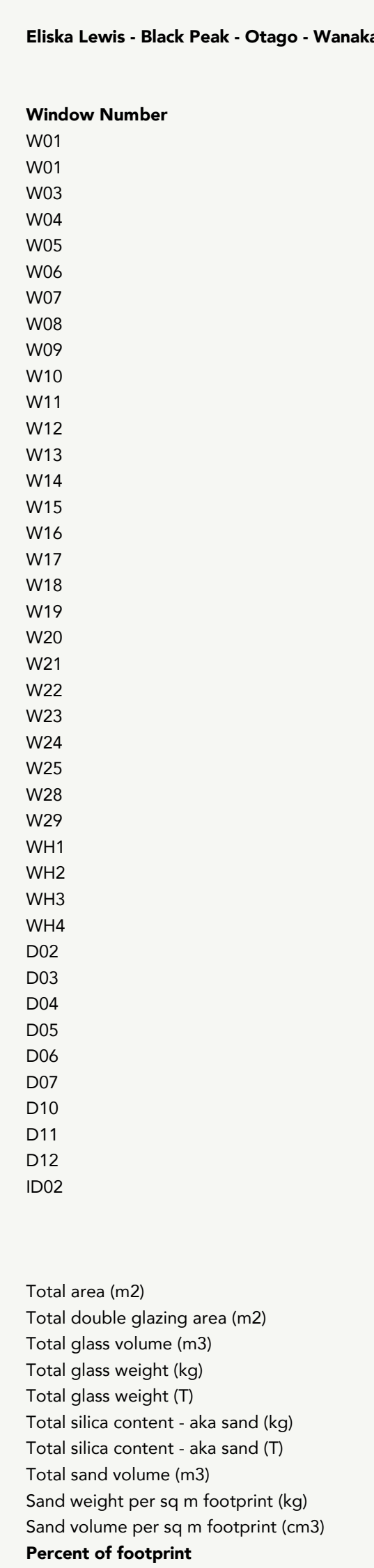

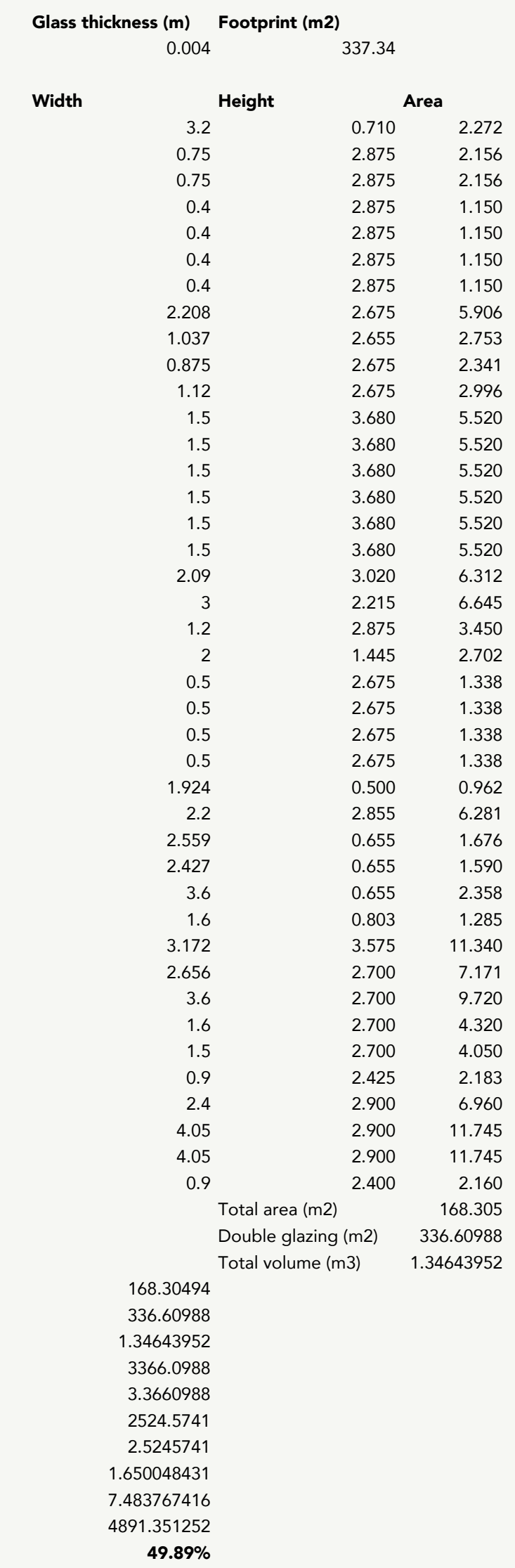




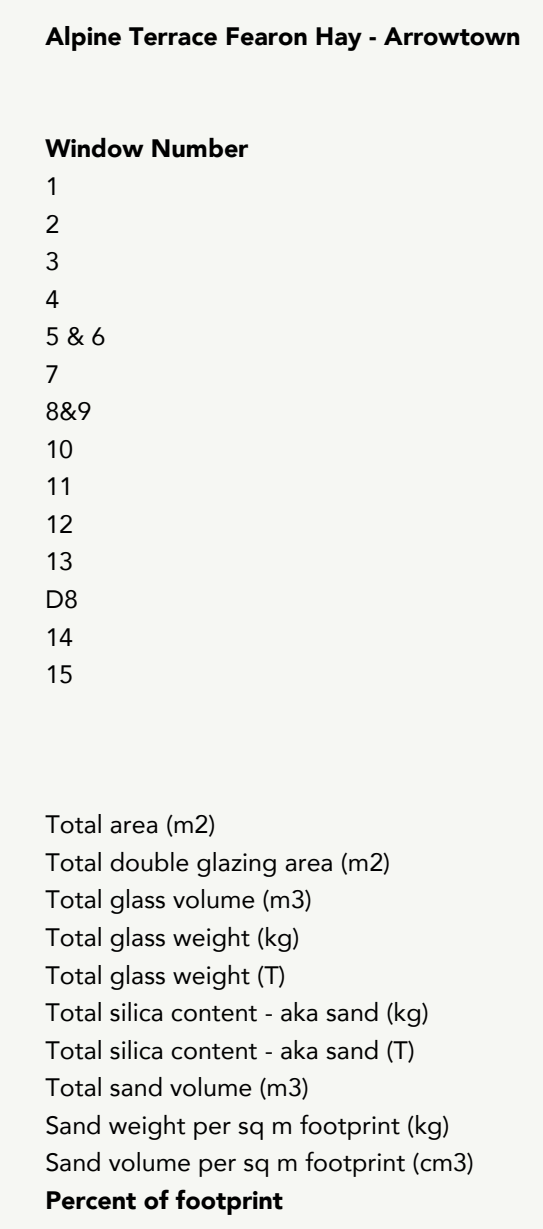

\begin{tabular}{|c|c|c|}
\hline Glass thickness (m) & \multicolumn{2}{|l|}{ Footprint (m2) } \\
\hline Width & Height & Area \\
\hline 3.38 & 3.090 & 10.444 \\
\hline 1.93 & 3.090 & 5.964 \\
\hline 3.4 & 3.090 & 10.506 \\
\hline 3.26 & 3.090 & 10.073 \\
\hline 11.69 & 3.000 & 35.070 \\
\hline 2.46 & 3.000 & 7.380 \\
\hline 11.41 & 3.000 & 34.230 \\
\hline 5.17 & 2.530 & 13.08 \\
\hline 5.7 & 2.530 & 14.421 \\
\hline 4.68 & 2.530 & 11.840 \\
\hline 2.16 & 2.800 & 6.048 \\
\hline 1.2 & 2.400 & 2.880 \\
\hline 1.74 & 2.350 & 4.089 \\
\hline 4.13 & 3.000 & 12.390 \\
\hline & Total area (m2) & 178.416 \\
\hline & Double glazing (m2) & 356.8316 \\
\hline & Total volume (m3) & 1.4273264 \\
\hline 178.4158 & & \\
\hline 356.8316 & & \\
\hline 1.4273264 & & \\
\hline 3568.316 & & \\
\hline 3.568316 & & \\
\hline 2676.237 & & \\
\hline 2.676237 & & \\
\hline 1.74917451 & & \\
\hline 7.715277838 & & \\
\hline 5042.665253 & & \\
\hline $51.44 \%$ & & \\
\hline
\end{tabular}

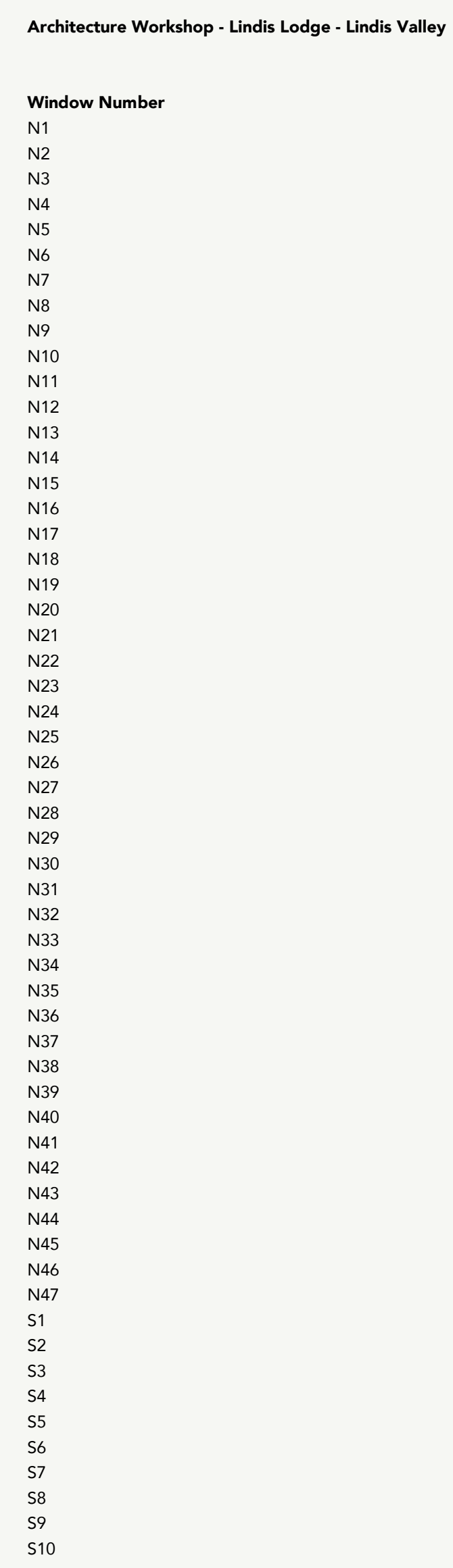



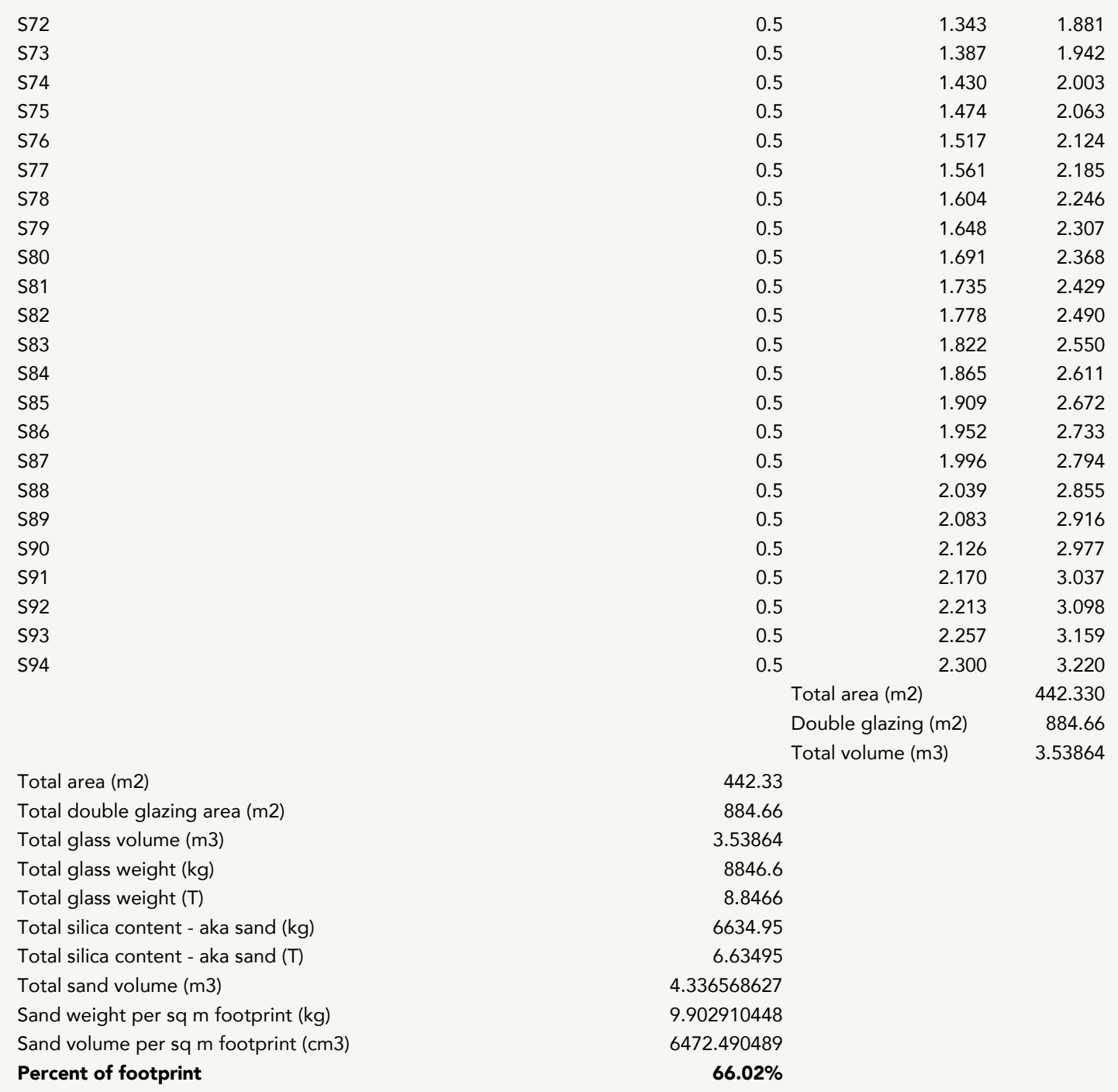
eHaus Te Miro Passive House - Waikato

Glass thickness ( $m$ ) Footprint (m2)

$$
0.004
$$

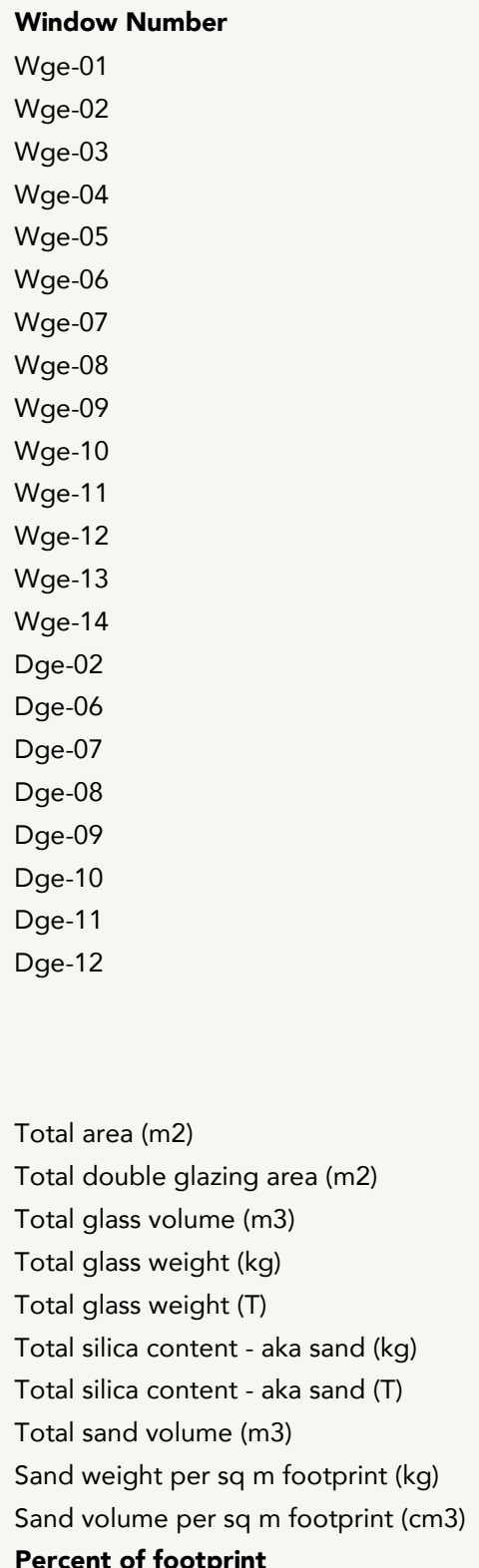

Width

\begin{tabular}{rrr} 
Height & \multicolumn{2}{c}{ Area } \\
0.7 & 2.22 & 1.554 \\
1.14 & 2.22 & 2.5308 \\
2.8 & 1.1 & 3.08 \\
0.8 & 1.8 & 1.44 \\
1.6 & 1.1 & 1.76 \\
1 & 2.22 & 2.22 \\
1 & 2.22 & 2.22 \\
2.6 & 2.22 & 5.772 \\
3.4 & 2.22 & 7.548 \\
1.9 & 0.8 & 1.52 \\
1.9 & 0.8 & 1.52 \\
1.6 & 0.8 & 1.28 \\
0.9 & 2.22 & 1.998 \\
0.9 & 2.22 & 1.998 \\
0.8 & 2.22 & 1.776 \\
1.3 & 2.22 & 2.886 \\
1.3 & 2.22 & 2.886 \\
1.3 & 2.22 & 2.886 \\
2.6 & 2.22 & 5.772 \\
2.6 & 2.22 & 5.772 \\
2.6 & 2.22 & 5.772 \\
3.4 & 2.22 & 7.548 \\
\multicolumn{1}{l}{ Total area (m2) } & 71.7388 \\
Double glazing (m2) & 143.4776 \\
Total volume (m3) & 0.5739104 \\
71.7388 & & \\
215.2164 & & \\
0.8608656 & & \\
2152.164 & & \\
2.152164 & & \\
1614.123 & & \\
1.614123 & & \\
1.054982353 & & \\
5.012804348 & & \\
3276.342711 & & \\
$\mathbf{2 2 . 2 8 \%}$ & & \\
& & \\
& & \\
& &
\end{tabular}

Rafe Maclean - George Passive House

Window Number
EJ01
EJ02
EJ03
EJ04
EJ05
EJ06
EJ07
EJ08
EJ09
EJ10
EJ11
EJ12
EJ13
EJ14
EJ15
EJ16
IJ02
IJ07
IJ09
IJ10
IJ11

Total area (m2)

Total double glazing area $(\mathrm{m} 2)$

Total glass volume $(\mathrm{m} 3)$

Total glass weight (kg)
Total glass weight $(T)$

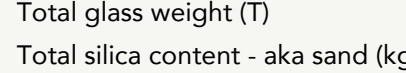

Total silica content - aka sand (T)

Total sand volume ( $\mathrm{m} 3)$

Sand weight per sq $\mathrm{m}$ footprint $(\mathrm{kg})$

Sand volume per sq $\mathrm{m}$ footprint $(\mathrm{cm} 3)$

Percent of footprint
Glass thickness ( $m$ ) Footprint (m2)

$0.004 \quad 211$

Width

Height Area

$\begin{array}{rrr}0.89 & 2.4 & 2.136 \\ 3 & 175 & 6052\end{array}$

$\begin{array}{rrr}0.89 & 2.4 & 2.136 \\ 3.46 & 2.4 & 6.055 \\ 1.51 & 2.4 & 3.624 \\ 3.115 & & 7.476\end{array}$

$\begin{array}{lll}3.115 & 2.4 & 7.476 \\ 2.69 & 2.4 & 0.456\end{array}$

$\begin{array}{rrr}2.69 & 2.4 & 6.456 \\ 1.91 & 1.145 & 2.18695\end{array}$

$\begin{array}{lll}1.82 & 2.4 & 4.368 \\ 1.195 & 1.3 & 1.555\end{array}$

$\begin{array}{rrr}1.82 & 1.3 & 1.5535 \\ 0.88 & 1.3 & 1.144 \\ 0.68 & 1.3 & 0.884\end{array}$

$\begin{array}{lll}0.68 & 1.3 & 0.884 \\ 0.86 & 2.4 & 2.064\end{array}$

$\begin{array}{lll}0.86 & 205-1.065 \\ 1.82 & 1 & 1.205\end{array}$

$\begin{array}{lll}1.82 & 1 & 1.82 \\ 1.82 & 1.65 & 3.03\end{array}$

$\begin{array}{lrr}1.82 & 1.65 & 3.003 \\ 1.82 & 1.65 & 3.003 \\ 1.025 & 1.65 & 1.775\end{array}$

$\begin{array}{lll}1.035 & 1.65 & 1.70775 \\ 0.86 & 1.08\end{array}$

$\begin{array}{lrr}1.035 & 1 & 0.86 \\ 0.86 & 2.4 & 2.064\end{array}$

$\begin{array}{lll}0.81 & 1.98 & 1.0638 \\ 0.81 & 1.98 & 1.0038\end{array}$

$\begin{array}{lll}0.81 & 1.98 & 1.6038 \\ 0.86 & 2.4 & 2.064\end{array}$

Total area $(\mathrm{m} 2) \quad 56.8818$

Triple glazing $(m 2) \quad 170.6454$

56.8818

170.6454

0.6825816

1706.454

1.706454

1279.8405

1.2798405

0.836497059

6.065594787

3964.441037 
eHaus St Clair Passive House - Dunedin

Glass thickness ( $m$ ) Footprint (m2)

$$
0.004
$$

Window Number
Entry
Kitchen
Dining
Living 1
Living 2
Ensuite
Master Bed
Bed 2
Bath
Bed 3
Media room
Utility
Garage

Total area (m2)

Total double glazing area $(\mathrm{m} 2)$

Total glass volume ( $\mathrm{m} 3)$

Total glass weight (kg)

Total silica content - aka sand (kg)

Total silica content - aka sand (I)

Total sand volume ( $\mathrm{m} 3$ )

Sand weight per sq $\mathrm{m}$ footprint $(\mathrm{kg})$

Sand volume per sq $\mathrm{m}$ footprint $(\mathrm{cm} 3)$

Percent of footprint
Width

Height
0.5
0.9
3.7
3.6
3.2
1.8
1.6
2.2
1.2
2.2
2.2
0.8
2.4
Total area $(\mathrm{m} 2)$
Double glazing $(\mathrm{m} 2)$
Total volume $(\mathrm{m} 3)$
0.35

\begin{tabular}{lr} 
Area & \\
\hline 1 & 1.05 \\
2.1 & 1.89 \\
21 & 7.77 \\
1 & 7.56 \\
1 & 6.72 \\
1 & 2.88 \\
8 & 2.88 \\
8 & 1.76 \\
.6 & 0.72 \\
8 & 1.76 \\
8 & 1.76 \\
1 & 1.68 \\
8 & 1.92 \\
& 40.35 \\
& 80.7 \\
& 0.3228
\end{tabular}

$$
\begin{array}{r}
40.35 \\
121.05
\end{array}
$$$$
121.05
$$$$
0.4842
$$$$
\begin{aligned}
& 1210.5 \\
& 1.2105
\end{aligned}
$$$$
907.875
$$

0.907875

0.593382353

3.846927966

14.332004
$17.10 \%$
eHaus Taupiri Passive House - Dunedin

Window Number
Entry
Living 1
Living 2
Living 3
Dining 1
Dining 2
Lounge 1
Lonnge 2
Hall
Master Bed 1
Master Bed 2
Ensuite
Bed 2
Bed 3
Bath
Toilet
Laundry
Garage
Office

Total area (m2)
Total double glazing area (m2)
Total glass volume $(\mathrm{m} 3)$
Totat glass weight (kg)
Total glass weight (T)
Total silica content - aka sand (kg)
Total silica content - aka sand (T)
Total sand volume ( $\mathrm{m} 3$ )
Sand weight per sq $\mathrm{m}$ footprint $(\mathrm{kg})$
Sand volume per sq $\mathrm{m}$ footprint (cm3)
Percent of footprint

Glass thickness ( $m$ ) Footprint (m2)

$0.004 \quad 252$

Width

\begin{tabular}{|l} 
Height \\
0.6 \\
0.6 \\
0.8 \\
2.6 \\
2 \\
1.2 \\
2.6 \\
2 \\
2 \\
2.6 \\
0.7 \\
1 \\
1.6 \\
1.6 \\
1.4 \\
0.6 \\
1.4 \\
0.8 \\
0.8 \\
Total area (m2) \\
Double glazing (m2) \\
Total volume (m3) \\
51.49 \\
154.47 \\
0.61788 \\
1544.7 \\
1.5447 \\
1158.525 \\
1.158525 \\
0.757205882 \\
4.597321429 \\
3004.785247 \\
$20.43 \%$ \\
\hline
\end{tabular}

Area

$2.1 \quad 1.26$

$2.1 \quad 1.26$

$2.1 \quad 1.68$

$\begin{array}{rr}2.1 & 5.46 \\ 1.6 & 3.2 \\ 2.1 & 2.52\end{array}$

1.52
2.52

$\begin{array}{rr}2.1 & 5.46 \\ .1 & 4.2 \\ 1.6 & 3.2\end{array}$

$\begin{array}{rr}2.6 & 3.2 \\ 2.1 & 5.46\end{array}$

$\begin{array}{rr}1.6 & 3.46 \\ 2.1 & 1.47 \\ 2.1 & 2.1\end{array}$

$\begin{array}{rr}2.1 & 2.1 \\ 1.6 & 2.56 \\ 1.6 & 2.56\end{array}$

$\begin{array}{ll}1.6 & 2.56 \\ 1.4 & 1.96\end{array}$

1.84
2.89

$\begin{array}{ll}1.4 & 0.84 \\ 2.1 & 2.94 \\ 21 & 1.68\end{array}$

$\begin{array}{rr}2.1 & 1.68 \\ 21 & 1.68\end{array}$

51.49
102.98

102.98

0.41192 
Rafe Maclean Passive House - Dunedin

Glass thickness ( $m$ ) Footprint ( $m 2$ )

$$
0.004
$$

Window Number
Living 1
Living 2
Living 3
Dining
Kitchen
Studio
Laundry
Stair
Master 1
Master 2
Shower
Bed 2
Bed 3
Common 1
Common 2

Total area (m2)

Total double glazing area ( $\mathrm{m} 2$

Total glass volume ( $\mathrm{m} 3)$

Total glass weight $(\mathrm{kg})$
Total glass weight $(\mathrm{T})$

Total silica content - aka sand (kg)

Total silica content - aka sand (I)

Total sand volume ( $\mathrm{m} 3$ )

Sand weight per sq $\mathrm{m}$ footprint $(\mathrm{kg})$

Sand volume per sq $\mathrm{m}$ footprint $(\mathrm{cm} 3)$

Percent of footprint

\begin{tabular}{|c|c|c|c|}
\hline \multicolumn{2}{|r|}{ Height } & \multicolumn{2}{|c|}{ Area } \\
\hline 0.55 & & 2.1 & 1.155 \\
\hline 2 & & 2.1 & 4.2 \\
\hline 0.9 & & 2.1 & 1.89 \\
\hline 0.9 & & 2.1 & 1.89 \\
\hline 0.9 & & 2.1 & 1.89 \\
\hline 1.2 & & 2.1 & 2.52 \\
\hline 0.55 & & 2.1 & 1.155 \\
\hline 0.55 & & 2.1 & 1.155 \\
\hline 1.8 & & 2.1 & 3.78 \\
\hline 0.9 & & 2.1 & 1.89 \\
\hline 0.9 & & 1 & 0.9 \\
\hline 0.9 & & 1 & 0.9 \\
\hline 1.2 & & 1 & 1.2 \\
\hline 0.9 & & 2.1 & 1.89 \\
\hline 0.9 & & 2.1 & 1.89 \\
\hline \multicolumn{2}{|r|}{ Total area (m2) } & & 28.305 \\
\hline \multirow{2}{*}{\multicolumn{3}{|c|}{$\begin{array}{l}\text { Double glazing (m2) } \\
\text { Total volume (m33) }\end{array}$}} & 56.61 \\
\hline & & & 0.22644 \\
\hline \multicolumn{4}{|l|}{28.305} \\
\hline \multirow{2}{*}{\multicolumn{4}{|c|}{$\begin{array}{r}84.915 \\
0.33966\end{array}$}} \\
\hline & & & \\
\hline \multicolumn{4}{|l|}{$\begin{array}{r}0.35700 \\
849.15\end{array}$} \\
\hline \multicolumn{4}{|l|}{0.84915} \\
\hline \multicolumn{4}{|l|}{$\begin{array}{r}636.8625 \\
0.6368625\end{array}$} \\
\hline \multicolumn{4}{|l|}{0.6368625} \\
\hline \multirow{2}{*}{\multicolumn{4}{|c|}{$\begin{array}{r}0.41625 \\
5.443269231\end{array}$}} \\
\hline & & & \\
\hline \multicolumn{4}{|l|}{3557.692308} \\
\hline $24.19 \%$ & & & \\
\hline
\end{tabular}

Öko Barn

Window Number
W1
W2
W3
W4
W5
W6
W7
W8
W9
W10
W11
W12
W13
W14
W15
W16
W17
W18
W19
SKY W20
SKY W21
SKY W22
SKY W23
SKY W24
D4
D5
D6
D7

Total area ( $m 2)$

Total double glazing area (m2)

Total glass volume (m3)

Total glass weight $(\mathrm{kg})$

Total glass weight (T)

Total silica content - aka sand (kg)

Total silica content - aka sand (T)

Total sand volume ( $\mathrm{m} 3$ )

Sand weight per sq $\mathrm{m}$ footprint $(\mathrm{kg})$

Sand volume per sq $\mathrm{m}$ footprint $(\mathrm{cm} 3)$

Percent of footprint
Glass thickness (m) Footprint (m2)

$0.004 \quad 288$

Width

\begin{tabular}{|c|c|c|c|}
\hline & Height & & \\
\hline 0.6 & & 1.8 & 1.08 \\
\hline 1.2 & & 1.8 & 2.16 \\
\hline 0.6 & & 2.4 & 1.44 \\
\hline 1.6 & & 1.6 & 2.56 \\
\hline 0.5 & & 2.2 & 1.1 \\
\hline 0.5 & & 2.2 & 1.1 \\
\hline 0.7 & & 2.3 & 1.61 \\
\hline 0.7 & & 2.3 & 1.61 \\
\hline 0.6 & & 2.2 & 1.32 \\
\hline 0.4 & & 2.2 & 0.88 \\
\hline 0.4 & & 2.2 & 0.88 \\
\hline 1.8 & & 1.8 & 3.24 \\
\hline 2.7 & & 0.8 & 2.16 \\
\hline 0.8 & & 0.8 & 0.64 \\
\hline 0.8 & & 0.8 & 0.64 \\
\hline 2.7 & & 0.8 & 2.16 \\
\hline 1 & & 0.8 & 0.8 \\
\hline 1 & & 0.8 & 0.8 \\
\hline 0.6 & & 2.6 & 1.56 \\
\hline 0.9 & & 0.9 & 0.81 \\
\hline 0.9 & & 0.9 & 0.81 \\
\hline 0.9 & & 0.9 & 0.81 \\
\hline 0.9 & & 0.9 & 0.81 \\
\hline 0.9 & & 0.9 & 0.81 \\
\hline 0.9 & & 2.2 & 1.98 \\
\hline 2.5 & & 2.2 & 5.5 \\
\hline 2.4 & & 2.2 & 5.28 \\
\hline 0.8 & & 2.2 & 1.76 \\
\hline & Total area $(\mathrm{m} 2)$ & & 46.31 \\
\hline & Double glazing ( $\mathrm{m} 2$ & & 92.62 \\
\hline & Total volume (m3) & & 0.37048 \\
\hline 46.31 & & & \\
\hline 138.93 & & & \\
\hline 0.55572 & & & \\
\hline 1389.3 & & & \\
\hline 1.3893 & & & \\
\hline 1041.975 & & & \\
\hline 1.041975 & & & \\
\hline 0.681029412 & & & \\
\hline 3.61796875 & & & \\
\hline 2364.685458 & & & \\
\hline & & & \\
\hline
\end{tabular}




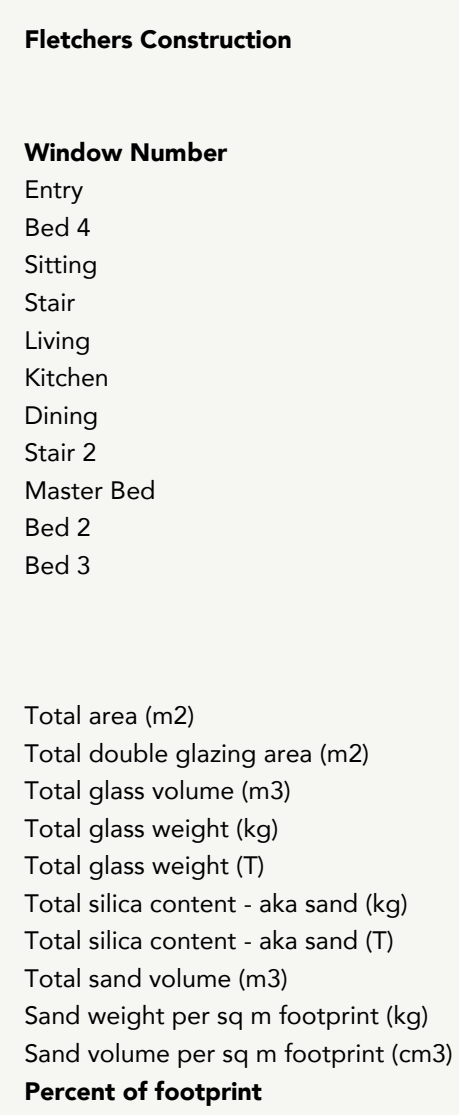

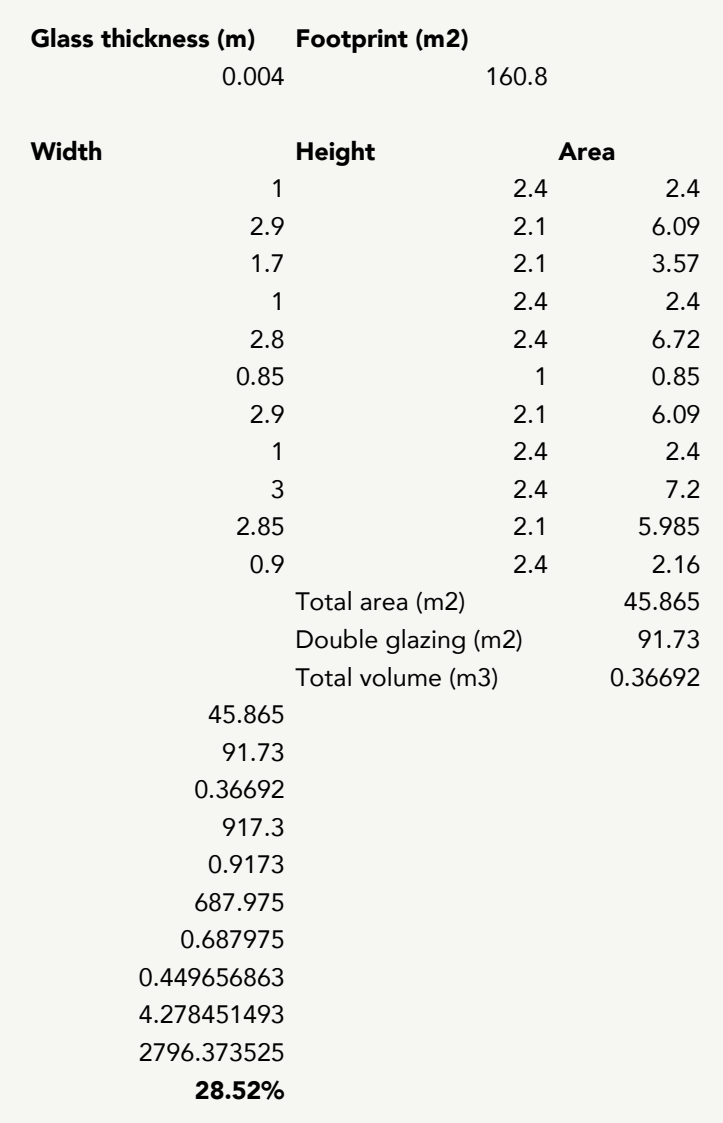

Landmark Homes
Window Number
Garage
Laundry
Bed 3
Bath
Bed 2 a
Bed 2 b
Lounge
Family a
Family b
Family c
Family d
Kitchen a
Kitchen b
Ensuite
Bed 1 a
Bed 1 b
Bed 1 c
Entry
Study
Hall

Total area (m2)
Total double glazing area (m2)
Total glass volume ( $\mathrm{m} 3$ )
Total glass weight (kg)
Total glass weight $(\mathrm{T})$
Total silica content - aka sand (kg)
Total silica content - aka sand (T)
Total sand volume ( $\mathrm{m} 3$ )
Sand weotgigt per $\mathrm{q} \mathrm{m}$ footprint $(\mathrm{kg})$
Sand volume per sq $\mathrm{m}$ footprint (cm3)
Percent of footprint

Glass thickness ( $m$ ) Footprint (m2)

Width

\begin{tabular}{crr} 
Height & \multicolumn{1}{c}{ Area } \\
2.6 & 1 & 2.6 \\
0.6 & 1 & 0.6 \\
2.2 & 1 & 2.2 \\
0.8 & 1 & 0.8 \\
2.2 & 1 & 2.2 \\
2.6 & 2.1 & 5.46 \\
3.3 & 2.1 & 6.93 \\
4.2 & 2.1 & 8.82 \\
4.5 & 2.7 & 12.15 \\
0.8 & 2.4 & 1.92 \\
0.8 & 2.4 & 1.92 \\
0.8 & 2.1 & 1.68 \\
1.6 & 1 & 1.6 \\
1.6 & 1 & 1.6 \\
2.6 & 1.4 & 3.64 \\
2.6 & 1.4 & 3.64 \\
0.8 & 1.4 & 1.12 \\
0.5 & 1.98 & 0.99 \\
1.6 & 1.4 & 2.24 \\
0.8 & 1.4 & 1.12 \\
Total area (m2) & & 63.230 \\
Double glazing (m2) & 126.46 \\
Total volume (m3) & & 0.50584 \\
63.230 & & \\
126.46 & & \\
0.50584 & & \\
1264.6 & & \\
1.2646 & & \\
948.45 & & \\
0.94845 & & \\
0.619901961 & & \\
3.581759819 & & \\
2341.019489 & & \\
$\mathbf{2 3 . 8 8 \%}$ & &
\end{tabular}




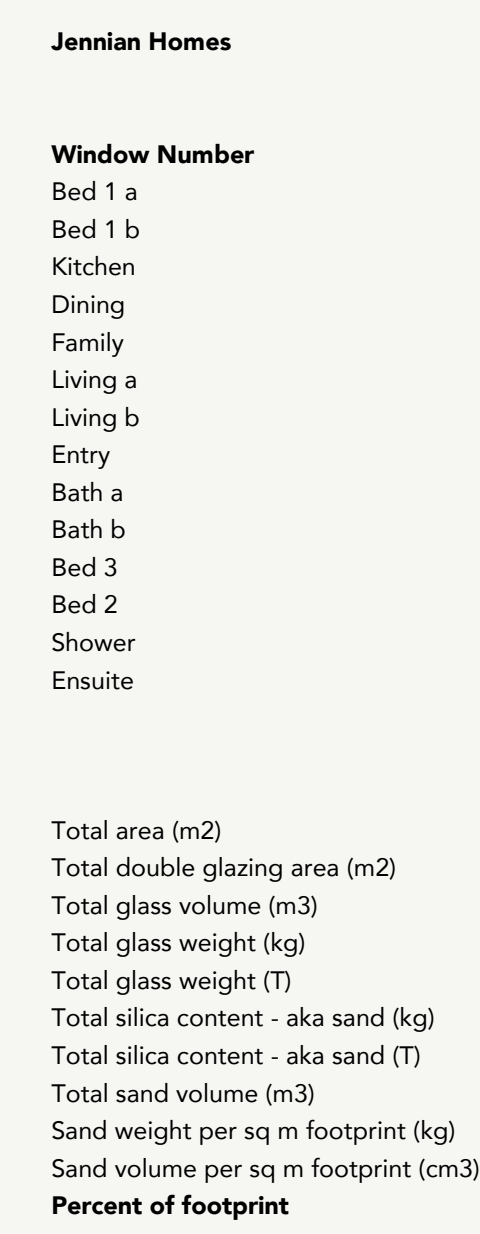

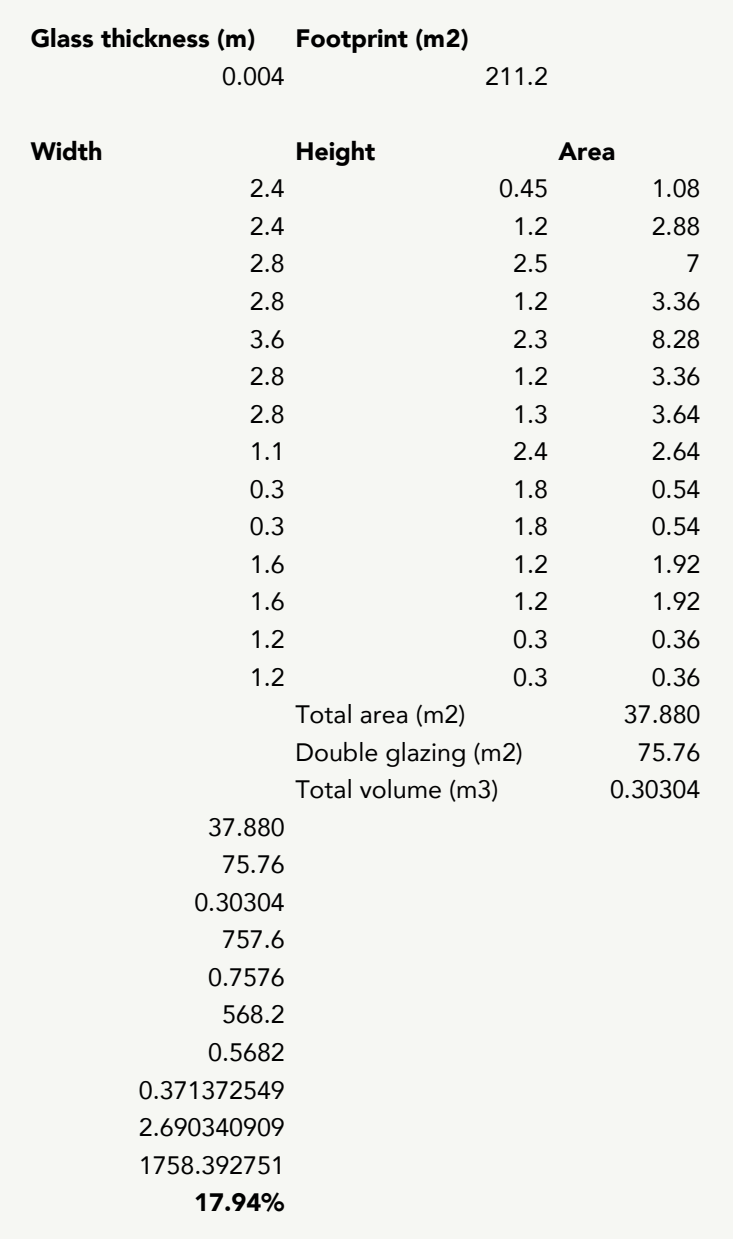

Stonewood Homes
Window Number
Entry
Dining a
Lounge a
Lounge b
Lounge c
Dining b
Kitchen
Scullery
Wardrobe a
Wardrobe b
Master bed a
Master bed b
Master bed c
Ensuite
Laundry
Bath
Bed 4
Bed 3 a
Bed 3 b
Bed a a
Bed 2 b
Hall
Stair
Sky 1
Sky 2
Sky 3
Sky 4
Syy 5
Sky 6
Sky 7
Sky 8
Sky 9

\begin{tabular}{|c|c|c|c|}
\hline $\begin{array}{r}\text { Glass thickness }(\boldsymbol{m}) \\
0.004\end{array}$ & Footprint (m2) & \multicolumn{2}{|l|}{244} \\
\hline Width & Height & & \\
\hline 0.75 & & 2.4 & 1.8 \\
\hline 4.8 & & 2.4 & 11.52 \\
\hline 1 & & 2.4 & 2.4 \\
\hline 4.2 & & 2.4 & 10.08 \\
\hline 1 & & 2.4 & 2.4 \\
\hline 2.4 & & 2.4 & 5.76 \\
\hline 1.8 & & 0.7 & 1.26 \\
\hline 1.2 & & 1.2 & 1.44 \\
\hline 0.6 & & 1.2 & 0.72 \\
\hline 0.6 & & 1.2 & 0.72 \\
\hline 2.7 & & 2.4 & 6.48 \\
\hline 1.5 & & 2.4 & 3.6 \\
\hline 2.7 & & 0.9 & 2.43 \\
\hline 1.2 & & 0.9 & 1.08 \\
\hline 0.5 & & 1.1 & 0.55 \\
\hline 1.2 & & 0.9 & 1.08 \\
\hline 1.5 & & 2.4 & 3.6 \\
\hline 0.9 & & 2.7 & 2.43 \\
\hline 1.8 & & 1.5 & 2.7 \\
\hline 1.8 & & 1.5 & 2.7 \\
\hline 1.5 & & 2.4 & 3.6 \\
\hline 0.9 & & 1.2 & 1.08 \\
\hline 0.9 & & 1.2 & 1.08 \\
\hline 1 & & 0.8 & 0.8 \\
\hline 1 & & 0.8 & 0.8 \\
\hline 1 & & 0.8 & 0.8 \\
\hline 1 & & 0.8 & 0.8 \\
\hline 1 & & 0.8 & 0.8 \\
\hline 1 & & 0.8 & 0.8 \\
\hline 1 & & 0.8 & 0.8 \\
\hline & & 0.8 & 0.8 \\
\hline 1 & & 0.8 & 0.8 \\
\hline & Total area (m2) & & 77.710 \\
\hline & Double glazing ( $\mathrm{m} 2$ & & 155.42 \\
\hline & Total volume (m3) & & 0.62168 \\
\hline 77.710 & 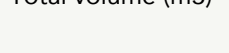 & & \\
\hline 155.42 & & & \\
\hline 0.62168 & & & \\
\hline 1554.2 & & & \\
\hline 1.5542 & & & \\
\hline 1165.65 & & & \\
\hline 1.16565 & & & \\
\hline 0.761862745 & & & \\
\hline 4.777254098 & & & \\
\hline 3122.3883 & & & \\
\hline $31.85 \%$ & & & \\
\hline
\end{tabular}




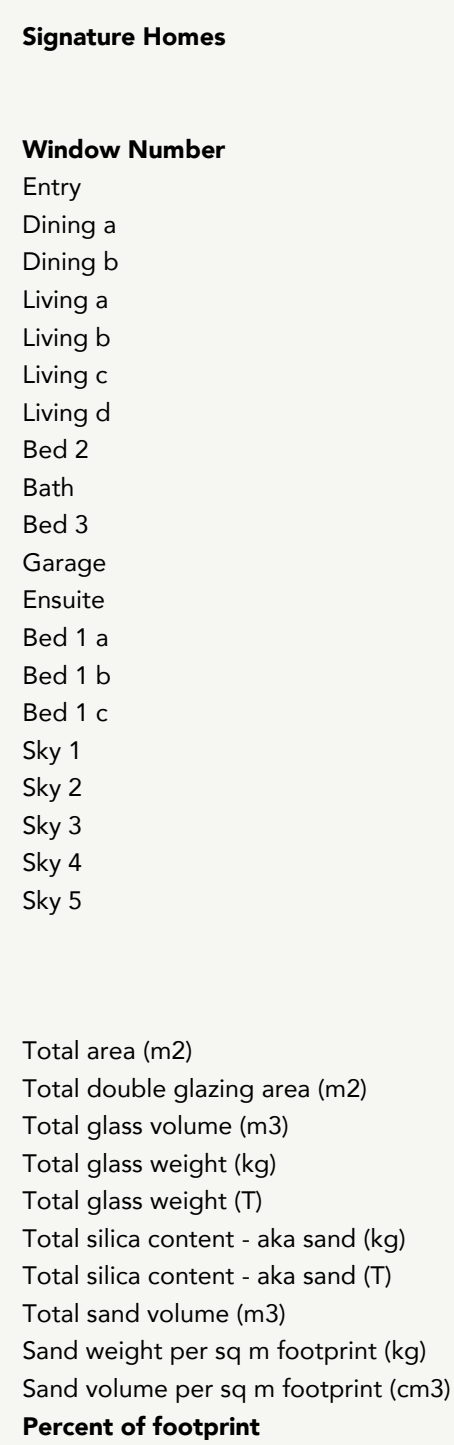

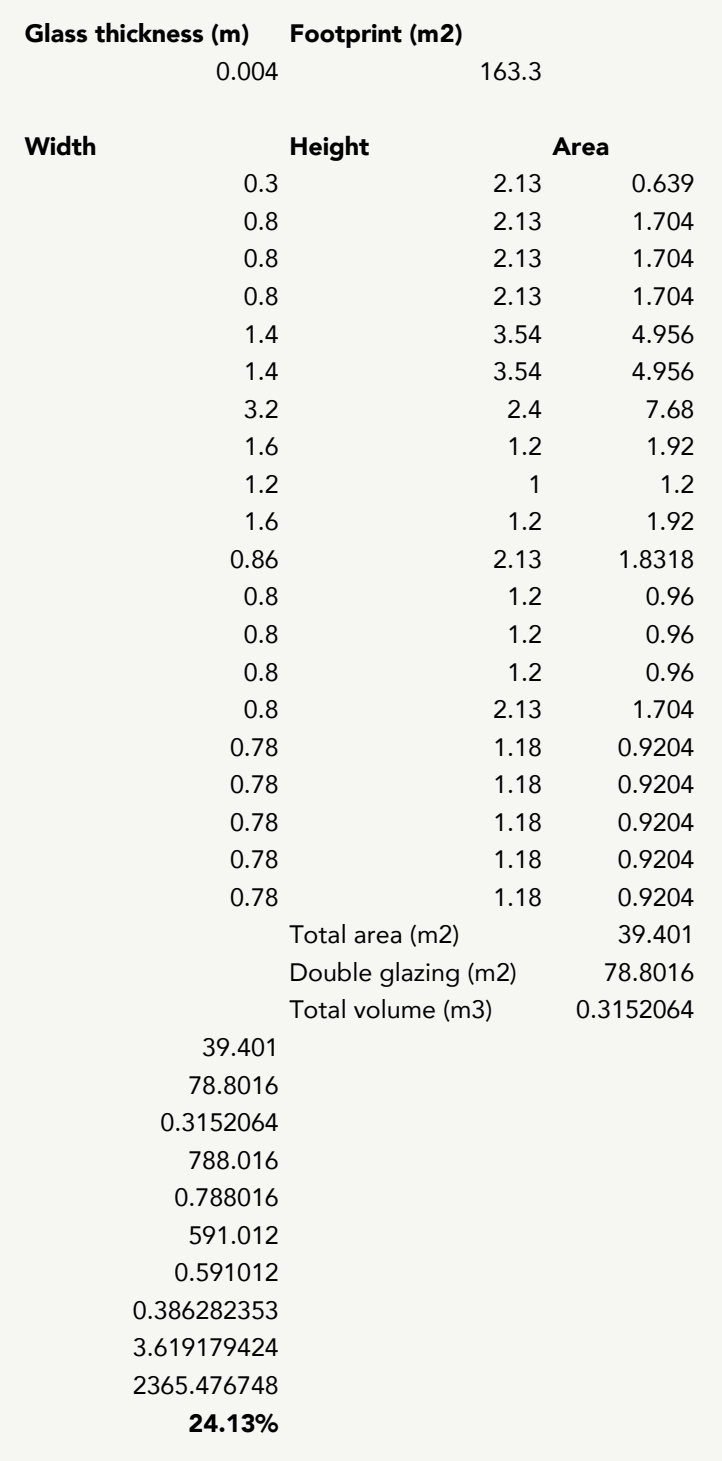

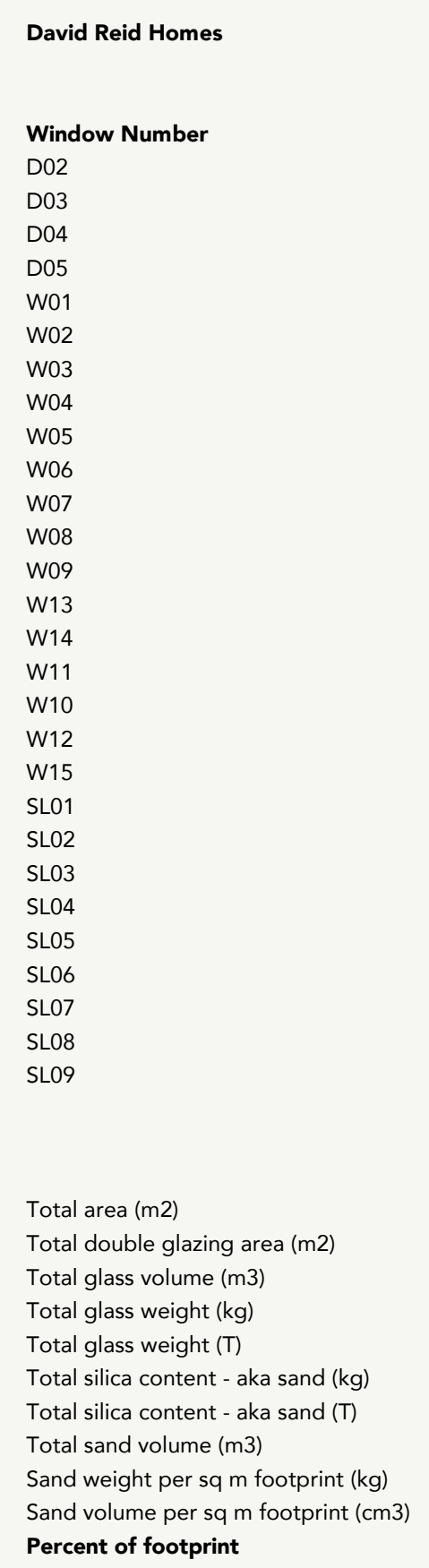

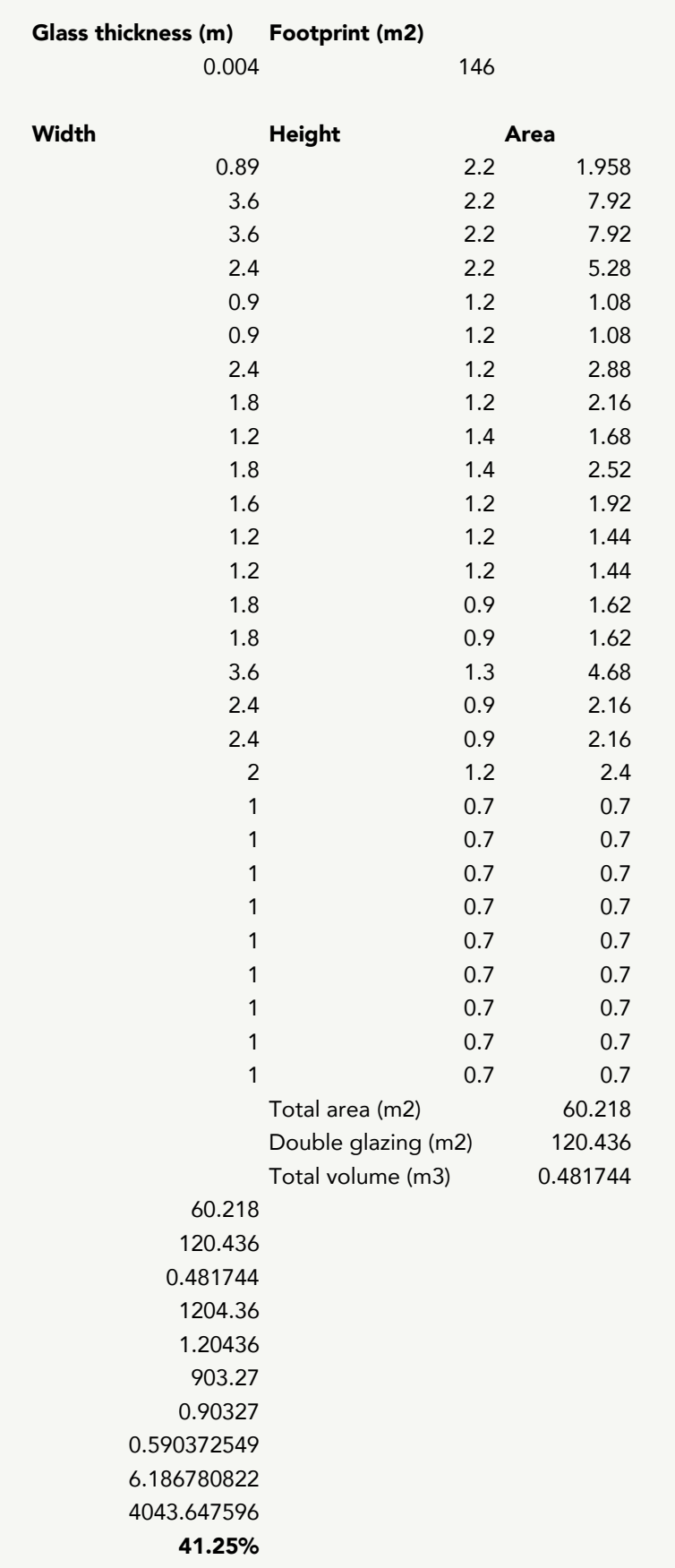


